\title{
Bubble Size Effects in Coal Flotation and Phosphate Reverse Flotation using a Pico-nano Bubble Generator
}

\author{
Yu Xiong \\ West Virginia University
}

Follow this and additional works at: https://researchrepository.wvu.edu/etd

\section{Recommended Citation}

Xiong, Yu, "Bubble Size Effects in Coal Flotation and Phosphate Reverse Flotation using a Pico-nano Bubble Generator" (2014). Graduate Theses, Dissertations, and Problem Reports. 469.

https://researchrepository.wvu.edu/etd/469

This Dissertation is protected by copyright and/or related rights. It has been brought to you by the The Research Repository @ WVU with permission from the rights-holder(s). You are free to use this Dissertation in any way that is permitted by the copyright and related rights legislation that applies to your use. For other uses you must obtain permission from the rights-holder(s) directly, unless additional rights are indicated by a Creative Commons license in the record and/ or on the work itself. This Dissertation has been accepted for inclusion in WVU Graduate Theses, Dissertations, and Problem Reports collection by an authorized administrator of The Research Repository @ WVU.

For more information, please contact researchrepository@mail.wvu.edu. 


\title{
Bubble Size Effects in Coal Flotation and Phosphate Reverse Flotation using a Pico-nano Bubble Generator
}

\author{
Yu Xiong \\ Dissertation submitted to \\ Benjamin M. Statler College of Engineering and Mineral Resources \\ At West Virginia University \\ In partial fulfillment of the requirements \\ For the degree of \\ Doctor of Philosophy in Mining Engineering
}

Felicia F. Peng, Ph.D., Chair

Christopher Bise, Ph.D.

Yi Luo, Ph.D.

Lian-Shin Lin, Ph.D.

Yunqing Zhang, Ph.D.

Department of Mining Engineering

West Virginia University

2014

Keywords: pico-nano bubble, cavitation, coal flotation, phosphate reverse flotation 


\section{ABSTRACT \\ Bubble Size Effects in Coal Flotation and Phosphate Reverse Flotation using a Pico-nano Bubble Generator}

\section{Yu Xiong}

Froth flotation is widely used in minerals industry. However, it is effective in a narrow size range, nominally $45-250 \mu \mathrm{m}$ for coal and $10-150 \mu \mathrm{m}$ for minerals. And the flotation performance of coal and minerals beyond this size range is not quite satisfactory. It is now recognized that the low-flotation efficiency of ultrafine particles is mainly due to the low probability of bubble-particle collision while the main reason for poor flotation recovery of coarse particles is the high probability of detachment of particles from the bubble surface.

Pico-nano bubbles refer to tiny bubbles smaller than $0.5 \mu \mathrm{m}$, which can be produced using ultrasonic or hydrodynamic cavitation method. A fundamental analysis has shown that pico-nano bubbles will serve as a secondary collector, bridging between hydrophobic particles and conventional sized bubbles, which can significantly improve the flotation recovery of hydrophobic particles by increasing the probability of collision and attachment and reducing the probability of detachment.

In order to obtain an optimal designed cavitation venturi tube for pico-nano bubbles' generation, different designs of cavitation venturi tubes were fabricated and tested in this study. The test results showed that maximum volume of pico-nano bubbles, $65 \%$ to $75 \%$, and minimum mean pico-nano bubble size, 150 to $240 \mathrm{~nm}$, were achieved at the medium ratio of the diameter of throat and outlet of the venturi tube (3 to 4 ), medium outlet angle $\left(11^{\circ}\right.$ to $\left.13^{\circ}\right)$, high inlet angle $\left(26^{\circ}\right.$ to $\left.27^{\circ}\right)$ and high ratio of the length of the throat and the diameter of throat (2.3 to 3 ).

The laboratory-scale coal flotation tests showed that, the combustible material recoveries for coarse fractions, $-700+355 \mu \mathrm{m}$, and ultrafines fraction, $-75 \mu \mathrm{m}$, were remarkably increased in the presence of pico-nano bubbles in coal flotation. The maximum combustible recovery of 85 to $90 \%$ and minimum clean coal ash of 9.5 to $11 \%$ were achieved from $29.6 \%$ ash content of Pittsburgh No. 8 seam coal. At a given flotation combustible material recovery, more than half of the collector can be saved by using pico-nano bubbles in the column flotation. The frother dosage was also reduced to half.

The laboratory-scale phosphate reverse flotation tests revealed that both the $\mathrm{P}_{2} \mathrm{O}_{5}$ grade and $\mathrm{P}_{2} \mathrm{O}_{5}$ recovery had been greatly improved in the presence of pico-nano bubbles. The column flotation using pico-nano bubble was capable of extending to float minus $75 \mu \mathrm{m}$ and 355-700 $\mu \mathrm{m}$ particle size ranges much more effectively than column flotation with conventional sparger devices. The economic analysis performed in this study demonstrated that the application of pico-nano bubbles in both phosphate reverse flotation and coal flotation were economically feasible. 


\section{Acknowledgements}

The author would like to express his deep appreciation to his advisor, Dr. Felicia Peng, for her guidance, motivation, and continual support throughout this work. The valuable suggestions and comments by dissertation committee members, Dr. Christopher Bise, Dr. Yi Luo, Dr. Lian-Shin Lin and Dr. Yunqing Zhang are greatly appreciated.

Special acknowledge is due to the financial support to this research projects provided by West Virginia State Coal and Energy Research Bureau (CERB), and the Department of Mining Engineering. The coal samples supplied by Alpha Natural Resources, and the phosphate samples provided by the Mosaic Company are greatly appreciated.

The author would also like to express his sincere thanks to Dr. James Zhenxing Gu, senior metallurgist at Arr-Maz Custom Chemicals, for providing flotation reagents, Dr. Daniel Tao and Dr. Jack Groppo of the Center for Applied Energy Research, University of Kentucky, for their willingness of utilizing their particle size analyzer are greatly appreciated. Special thanks to late Mr. William Comstock for his assistance in making venturi tubes, and his effort of ensuring that the laboratory equipment is as practical and efficient as plausible.

Finally, the author wishes to give particular thanks to his wife, Shengjue Yang, and family members in China for their consistant encouragement and moral support. The author also wants to give special thanks to his seventy-seven year old grandmother, Fengmei Liu, his father, Xiangsheng Xiong, his mother, Ling Yu, his aunt, Sanmei Yu and parents-in-laws, Cheng Yang and Meilan Zhang, for their understanding and unconditional support. 


\section{Table of Content}

Page

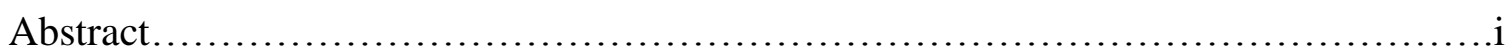

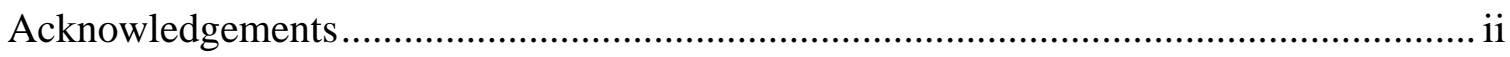

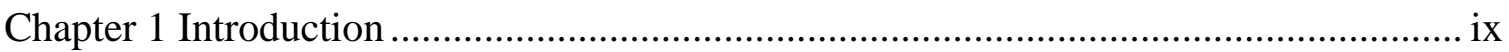

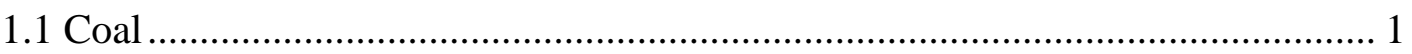

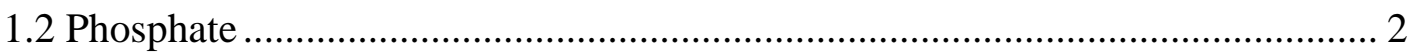

1.3 Particle size limitation in froth flotation .......................................................... 4

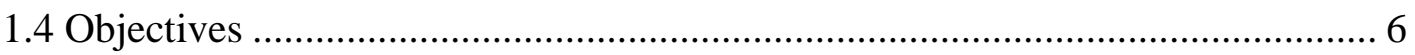

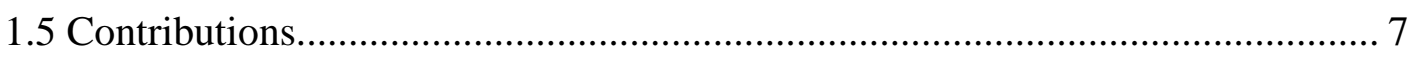

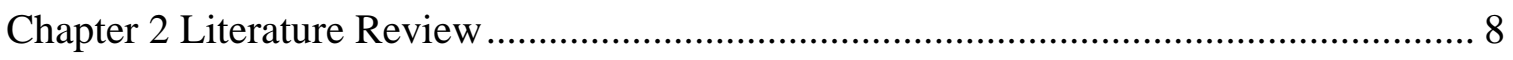

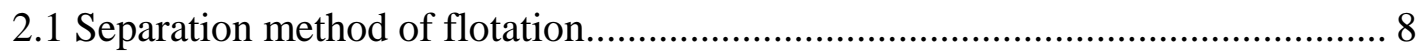

2.2 Effects of particle and bubble size in flotation .............................................. 9

2.2.1 Effect of particle and bubble size on collision...................................... 10

2.2.2 Effect of particle and bubble size on attachment ................................... 11

2.2.3 Effect of particle and bubble size on detachment .................................. 14

2.2.4 Effect of bubble size on gas holdup .................................................... 16

2.2.5 Effect of nanobubble on flotation of coarse, fine and ultrafine particles

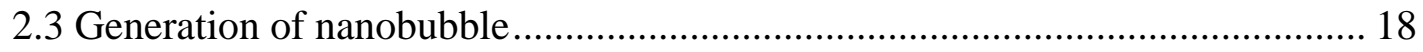

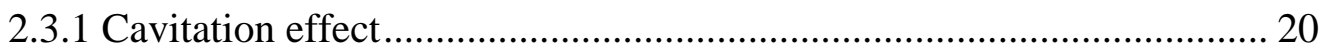


2.3.2 Effect of design parameters of cavitation tube on nanobubble generation

2.3.3 Effect of agitation on nanobubble generation

2.3.4 Effect of dissolved gas on nanobubble generation

2.3.5 Effect of surfactant on nanobubble generation 26

2.3.6 Effect of solid addition in solution on nanobubble generation 27

2.3.7 Effect of flow superficial velocity on nanobubble generation..... 28

2.3.8 Effect of saturation pressure on nanobubble generation

2.3.9 Effects of addition of mixer and air intake location on nanobubble generation. 30

2.4 Application of cavitation in flotation

Chapter 3 Materials and Methodology for Coal Flotation 33

3.1 Characterization of coal sample 33

3.2 Reagents for coal flotation 34

3.3 Equipment and Design of Experiment for coal flotation 35

3.3.1 Bubble size analysis system. 35

3.3.2 Effect of different designs of cavitation venturi tube on bubble distribution

3.3.3 Effects of different types frother and frother dosage on pico-nano bubble generation. 40

3.3.4 Design and set up a pico-nano bubble enhanced flotation column 40 
3.3.5 Perform two-stage Design of Experiment and single factor test for coal flotation.

3.3.5.1 Six-factor three-level experimental design 41

3.3.5.2 Three-factor three-level central composite Design of Experiment..... 45

3.3.5.3 Single factor experimental test 46

3.3.6 Study the effect of particle size on separation efficiency and combustible material recovery.

3.3.7 Compare the flotation results of pico-nano bubble column flotation with that of release analysis. 47

Chapter 4 Materials and Methodology for Phosphate Reverse Flotation ........................ 50

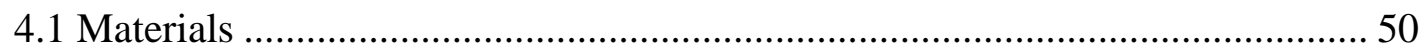

4.1.1 Size distribution and chemical analysis ..................................... 51

4.1.2 Mineral liberation................................................................. 54

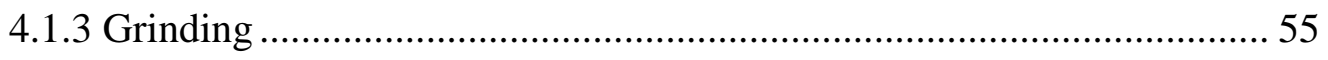

4.1.4 Characterization for phosphate reverse flotation feed ........................ 57

4.2 Reagents for phosphate reverse flotation reagents..................................... 58

4.3 Equipment and Design of Experiment for Phosphate Reverse Flotation .......... 59

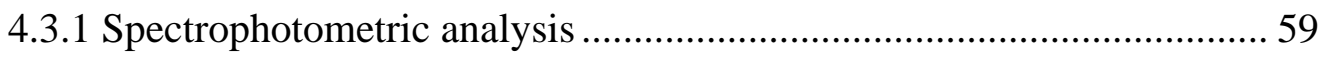

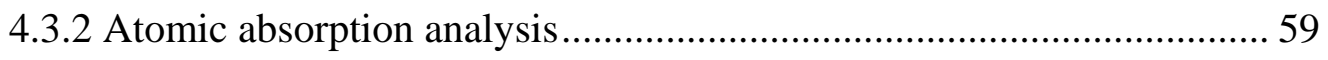

4.3.3 Batch flotation experiments of phosphate sample ............................6 60

4.3.4 Pico-nano bubble column flotation ................................................. 61 
4.3.5 Develop a method for domomitic phosphate flotation 62

4.3.6 Froth Stability Measurement. 65

4.3.7 Study on the effects of different collectors in phosphate reverse flotation 65

4.3.8 Perform two-stage Design of Experiment and single factor test of phosphate reverse flotation. 66

4.3.8.1 Two-stage Design of Experiment 66

4.3.8.2 Single factor test 68

4.3.9 Perform Denver mechanical cell flotation 69

Chapter 5 Results and Discussions for Coal Flotation. 70

5.1 Effects of venturi tube design for pico-nano bubbles and nanobubbles generation 70

5.1.1 Design of venturi tube for pico-nano bubbles and nanobubbles generation and measurement.

5.1.2 Properties of pico-nano bubbles and nanobubbles. 83

5.1.2.1 Effect of different configurations of pico-nano bubbles, nanobubbles and microbubbles generators on bubble size distribution. 83

5.1.2.2 Effect of selected frother on pico-nano bubble size distribution 87

5.2 Column flotation of bituminous coal using cavitation venturi tube for pico-nano bubbles and nanobubbles generation 89

5.2.1 Design of Experiment and Statistical Analysis Method 89 
5.2.1.1 Six-factor three-level experimental design

5.2.1.2 Three-factor three-level central composite experimental design...... 102

5.2.2 Single factor experimental test.

5.3 Effects of particle density and size distributions in coal flotation pico-nano

bubbles environment

5.3.1 Particle size and density frequencies 116

5. 3.2 Pico-nano bubble Column Flotation Test

5.3.2.1 Effect of pico-nano bubbles on flotation of coarse and ultrafine fractions of coal particles 118

5.3.2.2 Effect of pico-nano bubbles on flotation particle size ranges

5.3.2.3 Effect of pico-nano bubbles on flotation ash rejection

5.3.2.4 Effect of pico-nano bubbles on overall performance

5.3.2.5 Pico-nano bubbles and nanobubbles percent effect on separation efficiency of column flotation for bituminous coal

5.3.2.6 Effect of particle size on separation efficiency and combustible material recovery

5.4 Economic evaluation of the application of pico-nano bubbles in coal flotation

Chapter 6 Results and Discussions for Phosphate reverse Flotation

6.1 Measurement of frothability and froth stability 135

6.1.1 Effect of selected surfactant on collector frothability 135 
6.1.2 Effect of selected surfactant on collector froth stability

6.1.3 Effect of different collector on dolomite flotation

6.2 Design of Experiment and Statistical Analysis Method

6.2.1 Seven-factor two-level fractional factorial experimental design

6.2.2 Five-factor two-level fractional factorial experimental design.

6.2.3 Single factor experimental test.

6.2.3.1 Collector dosage effect 160

6.2.3.2 $\mathrm{pH}$ effect.

6.2.4 Amine flotation to remove silica impurity. 164

6.2.5 Correlation between grade and recovery 166

6.2.6 Effect of pico-nano bubbles on $\mathrm{P}_{2} \mathrm{O}_{5}$ recovery of varying sizes 167

6.3 Economic evaluation of pico-nano bubble enhanced phosphate reverse flotation

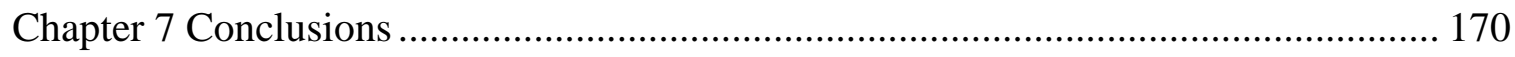

Chapter 8 Recommendations for Future Work ……………....................................... 175

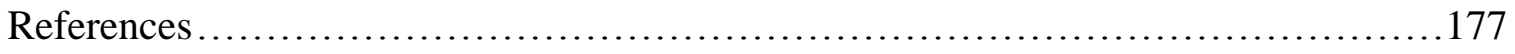

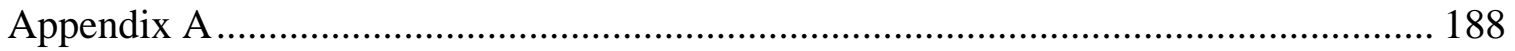

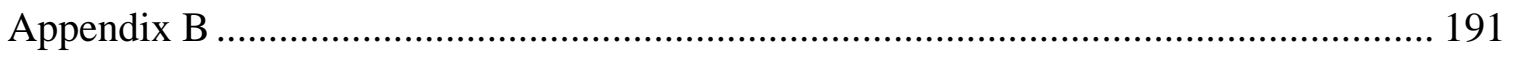

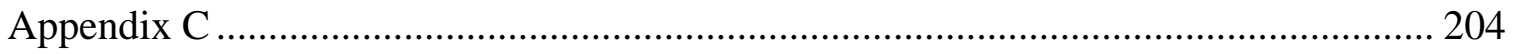

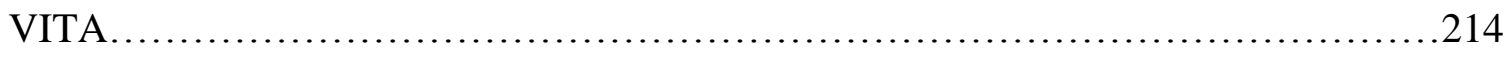




\section{List of Tables}

Page

Table 1-1 World Coal Production Reserve (2011)a. .................................................... 2

Table 1-2 Domestic Coal Reserve of U.S. (2012)c. ..................................................... 2

Table 1-3 World Phosphate Production Reserve. ........................................................ 3

Table 3-1 Particle size and ash distributions for flotation feed of ................................. 33

Table 3-2 Flotation conditions for pico and nano bubble generation. ............................ 37

Table 3-3 Levels of variables for a four-factor three-level design of venturi-tube .......... 38

Table 3-4 Four-factor three-level experimental design of venturi-tube design tests........ 39

Table 3-5 Levels of variables for a six-factor three-level design for column flotation

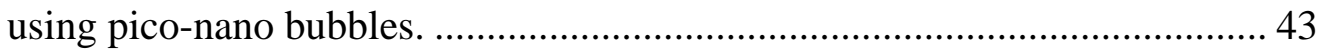

Table 3-6 Six-factor three-level experimental design for column flotation using

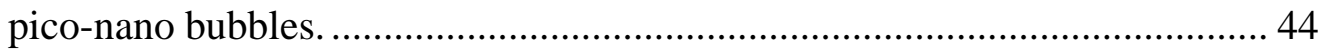

Table 3-7 Levels of variables for a three-factor three-level design for column flotation using pico-nano bubbles.

Table 3-8 Three-factor three-level central composite design for column flotation using pico-nano bubbles. 45

Table 3-9 Process parameters and operational conditions........................................ 46

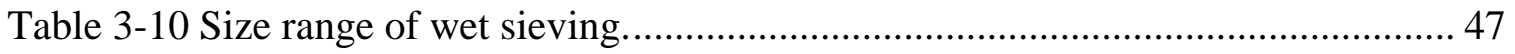

Table 4-1 Chemical analysis of the as-received dolomotic phosphate sample................ 51

Table 4-2 Size distribution and chemical analysis of as-received dolomitic phosphate pebble sample. 
Table 4-3 Size distribution and chemical analysis of as-received dolomitic phosphate pebble sample 53

Table 4-4 Percentage of liberated dolomitic phosphate sample 54

Table 4-5 Stainless steel grinding media for rod mill. 55

Table 4-6 Size distribution at different grinding time for. 56

Table 4-7 Size distribution at different grinding time for. 56

Table 4-8 Size distribution and chemical analysis of dolomitic phosphate sample. 57

Table 4-9 Summary of Processes Developed for Florida Dolomitic Phosphate. 62

Table 4-10 Process parameters and operational conditions. 66

Table 4-11 Experiment design for the first set of test runs. 67

Table 4-12 Process parameters and operational conditions. 67

Table 4-13 Experiment design for the second set of test runs. 68

Table 4-14 Process parameters and operational conditions. 68

Table 5-1 Estimated coefficients, t-ratios and p-values 72

Table 5-2 ANOVA table derived for the Pico-nano bubble Volume and Mean Pico-nano bubble Size models. 73

Table 5-3 Estimated coefficients, t-ratios and p-values. 90

Table 5-4 ANOVA table derived for the combustible material recovery and clean coal ash models 91

Table 5-5 Estimated coefficients, t-ratios and p-values 102

Table 5-6 ANOVA table derived for the recovery and clean coal ash models derived from the results. 103 
Table 5-7 Column flotation test conditions for bituminous coal using optimal designed cavitation venturi tube 130

Table 6-1 Estimated coefficients, t-ratios and p-values........................................... 145

Table 6-2 Main Effects of the Factors for Factorial Design...................................... 151

Table 6-3 Estimated coefficients, t-ratios and p-values.......................................... 153

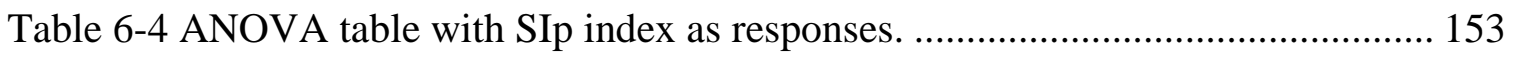

Table 6-5 Main Effects of the Factors for Factorial Design. ..................................... 158

Table 6-6 Material balance of dolomite flotation followed by silica amine flotation. ... 165

Table A-1 Results of four-factor three-level experimental design of venturi-tube design tests.

Table B-1 Results of six-factor three-level experimental design for column flotation using pico-nano bubbles.

Table B-2 Results of three-factor three-level central composite design for column flotation using pico-nano bubbles.

Table B-3 Effect of collector dosage on clean coal and combustible material recovery.195 Table B-4 Effect of solid Concentration on clean coal and combustible material recovery.

Table B-5 Effect of feed rate on clean coal and combustible material recovery. 196

Table B-6 Effect of pico-nano bubbles and coal particle density on the coal flotation performance. 196

Table B-7 Density and ash distributions of fine raw coal sample 197

Table B-8 Effect of pico-nano bubble on yield and combustible material recovery..... 198 
Table B-9 Effect of pico-nano bubbles on the flotation product particle size distributions of $-700+150 \mu \mathrm{m}$ and $-150 \mu \mathrm{m}$ raw coal feed in the presence and absence of pico-nano bubbles.

Table B-10 Effect of pico-nano bubble on flotation ash rejection for various particle sizes. 200

Table B-11 Effect of pico-nano bubbles on flotation yield. 201

Table B-12 Effect of pico-nano bubble on combustible material recovery. 202

Table B-13 Particle size effect on separation efficiency and combustible material recovery with pico-nano bubbles. 203

Table C-1 Effect of CF 413 B on dolomite flotation..................................................... 205

Table C-2 Effect of CF 413 on dolomite flotation.................................................... 206

Table C-3 Effect of the mixture of CF 413 and MIBC on dolomite flotation................ 207

Table C-4 Effect of the mixture of CF 413B and MIBC on dolomite flotation............ 208

Table C-5 Results of seven-factor two-level fractional factorial experimental design. . 209

Table C-6 Results of five-factor two-level fractional factorial experimental design. .... 210

Table C-7 Effect of pH on dolomite flotation............................................................. 211

Table C-8 Effect of collector dosage on dolomite flotation. ....................................... 212

Table C-9 Effect of pico-nano bubbles on $\mathrm{P}_{2} \mathrm{O}_{5}$ recovery of varying sizes................... 213 


\section{List of Figures}

Page

Figure 2-1 Particle-bubble collision, adhesion, and detachment. ..................................... 9

Figure 2-2 Collision probability as a function of bubble size.......................................... 11

Figure 2-3 Role of nanobubbles in enlarging contact angle: ........................................ 12

Figure 2-4 Attachment probability as a function of bubble size...................................... 14

Figure 2-5 Different Forces as a function of bubble size by Fan et al. (2010a).............. 15

Figure 2-6 Effect of pico-nano bubbles on coarse, fine and ultrafine particles................ 18

Figure 2-7 Effect of dissolved air on bubble generation without added air...................... 25

Figure 2-8 Bubble collapse behavior at different superficial velocity ............................. 28

Figure 2-9 Effect of liquid release velocity on bubble formation as evaluated by gas holdup (note: the dotted lines connect the points with same saturation

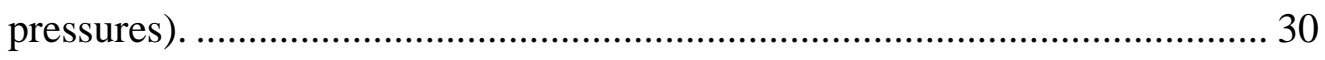

Figure 3-1 Size and ash distribution for Pittsburgh No. 8 seam coal sample................... 34

Figure 3-2 Schematic diagram of the pico-nano bubble measurement system. ……....... 35

Figure 3-3 Malvern Mastersizer 2000 laser particle size analyzer and the pico-nano bubble measurement system ...................................................................... 36

Figure 3-4 Skematic diagram of cavitation venturi tube. ............................................ 38

Figure 3-5 Schematic diagram of flotation column with static mixer and venturi tube for pico and nano bubble generation. ................................................................ 41

Figure 3-6 Schematic diagram of the reverse release analysis procedure. ....................... 48

Figure 4-1 Percent passing as a function of grinding time. ……….................................. 57

Figure 4-2 The Spectronic 200 used for phosphorus and $\mathrm{P}_{2} \mathrm{O}_{5}$ content analysis............. 59 
Figure 4-3 The AAnalyst 200 used for $\mathrm{MgO}$ and $\mathrm{CaO}$ content analysis. 60

Figure 4-4 Procedures for Processing Florida Dolomitic Phosphate Peddle Sample....... 63

Figure 5-1 Comparison of the observed responses and predicted 74

Figure 5-2 Effect of the ratio of the diameter of throat and outlet of the venturi tube $\left(D_{\text {in }} / D_{t}\right)$ and the ratio of the length of the throat and the diameter of throat $\left(\mathrm{L}_{\mathrm{t}} / \mathrm{D}_{\mathrm{t}}\right)$ on the pico-nano bubble volume and mean pico-nano bubble size..... 78

Figure 5-3 Effect of the ratio of the diameter of throat and outlet of the venturi tube $\left(\mathrm{D}_{\text {in }} / \mathrm{D}_{\mathrm{t}}\right)$ and the inlet angle on the pico-nano bubble volume and mean piconano bubble size. 80

Figure 5-4 Effect of the ratio of the diameter of throat and outlet of the venturi tube $\left(\mathrm{D}_{\text {in }} / \mathrm{D}_{\mathrm{t}}\right)$ and the outlet angle on the Pico-nano bubble volume and mean piconano bubble size 83

Figure 5-5 Bubbles generated by static mixer -venturi tube, static mixer only and venturi tube only with 20 ppm MIBC. 86

Figure 5-6 Pico-nano Bubble generated at varying concentration of MIBC. 87

Figure 5-7 Bubble size distribution curve in water solution with 20 ppm MIBC, and TTT frother.

Figure 5-8 Comparison of the observed responses and predicted responses with reduced model. 92

Figure 5-9 Effect of gas flow rate and collector dosages on CMR and clean coal ash. ... 94 Figure 5-10 Effect of gas flow rate and wash water rate on CMR and clean coal ash.... 96 Figure 5-11 Effect of gas flow rate and frother dosage on CMR and clean coal ash...... 97 
Figure 5-12 Effect of gas flow rate and solids concentration on CMR and clean coal ash.

Figure 5-13 Effect of gas flow rate and feed rate on CMR and clean coal ash.

Figure 5-14 Combustible material recovery versus clean coal ash for column flotation and release analysis flotation results.

Figure 5-15 Effect of solids concentration and collector dosages on CMR and clean coal ash. 106

Figure 5-16 Effect of feed rate and collector dosages on CMR and clean coal ash...... 109 Figure 5-17 Effect of solids concentration and feed rate on CMR and clean coal ash... 111 Figure 5-18 Combustible material recovery versus clean coal ash content for column flotation and release analysis flotation results. 112

Figure 5-19 Combustible material recovery and clean coal ash content as a function of collector dosage. 114

Figure 5-20 Combustible material recovery and clean coal ash content as a function of solid concentration. 114

Figure 5-21 Combustible material recovery and clean coal ash content as a function of feed rate. 115

Figure 5-22 Density and ash distributions of fine raw coal sample.... 118

Figure 5-23 Effect of pico-nano bubbles on coal flotation recovery. 120

Figure 5-24 Effect of pico-nano bubble on yield and combustible material recovery... 121

Figure 5-25 Cumulative particle size distributions of clean coal with and without piconano bubbles. 123 
Figure 5-26 Effect of pico-nano bubble on flotation ash rejection for various particle sizes.

Figure 5-27 Effect of pico-nano bubbles on flotation yield.

Figure 5-28 Effect of pico-nano bubble on combustible material recovery. 128

Figure 5-29 Combustible material recovery and clean coal ash content as a function of

Pico-nano and nanobubble percent. 130

Figure 5-30 Particle size effect on separation efficiency and combustible material recovery. 131

Figure 5-31 The photo shows the clean coal (left), middlings (middle) and tailings (right) of pico-nano bubbles flotation for Pittsburgh No.8 seam coal.

Figure 6-1 Froth height as a function of collector dosage with different surfactants.... 136

Figure 6-2 Froth life time as a function of collector dosage with different surfactants.. 137

Figure 6-3 Effect of selected surfactants on the yield of the floats using different collector with and without surfactant 138

Figure 6-4 Effect of selected surfactants on the $\mathrm{MgO}$ grade in the float using different collector with and without surfactant. 140

Figure 6-5 Effect of selected surfactants on the $\mathrm{MgO}$ recovery in the float using different collector with and without surfactant. 140

Figure 6-6 Effect of selected surfactants on the $\mathrm{P}_{2} \mathrm{O}_{5}$ grade in the float using different collector with and without surfactant. 141

Figure 6-7 Effect of selected surfactants on the $\mathrm{P}_{2} \mathrm{O}_{5}$ loss in the float using different collector with and without surfactant. 
Figure 6-8 Effect of selected surfactants on the $\mathrm{MgO}$ grade in the sink using different collector with and without surfactant.

Figure 6-9 Effect of selected surfactants on the $\mathrm{MgO}$ recovery in the sink using different collector with and without surfactant. 144

Figure 6-10 Comparison of the observed responses and predicted responses. 145

Figure 6-11 Effect of $\mathrm{pH}$ and collector dosages on SIp index. 146

Figure 6-12 Effect of feed rate and collector dosages on SIp index.....

Figure 6-13 Effect of feed solid concentration and collector dosages on SIp index. ..... 148

Figure 6-14 Effect of frother dosages and collector dosages on SIp index. 149

Figure 6-15 Effect of gas flow rate and collector dosages on SIp index. 150

Figure 6-16 Effect of wash water flow rate and collector dosages on SIp index. 150

Figure 6-17 Comparison of the observed responses and predicted responses.

Figure 6-18 Effect of $\mathrm{pH}$ and feed rate on SIp index 155

Figure 6-19 Effect of frother dosage and $\mathrm{pH}$ on SIp index. 156

Figure 6-20 Effect of collector dosages and pH on SIp index.

Figure 6-21 Effect of feed solid concentration and $\mathrm{pH}$ on SIp index.

Figure 6-22 $\mathrm{MgO}$ grade in the sink and $\mathrm{MgO}$ recovery in the dolomite flotation float as a function of collector dosage. 160

Figure 6-23 $\mathrm{P}_{2} \mathrm{O}_{5}$ grade and recovery in the dolomite flotation sink and the separation selectivity index as a function of collector dosage. 161

Figure 6-24 $\mathrm{MgO}$ grade in the sink and $\mathrm{MgO}$ recovery in the dolomite flotation float as a function of $\mathrm{pH}$. 162 
Figure 6-25 $\mathrm{P}_{2} \mathrm{O}_{5}$ grade and recovery in the dolomite flotation sink and the separation selectivity index as a function of $\mathrm{pH}$

Figure 6-26 Relationship between $\mathrm{P}_{2} \mathrm{O}_{5}$ grade and $\mathrm{P}_{2} \mathrm{O}_{5}$ recovery in the sink product of dolomite flotation...... 166

Figure 6-27 $\mathrm{P}_{2} \mathrm{O}_{5}$ grade and recovery in the dolomite flotation sink and the separation selectivity index as a function of $\mathrm{pH}$. 167

Figure 6-28 $\mathrm{P}_{2} \mathrm{O}_{5}$ grade vs. $\mathrm{P}_{2} \mathrm{O}_{5}$ recovery for $-700+150 \mu \mathrm{m}$ phosphate particles with and without pico-nano bubbles. 168

Figure 6-29 $\mathrm{P}_{2} \mathrm{O}_{5}$ grade vs. $\mathrm{P}_{2} \mathrm{O}_{5}$ recovery for $-150 \mu \mathrm{m}$ phosphate particles with and without pico-nano bubbles. 168 


\section{Chapter 1 Introduction}

\subsection{Coal}

Coal is a nonrenewable resource formed from the decomposition of organic materials that have been subjected to geologic heat and pressure over millions of years. It provides $30.3 \%$ of global primary energy needs and generates $42 \%$ of the world's electricity. In 2011 coal was the fastest growing form of energy outside renewables. Its share in global primary energy consumption increased to $30.3 \%$ - the highest since 1969. It can be seen from Table 1-1 that the United States is the second largest coal producer in the world with the largest coal reserves. Montana, Illinois, Wyoming, West Virginia and Kentucky takes up $70.29 \%$ of the coal reserves in US. About $37.4 \%$ of the electricity was generated by coal, more than any other source of electricity in 2013, and Coal's share of electricity generation increased to 40 percent during the first quarter of 2013, an 8.7 percent increase over last year. As been reported by Energy Information Administration (EIA), coal is projected to remain the dominant fuel for electricity generation in the U.S. through 2040 . It is never overstated that "Coal Keeps the Lights On".

As more and more advanced mining methods been applied, more and more fine and ultrafine coal particles has been produced in coal mining process, which now counts for $20 \%$ of coal shipments by weight. Coal companies needs more effective flotation processes to remove mineral impurities from fine and ultra fine coal and recover the high quality coal fractions which often lost during conventional separation processes. On the other hand, when coal is ground to ultra fine (below $10 \mu \mathrm{m}$ ), almost all mineral impurities 
are liberated from coal's molecular matrix. The successful flotation of ultra fine coal will greatly enhance energy conservation and environmental protection.

Table 1- 1 World Coal Production Reserve (2012) .

\begin{tabular}{|c|c|c|c|c|}
\hline Country & $\begin{array}{c}\text { Production } \\
\text { (million tonnes) }\end{array}$ & $\begin{array}{c}\text { Share of total } \\
\text { production } \\
(\%)\end{array}$ & $\begin{array}{c}\text { Reserves } \\
\text { (million tones) }\end{array}$ & $\begin{array}{c}\text { Share of total } \\
\text { Reserves } \\
(\%)\end{array}$ \\
\hline PR China & 1825 & 47.5 & 114500 & 13.30 \\
\hline USA & 515.9 & 13.4 & 237295 & 27.60 \\
\hline India & 228.8 & 6.0 & 60600 & 7.00 \\
\hline
\end{tabular}

${ }^{\text {a }}$ Source: 2013 Edition of the IEA( INTERNATIONAL ENERGY AGENCY) Coal Information, 2013 Edition of the BP Statistical Review of World Energy

${ }^{\mathrm{b}}$ Commercial solid fuels only, i.e. bituminous coal and anthracite (hard coal), and lignite and brown (sub-bituminous) coal.

Table 1- 2 Domestic Coal Reserve of U.S. (2012) ${ }^{\mathrm{c}}$.

\begin{tabular}{|l|c|c|}
\hline \multicolumn{1}{|c|}{ State } & $\begin{array}{c}\text { Domestic reserves } \\
\text { (million tones) }\end{array}$ & $\begin{array}{c}\text { Share of total reserve } \\
(\%)\end{array}$ \\
\hline Montana & 74644 & 28.97 \\
\hline Illinois & 37835 & 14.68 \\
\hline Wyoming & 37413 & 14.52 \\
\hline West Virginia & 17013 & 6.6 \\
\hline Kentucky & 14213 & 5.52 \\
\hline
\end{tabular}

${ }^{\mathrm{c}}$ Source: U.S. Energy Information Administration Form EIA-7A, Coal Production and Preparation Report, and U.S. Department of Labor, Mine Safety and Health Administration Form 7000-2, Quarterly Mine Employment and Coal Production Report, 2012.

\subsection{Phosphate}

Phosphate rock is a non-renewable, non-detrital sedimentary rock which contains high amounts of phosphate bearing minerals (Gurr, 2001). It has been applied to the current world agricultural system and for other uses. Major application of phosphate is the 
production of phosphate fertilizers, which takes up almost $90 \%$ of the phosphate produced. Other of them is used by other industries, such as manufacturing of detergents, water softeners, cleaners, insecticides, dental products, animal food, and soft drink we drink every day (Houot, 1982). It is no exaggeration to say that "every living thing on this planet cannot live without it". The increasing population results in the long term growth in the world phosphate rock production. Table 1-3 shows the world phosphate production and reserves. As shown in Table 1-3, the United States rank seventh in phosphate reserves but ranked as the second largest country of phosphate production. Florida and North Carolina accounted for more than $85 \%$ of total domestic output, the remainder was produced in Idaho and Utah. During the phosphate beneficiation process, about $20 \%$ to one third of the matrix phosphate value will be lost in the phosphatic clays because of the low recovery of fine and ultrafine particles (Moudgil and Somasundaran, 1986). The reserves of phosphate will be depleted much sooner than other countries if there is no significant improvement in the phosphate production.

Table 1- 3 World Phosphate Production Reserve. (thousand metric tons) $^{\mathrm{d}}$

\begin{tabular}{|c|c|c|c|}
\hline \multirow{2}{*}{ Country } & \multicolumn{2}{|c|}{ Phosphate production } & \multirow{2}{*}{ Reserves } \\
\cline { 2 - 3 } & 2011 & 2012 & \\
\hline China & 81,000 & 89,000 & $3,700,000$ \\
\hline United States & 28,100 & 29,200 & $1,400,000$ \\
\hline Morocco & 28,000 & 28,000 & $50,000,000$ \\
\hline Algeria & 1,500 & 1,500 & $2,200,000$ \\
\hline Jordan & 6,500 & 6,500 & $1,500,000$ \\
\hline South Africa & 2,500 & 2,500 & $1,500,000$ \\
\hline Syria & 3,100 & 2,500 & $1,800,000$ \\
\hline World total (rounded) & 198,000 & 210,000 & $67,000,000$ \\
\hline
\end{tabular}

${ }^{\mathrm{d}}$ Source: U.S. Geological Survey, Mineral Commodity Summaries, January 2013. 
The criteria of phosphate in fertilizer industry requires (1) $\mathrm{P}_{2} \mathrm{O}_{5}$ content larger than $30 \%$, and (2) $\mathrm{MgO}$ content less than $1 \%$. If the phosphate ore doesn't meet the criteria, certain beneficiation process will be applied to reduce the impurities, such as quartz, mica, dolomite, etc. Froth flotation is the most widely used phosphate beneficiation process (Hernainz et al., 2004), which has been used in two-thirds of the phosphate ore production in Florida and more than half of the world's phosphate production (Sis and Chander, 2003).

\subsection{Particle size limitation in froth flotation}

Froth Flotation process is hydrophobic surface-based particle separation technique. The separation efficiency of column flotation is determined by raw coal feed or phosphate ore feed characteristics, and operating parameters associated with feed slurry-reagent conditioning, air-hydrophobic particles contacting, attachment, detachment, and size of air bubbles. This process is known to be more efficient and cost effective than other fine particle separation techniques such as tabling, high-gradient magnetic separation, oil agglomeration. However, it is efficient only for particles within a narrow size range, nominally from 10 to $150 \mu \mathrm{m}$ for minerals and from $45 \mu \mathrm{m}$ to $250 \mu \mathrm{m}$ for coal (King et al. 1982; Feng, et al. 1999; Crozier, 1992). Fine particles are known to have low momentum during the particle-air bubble collision due to low mass of fine particles. This resulted in low attachment and thus low flotation rate (Trahar and Warren, 1976; Derjaguin et al. 1984). For coarser coal and mineral particles, since particles have higher mass, with weak attachment force between the coarser particles and air bubbles, often resulted in high detachment of particles from air bubbles, thus lower the flotation rate (Yoon, 2000; Tao, 2004). Research effort has been centered on the development of air bubbles sparger 
design to generate the tiny bubbles for better attachment and lower detachment probabilities during the flotation over past two-three decades. The recent development of bubble generation through the use of properly and selective design of cavitation venturi tube, make it possible, to produce pico-nano size range bubbles (Tao et al. 2006b; Fan, et al. 2010b; Peng and Xiong, 2012, 2013).

Pico-nano bubbles refer to tiny bubbles smaller than $0.5 \mu \mathrm{m}$, which can be produced using hydrodynamic cavitation method (Zhou et al. 1997b, Fan, et al. 2010b; Peng and Xiong, 2012, 2013). Pico-nano bubbles preferentially nucleate at the surface of hydrophobic particles (Zhou et la. 1997a). This is because work of adhesion $\mathrm{W}_{\mathrm{a}}$ between a solid particle and water, which is equal to $\gamma_{1}(1+\operatorname{Cos} \theta)$, where $\gamma_{1}$ is water surface tension and $\Theta$ is contact angle, is always smaller than work of cohesion of water $\mathrm{W}_{\mathrm{c}}$ or 2 $\gamma_{1}$. Furthermore, $\mathrm{W}_{\mathrm{a}}$ decreases with increasing solid surface hydrophobicity measured by contact angle. In other words, ultrafine particles can adhere to pico-nano bubbles without the need of collision, which is often the rate-determining step in froth flotation for ultrafine particles (Weber and Paddock, 1983; Yoon and Luttrell, 1989; Tao et al. 2006c). Pico-nano bubbles absorbed on particle surface also serve as a secondary collector, improving the probability of adhesion and reducing the need for the hydrophobic chemical (Zhou, 1997a; Luttrell and Yoon, 1992, Peng and Xiong, 2013). In addition, particles are less likely to detach from smaller bubbles due to their lower upward velocity and centrifugal force associated with the detachment process, reducing the probability of detachment.

A selectively designed cavitaion venture tube can be used to generate very high numbers of pico-nano bubbles to flotation column. Fully embraced by those high numbers of tiny 
bubbles, hydrophobic particles are readily attracting those tiny bubbles to their surfaces, after that, it will attach to larger bubbles, and eventually report to the froth zone. With the connection of pico-nano bubbles as a bridge between fine/coarse particles and conventional sized bubbles, the separation performance of flotation will be improved comparing to that of conventional flotation.

\subsection{Objectives}

The objective of this study is to improve the separation efficiency of fine and coarse particles in froth flotation by introducing pico-nano bubbles into the column flotation system. The details of the objectives of this study are given below:

(1) To study the effectiveness of different designs of cavitation venturi tube on pico-nano bubble generation, and determine the optimal design of cavitation venturi tube;

(2) To study the effectiveness of pico-nano bubbles in coal flotation of coarse $(-700+355$ $\mu \mathrm{m})$ and ultrafine $(-150 \mu \mathrm{m})$ particles;

(3) To study the effectiveness of pico-nano bubbles in phosphate reverse flotation (dolomitic carbonates flotation and silica flotation) of coarse $(-700+355 \mu \mathrm{m})$ and ultrafine $(-150 \mu \mathrm{m})$ particles.

To improve the essential flotation steps of collision and attachment, and reduce detachment probabilities between air bubbles and hydrophobic particles, a specially designed flotation column with a pico-nano bubble generator is developed for enhancing the recovery of coarse $(-700+355 \mu \mathrm{m})$ and ultrafine $(-150 \mu \mathrm{m})$ coal particles and phosphate particles are difficult to float with a conventional flotation process. Pico-nano bubbles are produced by cavitation venturi tube based on the hydrodynamic cavitation principle. 


\subsection{Contributions}

This study is significant for five achievements.

1) This study identified effects of different designs of cavitation venturi tube on piconano bubbles generation and determined the optimal venturi design for pico-nano bubble generation. The optimal designed cavitation venturi tube were then used in flotation column to generate pico-nano bubbles. This specially designed flotation column were used to improve the flotation recovery of coarse $(-700+355 \mu \mathrm{m})$ and ultrafine $(-150 \mu \mathrm{m})$ particles.

2) Successfully confirmed the existence of pico-nano bubbles and obtained size distribution curve by using high precision particle size analyzer.

3) Further the understanding of the effects of different frother dosage necessary for the generation of pico-nano bubbles, which helped focus on achieving the best flotation recovery and product grade.

4) Provided the understanding of the discriminating effects of operation conditions in coal column flotation and dolomitic phosphate reverse flotation on recovery and product grade helped target the optimal operating conditions. Higher floatation recovery for the coarse $(-700+355 \mu \mathrm{m})$ and ultrafine $(-150 \mu \mathrm{m})$ hydrophobic particles were achieved. This will result in less energy used in the grinding process for the middlings in direct coarse mineral flotation, and more fine/ultrafine valuable minerals will be recovered by introducing pico-nano bubbles into flotation column.

5) Successfully applied this innovative column flotation with pico-nano bubble on coarse and fine/ultrafine particles. This is expected to help coal/mineral industries improve the recovery of coarse and fine/ultrafine valuable particles in their process plants. 


\section{Chapter 2 Literature Review}

\subsection{Separation method of flotation}

Forth Flotation is a highly versatile method for physically separation particles based on differences in the ability of air bubbles to selectively adhere to specific mineral surfaces in a mineral /water slurry. The particles with attached air bubbles are then carried to the surface and removed, while the particles that remain completely wetted stay in the liquid phase. Froth flotation can be adapted to a broad range of mineral separations, ranging from mineral separation to effluents de-oiling and soil remediation. Froth flotation, as one of the outstanding achievements through continuous 100 years of development, has contributed immeasurably to the vast expansion of raw material industry and gained a significant success in cleaning fine coal and recovering valuable minerals from the most complex ores. In coal and mineral processing industry, froth flotation also provides many environmental benefits by removing varying amounts of ash-forming and sulfur-bearing minerals, mercury and other hazardous air or water pollutant precursors (Taggart, 1927). In general, flotation can be macroscopically divided into two processes; selective collection of hydrophobic particles by bubbles, and separation of hydrophobic particlebubble aggregates from hydrophilic particles. In coal and minerals froth flotation, particle size and surface hydrophobicity are two main parameters that affect three key mechanisms in froth flotation process, which are particle-bubble collision, adhesion, and detachment, as illustrated in Figure 2-1. 
The low flotation recovery of fine particles is mainly due to the low probability of bubble-particle collision, while the main reason for poor flotation recovery of coarse particles is the high probability of detachment of particles from the bubble surface (Ralston et al. 1999b). The efficient capture of hydrophobic particles by air bubbles is the key to effective flotation. A flotation machine should be designed to provide an optimal environment for capturing and transporting hydrophobic particles away from hydrophilic ones, knowledge of where and how collection occurs is obviously a vital first step in a more scientific approach to flotation cell design (Edzwald, 1995).

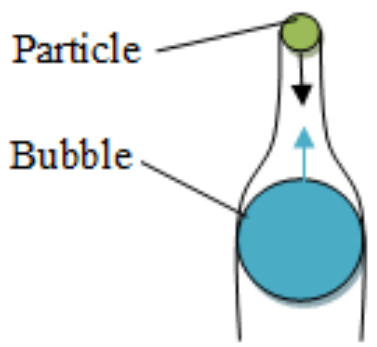

Collision

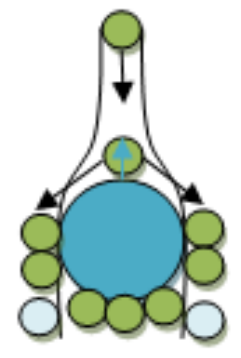

Attachment

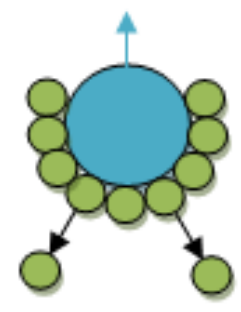

Detachment

Figure 2- 1 Particle-bubble collision, adhesion, and detachment.

\subsection{Effects of particle and bubble size in flotation}

Particle size is an important parameter in flotation and has been the focus of the flotation research for decades. Flotation recovery of both fine and coarse particles is usually remarkably low, leading to the "elephant" shape of the recovery versus particle size curves. Coarse particles badly float mostly because the bubble-particle aggregates are not strong enough to prevent the particle detachment from the bubble surface caused by the 
particle weight and turbulence eddies during the rise of the aggregates in the pulp phase to the froth phase and then to the froth launder. Efficiency of the bubble-particle stability depends on the particle size, particle hydrophobicity and external detaching forces. Even in the flotation of fine particles, the bubble-particle detachment can significantly influence the kinetics of flotation taking place in mechanical cells by intensive turbulent agitation (Deglon et al., 1999). For these fine particles, the bubbles-particle detachment is usually allegedly neglected.

\subsubsection{Effect of particle and bubble size on collision}

A particle is collided with a bubble as a result of a sufficiently close encounter, which is determined by the hydrodynamics of flotation environment. Hydrodynamic interactions are dominant in the collision efficiency while interfacial forces play a major role in the attachment efficiency. The stability of the bubble-particle aggregate is a function of both hydrodynamics and interfacial forces (Duan et al., 2003). The probability of collision (Pc) can be calculated from stream functions for quiescent conditions. Figure 2-2, predicted by Eq (2-1) (Yoon and Luttrell, 1989), shows that Pc increases with increasing particle size and decreasing bubble size. Fine particles have low momentum, resulted in low probabilities of collision with bubbles, thus difficult to be caught by conventional size bubbles.

$$
\mathrm{P}_{\mathrm{c}}=\left[\frac{3}{2}+\frac{4 \mathrm{Re}^{0.72}}{15}\right]\left(\frac{\mathrm{D}_{\mathrm{p}}}{\mathrm{D}_{\mathrm{b}}}\right)^{2}
$$

Where $D_{b}$ is the bubble size, $D_{p}$ is the particle size, and Re is the Reynolds number.

The smaller particles have low momentum is the main reason for low flotation rate of fine particles. Figure 2-2 also suggests that nanobubbles generated in the liquid will 
increase the collision probability with particles. The existant of the dense distributed nanobubbles is the reason why the collision probability with particles is higher.

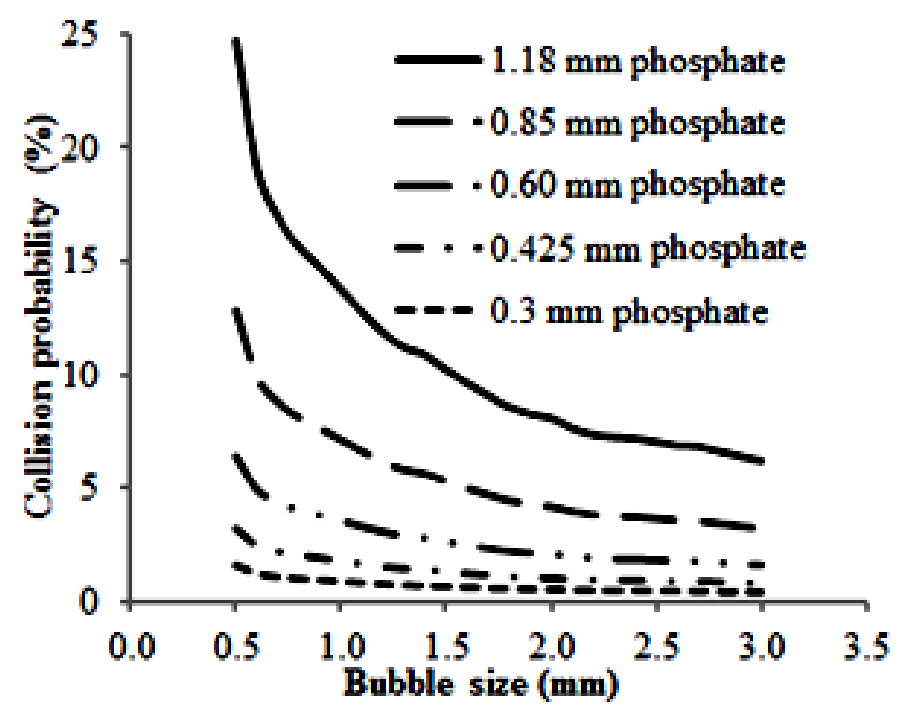

Figure 2- 2 Collision probability as a function of bubble size.

\subsubsection{Effect of particle and bubble size on attachment}

The flotation of fine particles poses a major challenge to mineral processing engineers.

One of the key problems in flotation of fine particles is their low inertia, meaning they tend to follow and be carried by liquid streamlines around a bubble, resulting in low collision probabilities. Their low inertia also implies that fine particles may not have sufficient kinetic energy to rupture the liquid film between particles and bubbles to form three-phase contact, resulting in low attachment probabilities.

The attachment of a particle to a bubble is a very complex process, which is influenced by the surface roughness, contact angle, particle size and surface forces of particles and bubbles. The surfaces of mineral particles are heterogeneous in terms of chemistry (Piantadosi et al., 2000) and roughness (Krasowska et al., 2009), resulting in differences 
in wetting behaviour. The stability efficiency may be expected to be the same for particles of the same mineral and size with the same contact angle (Muganda et al., 2010). The contact angle and contact area between a bubble and a particle in the presence of nanobubbles can be increased by using hydrodynamic cavitation-generated nanobubbles as shown in Figure 2-3. Besides, the nanobubbles can also coat over the particles, thus reducing collector consumption and expanding the range of floatable particle size. The role of collector is to increase particle hydrophobicity, thereby accelerating liquid film drainage and particle-bubble attachment. The increase in contact angle also increases the attachment force of particles to bubbles, leading to a reduced probability of particle detachment from the bubble, and recovery of coarser particles (Gontijo et al., 2007).

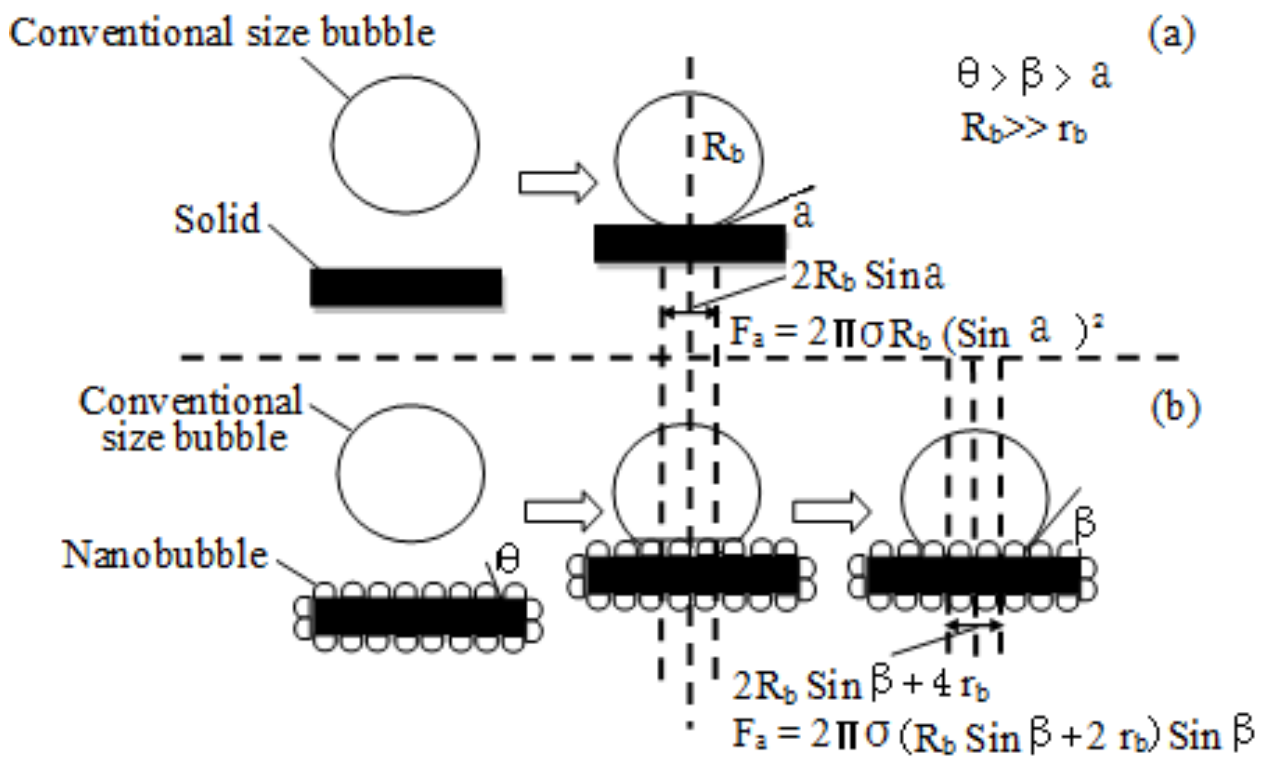

Figure 2- 3 Role of nanobubbles in enlarging contact angle:

(a) without nanobubbles coating on solid surface;

(b) with nanobubbles coating on solid surface. 
If a particle is sufficiently hydrophobic, the liquid film between the bubble and the particle thins and ultimately ruptures as a result of the attractive surface forces. This is followed by the establishment of the three-phase contact line. Only those hydrophobic particles, including particles coated over nanobubbles, whose induction time is smaller than the sliding time can be attached to air bubbles. Obviously the attachment process is selective and the difference in attachment probability of different particles determines the selectivity of flotation.

The attachment process is also determined by hydrodynamic and surface forces of particles and bubbles. Yoon (2000) has shown that the probability of adhesion can be predicted using various surface chemistry parameters that determine the surface forces of particles and bubbles, as shown in Eq (2-2).

$$
\mathrm{P}_{\mathrm{a}}=\sin ^{2}\left[2 \arctan \exp \left(-\frac{\left(45+8 \mathrm{Re}^{0.72}\right) \mathrm{V}_{\mathrm{b}} \mathrm{t}_{\mathrm{i}}}{15 \mathrm{D}_{\mathrm{b}}\left(\frac{\mathrm{D}_{\mathrm{b}}}{\mathrm{D}_{\mathrm{p}}}+1\right)}\right)\right.
$$

Where $\mathrm{V}_{\mathrm{b}}$ is the bubble rise velocity and $t_{\mathrm{i}}$ is the induction time. The contact time for a particle colliding with a bubble is very short, usually about $10^{-2} \mathrm{~s}$ or less. In order to make sure the flotation occurs, the induction time must be less than the contact time, which includes the collision time and the sliding time.

Figure 2-4 shows the effect of bubble size on bubble-particle attachment probability predicted by Eq (2-2), the attachment probability decreases with increasing bubble size and particle size. Ralston et al. (1999a) studied the effect of particle size on attachment efficiency both experimentally and analytically. They also found that probability decreases with increasing particle size and increases with increasing particle hydrophobicity. 


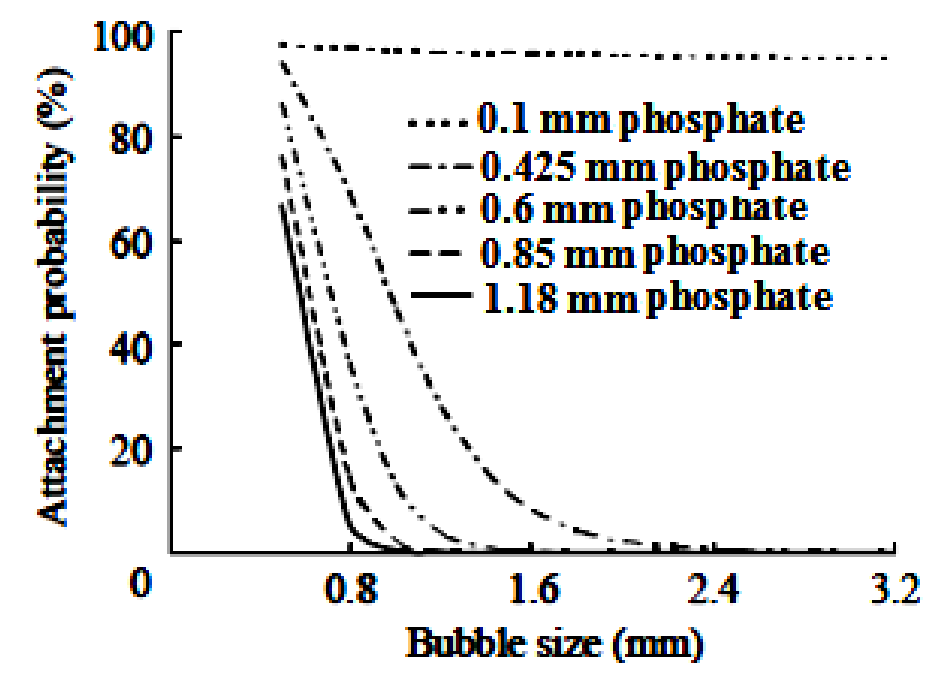

Figure 2- 4 Attachment probability as a function of bubble size.

\subsubsection{Effect of particle and bubble size on detachment}

After collision and attachment, all particles attached to air bubbles do not report to the froth phase. Some of them detach from bubble surface and fall back into the pulp phase. The flotability of coarse particles are poor because the bubble-particle aggregates are not strong enough to prevent the particle detachment from the bubble surface caused by the particle weight and turbulence eddies during the rise of the aggregates in the pulp. Particle detachment occurs when detachment forces exceed the maximum adhesive forces. One potential source of excessive forces is bubble oscillations caused by particle-bubble collisions. Kirchberg and Topfer (1964) showed that bubble collisions with large particles resulted in detachment of many particles from the bubble surface. Cheng and Holtham (1995) measured particle-bubble detachment forces by means of a vibration technique and found that the amplitude of oscillations imposed on the bubble is the dominant factor in the detachment process. There are many forces acting between a bubble and an attached particle. These forces are usually classified into four categories, including 
capillary force, $\mathrm{Fp}$, excess force, $\mathrm{Fe}$, which is the difference between the excess pressure in the bubble (favorable to attachment) and the hydrostatic force (favorable to detachment), real weight of particle in the liquid medium, $\mathrm{Fw}$, and other forces such as the hydrodynamic drag force, Fd (Fan et al., 2010b). Falutsu (1994) presented a fundamental analysis of the stability of the bubble-particle aggregate in column froths. The approach involved identifying forces acting on the bubble-particle system at equilibrium, during detachment, and during reattachment. Forces involved at equilibrium include: (a) the gravity force; (b) the static buoyancy of the immersed particle; (c) the hydrostatic pressure of the liquid column of height on the contact area; (d) the capillary force at the three-phase interface; and (e) the capillary pressure. Destructive forces identified during detachment were: (a) liquid flow (drag force); (b) slippage (combination of a centrifugal force and the gravity force); (c) bubble deceleration; and (d) bubble oscillation. Figure 2-5 shows that $\mathrm{Fw}$ increases more significantly than the other three forces with increasing the coal particle size, and becomes the dominant force among the four forces when the particle size is larger than $3 \mathrm{~mm}$.

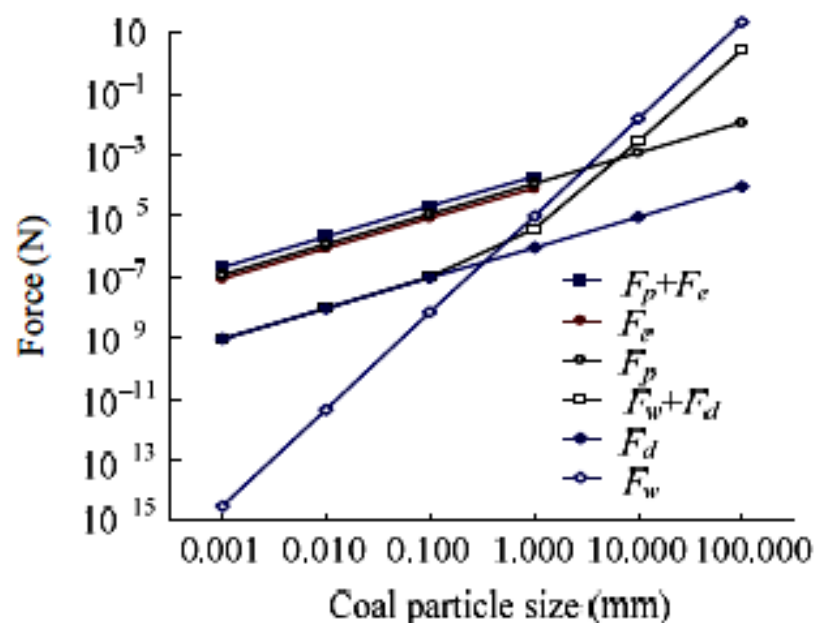

Figure 2- 5 Different Forces as a function of bubble size by Fan et al. (2010a). 
It is worth pointing out specifically that the excess force increases with decreasing bubble size, which means that smaller bubbles can be used to reduce coarse particle detachment and increase the upper flotation limit. This finding is significant since it proves from the viewpoint of flotation fundamentals that flotation recovery of coarse particles can be enhanced using smaller rather than larger bubbles. The existence of nanobubbles in flotation slurry reduced the rinsing velocity of conventional size flotation bubbles. Thus it can increase the bubble-particle sliding time, decrease the tangential velocities of particle sliding on bubble surface, and increase the bubble-particle attachment probability and decrease the detachment probability.

\subsubsection{Effect of bubble size on gas holdup}

Fine bubbles have significant effects on gas holdup, which is very essential in froth floatation cell of mineral based process industries.

The gas holdup and gas-holdup-gas-rate relationship has been used to identify the flow regime (Finch and Dobby, 1991). This work has shown, for example, that column flotation is best conducted under bubbly flow conditions and that a maximum gasholdup-gas-rate combination can be defined based on transition from bubbly to churn-turbulent flow (Xu et al., 1991; Finch and Dobby, 1991; Ityokumbul, 1993). Most of the work on gas holdup, however, has been done on two phase water-air systems, largely because of the difficulty of measuring gas holdup in the three-phase system. The implicit assumption is that the presence of solids will not alter the gas holdup substantially, while the effect of hydrophobic particles on the gas hold up investigated by Banisi et al. (1995) using coal at a concentration of $15 \% \mathrm{v} / \mathrm{v}$ shows that the presence of coal decreased the gas holdup, the reduction is similar in magnitude to that for 
hydrophilic solids. In contrast to the hydrophilic particles, hydrophobic particles become attached to bubbles which may alter their motion sufficiently to have an additional effect on gas holdup (Yianatos et al., 1988; Tustsumi et al., 1991). Zhou et al. (1998) also reported that increasing either the number of gas nuclei and nucleation sites, or the quantity of gas molecules dissolved in water under dynamic conditions may enhance bubble formation and lead to a higher gas holdup.

\subsubsection{Effect of nanobubble on flotation of coarse, fine and ultrafine particles}

Figure 2-6 shows that nanobubbles on particle surface activate flotation by promoting the attachment of larger bubbles since attachment between nanobubbles or gas nuclei and conventional size bubbles is more favored than bubble/solid attachment. That means nanobubbles act as a secondary collector for particles, reducing flotation collector dosage, enhancing particle attachment probability and reducing the detachment probability. This leads to substantially improved flotation recovery of poorly floating fine and ultrafine particles. The potential of cavitation generated picobubbles in improving fine particle froth flotation recovery has been demonstrated by tests on fine silica (Zhou et al., 1997b), inserting a cavitation tube with addition of small amount of air in the feed stream $(0.15 \mathrm{l} / \mathrm{min})$ showed a significant increase in fine silica recovery from $30 \%$ to $52 \%$. The results were better than using a static mixer in the feed stream. A similar conclusion was reached by Xu et al. (1996).

The advantage of cavitation generated pico-nano bubbles incorporating with conventional size bubbles in flotation has been explained by two factors that contribute to the increased flotation rate constant: a) the pico-nano bubbles formed in situ on hydrophobic particles may cause flocculation by a bubble-bridging mechanism, resulting in increasing the 
collision probability with the bubbles; b) particles frosted with pico-nano bubbles may present a surface favorable attachment to flotation sized bubbles (Fan, 2008). Besides, experiments on generating nanobubbles by hydrodynamic cavitation revealed that the energy dissipation levels for cavity formation in a flowing liquid could be much lower than predicted, depending on the content of dissolved gases, presence of free gas nuclei and design of cavitation tubes (Zhou et al, 2009).

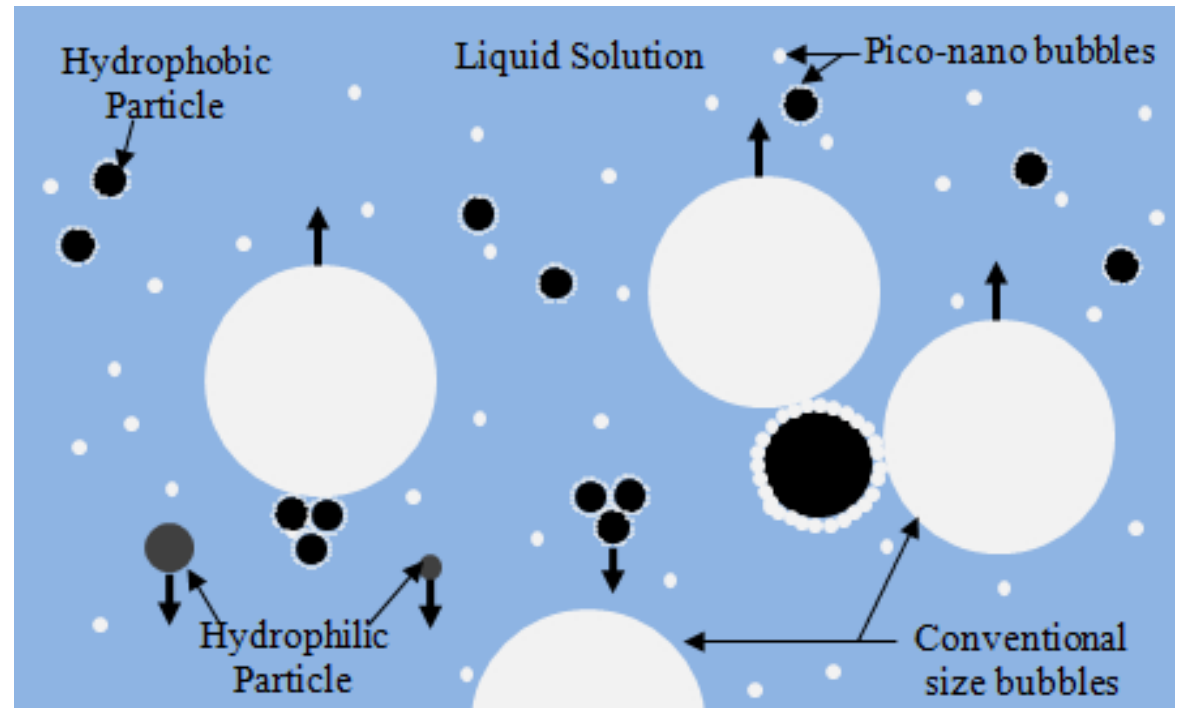

Figure 2- 6 Effect of pico-nano bubbles on coarse, fine and ultrafine particles.

\subsection{Generation of nanobubble}

For gas-supersaturated systems such as in dissolved air flotation or vacuum flotation, the formation of bubbles occurs as a result of various interactions between the liquid, the solid particles and dissolved gas. Bubble formation events are triggered by energy and density fluctuations at the molecular level not readily predictable from the continuum macroscopic equilibrium properties of the liquid-gas system (Hemmingsen, 1978). It is generally accepted that water undergoes very rapid fluctuations in molecular density and structural configurations due to the random motion of the water molecules individually or 
in clusters, leading to a continuous formation and collapse of molecular voids (Hemmingsen, 1990). It is likely that such voids serve as the foci or nuclei for the initial cavities. On the other hand, gas molecules dissolved in water may occupy some of these structural voids. Successful bubble nucleation depends on the availability of a large number of adjacent gas molecules, which must simultaneously obtain sufficient kinetic energy to overcome the forces of attraction between them, to enter into and be retained in the void to prevent its immediate collapse (Dean, 1944). This requires that the gas have a higher tendency to transfer from the water to the "gas phase" by diffusion than in the reverse direction. However, such voids rarely have radii greater than $10-20 \hat{\mathrm{A}}$, and their lifetimes are in the order of $10^{-12}$ second or less (Walstra, 1989). If such voids could survive, they will have to withstand a pressure of about 1440 atms (Walstra, 1989). Therefore, spontaneous, homogenous nucleation of gas bubbles in a supersaturated liquid should not occur under practical conditions (Walstra, 1989). However, samples of sea water, tap water, or even distilled water form visible bubbles when subjected to tensile, ultrasonic, or supersaturation pressures as small as 1 atm (Yount, 1976). In dissolved air flotation, usually 3-5 atm pressures are used to generate a sufficient amount of tiny bubbles $(<100 \mu \mathrm{m})$ to float aggregates and fine minerals (Gochin and Solari, 1983). This level of pressure is two orders of magnitude lower than the supersaturation required for spontaneous nucleation of bubbles in bulk water (Hemmingsen, 1977), and it implies that cavitation must be initiated by processes other than modest changes in pressure and the random motion of water and gas molecules (Yount, 1975). 


\subsubsection{Cavitation effect}

Cavitation is a process of in situ formation, growth and subsequent collapse of gas and/or vapor-filled cavities (microbubbles) in a fluid, while the first stage of cavitation, i.e., the creation or the birth of cavities is defined as nucleation (Knapp et al. 1970). Compared with other particle-bubble attachment mechanisms, cavitation/gas nucleation is a rapid process. Its` possible application in accelerating flotation rates is therefore attractive (Hemmingsen, 1975). Generating a large quantity of gas nuclei in slurry should be beneficial to flotation performance. Gas nuclei (cavities) and tiny bubbles can be generated, according to cavitation principles, by strong shear or turbulence and high fluid velocities which create the necessary pressure fluctuations in the bulk liquid so that at some locations the pressure drops below a critical value. High dissolved gas content, the presence of solid particles in the liquid and the surface roughness of the container and particles facilitate the initiation of cavities. Whether the gas nuclei will stabilize, and grow or collapse is determined by the mechanical strength of any surface film of adsorbed surfactants and gas diffusion rates. High dissolved gas content in a liquid will accelerate the rate of gas diffusion into and retention by the cavities thus preventing their immediate collapse. The presence of surfactants on the bubble surface retards the gas flow into or out of the bubble, thus reducing bubble growth/shrinkage rates and increasing the life time of the bubble in the liquid. Increasing the adsorption rates of surfactants, either by adding salts or increasing concentration, has a profound effect on reducing the gas diffusion rate, thus generating smaller bubbles. At the same time, the adsorbed surfactant film provides the mechanical strength to oppose shrinkage by changes in the hydrostatic pressure, making gas nuclei more stable. It should be noted, 
however, that gas nuclei alone may not induce flotation, due to their small size and buoyancy (Pease and Blinks, 1947). Hydrodynamic cavitation caused by fast flow of slurry $(>2 \mathrm{~m} / \mathrm{s})$ in the presence of surfactants may convert a limited number of tiny gas nuclei to bubbles large enough to levitate particles (Westwater, 1964). A more convenient approach is to produce relatively large bubbles elsewhere and bring them into contact with these gas nuclei frosted particles. These bubbles can be generated either by mechanical means, sparging or by air aspiration. Therefore, both tiny gas nuclei and flotation-sized bubbles are available for improving flotation performance.

To initiate cavitation, energy is needed since cavity formation involves creation of new interfaces. The input energy causes a local pressure fluctuation (e.g., acoustic cavitation by ultrasound), or through turbulence, creates velocity differences to reduce the local pressure below the liquid vapor pressure (e.g., hydrodynamic cavitation by fast liquid flow). Under such conditions vapor cavities form to counter-balance the local pressure gradient (Young, 1989). When cavities are brought to a relatively high pressure region in the liquid, they collapse, releasing high energy in a short time period (milli- or microseconds). Research indicates that at the moment of cavity collapse, the local conditions could reach 100-5000 atm and 1000-5000 atm (Flanngingan and Suslick, 2005). Such high energy release produces intense shock waves (with velocities exceeding the speed of sound (Prozorov et al., 2004), causing liquid micro jets and interfacial turbulence (Gogate and Pandit, 2001) which in turn intervene chemical reactions (Didenko and Suslick, 2002). The high speed liquid micro jets disturb the boundary layer at the solid surface, leading to the increased mass transfer and fragmentation of the particles (Momber, 2004; Rykaart and Haarhoff, 1995). In devices such as propellers and pumps, collapsing cavity 
bubbles causes a great deal of noise, damage to components, and a loss of efficiency (Brennen, 1995).

The use of cavitation to produce nanobubble, enhancing the flotation of minerals and coal has been studied for a long time. Nicol et al. (1986) reported that the use of a superimposed acoustic field nucleated precipitation of extremely small air bubble, nanobubble, on the surface of coal particles, resulting in an increase in the effective hydrophobicity of particle in the same manner as the coating of hydrocarbon collector on the coal surface. The work by Attalla et al. (2000) showed that cavitation, induced by an acoustic field, can increase product yields and reduce collector additions for a given yield, it was suggested that it may be better to induce cavitation by a mechanical means, and Hart et al. (2002) proved that by using a statistically based test program to investigate the effect of the generation of nanobubbles in flotation feed later on. Studies of Hampton and Nguyen (2010) also reported that nanobubbles, generated by hydrodynamic cavitation, were found to change the surface characters of minerals, increase contact angle of solids, and hence attachment force, bridge fine particles to form aggregates, minimize slime coating, remove oxidation layers on particle surfaces. In consequence utilizing nanobubbles reduce reagents consumption, therefore the presence of nanobubble in flotation pulp can widen the coal and minerals flotation particle size range, as well as increase the particle surface hydrophobicity. Comparing to other cavitation methods, hydrodynamic cavitation is the cheapest and most energy efficient method by using simple equipment with low maintenance cost. 


\subsubsection{Effect of design parameters of cavitation tube on nanobubble generation}

The factors affecting bubble formation by hydrodynamic cavitation include (Zhou, 1996a,b):

(1) Nozzle size. For a given length, higher liquid flow velocities through nozzle were needed to initiate cavitation with the smaller orifices as compared with the larger ones, probably due to a higher energy loss resulting from the flow contraction and friction in the smaller orifice (Ponasse et al. 1998).

(2) Nozzle length. The nozzle with a shorter tip length and larger diameter produced fewer bubbles. The same phenomenon was reported by Ross (1976).

Numerical analysis of hydrodynamics in a cavitation tube used for cavity bubble generation was conducted to estimate the pressure changes inside the nozzle and energy loss related to the ratio of throat-to-entrance diameter (Hu et al., 1998). By changing this ratio and the length of the nozzle, it is possible to determine optimum configuration of the lowest energy loss without sacrificing bubble formation by cavitation.

There are several designs of cavitation tube, such as orifice plate, nozzle and venturi, all of which are capable of producing cavitation at a desired point of the flow, while the venturi is chosen as the best option to generate pico-nano bubbles in this test, because the gradual reduction and the subsequent gradual expansion of venturi reduced the possibility of blockage. The venturi also has very low head loss characteristics resulting in minimal impact on the pump capacity in a plant. The permanent head loss of the other two options could be as high as 3-4 times greater than the venturi. Also, the ability to vary the throat length, which is a very important factor of the design of cavitation tube, in the venturi is 
also an advantage. By controlling the geometric and operating conditions, the cavitation can be achieved with maximum energy efficiency.

\subsubsection{Effect of agitation on nanobubble generation}

Hydrodynamic cavitation could provide a simple and practical method to create tiny bubbles in situ in flotation systems. In mechanical flotation cells, the strong shear induced by impeller action favors bubble formation by cavitation. For example, in the absence of added air, tiny bubbles formed near the agitation zone in a laboratory mechanical flotation cell (Grainer-Allen, 1970; Schubert, 2005; Zhou and Chow, 2006). The bubble creation zone expanded with increasing agitation intensity (i.e., rpm), as anticipated (Zhou and Chow, 2005). Senthikumar and Pandit (1999) also showed that the pressure for cavity cluster to collapse increased with increasing rotor speed in a high speed homogenizer. However, these cavity bubbles generated were short-lived, disappearing beyond the agitation zone.

Therefore, increasing shear or agitation inside a pressure chamber or increasing liquid release velocity should promote the formation of cavities. Any method to preserve the cavities generated would enhance bubble formation. This could be accomplished by: increasing dissolved gas content (either by using a higher saturation pressure, or using high solubility gases in water), adding surfactants, and adding solids.

\subsubsection{Effect of dissolved gas on nanobubble generation}

To evaluate the effect of dissolved gas in cavity formation, freshly boiled tap water was tested immediately. In this case, most pre-existing gas nuclei and dissolved gas in water would have been removed (Zhou et al., 1997). Compared to undraerated water, no cavity bubbles could be observed upon agitation (Figure 2-7a and b), even though a similar 
amount of air would have been entrained into the water under the same agitation conditions. This observation confirms that air entrainment is not a dominant factor for cavity bubble formation by agitation. However, after the boiling water cooled down overnight to equilibrate with the environment, cavity bubbles were observed again upon agitation (Figure 2-7c) (McNamara et al. 1999). In this case, the amount of dissolved air in water returned to the equilibrium value. The fact that agitation with air-saturated water produced cavity bubbles suggested that the formation of cavity bubbles was much easier in the presence of dissolved air, with or without pre-existing gas nuclei. To prevent or minimize the immediate collapse of cavity bubbles generated by hydrodynamic cavitation, at least a certain amount of dissolved gas should be present in the water ( Yalcin et al. 2002; Yalcin and Byers, 2006).

Fresh tap water $20^{\circ} \mathrm{C}$

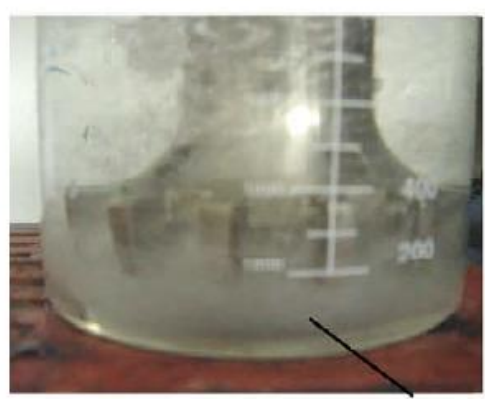

Bubble zone
Boiled tap water $83^{\circ} \mathrm{C}$

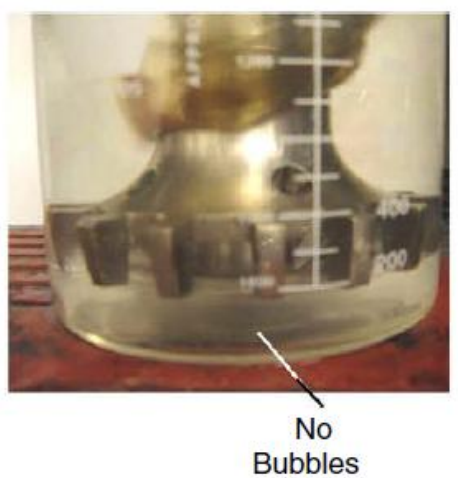

Boiled tap water Overnight, $20^{\circ} \mathrm{C}$

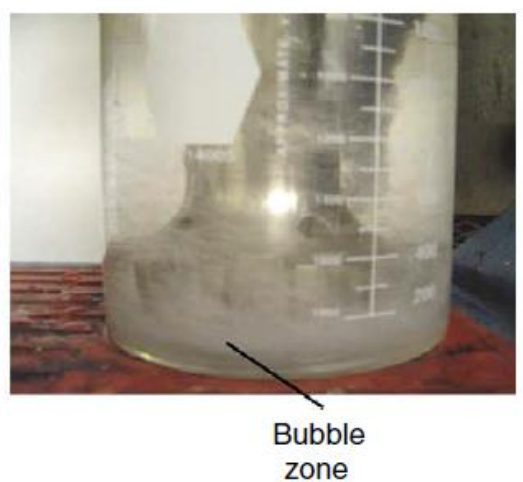

Figure 2- 7 Effect of dissolved air on bubble generation without added air.

(1400 ml tap water, $1200 \mathrm{rpm}$, Denver cell).

(Source: Zhou et al., 2005)

Similar observations were made for de-gassed slurry under vacuum (Xu et al., 2006). Using a high intensity agitation (HIA) cell in the absence of added air, tiny bubbles were generated in de-ionized water during HIA. After removing the dissolved gas in a vacuum oven $(\sim 90 \mathrm{kPa})$ at room temperature $\left(22^{\circ} \mathrm{C}\right)$ for $3 \mathrm{~h}$, however, the water was clear without 
any visible bubbles during HIA. Increasing agitation intensity produced more and smaller cavity bubbles. Cavity bubbles as small as $5 \mu \mathrm{m}$ were detected using a visualization system (Xu et al., 2006). Therefore in conventional mechanical flotation processes, at least three types of bubbles exist in the agitation zone, namely: water vapor cavity bubbles, bubbles containing both water vapor and dissolved gas, and air bubbles due to breakup of the air stream. All these three types of bubbles will interact in some fashion with suspended solids, contributing to the final particle-bubble attachment. The relative importance of these bubbles in fine particle flotation remains to be determined.

\subsubsection{Effect of surfactant on nanobubble generation}

Systematic experiments were carried out to examine factors affecting hydrodynamic cavitation by forcing water through a restriction (nozzle) in a flowing stream (Zhou et al., 1999). The bubble formation was detected by a light transmission method. In the presence of surfactant (Dowfroth 250 or DDA, dodecylamine), the critical liquid flow velocity for cavity bubble inception did not change (Zhou et al., 1997a). Hemmingsen (1978) also reported little effect of surfactant (and electrolyte) on the onset of cavitation. The presence of surfactant, however, did reduce the transmittance, suggesting an increase in the number of bubbles formed (or possibly a change in bubble size). An increase in the number of bubbles could also be due to stabilization of cavities by the adsorption of surfactant, which provide mechanical strength to resist the large pressure fluctuations (Wu, 1969). The presence of surfactants at cavity/water interface could also reduce the intensity of bubble bursts (Gogate and Pandit, 2001).

Klassen (1963) also observed that when frother was used, the quantity of gas released from the air-supersaturated water under dynamic conditions, over a given time interval, 
was higher than when no frother was added, the amount of released gas increasing with the frother concentration. As discussed earlier, adding frothers protects the cavities or gas nuclei formed from immediate collapse. These gas nuclei could have been crushed and eliminated if there was no frother present. Therefore, there are relatively more gas molecules in the form of gas aggregates or gas nuclei in the liquid. Such gas nuclei will have a size much larger than the molecules, depending on the super saturation pressures applied, typically in the range of about 1-10 $\mu \mathrm{m}$ (Flynn, 1964), and they will have higher rise velocities (or gas transfer rates) in the liquid, thus giving higher evolution rates.

\subsubsection{Effect of solid addition in solution on nanobubble generation}

Harvey et al. (1947) found that the critical velocity for cavity bubble formation could be less than $3 \mathrm{~m} / \mathrm{s}$ if hydrophobic particles were present. However, this critical velocity could be greater than $37 \mathrm{~m} / \mathrm{s}$ if free of hydrophilic particles.

Zhou et al. (1998) reported that the presence of solids in water could lead to different effects on bubble formation, depending on the surface properties of the solids. The presence of naturally hydrophobic coal and chemically (dodecylamine, DDA) induced hydrophobic silica enhanced bubble formation in gas-supersaturated water for a given range of solids content. Adding hydrophilic silica, on the other hand, reduced bubble formation in water. In gas-supersaturated systems, the rate of bubble evolution in the presence of solids may be governed by the nucleation process, the rate at which nuclei grow, or a combination of both, and/or the kinetics of detachment of bubbles from solid

surfaces (Carr et al., 1995; Gerth and Hemmingsen, 1980). Consequently, increasing either the number of gas nuclei and nucleation sites, or the quantity of gas molecules 
dissolved in water under dynamic conditions may enhance bubble formation and lead to a higher gas holdup.

\subsubsection{Effect of flow superficial velocity on nanobubble generation}

Nomura et al. (2011) also found that different flow superficial velocity greatly affected bubble formation.

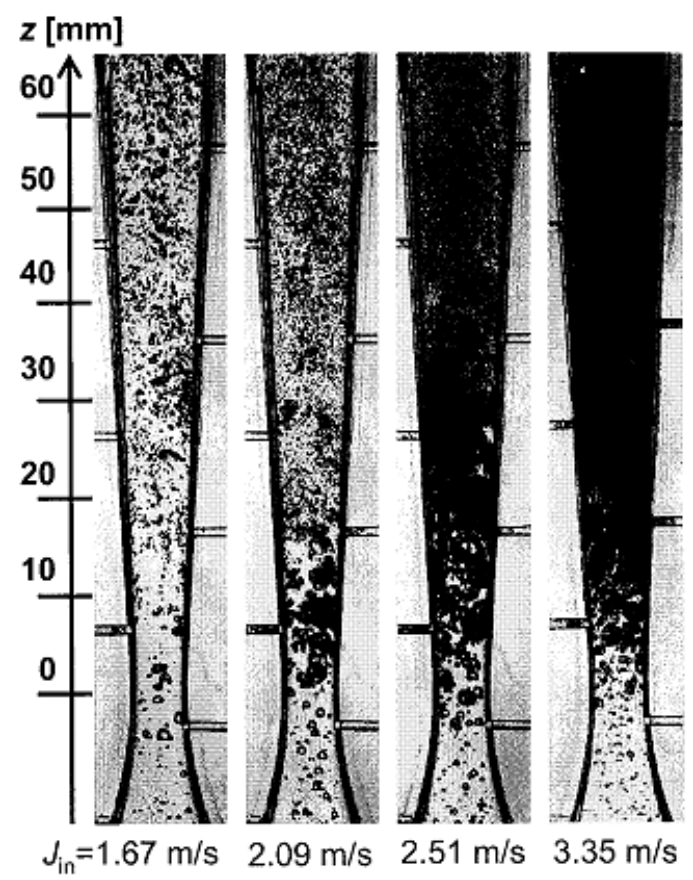

Figure 2- 8 Bubble collapse behavior at different superficial velocity

(Nomura et al, 2011)

It can be seen from Figure $2-8$ that when $\mathrm{J}_{\text {in }}=1.67 \mathrm{~m} / \mathrm{s}$, the bubble flowing into the diverging section break up into several small bubbles by shearing around the throat, when $\mathrm{J}_{\text {in }}$ increases to $2.09 \mathrm{~m} / \mathrm{s}$, the bubbles passed the throat expand toward downstream. The bubbles shrink rapidly and break into the tiny bubbles around $\mathrm{z}=10 \mathrm{~mm}$. In the case of $\mathrm{J}_{\text {in }}$ $=2.51 \mathrm{~m} / \mathrm{s}$, the tiny bubbles are suddenly generated drastic expansion and shrinkage as same as in the case of $\mathrm{J}_{\text {in }}=2.09 \mathrm{~m} / \mathrm{s}$. However the bubble breakup positions are around $\mathrm{Z}=20 \mathrm{~mm}$, where more downstream than it in $\mathrm{J}_{\mathrm{in}}=2.09 \mathrm{~m} / \mathrm{s}$. The expanded bubbles seem 
to coalesce and expand in the whole tube. The expanded bubbles change in a cloud of tiny bubbles. Therefore, it is confirmed that more bubble would be generated by increasing the superficial velocity in the inlet, and also the position where bubble breakup occurs moves downstream. Both cavity formation and dissolved gas content in water, therefore, determine the degree of bubble generation (Dupre et al. 1998; Soubiran and Sherwood, 2000).

\subsubsection{Effect of saturation pressure on nanobubble generation}

The extent of bubble formation in gas supersaturated solution was evaluated using gas holdup measurements (Zhou et al., 1995, 1998). (A similar method was recently used by Sahu et al. (2006) to evaluate bubble formation in soft drinks by ultrasonic excitation.) A sharp increase in gas holdup at $\mathrm{CO}_{2}$ super saturation pressures above $\sim 170 \mathrm{kPa}$ was reported. The critical velocity of $10-15 \mathrm{~m} / \mathrm{s}$ needed for cavitation of water without added gas was reduced to $5-7 \mathrm{~m} / \mathrm{s}$ by dissolving gas into the water. Stabilization provided by diffusion of gas molecules into the cavities was likely responsible for this observation.

Both cavity formation and dissolved gas content in water, therefore, determine the degree of bubble generation.

It can be seen from Figure 2-9 that higher saturation pressures (i.e., higher dissolved gas content in solution), did not guarantee production of more bubbles and higher gas holdups. This observation indicates that the generation and stabilization of bubbles are controlled by the diffusion of dissolved gas molecules into pre-existing gas nuclei and any cavities created. For example, the gas holdup was lower for a 1-mm release tube at a higher saturation pressure $(310 \mathrm{kPa})$ than that for a $1.5-\mathrm{mm}$ release tube at a lower saturation pressure $(241 \mathrm{kPa})$, because of a lower release velocity in the smaller tube. 
Figure 2-9 also shows that at the same super saturation pressure (e.g., $310 \mathrm{kPa}$ ), gas holdup increases with liquid release velocity. This suggests that more cavities were formed in the stream at higher release velocities, due to more turbulent flow conditions, with sufficient dissolved gas being present to diffuse into the cavities to prevent their collapse. The findings were consistent with the observations of Takahashi et al. (1979) and Jackson (1994) that the number of bubbles produced was strongly influenced by airsaturation pressure and increased with increasing liquid release rate.

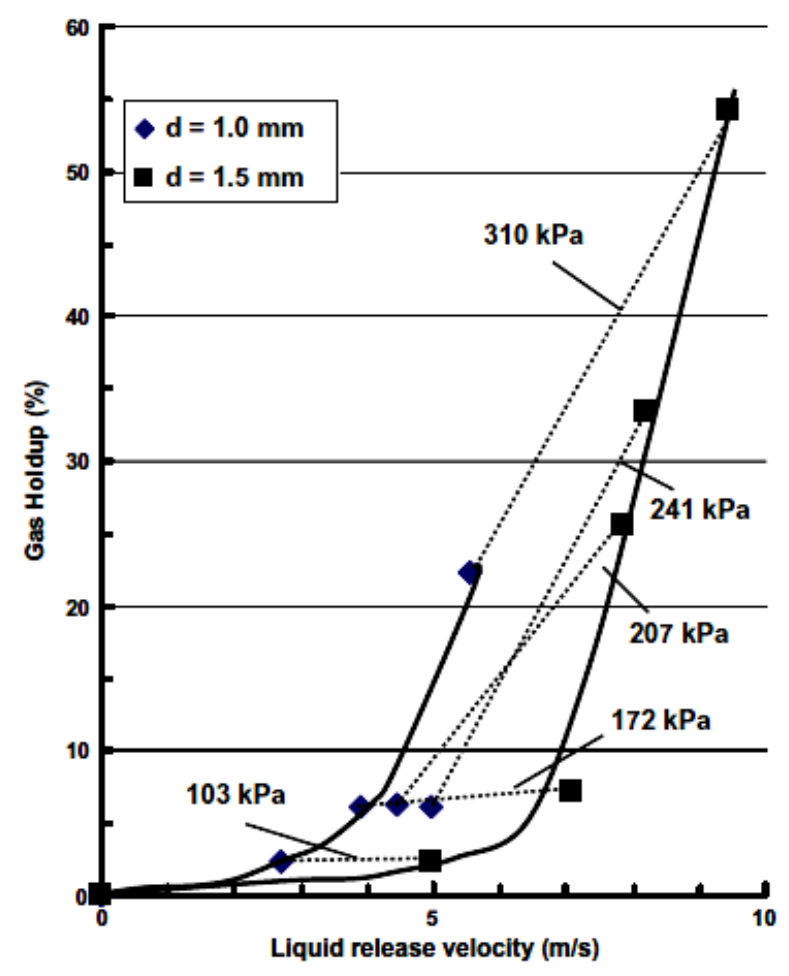

Figure 2- 9 Effect of liquid release velocity on bubble formation as evaluated by gas holdup (note: the dotted lines connect the points with same saturation pressures).

(Source: Zhou et al., 1996 b)

\subsubsection{Effects of addition of mixer and air intake location on nanobubble generation}

In dissolved air flotation, it was reported (Rees et al., 1980a, b;) that introducing the air on the suction side of the recycle pump gave saturation levels (i.e ., the ratio of the 
released amount of air from the supersaturated water to the theoretical value) from 60 to $80 \%$, which could be increased to $90 \%$ by fitting a turbine type mixer in the saturation vessel. From the earlier discussion on cavitation, it suggests: 1) injecting air and high dissolved gas content in water facilitate cavitation; 2). mixers increase the turbulence in the stream. And disperse the air more effectively; and the combination produces more stable cavities, which increase the gas evolution rate or saturation level for a given time.

The above argument can also be justified from the measurements made by Klassen (1963).

\subsection{Application of cavitation in flotation}

In the nano-bubble flotation columns (Yoon et al., 1988) and the bubble-injected hydrocyclone flotation cells (Jordan and Susko, 1992), both high feed injection speeds and static mixers are used. The frequent change of direction or a convergence of streamlines and the pressure fluctuations in the bulk liquid caused by the mixers are anticipated to promote cavitation and nucleation. Adding air further enhances this effect and makes the cavitation easier. While it may be argued that the high flotation rates obtained by using static mixers could be mainly caused by shearing to break the air stream into small bubbles, the contact cell (Amelunxen, 1993) and Ken-float cell appear to be two examples of direct exploitation of cavitation and gas nucleation. Basically, these cells can be considered as a combination of dissolved air flotation with conventional column flotation, the only main difference being that the contact cell does not have air spargers in the column. Therefore, Ken-float cells may be considered as an example of the application of two-stage attachment model, with gas nuclei and tiny 
bubbles generated in the dissolved air flotation chamber, and flotation-sized bubbles provided in a flotation column.

In mineral flotation, pneumatic cells (Bahr, 1985) and Jameson cells (Jameson, 1988) are reported to give high flotation rates. A key feature of these cells is a high slurry velocity, ranging from 6 to $12 \mathrm{~m} / \mathrm{s}$ generated through an injection nozzle. One of the reasons for the jet is to aspirate and disperse air into the receiving chamber (a similar mechanism to that used in venturi tubes (Jackson and Collisions, 1964)). High slurry velocities with a high concentration of solid particles could initiate cavitation in the stream and gas nucleation on the particle surface. When the feed emerges from the feed nozzle, gas nuclei in the slurry and those attached to hydrophobic particles expand, due to the sudden reduction in pressure. These gas-nucleated particles then contact with relatively large bubbles at high gas holdups (up to $50-60 \%$ ), which ensures high collision and attachment probabilities resulting in high flotation rates. This may be another example of two-stage attachment process (Dziensiewicz and Pryor, 1950) in action.

It should be noted, however, that gas nuclei alone may not induce flotation, due to their small size and buoyancy. Hydrodynamic cavitation caused by fast flow of slurry ( $>2 \mathrm{~m} / \mathrm{s}$ ) in the presence of surfactants may convert a limited number of tiny gas nuclei to bubbles large enough to levitate particles. A more convenient approach is to produce relatively large bubbles elsewhere and bring them into contact with these gas nuclei frosted particles. These bubbles can be generated either by mechanical means, sparging or by air aspiration. Therefore, both tiny gas nuclei and flotation-sized bubbles are available for improving flotation performance. 


\section{Chapter 3 Materials and Methodology for Coal Flotation}

\subsection{Characterization of coal sample}

Bituminous coal sample from Pittsburgh No. 8 seam was acquired from Green County, Pennsylvania, USA. After a three-day air dry, the coal sample was crushed to 1/4-in size, split and stored for further use. Prior to flotation test, portion of the minus 1/4-in size coal sample was grounded and pulverized through Holms mill for the pico-nano bubble flotation tests. The feed coal particle size and ash distributions are determined by the wet sieving method and ash analysis following ASTM method. The results given in Figure 31 are distributed over a wide size range with $28.25 \%$ particles being larger than $250 \mu \mathrm{m}$ and $28.16 \%$ particles being finer than $45 \mu \mathrm{m}$. The feed ash content is $30.64 \%$.

Table 3- 1 Particle size and ash distributions for flotation feed of

Pittsburgh No. 8 seam coal.

\begin{tabular}{|c|c|c|c|c|}
\hline \multirow{2}{*}{ Size, $\mu \mathrm{m}$} & \multicolumn{2}{|c|}{ Individual } & \multicolumn{2}{c|}{ Cumulative } \\
\cline { 2 - 5 } & $\mathrm{Wt}, \%$ & Ash, $\%$ & $\mathrm{Wt}, \%$ & Ash, \% \\
\hline$-700+600$ & 10.21 & 18.97 & 100 & 30.64 \\
\hline$-600+355$ & 11.82 & 18.94 & 89.79 & 31.97 \\
\hline$-355+250$ & 6.22 & 19.62 & 77.97 & 33.94 \\
\hline$-250+150$ & 9.16 & 19.92 & 71.75 & 35.18 \\
\hline$-150+75$ & 19.48 & 19.02 & 62.59 & 37.42 \\
\hline$-75+45$ & 14.95 & 26.03 & 43.11 & 45.73 \\
\hline-45 & 28.16 & 56.19 & 28.16 & 56.19 \\
\hline
\end{tabular}




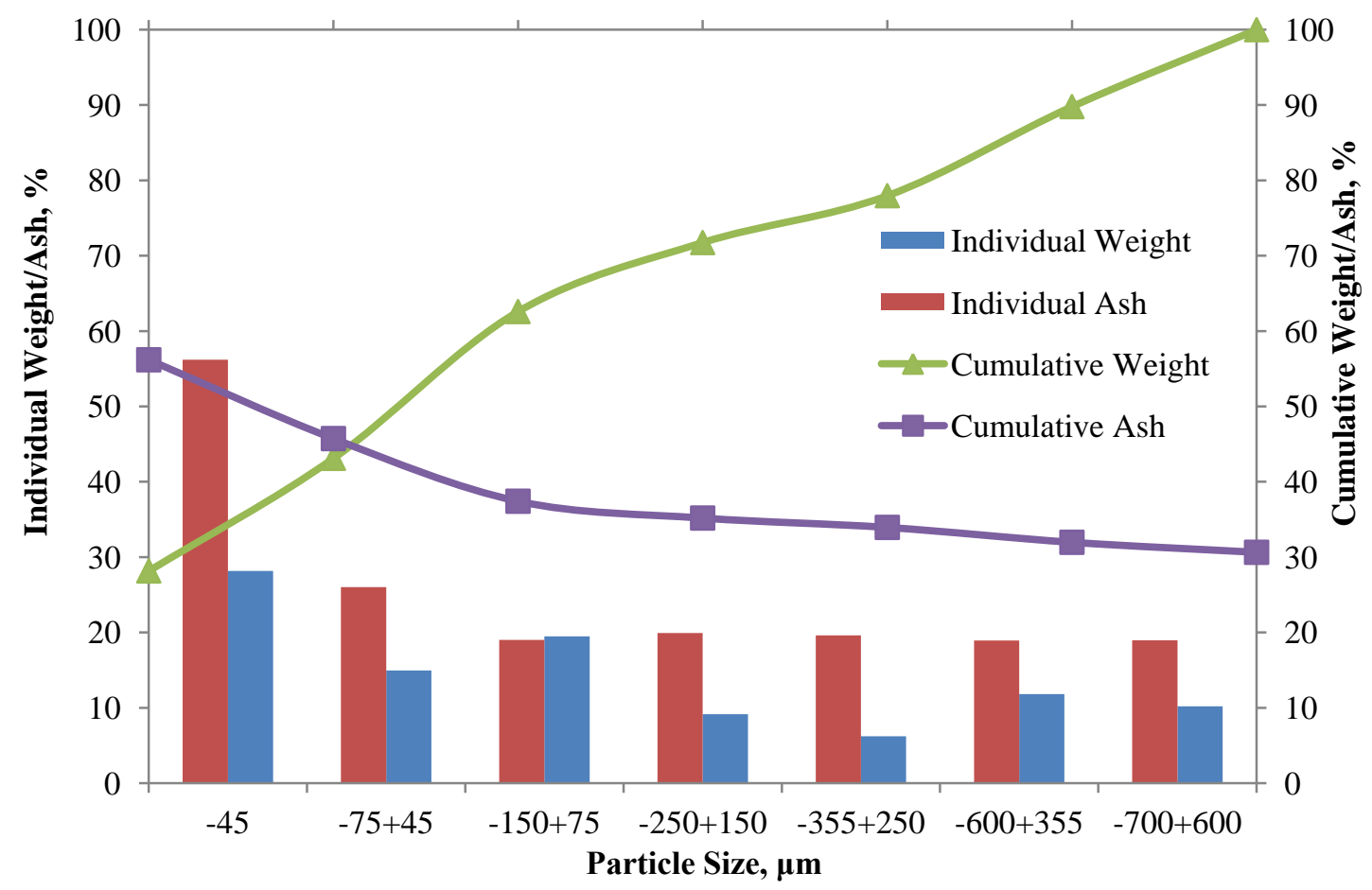

Figure 3- 1 Size and ash distribution for Pittsburgh No. 8 seam coal sample.

\subsection{Reagents for coal flotation}

The reagents used in this test are:

- Kerosene was used as a collector. It was supplied by Sigma-Aldrich, Inc., (St. Louis, MO).

- Methyl Isobutyl Carbinol (MIBC, $\mathrm{C}_{6} \mathrm{H}_{14} \mathrm{O}$ ) is a widely used frother in coal flotation. It was supplied by Aldrich Chemical Company (Miwaukee, WI).

- TTT frother is the blend of trimethyl pentanediol derivatives consists of trimethyl pentanediol monoisobutyrate, trimethyl pentanediol diisobutyrate, trimethyl pentanediol and surfactant such as fatty acid. These key ingredients are surface active materials. It was obtained from Zinkan Enterprises Inc (Twinsburg,OH). 


\subsection{Equipment and Design of Experiment for coal flotation}

\subsubsection{Bubble size analysis system}

For bubble size distribution determination, a smaller scale of column made of acrylic glass tubing with $5 \mathrm{~cm}$ in diameter and $67.3 \mathrm{~cm}$ in height was built. The lower section of the column is $15.2 \mathrm{~cm}$ in diameter and $18.4 \mathrm{~cm}$ in height. The larger diameter of the lower section of the column was to maintain a stability of the flow. The specially designed venturi tube and the static mixer were used to generate pico-nano bubbles and conventional sized bubbles, respectively. Figure 3-2 shows a schematic diagram of nanobubble generating and sampling system for measuring the bubble sizes and volume.

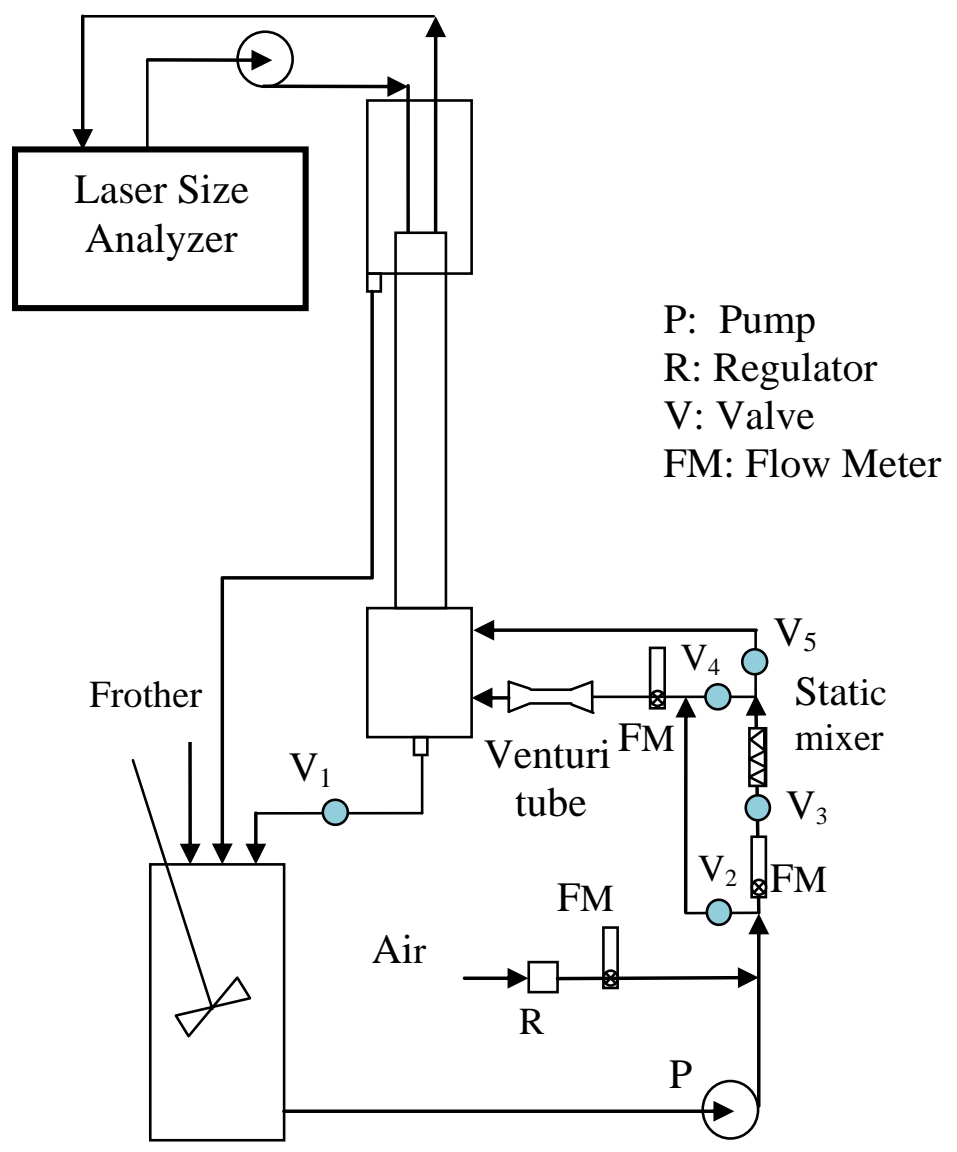

Figure 3-2 Schematic diagram of the pico-nano bubble measurement system. 
The recirculation flow rate through the static mix is $12 \mathrm{l} / \mathrm{min}$, which split at a two-way connector into the venturi tube and a pipe, directly connected to the lower section of the column. Different configurations of static mixer and venture tube can be made by controlling the valves. The pico-nano bubbles were generated from injecting air into the mixture of the recirculating solid-water and frother solution through the venturi tube. In the tests, MIBC and TTT were used as frothers. High purity silica in minus $20 \mu \mathrm{m}$ was treated with dodecylamine (DDA) to form a surface induced hydrophobic silica.

As shown in Figure 3-3, Malvern Mastersizer 2000 laser particle size analyzer was used to measure the size distributions of bubbles generated by Venturi tube and static mixer. The analysis is based on the principle of laser diffraction to analyze particles from 0.02 to $2000 \mu \mathrm{m}$ in size in a time span of several minutes.

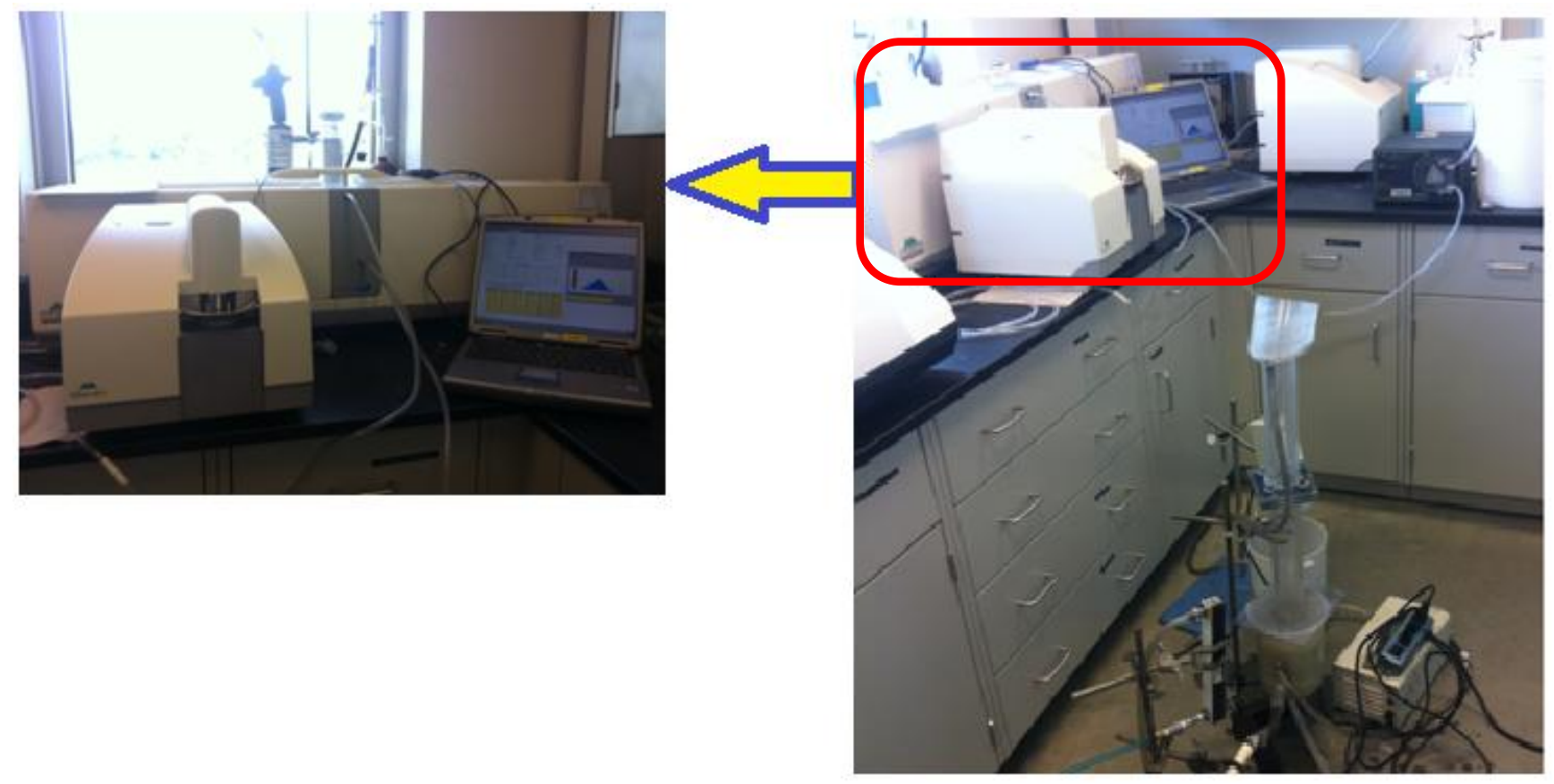

Figure 3- 3 Malvern Mastersizer 2000 laser particle size analyzer and the piconano bubble measurement system 
The cavitation tube generates pico-nano bubbles, which are mostly smaller than $0.5 \mu \mathrm{m}$, and nanobubbles. Most of the nanobubbles generated are smaller than $1 \mu \mathrm{m}$. On the other hand, the static mixer generated conventional sized bubbles in the range of 10 and 100 $\mu \mathrm{m}$. The bubbles and solid-solution mixture were pumped out of the Malvern Mastersizer 2000 laser particle size analyzer by a peristaltic pump. The bubble sample, which was pumped into the laser size analyzer, passes though the measurement area of the optical bench, where a laser beam illuminates the bubbles. A series of detectors then accurately measure the intensity of light scattered by the particles within the sample over a wide range of angles. This data is then analyzed to calculate the size of the bubbles that created the scattering pattern.

\subsubsection{Effect of different designs of cavitation venturi tube on bubble distribution}

The schematic diagram of venture tube used for pico-nano bubble generation is given in Figure 3-4.

Table 3- 2 Flotation conditions for pico and nano bubble generation.

\begin{tabular}{|l|l|}
\hline \multicolumn{1}{|c|}{ Feed solids \% } & $\begin{array}{l}1 \% \text { wt dodecylamine (DDA) } \\
\text { induced hydrophobic silica } \mathrm{SiO}_{2}\end{array}$ \\
\hline Frother & $20 \mathrm{ppm}$ MIBC \\
\hline Feed flow rate & $12 \mathrm{l} / \mathrm{min}$ \\
\hline Gas flow rate & $1.6 \mathrm{~cm} / \mathrm{s}$ \\
\hline
\end{tabular}

There are critical conditions to design the appropriate dimensions of the venture tube. The key critical conditions include i) the ratio of the diameter of throat and outlet of the venture tube, ii) the ratio of the length of the throat and the diameter of throat, and iii) input and output cone angles. They are also dependent upon column dimensions, solid carrying capacity, slurry characteristics, feed rate, etc. In order to study the effects of the 
dimensions of the venturi tube on bubbles distributions, a four-factor three-level Central Composite Experimental Design was conducted. Unless otherwise specified, the tests were performed under the conditions given in Table 3-2.

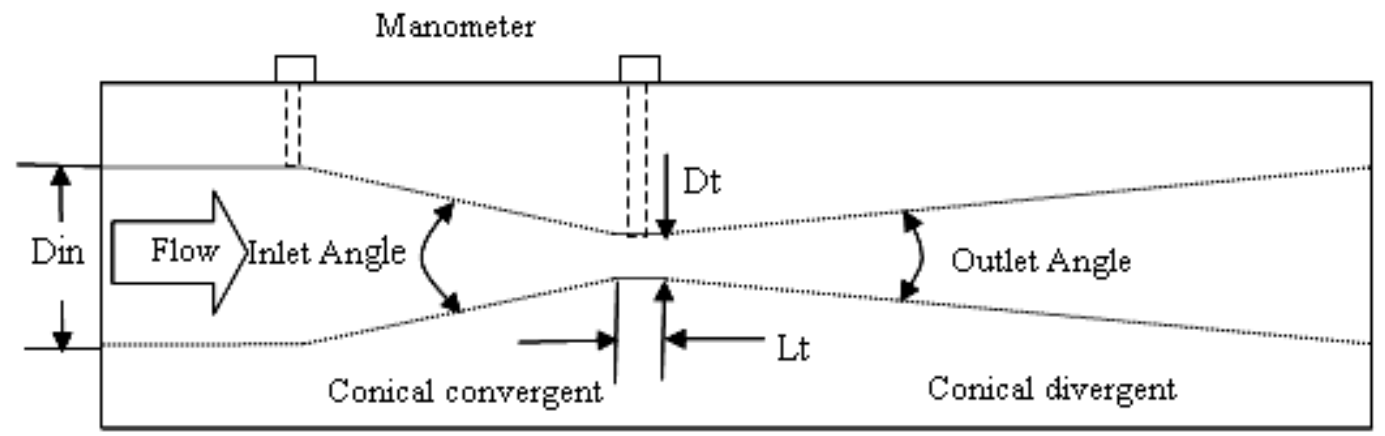

Figure 3-4 Skematic diagram of cavitation venturi tube.

Table 3-3 Levels of variables for a four-factor three-level design of venturi tube design tests.

\begin{tabular}{|c|c|c|c|c|}
\hline \multirow{2}{*}{ Variable } & \multirow{2}{*}{ Code } & \multicolumn{3}{|c|}{ Level } \\
\cline { 3 - 5 } & & Low & Middle & High \\
\cline { 3 - 5 } & & -1 & 0 & 1 \\
\hline $\mathrm{D}_{\text {in }} / \mathrm{D}_{\mathrm{t}}$ & $\mathrm{A}$ & 2 & 4 & 6 \\
\hline $\mathrm{L}_{\mathrm{t}} / \mathrm{D}_{\mathrm{t}}$ & $\mathrm{B}$ & 1 & 2 & 3 \\
\hline Inlet Angle ( Degree) & $\mathrm{C}$ & 15 & 21 & 27 \\
\hline Outlet Angle (Degree) & $\mathrm{D}$ & 8 & 12 & 16 \\
\hline
\end{tabular}

Note: $\mathrm{D}_{\text {in }}$ is a constant with the value of $5 \mathrm{~cm}$ in this test.

Response surface methodology was used to analyze the four-factor three-level Central Composite experiment data. Response surface and contours were generated for the piconano bubble volume and mean pico-nano bubble size as a function of four key process parameters include the ratio of the diameter of throat and outlet of the venture tube $\left(\mathrm{D}_{\text {in }} / \mathrm{D}_{t}\right)$, the ratio of the length of the throat and the diameter of throat $\left(\mathrm{L}_{\mathrm{t}} / \mathrm{D}_{\mathrm{t}}\right)$, and inlet and outlet cone angles. The specific levels of individual variables are given in Table 3-3. The details of designed experiments are shown in Table 3-4. The test data was analyzed 
with the JUMP program (SAS Institute Inc., Cary, NC). The optimal designed venturi tube will be at the maximum pico-nano bubble volume and minimum mean pico-nano bubble size.

Table 3- 4 Four-factor three-level experimental design of venturi tube design tests.

\begin{tabular}{|c|c|c|c|c|}
\hline Run & $\mathrm{A}$ & $\mathrm{B}$ & $\mathrm{C}$ & $\mathrm{D}$ \\
\hline 1 & -1 & -1 & 1 & 1 \\
\hline 2 & 1 & -1 & 1 & 1 \\
\hline 3 & -1 & 1 & -1 & 1 \\
\hline 4 & 1 & -1 & -1 & 1 \\
\hline 5 & 1 & 1 & -1 & -1 \\
\hline 6 & 1 & -1 & 1 & -1 \\
\hline 7 & -1 & 0 & 0 & 0 \\
\hline 8 & 0 & 0 & 0 & 0 \\
\hline 9 & -1 & 1 & -1 & -1 \\
\hline 10 & 0 & 0 & 0 & 0 \\
\hline 11 & 0 & 1 & 0 & 0 \\
\hline 12 & 1 & 0 & 0 & 0 \\
\hline 13 & -1 & -1 & -1 & 1 \\
\hline 14 & -1 & 1 & 1 & 1 \\
\hline 15 & 0 & -1 & 0 & 0 \\
\hline 16 & 1 & -1 & -1 & -1 \\
\hline 17 & 0 & 0 & 1 & 0 \\
\hline 18 & -1 & -1 & 1 & -1 \\
\hline 19 & 0 & 0 & 0 & -1 \\
\hline 20 & 1 & 1 & -1 & 1 \\
\hline 21 & 1 & 1 & 1 & -1 \\
\hline 22 & 0 & 0 & 0 & 1 \\
\hline 23 & 1 & 1 & 1 & 1 \\
\hline 24 & -1 & 1 & 1 & -1 \\
\hline 25 & -1 & -1 & -1 & -1 \\
\hline 26 & 0 & 0 & -1 & 0 \\
\hline
\end{tabular}




\subsubsection{Effects of different types frother and frother dosage on pico-nano bubble generation.}

Two different types of frother, MIBC and TTT, were tested by using the optimal designed venturi tube. The frother dosage will be changed from $10 \mathrm{ppm}$ to $100 \mathrm{ppm}$ in order to study the effect of frother dosage on the pico-nano bubble distributions.

\subsubsection{Design and set up a pico-nano bubble enhanced flotation column.}

Figure 3-5 shows the schematic diagram of a $5 \mathrm{~cm}$ ID and $250 \mathrm{~cm}$ height open flotation column which is equipped with static-mixer and cavitation venturi tube for nano and picco bubble generating. The slurry feed is fed into a feed tank, and an appropriate amount of collector and frother are then added with a circulating loop and pump for preconditioning. The feed slurry is then fed into the upper part of the flotation column. The fresh water, air, and recirculating tailings are passed through the static-mixer and caviation venturi tube connected in a series before being injected into the lower part of the flotation column. The wash water spraying device is also installed over the froth, to flush down the entrained ultrafine mineral particles, prior to exit from flotation column. A specially designed tailings separator and discharge unit is added at the bottom of the column. This separator is used to improve the mixing and contacting of tiny bubbles and solids by recirculating about one third of solids from outer funnel back into the flotation column. The tailings from inner funnel of the separator are discharged from the column as reject. The cavitation venturi tube is specifically designed for generating the pico and nano bubbles as shown in Figure 3-4 (Young, 1989; ISO 5167-4:2003; Tao, 2004; Peng and Xiong, 2013). Pico-nano bubbles have low mobility characteristic than larger bubbles such as micro bubble and millimeter bubbles. The static mixer was used to produce the 
micro-bubbles and, more importantly to improve the mixing and contacting of bubbles and solids from the tailings re-circulating stream.

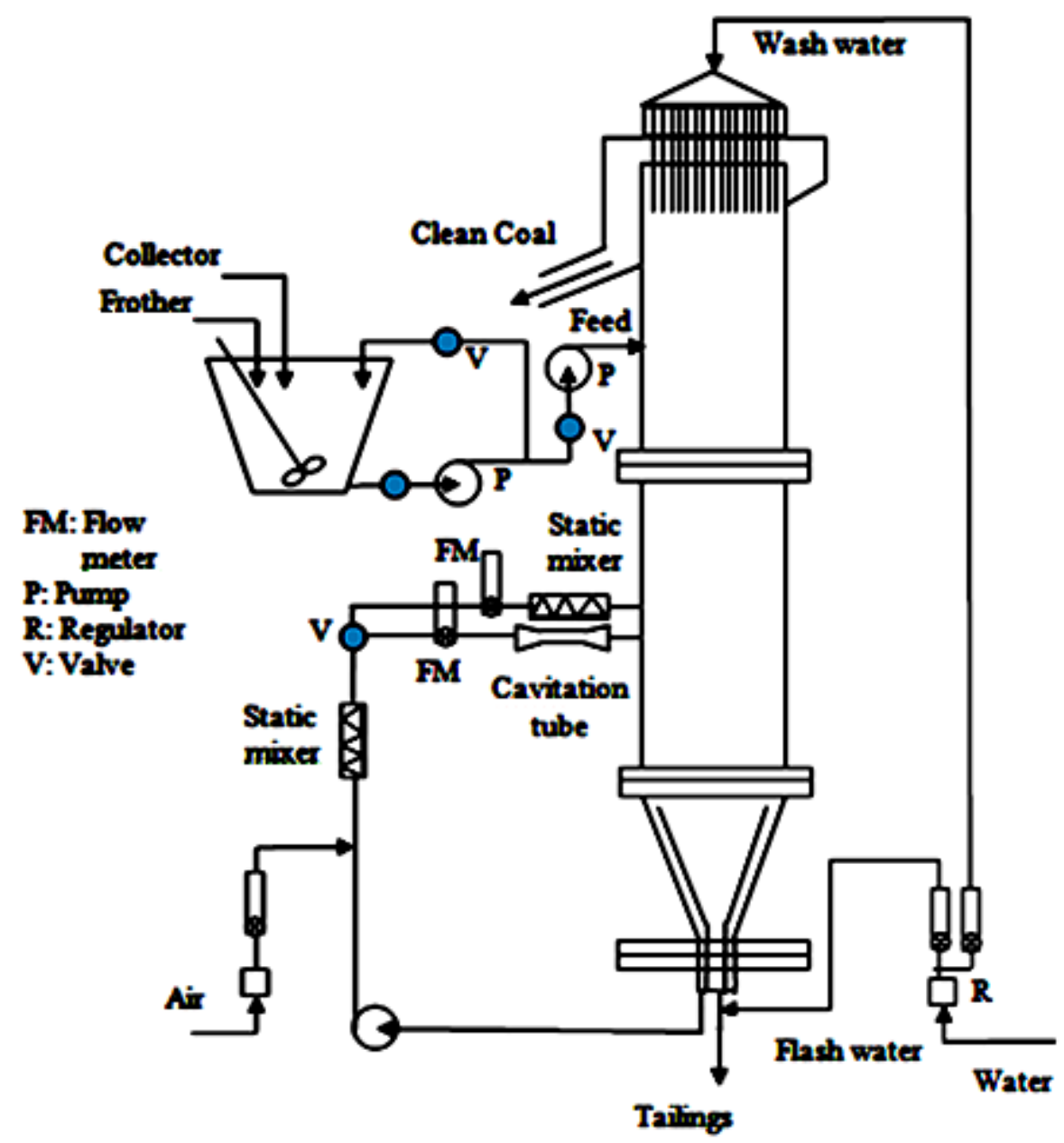

Figure 3- 5 Schematic diagram of flotation column with static mixer and venture tube for pico and nano bubble generation.

3.3.5 Perform two-stage Design of Experiment and single factor test for coal

\section{flotation.}

\subsubsection{Six-factor three-level experimental design}

In this study, combustible material recovery and clean coal ash were selected as the response surface. The formulas used for calculating clean coal yield, combustible 
material recovery, ash rejection, separation efficiency and pico-nano bubble and nano bubble percent are defined as follows:

$$
\begin{aligned}
\mathrm{Y}_{\mathrm{c}} \% & =\frac{\left(\mathrm{A}_{\mathrm{t}}-\mathrm{A}_{\mathrm{f}}\right)}{\left(\mathrm{A}_{\mathrm{t}}-\mathrm{A}_{\mathrm{c}}\right)} \% \\
\mathrm{R}_{\mathrm{c}} \% & =\mathrm{Y}_{\mathrm{c}} \% \frac{\left(100-\mathrm{A}_{\mathrm{c}}\right)}{\left(100-\mathrm{A}_{\mathrm{f}}\right)} \% \\
\mathrm{~A}_{\mathrm{rej}} \% & =\frac{\left(100-\mathrm{Y}_{\mathrm{c}}\right) \mathrm{A}_{\mathrm{t}}}{\mathrm{A}_{\mathrm{f}}} \% \\
\mathrm{E}_{\mathrm{sp}} \% & =\mathrm{R}_{\mathrm{c}} \%-\left(100-\mathrm{A}_{\mathrm{rej}}\right) \% \\
\mathrm{R}_{\mathrm{p}} \% & =100 * \frac{\mathrm{Vp} \%}{\mathrm{Vo} \%}
\end{aligned}
$$

Where:

$\mathrm{A}_{\mathrm{c}} \%=$ Clean coal product ash, $\%$

$\mathrm{A}_{\mathrm{f}} \%=$ Feed ash, $\%$

$\mathrm{A}_{\mathrm{t}} \%=$ Tailings ash, $\%$

$\mathrm{A}_{\text {rej }} \%=$ Ash rejection, $\%$

$\mathrm{E}_{\mathrm{sp}} \%=$ Separation efficiency, $\%$

$\mathrm{R}_{\mathrm{c}} \%$ = Combustible material recovery, $\%$

$\mathrm{R}_{\mathrm{p}} \%=$ Pico-nano and nano bubbles percent, $\%$

$\mathrm{V}_{\mathrm{p}} \%=$ Volume of Pico-nano and nano bubbles, $\%$

$\mathrm{V}_{\mathrm{o}} \%=$ Volume of all the bubbles, $\%$

$\mathrm{Y}_{\mathrm{c}} \%$ = Clean coal yield, $\%$

$\mathrm{Y}_{\mathrm{f}} \%=$ Feed yield, $\%$

Yt $\%=$ Tailings yield, $\%$

The levels of variables used in this design are given in Table 3-5. The six process parameters include collector dosage, frother concentration, gas flow rate, feed solids 
concentration, feed rate, and superficial wash water rate. Each numeric factor is varied over 3 levels: plus and minus 1 (factorial points) and the center point. The levels of process variables were coded as " -1 ", " 0 " and "+1", respectively, where "-" represents the low or middle-low level, "0" represents the middle level and "+" represents the middle-high or high level of the factors. The details of designed experiments are shown in Table 3-6.

Table 3- 5 Levels of variables for a six-factor three-level design for column flotation using pico-nano bubbles.

\begin{tabular}{|c|c|c|c|c|}
\hline \multirow{2}{*}{ Variable } & \multirow{2}{*}{ Code } & \multicolumn{3}{|c|}{ Level } \\
\cline { 3 - 5 } & & Low & Middle & High \\
\cline { 3 - 5 } & & -1 & 0 & 1 \\
\hline Gas flow rate( cm/s) & $\mathrm{A}$ & 0.5 & 1.5 & 2.5 \\
\hline Collector dosage $(\mathrm{lb} /$ ton$)$ & $\mathrm{B}$ & 0.3 & 0.9 & 1.5 \\
\hline Frother dosage $(\mathrm{ppm})$ & $\mathrm{C}$ & 5 & 20 & 40 \\
\hline Solids concentration $(\%)$ & $\mathrm{D}$ & 5 & 10 & 20 \\
\hline Feed rate $(\mathrm{cm} / \mathrm{s})$ & $\mathrm{E}$ & 0.2 & 0.6 & 1 \\
\hline Superficial wash water rate $(\mathrm{cm} / \mathrm{s})$ & $\mathrm{F}$ & 0.1 & 0.3 & 0.5 \\
\hline
\end{tabular}

In running JMP program, "Stepwise" analysis method was selected. The stepwise regression procedure is applied by setting the probabilities ( $\mathrm{p}$-value) threshold for statistical analysis, which uses p-values (significance levels) to enter and remove effects from the model by setting the value of Probability to enter, which is the maximum pvalue that an effect must have to be entered into the model during a forward step, and Probability to leave, which is the minimum p-value that an effect must have to be removed from the model during a backward step. The value of the Probability to enter is 0.1 and the value of the Probability to leave is 0.05 in our experiment. The models will be developed through "forward" and "backward" procedures to select significant parameters. 
Table 3- 6 Six-factor three-level experimental design for column flotation using pico-nano bubbles.

\begin{tabular}{|c|c|c|c|c|c|c|}
\hline Run & A & B & C & $\mathrm{D}$ & $\mathrm{E}$ & $\mathrm{F}$ \\
\hline 1 & 0 & 1 & -1 & 0 & 1 & -1 \\
\hline 2 & -1 & 0 & 0 & 0 & 1 & 1 \\
\hline 3 & 1 & 0 & -1 & 1 & 1 & 0 \\
\hline 4 & 1 & 1 & 0 & -1 & 0 & -1 \\
\hline 5 & 0 & -1 & 0 & 1 & 0 & 1 \\
\hline 6 & 1 & 0 & -1 & 1 & 0 & -1 \\
\hline 7 & 1 & 0 & -1 & 1 & -1 & 1 \\
\hline 8 & 1 & 1 & 0 & -1 & 1 & 0 \\
\hline 9 & -1 & 1 & 1 & 1 & 1 & 1 \\
\hline 10 & -1 & -1 & -1 & -1 & 0 & 0 \\
\hline 11 & 0 & 1 & -1 & 0 & 0 & 1 \\
\hline 12 & 0 & 0 & 1 & -1 & 1 & -1 \\
\hline 13 & -1 & -1 & -1 & -1 & -1 & -1 \\
\hline 14 & -1 & 1 & 1 & 1 & 0 & 0 \\
\hline 15 & 1 & 1 & 0 & -1 & -1 & 1 \\
\hline 16 & -1 & 1 & 1 & 1 & -1 & -1 \\
\hline 17 & 0 & 0 & 1 & -1 & 0 & 1 \\
\hline 18 & 0 & 1 & -1 & 0 & -1 & 0 \\
\hline 19 & 0 & -1 & 0 & 1 & -1 & 0 \\
\hline 20 & -1 & 0 & 0 & 0 & 0 & 0 \\
\hline 21 & 1 & -1 & 1 & 0 & 0 & -1 \\
\hline 22 & -1 & -1 & -1 & -1 & 1 & 1 \\
\hline 23 & 1 & -1 & 1 & 0 & 1 & 0 \\
\hline 24 & 0 & 0 & 1 & -1 & -1 & 0 \\
\hline 25 & 0 & -1 & 0 & 1 & 1 & -1 \\
\hline 26 & 1 & -1 & 1 & 0 & -1 & 1 \\
\hline 27 & -1 & 0 & 0 & 0 & -1 & -1 \\
\hline
\end{tabular}




\subsubsection{Three-factor three-level central composite Design of Experiment}

After the first stage of Design of Experiment (DOE), the 6 factors were reduced to 3 factors as shown in Table 3-7. For the second set of tests was carried out using a threefactor three-level central composite experimental design with the Jump software.

Table 3- 7 Levels of variables for a three-factor three-level design for column flotation using pico-nano bubbles.

\begin{tabular}{|c|c|c|c|c|}
\hline \multirow{2}{*}{ Variable } & \multirow{2}{*}{ Code } & \multicolumn{3}{|c|}{ Level } \\
\cline { 3 - 5 } & & Low & Middle & High \\
\cline { 3 - 5 } & & -1 & 0 & 1 \\
\hline Collector dosage (lb/ton) & $\mathrm{A}$ & 0.3 & 0.6 & 0.9 \\
\hline Solids concentration (\%) & $\mathrm{B}$ & 4 & 7 & 10 \\
\hline Feed rate $(\mathrm{cm} / \mathrm{s})$ & $\mathrm{C}$ & 0.2 & 0.4 & 0.6 \\
\hline
\end{tabular}

Notes: Gas flow rate $(\mathrm{cm} / \mathrm{s}): 1.5$, Frother dosage $(\mathrm{ppm}): 20$, Superficial wash water rate $(\mathrm{cm} / \mathrm{s}): 0.3$.

Table 3- 8 Three-factor three-level central composite design for column flotation using pico-nano bubbles.

\begin{tabular}{|c|c|c|c|}
\hline Run & A & B & C \\
\hline 1 & -1 & -1 & -1 \\
\hline 2 & 1 & -1 & 1 \\
\hline 3 & 0 & 0 & -1 \\
\hline 4 & 0 & 0 & 0 \\
\hline 5 & 1 & 1 & -1 \\
\hline 6 & 1 & -1 & -1 \\
\hline 7 & -1 & 0 & 0 \\
\hline 8 & -1 & -1 & 1 \\
\hline 9 & 0 & 1 & 0 \\
\hline 10 & 0 & 0 & 1 \\
\hline 11 & 1 & 0 & 0 \\
\hline 12 & -1 & 1 & -1 \\
\hline 13 & -1 & 1 & 1 \\
\hline 14 & 1 & 1 & 1 \\
\hline 15 & 0 & -1 & 0 \\
\hline 16 & 0 & 0 & \\
\hline & & & \\
\hline
\end{tabular}


The three process parameters include collector dosage, feed solids concentration, and feed rate. Response surface methodology was used to analyze the three-factor three-level central composite experiment data. Response surface and contour curves were generated for the clean coal ash content and combustible material recovery as a function of the operating three process parameters. The three process parameters include collector dosage, feed solids concentration and Feed rate. Each numeric factor is varied over 3 levels: plus and minus 1 (factorial points) and the center point. The levels of process variables were coded as " -1 ", " 0 " and " +1 ", respectively, where " -" represents the low or middle-low level, " 0 " represents the middle level and "+" represents the middle-high or high level of the factors. The details of designed experiments are shown in Table 3-8.

\subsubsection{Single factor experimental test}

In order to further determine the optimization of process parameters, single factor experimental test was conducted by varying the collector dosage and feed rate.

Table 3- 9 Process parameters and operational conditions.

\begin{tabular}{|c|c|}
\hline Process parameters & Operation conditions \\
\hline Gas flow rate $(\mathrm{cm} / \mathrm{s})$ & 1.5 \\
\hline Collector dosage $($ kerosene $)(\mathrm{lb} / \mathrm{ton})$ & 0.1 to 0.9 \\
\hline Frother dosage $(\mathrm{ppm})$ & 20 \\
\hline Solids concentration $(\%)$ & 4 \\
\hline Feed rate $(\mathrm{cm} / \mathrm{s})$ & 0.2 to 0.5 \\
\hline Superficial wash water rate $(\mathrm{cm} / \mathrm{s})$ & 0.3 \\
\hline
\end{tabular}

The operation conditions of feed coal slurry, solids concentration and reagent dosages were kept constant, as given in Table 3-9. The optimal operation conditions will be 
achieved by maximizing the recovery of combustible materials with high quality of clean coal, at the same time, minimizing the clean coal ash content.

\subsubsection{Study the effect of particle size on separation efficiency and combustible material recovery.}

The clean coal and tailing obtained from column flotation with/without pico-nano bubble were used in this study. The particle size distribution of the tested samples was determined by wet sieve: the separation of fines from the coarse portion of the sample while suspended in water solution introduced to a testing sieve. The water medium was used to negate static charges, break down agglomerates and lubricate near-size particles. After the fines have been washed through the sieve, the residue was oven-dried and reweighed. The combustible material recovery and separation efficiency will be calculated based on the sieving results.

Table 3-10 Size range of wet sieving.

\begin{tabular}{|c|c|}
\hline US sieve No. & Size $(\boldsymbol{\mu m})$ \\
\hline 28 & 700 \\
\hline 30 & 600 \\
\hline 45 & 355 \\
\hline 60 & 250 \\
\hline 100 & 150 \\
\hline 200 & 75 \\
\hline 325 & 45 \\
\hline
\end{tabular}

\subsubsection{Compare the flotation results of pico-nano bubble column flotation with that of release analysis.}

Release analysis test was conducted in order to determine the ultimate recovery-grade relationship that can be achieved by any flotation process for the treatment of a given coal. Among all the existing procedures of release analysis, the reverse release analysis is 
shown to combine the best features of simplified release analysis and timed release analysis in terms of locating the elbow of the yield vs. ash curve and extending the curve into the low ash, low yield region (Randolph, 1997). So the reverse release analysis procedure was used in this study. The detailed procedure is illustrated schematically in Figure 3-6.

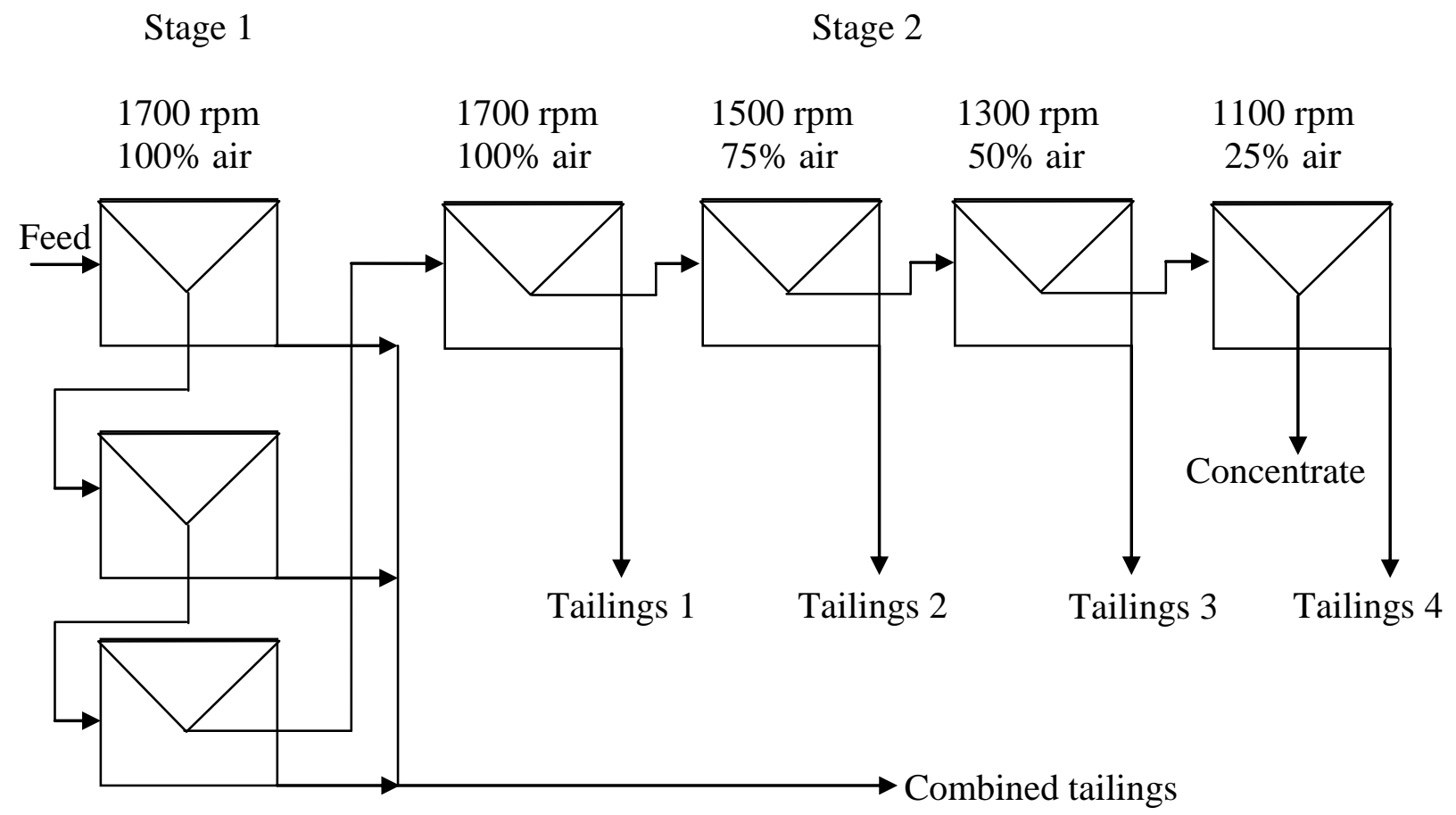

Figure 3- 6 Schematic diagram of the reverse release analysis procedure.

Reverse release analysis test procedure was carried out using a Denver D-12 model flotation machine in 2 liter cell. Two hundred grams coal sample was ground to a given particle size distribution for sufficient liberation, then mixed with distilled water to make 2 liter pulp with $10 \%$ solid concentration. The slurry was then conditioned for five minutes at $1700 \mathrm{rpm}$ with $1 \mathrm{lb} /$ ton MIBC. After that, the first phase of the simplified release analysis procedure was followed by adding in $2 \mathrm{lb} /$ ton kerosene to separate the 
floatable material from the non-floatable material. The tailings from the first phase were saved for analysis while the concentrate was reconditioned in order to begin the second phase of the test. A concentrate was then collected until the froth was barren at an impeller speed of $1700 \mathrm{rpm}$ and an aeration rate of $100 \%$. The tails were saved for analysis and the concentrate was refloated at $1500 \mathrm{rpm}$ and $75 \%$ air. This procedure was repeated two additional times, each time at a lower aeration rate and impeller speed, to produce five tailings fractions (including tails from the first phase) and one concentrate fraction. These fractions were then filtered, dried, weighed, and assayed to produce a release curve. 


\section{Chapter 4 Materials and Methodology for \\ Phosphate Reverse Flotation}

\subsection{Materials}

The dolomitic phosphate peddle (DDP) sample with high dolomite content was collected from Lakeland, Pork County, Florida. For phosphate production in Florida, the phosphate matrix is mined by high capacity dragline. The matrix mined is made into slurry using high pressure water jet and then pumped to the phosphate beneficiation plant for washing operation using spiral classifier. After washing, the matrix is split by screens and cyclones into three streams, usually $+1 \mathrm{~mm},-1+0.1 \mathrm{~mm}$ and $-0.1 \mathrm{~mm}$ size fractions. The minus $0.1 \mathrm{~mm}$ (- U.S. Sieve No.140) fines as phosphatic slimes, which is discarded into tailings ponds due to its high impurities and low $\mathrm{P}_{2} \mathrm{O}_{5}$ content. The size fraction of $-1+0.1$ $\mathrm{mm}$ is fed to conventional two stage "Crago" flotation process to recover phosphate concentrate by rejecting silica (Zhang, 1995; El-Shall, 2001). The plus $1 \mathrm{~mm}$ coarse size fraction is known as phosphate pebble. This fraction is usually mixed with flotation concentrate to form a composite product for downstream production, if its $\mathrm{MgO}$ content is lower than a certain limit, such as $1.0 \sim 1.5 \%$. If the $\mathrm{MgO}$ content is higher than certain amount, it is considered as dolomitic phosphate pebble (DPP) and will be discarded as waste. In Florida, there is a three-one-third principle, namely one third of the phosphate mineral is bound with slimes, one third is recovered with the "Crago" flotation process and another one third is contained in phosphate pebble. The Crago "Double Float" process is inefficient, as it floats about $30-40 \%$ of the sands in the flotation feed twice 
and requires a deoiling step (El-Shall et al., 1999; Anazia and Hanna, 1988; Lawendy and Mcclellan, 1993).

\subsubsection{Size distribution and chemical analysis}

Chemical analysis of the DPP sample is given in Table 4-1. It can be seen that the DPP sample contains $25.92 \% \mathrm{P}_{2} \mathrm{O}_{5}, 3.47 \% \mathrm{MgO}$ and $14.46 \% \mathrm{SiO}_{2}$. The beneficiation process should be capable of rejecting both dolomite and silica for obtaining an acceptable phosphate concentrate containing over $30 \% \mathrm{P}_{2} \mathrm{O}_{5}$ and less than $1 \% \mathrm{MgO}$ at the $\mathrm{P}_{2} \mathrm{O}_{5}$ recovery as high as possible.

Table 4- 1 Chemical analysis of the as-received dolomotic phosphate sample.

\begin{tabular}{|c|c|c|c|c|c|}
\hline Component & $\mathrm{P}_{2} \mathrm{O}_{5}$ & $\mathrm{MgO}$ & $\mathrm{Fe}_{2} \mathrm{O}_{3}$ & $\mathrm{CaO}$ & Insoluble \\
\hline$\%$ & 25.92 & 3.47 & 0.96 & 38.58 & 14.46 \\
\hline
\end{tabular}

Size distribution analysis of the as-received DPP sample is given in Table 4-2. As shown in the analysis results that plus $6.3 \mathrm{~mm}$ coarse fraction contains $3.97 \% \mathrm{MgO}$ content, and minus $0.1 \mathrm{~mm}$ fine fraction contains greater than $8 \% \mathrm{MgO}$ content. These size fractions have much higher $\mathrm{MgO}$ compared with other size fractions. Particularly the $\mathrm{P}_{2} \mathrm{O}_{5}$ grade in minus $0.1 \mathrm{~mm}$ size fraction is much lower than in plus $0.1 \mathrm{~mm}$ size fraction. This is mainly because the carbonate minerals such as dolomite and limestone are more fragile than apatite and easily to be fractured (Clerici, 1984). These data indicates that the minus $0.1 \mathrm{~mm}$ size fraction can be deslimed and discarded with very low $\mathrm{P}_{2} \mathrm{O}_{5}$ loss. Although the coarse size fraction also contains high $\mathrm{MgO}$ content, it is not economical to eliminate this fraction because it contains high $\mathrm{P}_{2} \mathrm{O}_{5}$ content (Rao, 1979). Table 4-3 shows the size distribution and chemical analysis after the rejection of minus $0.1 \mathrm{~mm}$ size fraction. This deslimed DDP sample is then used to prepare the flotation feed for this study. 
Table 4- 2 Size distribution and chemical analysis of as-received dolomitic phosphate pebble sample.

\begin{tabular}{|c|c|c|c|c|c|c|c|c|c|c|c|}
\hline \multirow{2}{*}{$\begin{array}{l}\text { Size } \\
(\mathrm{mm})\end{array}$} & \multirow{2}{*}{$\mathrm{Wt} \%$} & \multicolumn{5}{|c|}{ Grade, \% } & \multicolumn{5}{|c|}{ Recovery, \% } \\
\hline & & $\mathrm{P}_{2} \mathrm{O}_{5}$ & $\mathrm{MgO}$ & $\mathrm{Fe}_{2} \mathrm{O}_{3}$ & $\mathrm{CaO}$ & Insol. & $\mathrm{P}_{2} \mathrm{O}_{5}$ & $\mathrm{MgO}$ & $\mathrm{Fe}_{2} \mathrm{O}_{3}$ & $\mathrm{CaO}$ & Insol. \\
\hline+6.3 & 40.84 & 22.3 & 3.97 & 0.91 & 40.1 & 11.03 & 37.22 & 44.85 & 41.21 & 40.81 & 36.85 \\
\hline$-6.3+4.0$ & 29.54 & 26.82 & 3.90 & 0.87 & 42.01 & 10.89 & 32.38 & 31.87 & 28.50 & 30.92 & 26.31 \\
\hline$-4.0+2.38$ & 12.75 & 27.54 & 2.63 & 0.85 & 40.62 & 9.65 & 14.35 & 9.27 & 12.02 & 12.91 & 10.06 \\
\hline$-2.38+1.0$ & 8.62 & 28.1 & 1.46 & 0.76 & 40.34 & 14.32 & 9.90 & 3.48 & 7.26 & 8.67 & 10.10 \\
\hline$-1.0+0.5$ & 2.38 & 26.2 & 1.63 & 0.79 & 39.24 & 17.69 & 2.55 & 1.07 & 2.08 & 2.33 & 3.44 \\
\hline$-0.5+0.1$ & 2.14 & 18.9 & 1.22 & 0.61 & 24.61 & 48.03 & 1.65 & 0.72 & 1.45 & 1.31 & 8.41 \\
\hline-0.1 & 3.73 & 12.8 & 8.47 & 1.81 & 32.85 & 15.82 & 1.95 & 8.74 & 7.49 & 3.05 & 4.83 \\
\hline Total & 100 & 24.47 & 3.62 & 0.90 & 40.13 & 12.23 & 100.00 & 100.00 & 100.00 & 100.00 & 100.00 \\
\hline
\end{tabular}


Table 4- 3 Size distribution and chemical analysis of as-received dolomitic phosphate pebble sample.

\begin{tabular}{|c|c|c|c|c|c|c|c|c|c|c|c|}
\hline \multirow{2}{*}{$\begin{array}{l}\text { Size } \\
(\mathrm{mm})\end{array}$} & \multirow{2}{*}{$\mathrm{Wt} \%$} & \multicolumn{5}{|c|}{ Grade, $\%$} & \multicolumn{5}{|c|}{ Recovery, \% } \\
\hline & & $\mathrm{P}_{2} \mathrm{O}_{5}$ & $\mathrm{MgO}$ & $\mathrm{Fe}_{2} \mathrm{O}_{3}$ & $\mathrm{CaO}$ & Insol. & $\mathrm{P}_{2} \mathrm{O}_{5}$ & $\mathrm{MgO}$ & $\mathrm{Fe}_{2} \mathrm{O}_{3}$ & $\mathrm{CaO}$ & Insol. \\
\hline+6.3 & 42.42 & 22.3 & 3.97 & 0.91 & 40.1 & 11.03 & 37.96 & 49.14 & 44.54 & 42.10 & 38.69 \\
\hline$-6.3+4.0$ & 30.68 & 26.82 & 3.90 & 0.87 & 42.01 & 10.89 & 33.02 & 34.91 & 30.80 & 31.90 & 27.63 \\
\hline$-4.0+2.38$ & 13.24 & 27.54 & 2.63 & 0.85 & 40.62 & 9.65 & 14.63 & 10.16 & 12.99 & 13.31 & 10.57 \\
\hline$-2.38+1.0$ & 8.95 & 28.1 & 1.46 & 0.76 & 40.34 & 14.32 & 10.09 & 3.81 & 7.85 & 8.93 & 10.60 \\
\hline$-1.0+0.5$ & 2.47 & 26.2 & 1.63 & 0.79 & 39.24 & 17.69 & 2.60 & 1.17 & 2.25 & 2.40 & 3.61 \\
\hline$-0.5+0.1$ & 2.24 & 18.9 & 1.22 & 0.61 & 24.61 & 48.03 & 1.70 & 0.80 & 1.58 & 1.36 & 8.90 \\
\hline Total & 100 & 24.92 & 3.43 & 0.87 & 40.41 & 12.09 & 100.00 & 100.00 & 100.00 & 100.00 & 100.00 \\
\hline
\end{tabular}




\subsubsection{Mineral liberation}

A small representative dolomitic phosphate pebble sample was taken and milled to minus $0.71 \mathrm{~mm}$ (- 25 mesh). Microscopic observation was made on different size fractions of the milled sample to determine the percentage of liberated phosphate mineral in each size range. The results of the microscopic observation are presented in Table 4-4. It can be seen that the percentage of liberated phosphate particles increased as the particle size became finer, but there was no significant change after minis $150 \mu \mathrm{m}$ (- 100 mech). In order to achieve high quality phosphate concentrate, the sample should be ground to minus $700 \mu \mathrm{m}$ (- $25 \mathrm{mesh})$ for liberating phosphate from gangue minerals.

Table 4- 4 Percentage of liberated dolomitic phosphate sample with different size fractions.

\begin{tabular}{|c|c|c|}
\hline US sieve No. & $\begin{array}{c}\text { Size range } \\
(\mu \mathrm{m})\end{array}$ & Liberated phosphate, $\%$ \\
\hline$-28+30$ & $-700+600$ & 79 \\
\hline$-30+40$ & $-600+425$ & 82 \\
\hline$-40+45$ & $-425+355$ & 84 \\
\hline$-45+100$ & $-355+150$ & 86 \\
\hline$-100+140$ & $-150+106$ & 95 \\
\hline$-140+200$ & $-106+75$ & 95 \\
\hline-200 & -75 & 95 \\
\hline
\end{tabular}




\subsubsection{Grinding}

A laboratory sparser rod mill was employed to grind the sample to $700 \mu \mathrm{m}$ (- 25 mesh) for satisfactory liberation of phosphate from gangue minerals, particularly liberation of dolomite. The dimension of the rod mill is $200 \mathrm{~mm}$ ID and $250 \mathrm{~mm}$ length. The size, quatity, weight and percentage of the stainless steel rods used as grinding media are presented in Table 4-5.

Table 4- 5 Stainless steel grinding media for rod mill.

\begin{tabular}{|c|c|c|c|}
\hline $\begin{array}{c}\text { Rod diameter } \\
(\mathrm{mm})\end{array}$ & $\begin{array}{c}\text { Quantity } \\
\text { (No. of rods })\end{array}$ & $\begin{array}{c}\text { Weight } \\
(\mathrm{g})\end{array}$ & $\begin{array}{c}\text { Weight } \\
(\%)\end{array}$ \\
\hline 16 & 14 & 6732 & 50.51 \\
\hline 12 & 12 & 4283 & 32.14 \\
\hline 10 & 36 & 2313 & 17.35 \\
\hline Total & 10 & 13328 & 100.00 \\
\hline
\end{tabular}

A series of grinding tests were conducted to determine the grinding time to achieve sufficient liberation using $1000 \mathrm{~g}$ and $1500 \mathrm{~g}$ sample size for each batch, respectively. The particle size distribution at different grinding time is presented in Table 4-6 and 4-7, and also plotted in Figure 4-1.

It can be seen from Figure 4-1 that the steeper slope in the relationship between the percent passing for a given particle size, the shorter the grinding time to prepare the $100 \%$ passing $700 \mu \mathrm{m}$ size. 50 minutes is required to produce $100 \%$ passing $700 \mu \mathrm{m}$ size 
fraction for $1000 \mathrm{~g}$ sample, while 90 minutes is needed to generate $100 \%$ passing $700 \mu \mathrm{m}$ size fraction for $1500 \mathrm{~g}$ sample.

Table 4- 6 Size distribution at different grinding time for $1000 \mathrm{~g}$ dolomitic phosphate pebble sample.

\begin{tabular}{|c|c|c|c|}
\hline \multirow{2}{*}{$\begin{array}{c}\text { Grinding time } \\
(\text { min) }\end{array}$} & \multicolumn{3}{|c|}{ Wt. \% Passing } \\
\cline { 2 - 4 } & $-700 \mu \mathrm{m}$ & $-150 \mu \mathrm{m}$ & $-75 \mu \mathrm{m}$ \\
\hline 10 & 45.83 & 21.01 & 14.53 \\
\hline 20 & 64.74 & 33.37 & 20.26 \\
\hline 30 & 88.92 & 41.69 & 25.93 \\
\hline 40 & 95.07 & 56.81 & 36.47 \\
\hline 50 & 100.00 & 72.96 & 43.23 \\
\hline
\end{tabular}

Table 4- 7 Size distribution at different grinding time for $1500 \mathrm{~g}$ dolomitic phosphate pebble sample.

\begin{tabular}{|c|c|c|c|}
\hline \multirow{2}{*}{$\begin{array}{c}\text { Grinding time } \\
(\mathrm{min})\end{array}$} & \multicolumn{3}{|c|}{ Wt. \% Passing } \\
\cline { 2 - 4 } & $-700 \mu \mathrm{m}$ & $-150 \mu \mathrm{m}$ & $-75 \mu \mathrm{m}$ \\
\hline 50 & 68.35 & 37.01 & 18.72 \\
\hline 60 & 75.62 & 58.13 & 36.61 \\
\hline 70 & 83.61 & 68.92 & $39 . .53$ \\
\hline 80 & 96.87 & 75.68 & 43.36 \\
\hline 90 & 100.00 & 79.04 & 45.64 \\
\hline
\end{tabular}




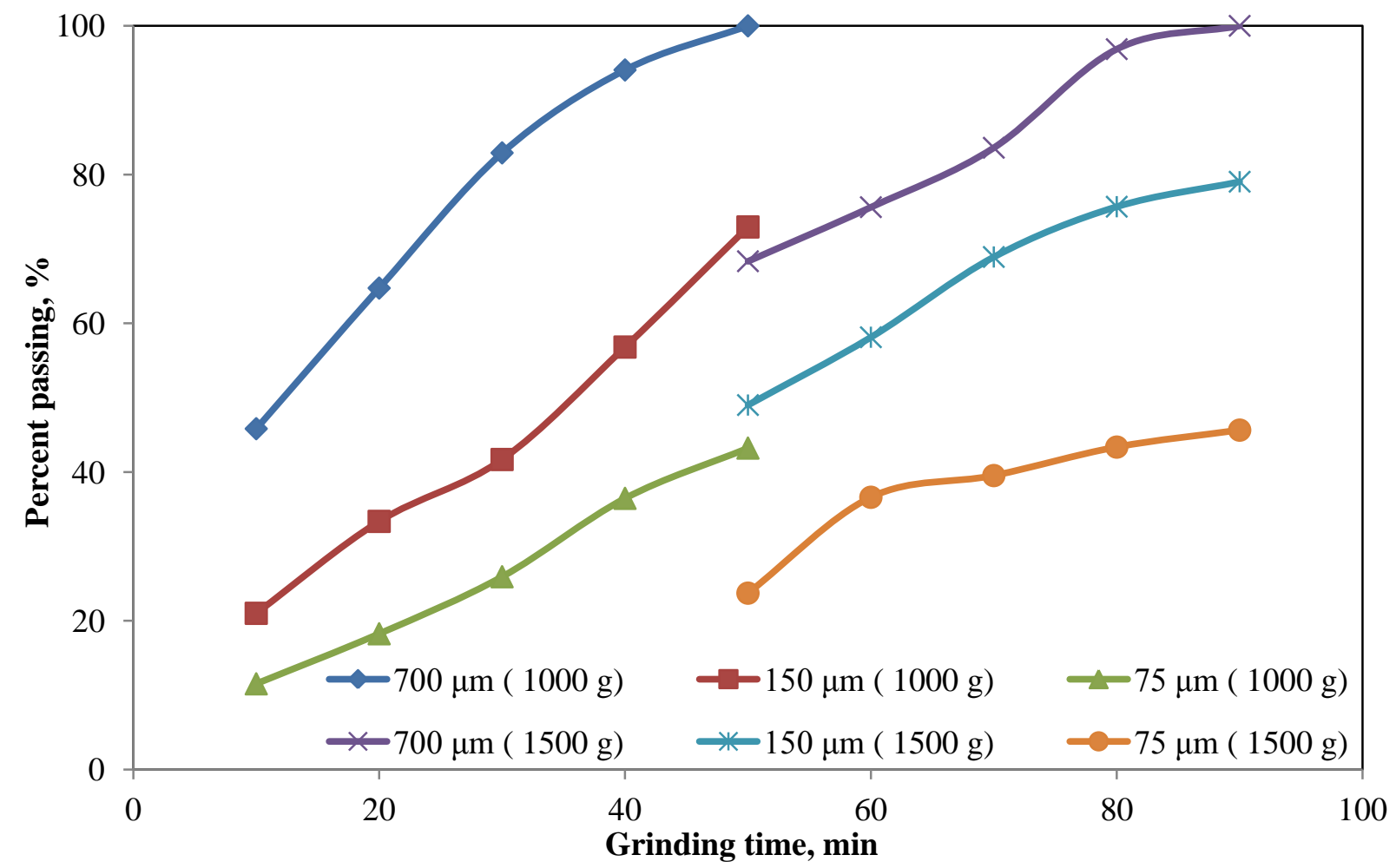

Figure 4- 1 Percent passing as a function of grinding time.

\subsubsection{Characterization for phosphate reverse flotation feed}

Size distribution analysis of the DPP sample for this test is given in Table 4-8.

Table 4- 8 Size distribution and chemical analysis of dolomitic phosphate sample.

\begin{tabular}{|c|c|c|c|c|c|}
\hline & & & \multicolumn{3}{|c|}{ Grade, \% } \\
\cline { 4 - 6 } US sieve No. & $\begin{array}{c}\text { Size range } \\
(\mu \mathrm{m})\end{array}$ & $\mathrm{Wt} \%$ & \multicolumn{3}{|c|}{} \\
\cline { 4 - 7 } & & & $\mathrm{P}_{2} \mathrm{O}_{5}$ & $\mathrm{MgO}$ & Insol. \\
\hline$-28+30$ & $-700+600$ & 10.84 & 23.48 & 2.58 & 9.53 \\
\hline$-30+40$ & $-600+425$ & 14.53 & 24.51 & 2.62 & 10.26 \\
\hline$-40+45$ & $-425+355$ & 12.86 & 26.63 & 2.77 & 10.93 \\
\hline$-45+100$ & $-355+150$ & 12.84 & 27.57 & 2.22 & 15.47 \\
\hline$-100+140$ & $-150+106$ & 17.48 & 25.96 & 2.63 & 18.23 \\
\hline$-140+200$ & $-106+75$ & 15.38 & 25.98 & 2.85 & 17.95 \\
\hline-200 & -75 & 16.07 & 25.2 & 4.52 & 12.34 \\
\hline Total & Total & 100.00 & 25.65 & 2.93 & 13.85 \\
\hline & & & & & \\
\hline
\end{tabular}


As shown in the analysis results that fine fraction $-150 \mu \mathrm{m}$ (US sieve No.100) of the flotation feed contains high $\mathrm{MgO}$ content. For example, the $\mathrm{MgO}$ grade in minus $75 \mu \mathrm{m}$ particle size is up to $4.52 \%$, much higher than that of feed which is only $2.93 \%$. The weight percentage of the sample is quite evenly distributed in all other size fractions. About $38.23 \%$ particles are larger than $355 \mu \mathrm{m}$, and $31.45 \%$ particles finer than $106 \mu \mathrm{m}$, these will be the size range being tested in this experiment.

\subsection{Reagents for phosphate reverse flotation reagents}

The reagents used in phosphate reverse flotation are given below:

- CF 413B: Sulfonated fatty acid collectors were provided by ARR-MAZ Products (Division of Process Chemicals, Winter Haven, Florida). It was used for dolomite flotation in acidic $\mathrm{pH}$, water solubale, it can be diluted with water.

- CF 413: Sulfonated fatty acid collectors were provided by ARR-MAZ Products (Division of Process Chemicals, Winter Haven, Florida). It was used for dolomite flotation in acidic $\mathrm{pH}$, water solubale, it can be diluted with water.

- Methyl Isobutyl Carbinol (MIBC, $\mathrm{C}_{6} \mathrm{H}_{14} \mathrm{O}$ ) is a widely used frother in coal flotation. It was supplied by Aldrich Chemical Company (Miwaukee, WI).

- CA 1250: Oil based amine was used for silica flotation, water soluble, it can be diluted with water. It was provided by ARR-MAZ Products (Division of Process Chemicals, Winter Haven, Florida).

- Phosphoric acid: $\mathrm{H}_{3} \mathrm{PO}_{4}$ was with chemical analysis grade having the purity of $85 \%$ $\mathrm{P}_{2} \mathrm{O}_{5}$ from Fisher Scientific (Pittsburgh, PA). It was used as both $\mathrm{pH}$ modifier and depressant of phosphate minerals in dolomitic phosphate reverse flotation. A five percent solution was prepared for use in the experiment. 
- Kerosene: Kerosene was used as a collector added in amine flotation for separating silica from phosphate. It was supplied by Sigma-Aldrich, Inc., (St. Louis, MO).

\subsection{Equipment and Design of Experiment for Phosphate Reverse Flotation}

\subsubsection{Spectrophotometric analysis}

Determination of phosphorus and $\mathrm{P}_{2} \mathrm{O}_{5}$ content in Florida phosphate reverse flotation sample was performed using the Spectronic 200 from Thermo Scientific, as shown in Figure 4-2.

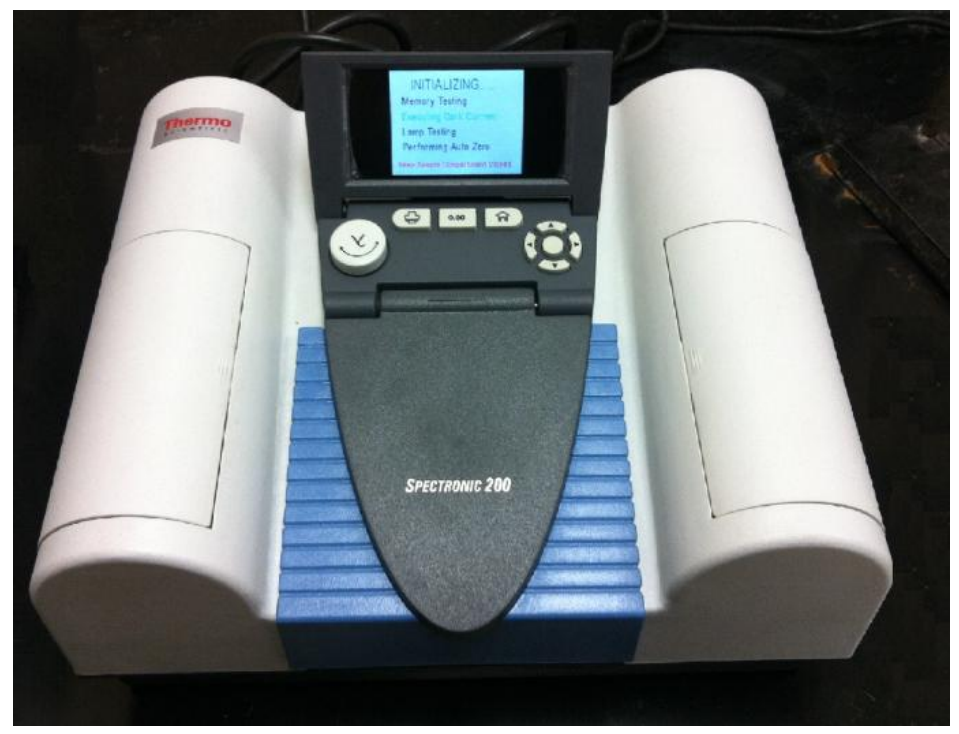

Figure 4- 2 The Spectronic 200 used for phosphorus and P2O5 content analysis.

\subsubsection{Atomic absorption analysis}

The magnesium oxide $(\mathrm{MgO})$ and calcium oxide $(\mathrm{CaO})$ contents were analyzed using AAnalyst 200 from PerkinElmer Instruments. 


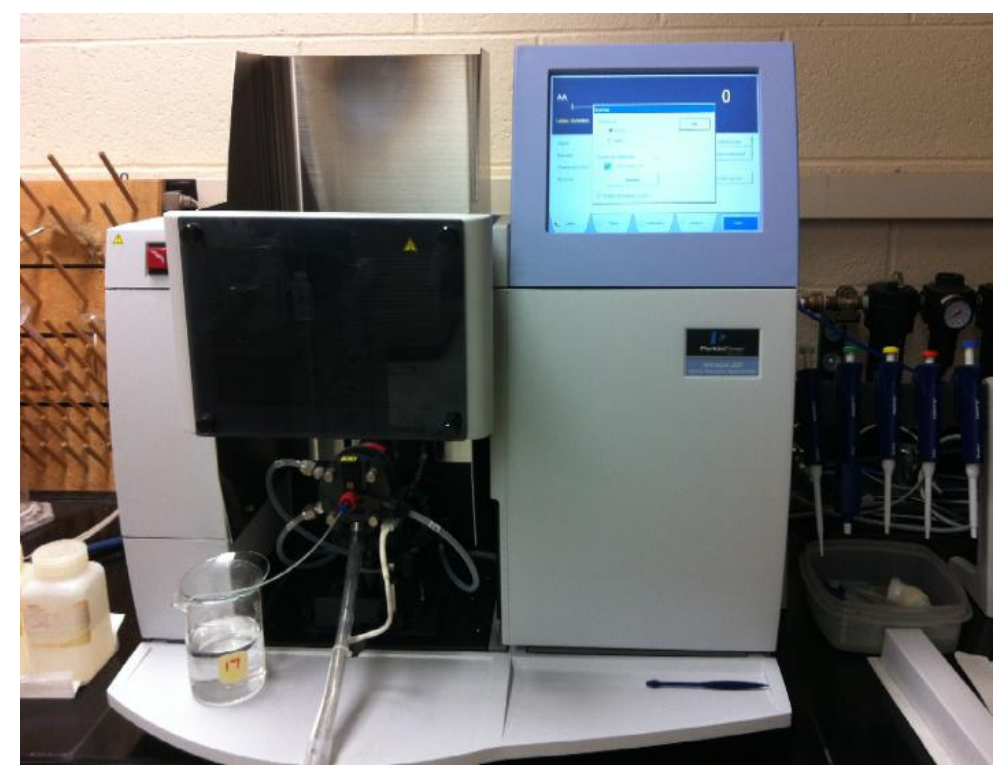

Figure 4- 3 The AAnalyst 200 used for $\mathrm{MgO}$ and $\mathrm{CaO}$ content analysis.

\subsubsection{Batch flotation experiments of phosphate sample}

Batch flotation tests on dolomitic phosphate ores were carried out with Denver D-12 model flotation machine and 2 liter cell. Five hundred grams dolomitic phosphate sample was ground to a given particle size for sufficient liberation. With the addition of distilled water, the slurry was adjusted to $2000 \mathrm{ml}$ pulp with $25 \%$ solid concentration. Phosphoric acid was used as both $\mathrm{pH}$ modifier and phosphate depressant. The slurry was conditioned with phosphoric acid for 1 minute. A predetermined amount of collector was added to the slurry and conditioned for two minutes. After conditioned with reagents, air was introduced to the flotation cell for one minute aeration. Flotation time was usually set for 6 minutes. All samples including float and sink were filtered, dried, weighed and analyzed. The float was dolomite tailings and the sink was the rougher concentrate. 


\subsubsection{Pico-nano bubble column flotation}

Several equations were used to evaluate the effectiveness of the separation process of phosphate reverse flotation. And they have been defined as follows:

$$
\begin{aligned}
& Y_{f}=\frac{W_{f}}{W_{f}+W_{s}} \times 100 \% \\
& Y_{s}=100-Y_{f} \\
& R_{d f}=\frac{Y_{f} \beta_{d}}{\alpha_{d}} \\
& R_{d s}=100-R_{d f} \\
& R_{p s}=\frac{Y_{s} \beta_{p}}{\alpha_{p}} \\
& R_{p f}=100-R_{p s}
\end{aligned}
$$

Where:

$\mathrm{Y}_{\mathrm{f}}=$ Yield of float, $\%$

$\mathrm{W}_{\mathrm{f}}=$ Weight of float or overflow, $\mathrm{g}$

$\mathrm{W}_{\mathrm{s}}=$ Weight of sink or underflow, $\mathrm{g}$

$\mathrm{Y}_{\mathrm{s}}=$ Yield of sink, $\%$

$\mathrm{R}_{\mathrm{df}}=$ Dolomite recovery in float, $\%$

$\mathrm{Y}_{\mathrm{f}}=$ Yield of float, $\%$

$\beta_{\mathrm{d}}=\mathrm{MgO}$ grade in float, $\%$

$\alpha_{\mathrm{d}}=\mathrm{MgO}$ grade in feed, $\%$

$\mathrm{R}_{\mathrm{ds}}=$ Dolomite recovery in the sink, \%

$\mathrm{R}_{\mathrm{ps}}=$ Phosphate recovery in the sink, \%

$\beta_{\mathrm{p}}=\mathrm{P}_{2} \mathrm{O}_{5}$ grade in the sink, $\%$ 
$\alpha_{\mathrm{p}}=\mathrm{P}_{2} \mathrm{O}_{5}$ grade in the feed, $\%$

$\mathrm{R}_{\mathrm{pf}}=$ Phosphate recovery in the float, $\%$

\subsubsection{Develop a method for domomitic phosphate flotation}

Different flotation methods have been developed since 1970s, such as International Mineral and Chemical Company (IMC) cationic process, Tennessee Valley Authority (TVA) diphosphonic acid process, University of Florida (UF) two stage conditioning process, University of Alabama (UA) no conditioning process, US Bureau of Mines (USBM) scrubbing and flotation process and so on. In 1995, Florida Institute of Phosphate Research conducted an in-house comprehensive evaluation on those processes with the results summarized in Table 4-9 (Gu et al., 2002).

Table 4- 9 Summary of Processes Developed for Florida Dolomitic Phosphate.

\begin{tabular}{|c|c|c|c|c|}
\hline \multirow{2}{*}{ Process } & \multirow{2}{*}{$\begin{array}{c}\text { Feed Size } \\
\end{array}$} & \multicolumn{3}{|c|}{ Concentrate, \% } \\
\cline { 3 - 5 } & $-425+106$ & $\mathrm{P}_{2} \mathrm{O}_{5}$ & $\mathrm{MgO}$ & $\mathrm{P}_{2} \mathrm{O}_{5}$ Recovery \\
\hline IMC & 31.66 & 0.84 & 58.4 \\
\hline USBM & $-600+106$ & 31.73 & 1.22 & 27.4 \\
\hline UF & $-425+106$ & 28.97 & 0.97 & 27.7 \\
\hline TVA & $-300+45$ & 30.73 & 1.51 & 66.0 \\
\hline UA & $-425+106$ & 26.20 & 1.19 & 87.1 \\
\hline
\end{tabular}

The most promising process is IMC cationic flotation process among those five beneficiation processes, a combination of silica flotation and phosphate flotation. Only the product of IMC meets the criteria of phosphate in fertilizer industry, containing $31.66 \%$ $\mathrm{P}_{2} \mathrm{O}_{5}$ and $0.84 \% \mathrm{MgO}$ at $58.4 \% \mathrm{P}_{2} \mathrm{O}_{5}$ recovery in the phosphate concentrate product. Other processes, generating either low $\mathrm{P}_{2} \mathrm{O}_{5}$ grade or high $\mathrm{MgO}$ content products, are all failed to produce an acceptable phosphate concentrate. 


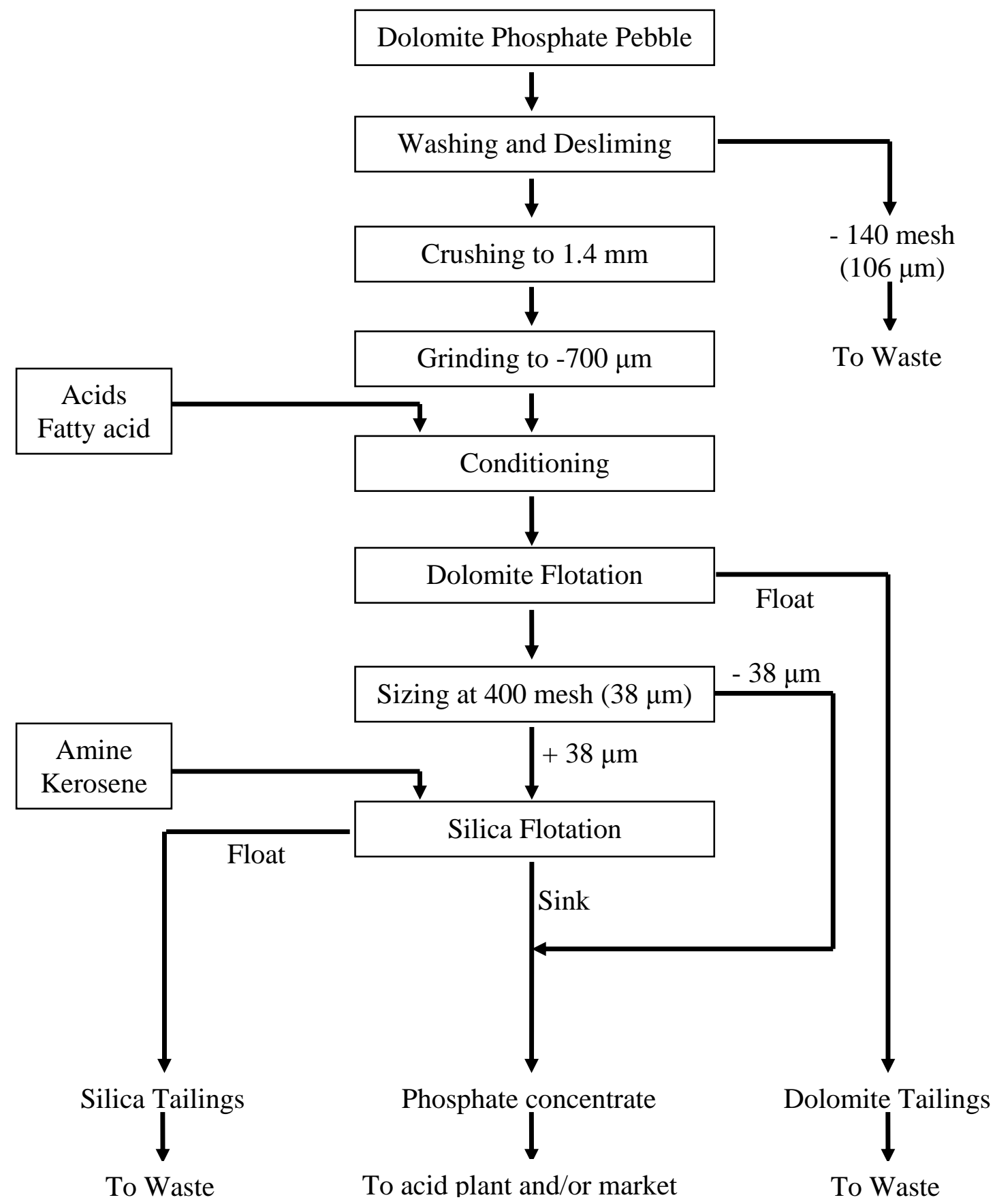

Figure 4- 4 Procedures for Processing Florida Dolomitic Phosphate Peddle Sample.

However, there are three disadvantages with the IMC cationic process. 1) Two types of amine collectors were used for both silica flotation and phosphate flotation, which will 
increase the cost of the process, because the price of cationic collector is much higher than fatty acid. 2) Most of the materials, about $90 \%$, were floated as concentrate in the second cationic flotation stage, and only $10 \%$ were kept in sink as tailings which might require higher reagent consumption. 3) Significant loss of phosphate values due to desliming after grinding, which is also one of the major problems with the previously developed phosphate flotation processes (Wiegel, 1999; Zhang and Bogan, 1997; Raden, 1979).

A flotation process was developed by China Lianyungang Design and Research Institute known as CLDRI fine particle flotation process had been developed and tested on Florida dolomitic phosphate ores at the size range of minus $150 \mu \mathrm{m}$ (Gu et al., 1999a), which makes up the shortcomings of IMC by using two-stage reverse flotation, dolomite flotation and silica flotation.

The CLDRI process has been made relatively simple by elimilating the desliming step after grinding, but prior to dolomite flotation. This improves flotation recovery and lowers production costs relative to other flotation processes. In this technique, high quality phosphate concentrates are achieved by rejecting both carbonates and silicates (Gu et al., 1999b).

High phosphate recovery is maintained since desliming losses are minimized and flotation performance is high. However, the CLDRI flotation process is efficient only for particles finer than $150 \mu \mathrm{m}$, in order to process coarse particles $(-700+355 \mu \mathrm{m})$, a specially designed flotation column with a pico-nano bubble generator will be used in the CLDRI flotation process. As shown in Figure 4-4, the modified CLDRI phosphate 
reverse flotation process is expected to float fine $(-150 \mu \mathrm{m})$ and coarse particles $(-700+355 \mu \mathrm{m})$, which includes reverse flotation of dolomite and silica.

\subsubsection{Froth Stability Measurement}

A laboratory column with $5 \mathrm{~cm}$ ID and $165 \mathrm{~cm}$ height equipped with static mixer and venturi tube was used as the experimental apparatus for the froth stability measurement. CF 413, CF 413B alone and its mixture with selected frother were studied as the frothing agents with the reagent concentration varied from 0.4 to $2.0 \mathrm{lb} /$ ton. The experiments were

carried out in the two phase system. i.e. air and water involved only. The pico-nano bubbles were produced using venturi tube. The pico-nano bubble generating circuit will keeping running for 15 minutes, and then air and the pump were completely shut off. The time period from shutting-off air until all bubbles disappeared was recorded as the lifetime of the froth which was used to express the froth stability.

\subsubsection{Study on the effects of different collectors in phosphate reverse flotation}

Investigate the effects of two different collectors (CF 413 and $\mathrm{CF} 413 \mathrm{~B}$ ), collector dosage and $\mathrm{pH}$ on dolomitic carbonates flotation by using pico-nano bubble column flotation. Keep collector dosage or $\mathrm{pH}$ value constant while the other one changed at different levels for two collectors. The optimal collector and operation conditions will be achieved by maximizing the recovery and grade of $\mathrm{P}_{2} \mathrm{O}_{5}$, at the same time, minimizing the $\mathrm{MgO}$ grade in the sink. 


\subsubsection{Perform two-stage Design of Experiment and single factor test of phosphate reverse flotation.}

\subsubsection{Two-stage Design of Experiment}

In order to refine the optimal operating conditions for phosphate reverse flotation, twostage Design of Experiment in a flotation column with optimal designed cavitation venturi tube will be conducted.

Table 4- 10 Process parameters and operational conditions.

\begin{tabular}{|c|c|c|c|}
\hline \multirow{2}{*}{ Variable } & \multirow{2}{*}{ Code } & \multicolumn{2}{|c|}{ Level } \\
\cline { 3 - 4 } & & Low & High \\
\cline { 3 - 4 } & & -1 & +1 \\
\hline Collector dosage $(\mathrm{lb} /$ ton $)$ & $\mathrm{A}$ & 1.5 & 2 \\
\hline $\mathrm{pH}$ & $\mathrm{B}$ & 6.0 & 6.5 \\
\hline Feed rate $(\mathrm{cm} / \mathrm{s})$ & $\mathrm{C}$ & 0.3 & 0.4 \\
\hline Solids concentration $(\%)$ & $\mathrm{D}$ & 15 & 20 \\
\hline Frother Dosage $(\mathrm{ppm})$ & $\mathrm{E}$ & 4 & 7 \\
\hline Gas flow rate $(\mathrm{cm} / \mathrm{s})$ & $\mathrm{F}$ & 1.5 & 2.5 \\
\hline Superficial wash water rate $(\mathrm{cm} / \mathrm{s})$ & $\mathrm{G}$ & 0.1 & 0.3 \\
\hline
\end{tabular}

The parameters selected in this study include $\mathrm{pH}$, collector dosage, feed rate, feed solid percent, frother dosage, air flow rate and wash water flow rate. As shown in Table 4-10 and Table 4-12, two sets of test runs are performed in screening experiment to indentify the factors that have significant effects for the operation levels and to determine the optimum operation conditions.

In order to evaluate the performance of the dolomite flotation, selectivity index (SIp) of separating dolomite from phosphate is defined as an evaluation criterion. This selectivity index, SIp is defined as:

$$
\operatorname{SIp}=\sqrt{\frac{\mathrm{R}_{\mathrm{cp}} \times\left(\mathrm{R}_{\mathrm{cp}}-\mathrm{R}_{\mathrm{cd}}\right) \times \mathrm{P}_{\mathrm{c}}}{\mathrm{P}_{\max }}}
$$


where $R_{c p}$ is recovery of phosphate in concentrate, $R_{c d}$ is the recovery of dolomite in concentrate, $\mathrm{P}_{c}$ is $\mathrm{P}_{2} \mathrm{O}_{5}$ grade in concentrate, and $\mathrm{P}_{\max }$ is theoretical $\mathrm{P}_{2} \mathrm{O}_{5}$ grade of the phosphate mineral in the sample. The mineralogical study determined the value of $P_{\max }=36 \%$ for the dolomitic phosphate sample used in this study.

Table 4- 11 Experiment design for the first set of test runs.

\begin{tabular}{|c|c|c|c|c|c|c|c|}
\hline Run & A & B & C & D & E & F & G \\
\hline 1 & 1 & -1 & -1 & 1 & 1 & 1 & -1 \\
\hline 2 & -1 & 1 & -1 & -1 & 1 & 1 & 1 \\
\hline 3 & -1 & -1 & -1 & 1 & -1 & -1 & 1 \\
\hline 4 & 1 & 1 & -1 & -1 & -1 & -1 & -1 \\
\hline 5 & 1 & 1 & 1 & 1 & 1 & -1 & 1 \\
\hline 6 & -1 & -1 & 1 & -1 & 1 & -1 & -1 \\
\hline 7 & -1 & 1 & 1 & 1 & -1 & 1 & -1 \\
\hline 8 & 1 & -1 & 1 & -1 & -1 & 1 & 1 \\
\hline
\end{tabular}

Table 4- 12 Process parameters and operational conditions.

\begin{tabular}{|c|c|c|c|}
\hline \multirow{2}{*}{ Factors } & \multirow{2}{*}{ Code } & \multicolumn{2}{|c|}{ Level } \\
\cline { 3 - 4 } & & Low & High \\
\cline { 3 - 4 } & & -1 & 1 \\
\hline $\mathrm{pH}$ & $\mathrm{A}$ & 5.5 & 6 \\
\hline Collector dosage (lb/ton) & $\mathrm{B}$ & 1 & 1.5 \\
\hline Feed rate $(\mathrm{cm} / \mathrm{s})$ & $\mathrm{C}$ & 0.2 & 0.3 \\
\hline Solids concentration (\%) & $\mathrm{D}$ & 20 & 25 \\
\hline Frother Dosage (ppm) & $\mathrm{E}$ & 7 & 10 \\
\hline
\end{tabular}

The fractional factorial design is one of the Experimental Design for screening experiment. In fractional factorial design, the resolution III designs could be constructed for investigating up to $\mathrm{k}=\mathrm{N}-1$ factors in only $\mathrm{N}$ runs, where $\mathrm{N}$ is a multiple of 4 . For the first set of test run, the screening experiment similar to the two-level fractional factorial design will be made. This design is quite similar to a $2^{7-4}$ III fractional factorial design. The combination is a one-sixteenth fraction of the $2^{7}$ and a resolution III design with 
which only main effect can be estimated and all main effects are aliased with two-factor interactions.

Table 4- 13 Experiment design for the second set of test runs.

\begin{tabular}{|c|c|c|c|c|c|}
\hline Run & A & B & C & D & E \\
\hline 1 & -1 & 1 & 1 & 1 & 1 \\
\hline 2 & -1 & 1 & -1 & 1 & -1 \\
\hline 3 & 1 & 1 & -1 & -1 & 1 \\
\hline 4 & 1 & 1 & 1 & -1 & -1 \\
\hline 5 & 1 & -1 & 1 & 1 & 1 \\
\hline 6 & -1 & -1 & 1 & -1 & -1 \\
\hline 7 & 1 & -1 & -1 & 1 & -1 \\
\hline 8 & -1 & -1 & -1 & -1 & 1 \\
\hline
\end{tabular}

After completion of the first set of test runs and effect analysis, the 7 factors will be reduced. For the second set of test runs with 5 factors, the JUMP statistics program is used to design the test conditions and only main effects can be analyzed and estimated.

\subsubsection{Single factor test}

In order to further determine the optimization of process parameters, single factor experimental test was conducted by varying the collector dosage and $\mathrm{pH}$. The operation conditions of feed slurry, solids concentration and reagent dosages were kept constant, as given in Table 4-14. The optimal operation conditions will be achieved by maximizing the recovery and grade of $\mathrm{P}_{2} \mathrm{O}_{5}$, at the same time, minimizing the $\mathrm{MgO}$ grade in the sink.

Table 4- 14 Process parameters and operational conditions.

\begin{tabular}{|c|c|}
\hline Process parameters & Operation conditions \\
\hline Collector dosage $(\mathrm{lb} / \mathrm{ton})$ & 0.5 to 1.5 \\
\hline Solids concentration $(\%)$ & $25 \%$ \\
\hline $\mathrm{pH}$ & 4.5 to 6.0 \\
\hline Feed rate $(\mathrm{cm} / \mathrm{s})$ & 0.2 \\
\hline Gas flow rate $(\mathrm{cm} / \mathrm{s})$ & 1.5 \\
\hline Wash water rate $(\mathrm{cm} / \mathrm{s})$ & 0.1 \\
\hline Frother $(\mathrm{ppm})$ & 15 \\
\hline
\end{tabular}




\subsubsection{Perform Denver mechanical cell flotation}

Amine flotation tests were conducted using the Denver D-12 model flotation machine and 1.2 liter mechanical flotation cell. The sink discharge was collected from dolomitic phosphate flotation in pico-nano bubble flotation column. The sink sample was sized at 38 um (400 mesh), and plus 38 um was subject to amine flotation to separate silica from

phosphate. The silica was collected as froth product, while the phosphate product was remained in the cell. 


\section{Chapter 5 Results and Discussions for Coal Flotation}

\subsection{Effects of venturi tube design for pico-nano bubbles and nanobubbles generation}

\subsubsection{Design of venturi tube for pico-nano bubbles and nanobubbles generation and measurement}

Cavitation is defined as the formation of bubbles(either gas or vapour filled cavities) in a flowing liquid due to the rupture of a liquid-liquid or a liquid- solid interface caused by reduction of local pressure to a critical value (Ross, 1976). Bernoulli's equation states that if the localized velocity increases, then, by conservation of energy, there must be a reduction in the absolute pressure at that point. If the pressure is reduced below a critical value, then the liquid will vaporize or boil at that point. The vaporization pressure is dependent upon both the properties and temperature of the working fluid.

Bernoulli's equation applied between two points (1 and 2) in the system can be written as:

$$
\frac{\mathrm{P}_{1}}{\rho}+\frac{1}{2} \mathrm{~V}_{1}^{2}+\mathrm{gz}_{1}=\frac{\mathrm{P}_{2}}{\rho}+\frac{1}{2} \mathrm{~V}_{2}^{2}+\mathrm{gz}_{2}
$$

Where $\mathrm{P}$ is static pressure, $\rho$ is density, $\mathrm{V}$ is linear velocity, $\mathrm{g}$ is gravity and $\mathrm{z}$ is height above an arbitrary horizontal datum line.

Cavitation results in the formation of large quantities of bubbles, which, as they move to a region of higher pressure, collapse as the vapour condenses.

There are several designs of cavitation tube, such as orifice plate, nozzle and venturi, all of which are capable of producing cavitation at a desired point of the flow, while the venturi is chosen as the best option to generate pico-nano bubbles in this test, because the gradual reduction and the subsequent gradual expansion of venturi reduced the possibility of blockage. The venturi also has very low head loss characteristics resulting in minimal 
impact on the pump capacity in a plant. The permanent head loss of the other two options could be as high as 3-4 times greater than the venturi. Also, the ability to vary the throat length, which is a very important factor of the design of cavitation tube, in the venturi is also an advantage. By controlling the geometric and operating conditions, the cavitation can be achieved with maximum energy efficiency.

A dimensionless number known as cavitation number $(\mathrm{Cv})$ has generally been used to relate the flow conditions with the cavitation intensity.

$$
\mathrm{Cv}=\frac{\mathrm{P}_{2}-\mathrm{P}_{\mathrm{v}}}{\frac{1}{2} \mathrm{\rho} \mathrm{V}_{\mathrm{th}}^{2}}
$$

Where $\mathrm{P}_{2}$ is the fully recovered downstream pressure, $\mathrm{P}_{\mathrm{v}}$ is the vapor pressure of the liquid and $\mathrm{V}_{\text {th }}$ is the velocity of the liquid at the throat of the constriction. With the presence of dissolved gases or some impurities in the liquid medium, cavitation has been found to occur at a higher cavitation number (for $\mathrm{C}_{\mathrm{v}}>1$ ) (Harrison and Pandit, 1992).

As long as the liquid speed is sufficiently subsonic $(\mathrm{V}<$ mach 0.3$)$, assume that the venturi tube is placed horizontally, which means the height is the same, then the incompressible bernoulli's equation (5-1) can be written as:

$$
\mathrm{P}_{\text {inlet }}-\mathrm{P}_{\mathrm{th}}=\frac{1}{2} \rho V_{\text {th }}^{2}-\frac{1}{2} \rho V_{\text {inlet }}^{2}
$$

Where $\mathrm{P}_{\text {inlet }}$ is the pressure in the inlet of the venturi tube, $\mathrm{P}_{\text {th }}$ is the pressure at the throat of the venturi tube, $\mathrm{V}_{\text {inle }}$ is the fluid velocity at the inlet of the venturi tube.

Using equation (5-2), the following equation can be derived for $\mathrm{C}_{\mathrm{v}}$ :

$$
C_{v}=\frac{2}{\rho V_{\text {th }}^{2}}\left(P_{\text {in }}-P_{v}\right)+\frac{V_{\text {inlet }}^{2}}{V_{\text {th }}^{2}}\left(\frac{D_{\text {inlet }}^{2}}{D_{\text {th }}^{2}}-1\right)
$$

$\mathrm{V}_{\text {inlet }}, \mathrm{P}_{\mathrm{v}}, \mathrm{P}_{\text {in }}$ and $\rho$ are all set to be constants in the tests. 
Table 5- 1 Estimated coefficients, t-ratios and p-values

\begin{tabular}{|l|l|l|l|l|l|l|}
\hline \multirow{2}{*}{ Term } & \multicolumn{4}{|l|}{ Mean Pico-nano bubble Size } \\
\cline { 2 - 7 } & Estimate & t Ratio & Prob. $>|\mathrm{t}|$ & Estimate & $\mathrm{t}$ Ratio & Prob. $>|\mathrm{t}|$ \\
\hline Intercept & -317.73 & -11.21 & $<0.0001^{*}$ & 4398.48 & 7.97 & $<0.0001^{*}$ \\
\hline $\mathrm{A}$ & 45.05 & 8.45 & $<0.0001^{*}$ & -301.41 & -2.91 & $0.0174^{*}$ \\
\hline $\mathrm{B}$ & -119.30 & -11.18 & $<0.0001^{*}$ & 1132.43 & 5.15 & $0.0006^{*}$ \\
\hline $\mathrm{C}$ & 19.83 & 6.96 & $<0.0001^{*}$ & -151.79 & -2.96 & $0.0160^{*}$ \\
\hline $\mathrm{D}$ & 30.23 & 8.12 & $<0.0001^{*}$ & -424.05 & -6.22 & $0.0002^{*}$ \\
\hline $\mathrm{A} \times \mathrm{B}$ & 4.18 & 8.81 & $<0.0001^{*}$ & -54.40 & -4.69 & $0.0011^{*}$ \\
\hline $\mathrm{A} \times \mathrm{C}$ & -1.07 & -13.53 & $<0.0001^{*}$ & 9.77 & 5.05 & $0.0007^{*}$ \\
\hline $\mathrm{A} \times \mathrm{D}$ & -0.10 & -0.88 & 0.3983 & -1.17 & -0.40 & 0.6968 \\
\hline $\mathrm{B} \times \mathrm{C}$ & 1.46 & 9.22 & $<0.0001^{*}$ & -1.56 & -0.40 & 0.6954 \\
\hline $\mathrm{B} \times \mathrm{D}$ & 0.92 & 3.87 & $0.0026^{*}$ & -12.42 & -2.14 & 0.0610 \\
\hline $\mathrm{C} \times \mathrm{D}$ & -0.30 & -7.62 & $<0.0001^{*}$ & 2.82 & 2.91 & $0.0173^{*}$ \\
\hline $\mathrm{A} \times \mathrm{A}$ & -4.11 & -6.93 & $<0.0001^{*}$ & 32.40 & 3.13 & $0.0122^{*}$ \\
\hline $\mathrm{B} \times \mathrm{B}$ & 17.35 & 7.31 & $<0.0001^{*}$ & -210.88 & -5.09 & $0.0007^{*}$ \\
\hline $\mathrm{C} \times \mathrm{C}$ & -0.29 & -4.45 & $0.0010^{*}$ & 1.06 & 0.92 & 0.3793 \\
\hline $\mathrm{D} \times \mathrm{D}$ & -1.06 & -7.14 & $<0.0001^{*}$ & 15.69 & 6.06 & $0.0002^{*}$ \\
\hline $\mathrm{N}$
\end{tabular}

Note: * means significant factors.

The main and interaction coefficients are evaluated and tested for significance as shown in Table 5-1. The main effects include the ratio of the diameter of throat and outlet of the venturi tube $\left(\mathrm{D}_{\mathrm{in}} / \mathrm{D}_{t}\right)$, the ratio of the length of the throat and the diameter of throat $\left(\mathrm{L}_{\mathrm{t}} / \mathrm{D}_{\mathrm{t}}\right)$, and input and output cone angles on pico-nano bubble volume and mean pico-nano bubble size are significant at $99.99 \%$ confidence level, as indicated by the Prob. $>|t|$ values less than 0.0001 when assessing the estimated coefficient.

As shown in Table 5-2, we split our ANOVA table into rows for Model and Error in order to examine how much error we have when we use our predictive equation, and to determine how much error has disappeared because we used our predictive equation. All major statistics analysis results in Table 5-2 shows that the models for pico-nano bubble 
volume and mean pico-nano bubble size models can adequately describe the effects of dimensions of the venturi design on the response variables. It can be seen from Table 5-2 that the adjusted $\mathrm{R}^{2}$ value of 0.98 and 0.95 imply that the model is significant. There is only a $0.01 \%$ chance that the error would occur due to the noise.

Table 5- 2 ANOVA table derived for the pico-nano bubble volume and mean pico-nano bubble size models.

\begin{tabular}{|c|c|c|c|c|c|c|c|}
\hline Pico-nano bubble Volume model \\
\hline Source & SS & F & F value & Prob. > F & $\mathrm{R}^{2}$ & $\begin{array}{c}\text { Adjusted } \\
\mathrm{R}^{2}\end{array}$ \\
\hline Model & 16685.87 & 4 & 82.55 & $<0.0001^{*}$ & 0.99 & 0.98 \\
\hline Lack of fit & 154.21 & 0 & 3.35 & 0.40 & & \\
\hline Mean Pico-nano bubble Size model & SS & F & F value & Prob. > F & $\mathrm{R}^{2}$ & $\begin{array}{c}\text { Adjusted } \\
\mathrm{R}^{2}\end{array}$ \\
\hline Source & 1879892.10 & 4 & 30.99 & $<0.0001^{*}$ & 0.98 & 0.95 \\
\hline Model & 38971.05 & 8 & 215.11 & 0.053 & & \\
\hline Lack of fit
\end{tabular}

Note: $\mathrm{DF}=$ Degree of freedom, SS = Sum of squares.

Based on the statistical analysis results, the models in terms of the factor levels is:

Pico-nano bubble Volume $(\%)=(-317.73)+45.05 \times \mathrm{A} \pm 119.30 \times \mathrm{B}+19.83 \times \mathrm{C}+$ $30.23 \times \mathrm{D}+4.18 \times \mathrm{A} \times \mathrm{B}+(-1.07) \times \mathrm{A} \times \mathrm{C}+(-0.10) \times \mathrm{A} \times \mathrm{D}+1.46 \times \mathrm{B} \times \mathrm{C}+0.92 \times \mathrm{B} \times \mathrm{D}+(-$

$0.30) \times C \times D+(-4.11) \times A^{2}+17.35 \times B^{2}+(-0.29) \times C^{2}+(-1.06) \times D^{2}$

Mean Pico-nano bubble Size $(\mathrm{nm})=4398.48 \pm 301.41 \times \mathrm{A}+1132.43 \times \mathrm{B} \pm 151.79 \times \mathrm{C} \pm$ $424.05 \times \mathrm{D}+(-54.40) \times \mathrm{A} \times \mathrm{B}+9.77 \times \mathrm{A} \times \mathrm{C}+(-1.17) \times \mathrm{A} \times \mathrm{D}+(-1.56) \times \mathrm{B} \times \mathrm{C}+(-12.42)$ $\times \mathrm{B} \times \mathrm{D}+2.82 \times \mathrm{C} \times \mathrm{D}+32.40 \times \mathrm{A}^{2}+(-210.88) \times \mathrm{B}^{2}+1.06 \times \mathrm{C}^{2}+15.69 \times \mathrm{D}^{2}$

Where A means the ratio of the diameter of throat and outlet of the venture tube $\left(D_{\text {in }} / D_{t}\right)$;

$B$ the ratio of the length of the throat and the diameter of throat $\left(\mathrm{L}_{t} / \mathrm{D}_{t}\right) ; \mathrm{C}$ input cone angles; and D output cone angles. 


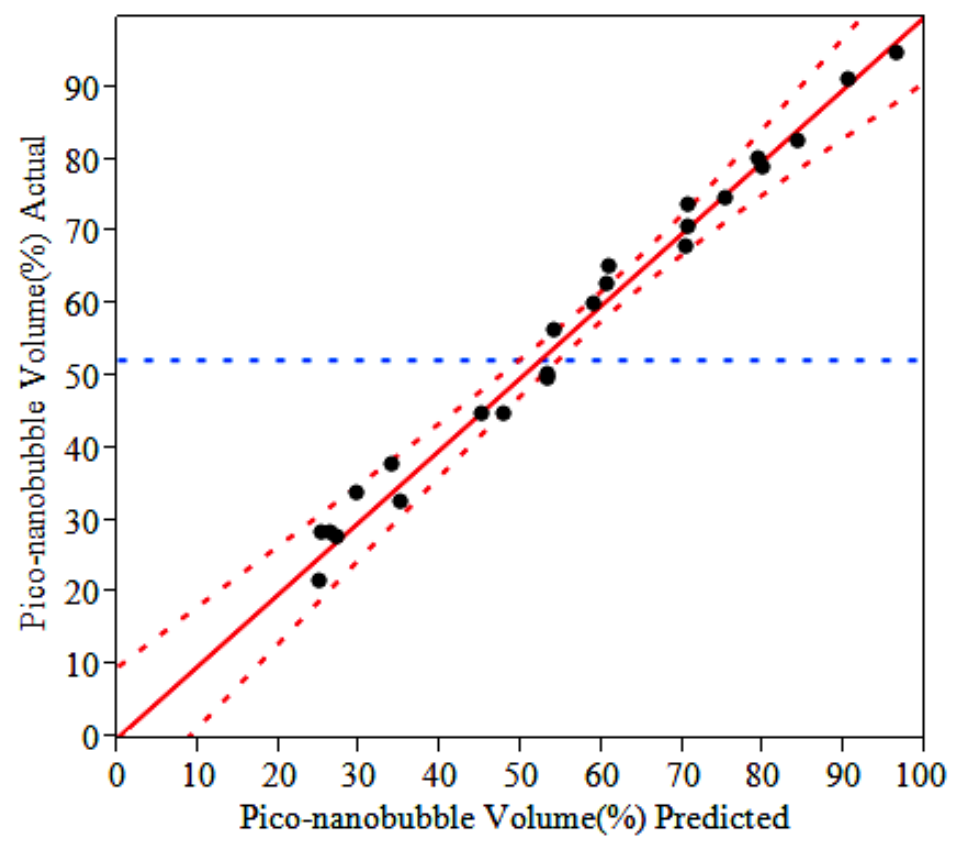

(a) Piconanobubble volume model

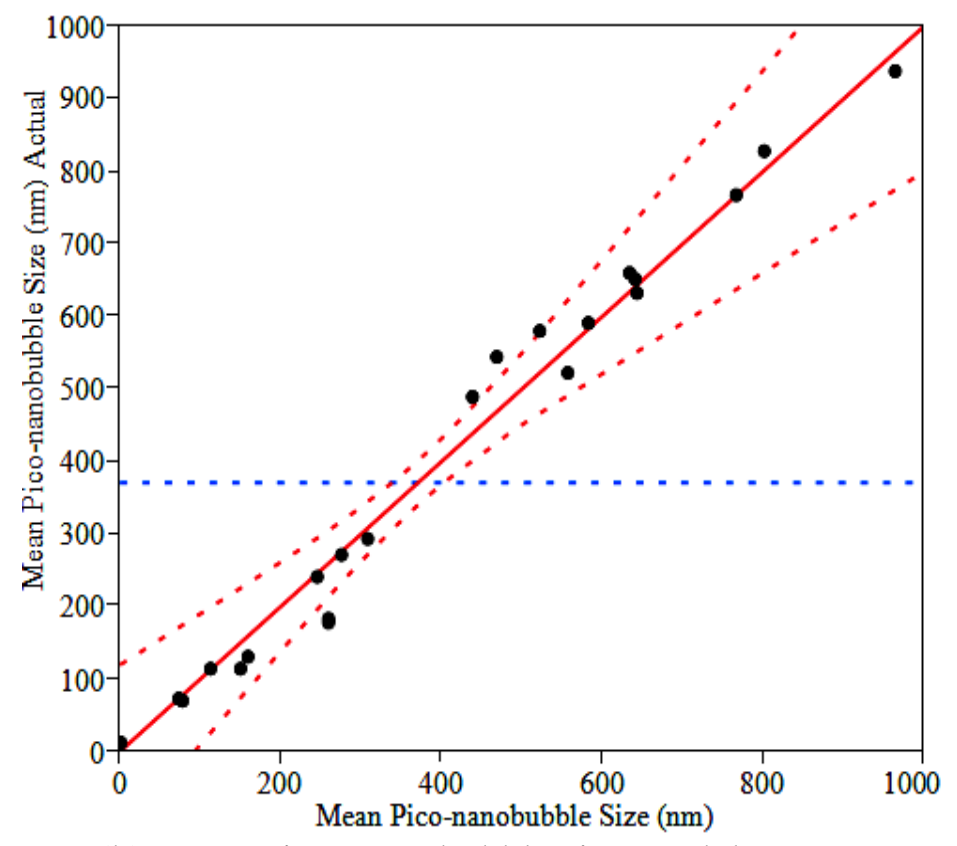

(b) Mean pico-nano bubble size model

Figure 5- 1 Comparison of the observed responses and predicted responses with models. 
The comparison of the observed responses and predicted responses are shown in Figure 5-1. The plot indicates that the models for pico-nano bubble volume and mean pico-nano bubble size can precisely predict the pico-nano bubble volume and mean pico-nano bubble size.

Figure 5-2 indicates the effects the ratio of the diameter of throat and outlet of the venture tube $\left(\mathrm{D}_{\text {in }} / \mathrm{D}_{\mathrm{t}}\right)$ and the ratio of the length of the throat and the diameter of throat $\left(\mathrm{L}_{\mathrm{t}} / \mathrm{D}_{\mathrm{t}}\right)$ on the pico-nano bubble volume and mean pico-nano bubble size when the inlet and outlet angles were $21^{\circ}$ and $12^{\circ}$, respectively. It can be clearly seen from the response surface and the contours of the pico-nano bubble volume shown in Figure 5-2a that the pico-nano bubble volume considerably increases from $60 \%$ to about $75 \%$ when the $D_{\text {in }} / D_{t}$ value ranges from 2 to 4 , after that, the pico-nano bubble volume decreases to $45 \%$ as increasing the $\mathrm{D}_{\mathrm{in}} / \mathrm{D}_{\mathrm{t}}$ value from 4 to 6 . The pico-nano bubble volume reduced about $10 \%$ as increasing the $L_{t} / D_{t}$ value from 1 to 2 , then slightly increases with increasing $L_{t} / D_{t}$ value. At the $D_{\text {in }} / D_{t}$ value of 4 , the pico-nano bubble volume increases from $62 \%$ to $80 \%$ as $L_{t} / D_{t}$ value increases from 1 to 3 . It can be clearly observed from the contours of the pico-nano bubble volume shown in Figure 5-2a that the highest volume of pico-nano bubble was achieved at the medium level of $D_{i n} / D_{t}$ value and the high level of $L_{t} / D_{t}$ value. It can be observed from the response surface and the contours of the mean pico-nano bubble size shown in Figure 5-2b that the mean pico-nano bubble size increases with increasing the $L_{t} / D_{t}$ value from 1 to 2 , and then decreases as increasing the $L_{t} / D_{t}$ value further to 3. The opposite trend of the mean pico-nano bubble size was observed with varying the $D_{\text {in }} / D_{t}$ value. The smallest mean size, which is about $200 \mathrm{~nm}$, of pico-nano bubbles can be achieved at medium level of $D_{\text {in }} / D_{t}$ value and high level of $L_{t} / D_{t}$ value. 
This is because that long throat length enables the critical pressure to be maintained, which allows the expansion of gas nuclei in the fluid before a region of high pressure is reached, where the bubbles to collapse. The tests results shown in Figure 5-2b were consistent with the observations given in Figure 5-2a. The larger volume of pico-nano bubbles achieved by changing the dimensions of $\mathrm{D}_{\mathrm{in}} / \mathrm{D}_{\mathrm{t}}$ and $\mathrm{L}_{\mathrm{t}} / \mathrm{D}_{\mathrm{t}}$ values indicate larger quantities of pico-nano bubbles was produced by the venture tube, which would result in the reduction in the mean pico-nano bubble size. According to equation 5-4, the cavitation number increases with increasing the $D_{\text {in }} / D_{t}$ value, which is consistent which the results when $D_{\text {in }} / D_{t}$ increases from 2 to 4 , while there is a decrease of the pico-nano bubble volume as the $D_{i n} / D_{t}$ increases to 6 , this is because of the energy loss of the violent change in the convergence of the venturi inlet dimensions.

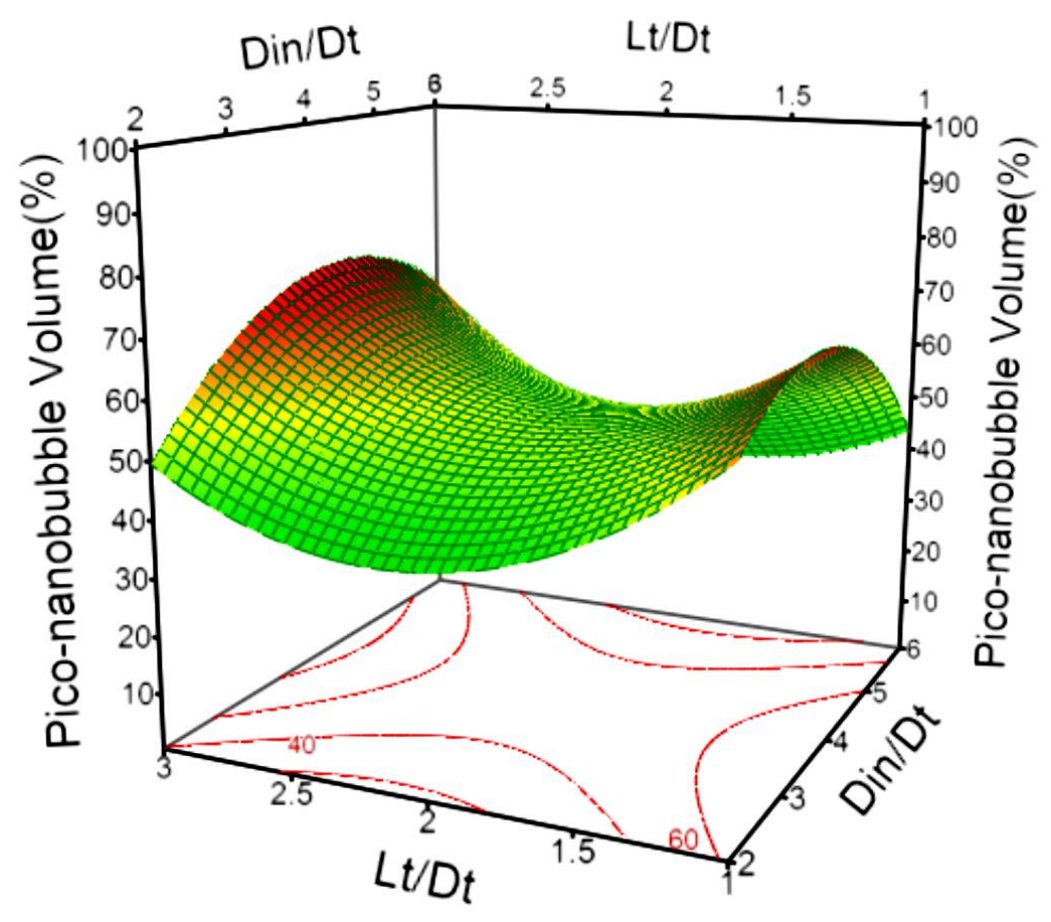




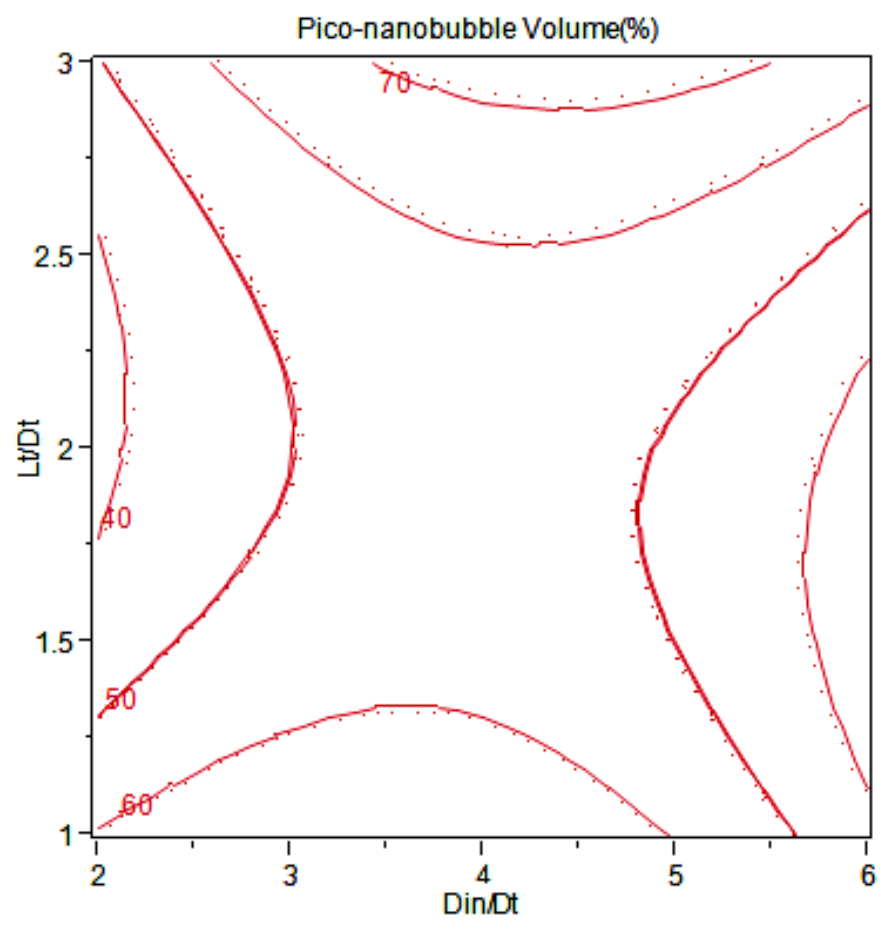

(a) Pico-nano bubble volume

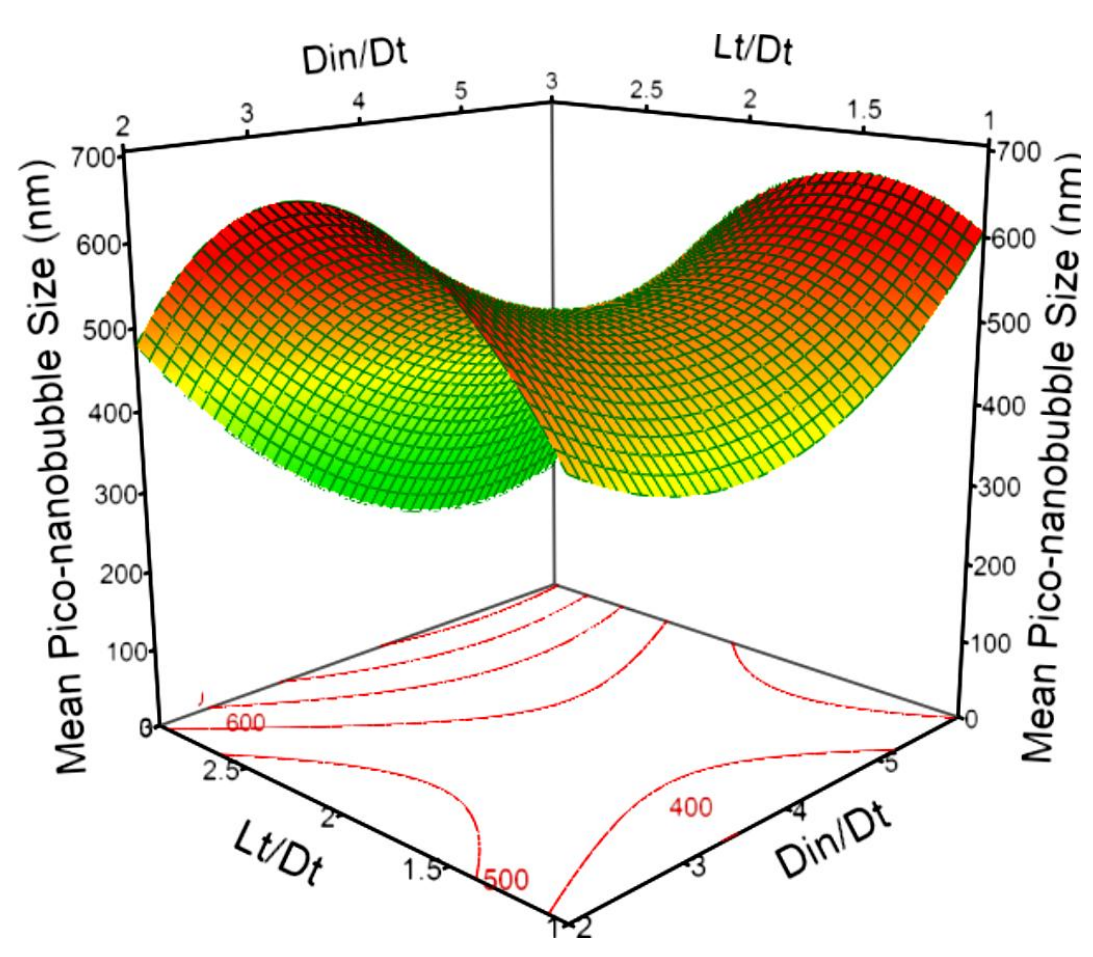




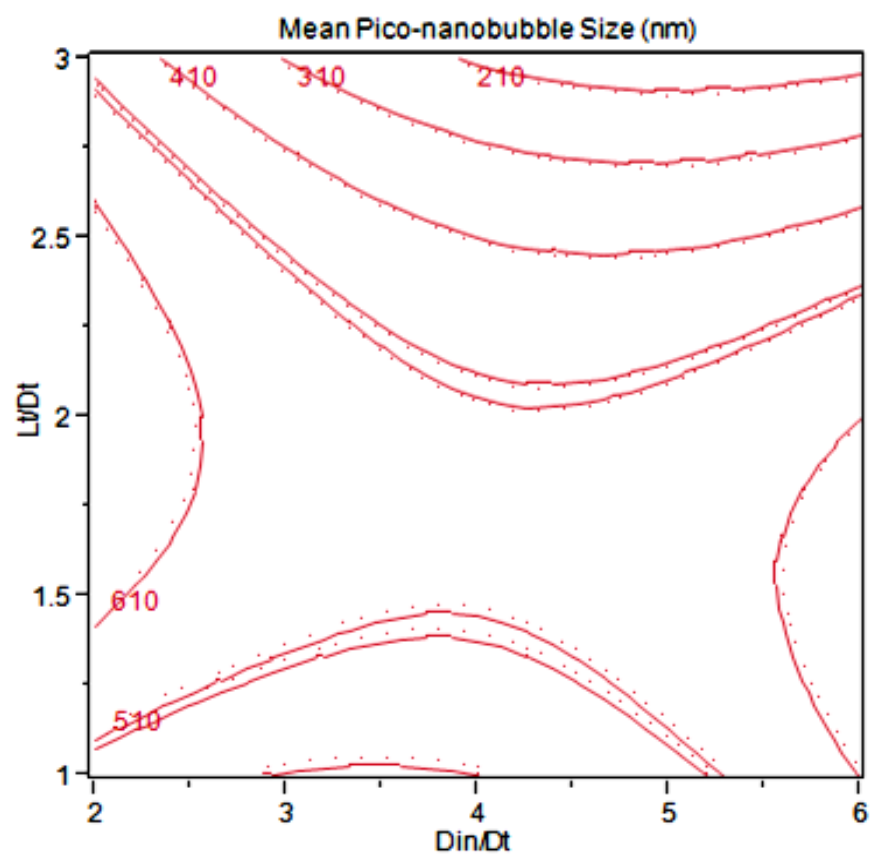

(b) Mean pico-nano bubble size

Figure 5- 2 Effect of the ratio of the diameter of throat and outlet of the venture tube $\left(\mathrm{D}_{\text {in }} / \mathrm{D}_{t}\right)$ and the ratio of the length of the throat and the diameter of throat $\left(\mathrm{L}_{t} / \mathrm{D}_{t}\right)$ on (a) the pico-nano bubble volume and (b) mean pico-nano bubble size.

Figure 5-3 indicates the effects the ratio of the diameter of throat and outlet of the venture tube $\left(\mathrm{D}_{\text {in }} / \mathrm{D}_{\mathrm{t}}\right)$ and the inlet angle on the pico-nano bubble volume and mean pico-nano bubble size when the ratio of the length of the throat and the diameter of throat $\left(\mathrm{L}_{\mathrm{t}} / \mathrm{D}_{\mathrm{t}}\right)$ and outlet angle were 3 and $12^{\circ}$, respectively. It can be seen from the response surface and the contours of pico-nano bubble volume shown in Figure 5-3a that the increasing of the inlet angle, from 15 to 27 , had significantly positive effect on the pico-nano bubble volume at the low level of $D_{\text {in }} / D_{t}$ value, however, at high level of $D_{\text {in }} / D_{t}$ value, the increasing of the inlet angle reduced the pico-nano bubble volume. As can be obviously observed in Figure 5-3b, the mean size of the pico-nano bubble decreases as increasing the inlet angle, which can be explained that the increases of the inlet angle lead to the increase of the pressure drop, resulting to the enhancement of cavitation. 

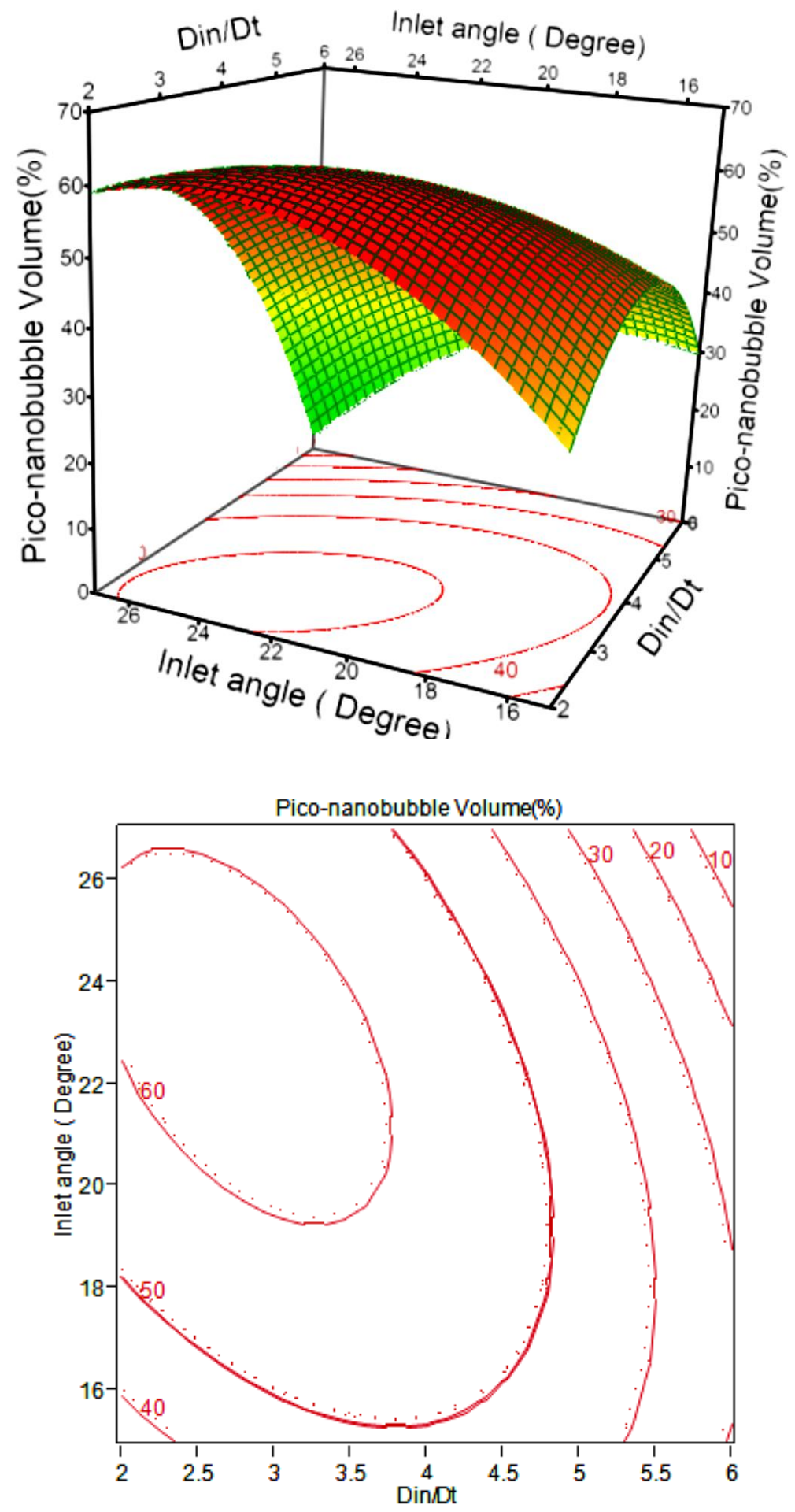

(a) Pico-nano bubble volume 

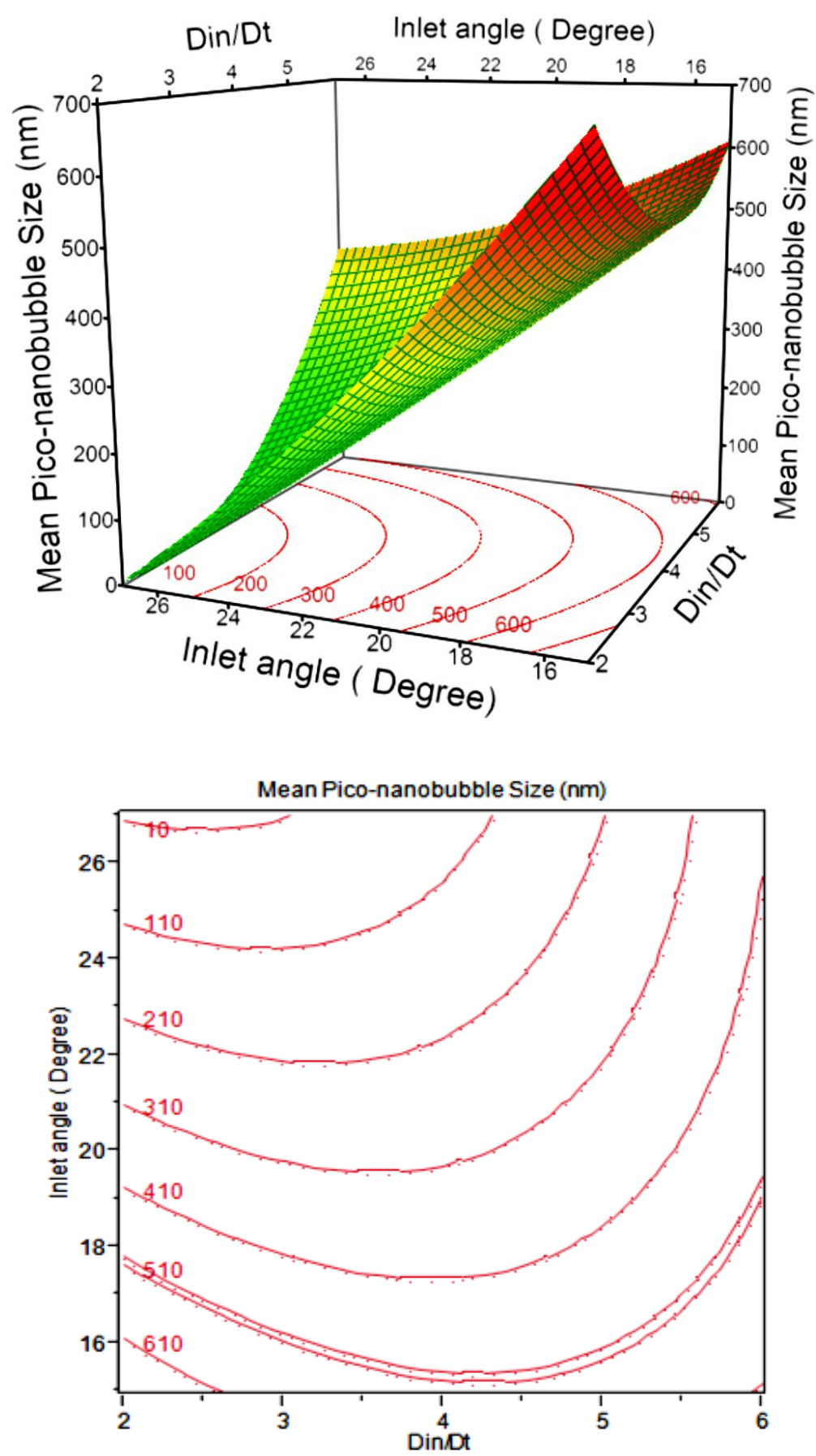

(b) Mean pico-nano bubble size

Figure 5- 3 Effect of the ratio of the diameter of throat and outlet of the venture tube $\left(D_{\text {in }} / D_{t}\right)$ and the inlet angle on the (a) pico-nano bubble volume and (b) mean piconano bubble size. 
Figure 5-4 depicts the effects of the ratio of the diameter of throat and outlet of the venture tube $\left(\mathrm{D}_{\mathrm{in}} / \mathrm{D}_{\mathrm{t}}\right)$ and the outlet angle on the pico-nano bubble volume and mean pico-nano bubble size when the ratio of the length of the throat and the diameter of throat $\left(\mathrm{L}_{\mathrm{t}} / \mathrm{D}_{\mathrm{t}}\right)$ and inlet angle were 3 and $21^{\circ}$, respectively. It can be obviously seen from Figure 5-4a that the pico-nano bubble volume increases with increasing the outlet angle from $8^{\circ}$ to $12^{\circ}$, while the pico-nano bubble volume decreases as the outlet angle keeps increasing from $12^{\circ}$ to $16^{\circ}$, this is very similar to the trend of the effect of $D_{\text {in }} / D_{t}$ value on the pico-nano bubble volume. And the highest volume of pico-nano bubbles is achieved at medium level of $D_{\text {in }} / D_{t}$ value and outlet angle. As can be seen in Figure 5-4b, when the outlet angle increases from $8^{\circ}$ to $16^{\circ}$, the mean pico-nano bubble size decreases from $610 \mathrm{~nm}$ to $490 \mathrm{~nm}, 550 \mathrm{~nm}$ to $450 \mathrm{~nm}$, and $780 \mathrm{~nm}$ to $610 \mathrm{~nm}$ at the $\mathrm{D}_{\mathrm{in}} / \mathrm{D}_{\mathrm{t}}$ value of 2, 4 and 6, respectively. This means that better results can be achieved at the medium level of the $D_{\text {in }} / D_{t}$ value, which has a positive effect on the cavition process.

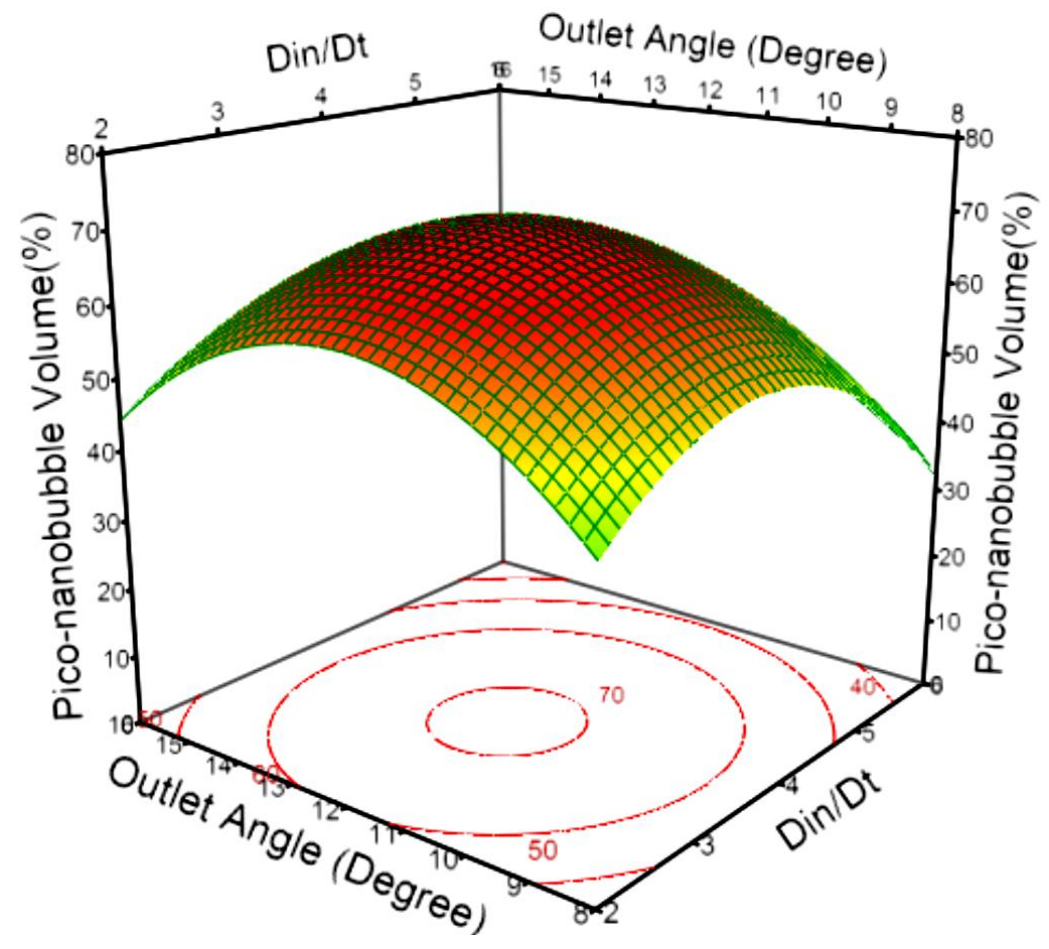




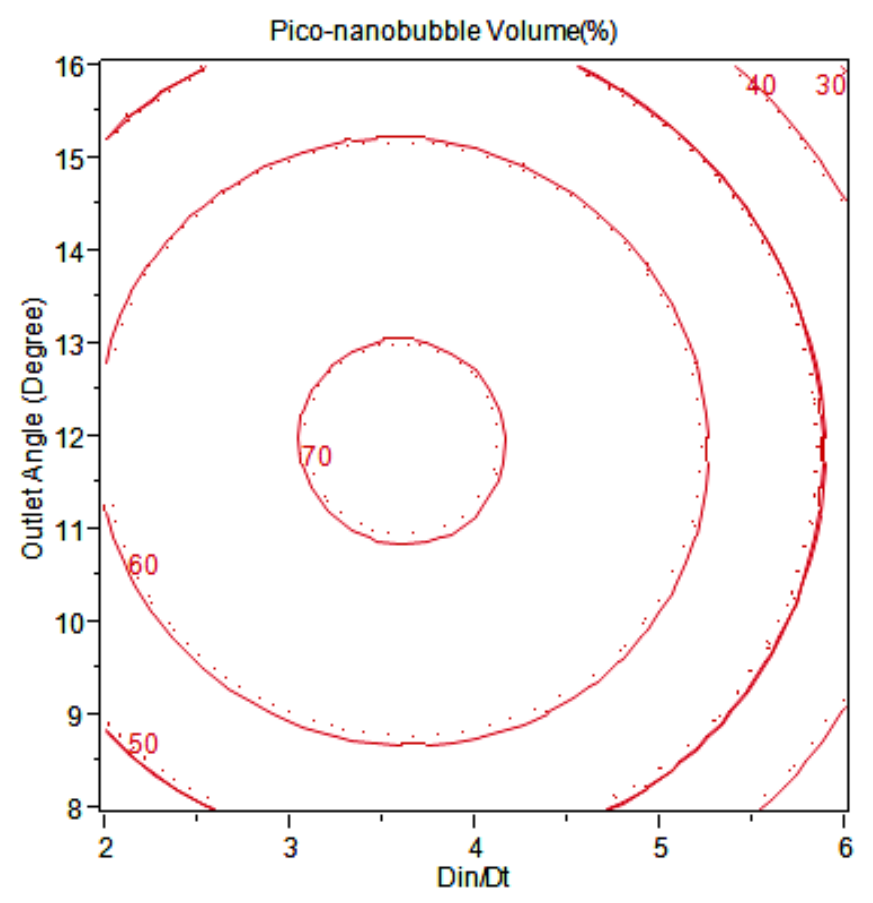

(a) Pico-nano bubble volume

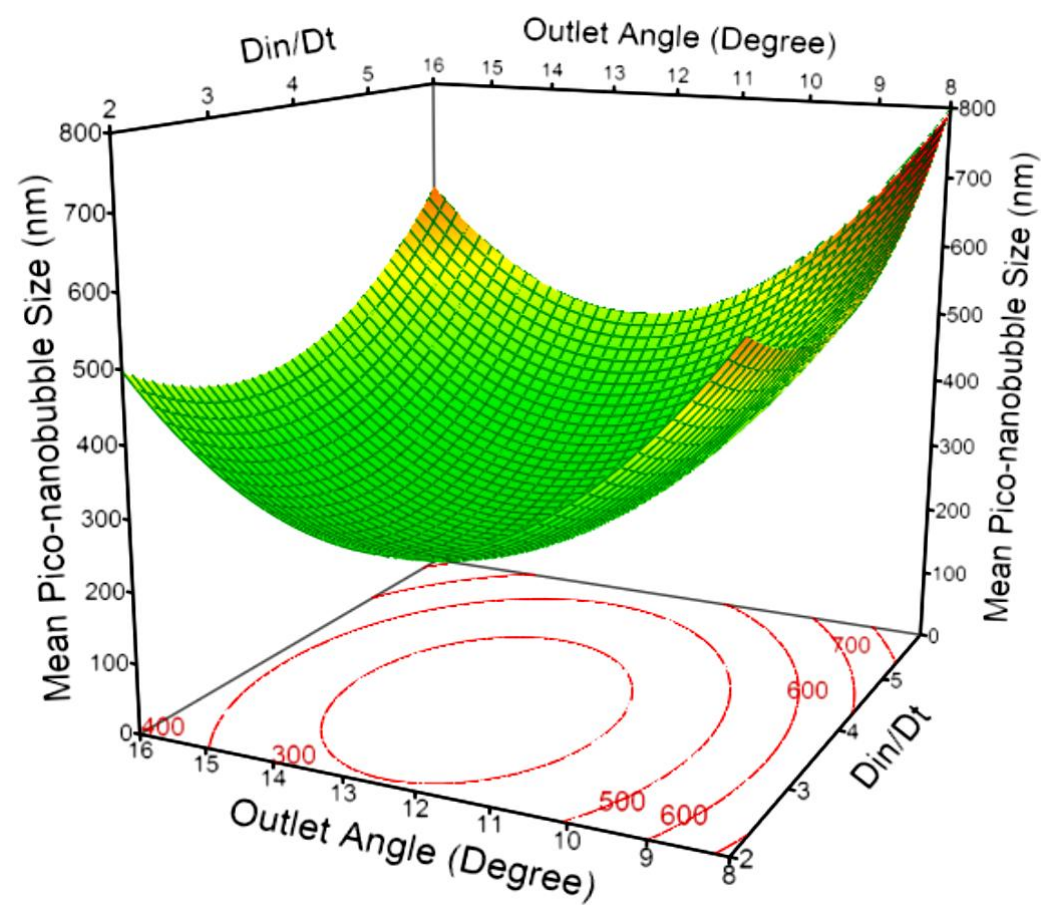




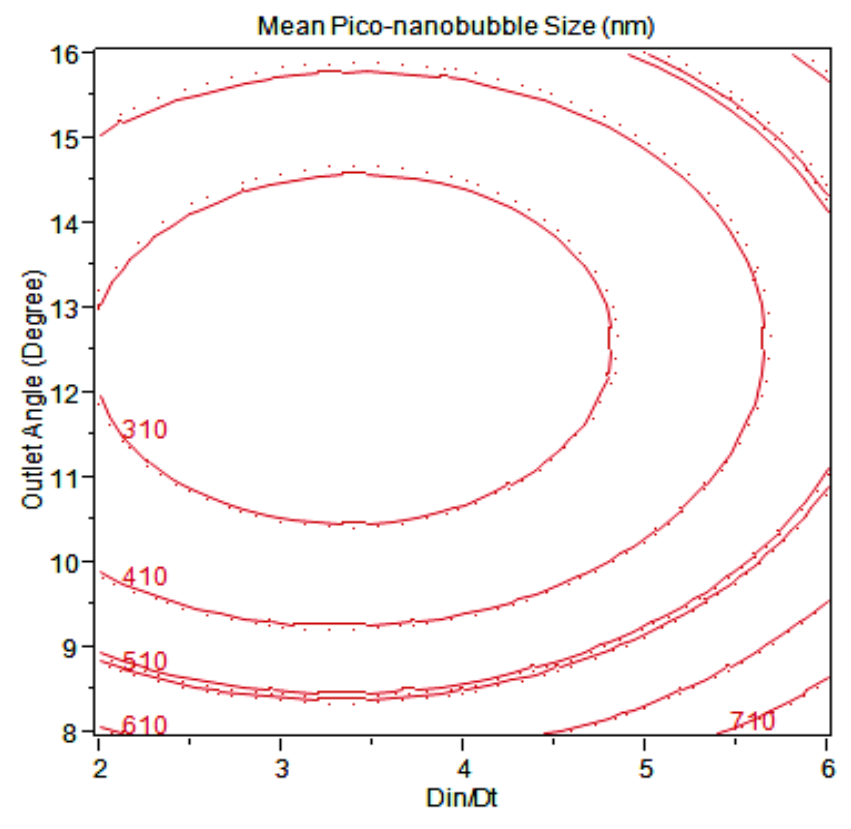

(b) Mean pico-nano bubble size

Figure 5- 4 Effect of the ratio of the diameter of throat and outlet of the venture tube $\left(\mathrm{D}_{\text {in }} / \mathrm{D}_{\mathrm{t}}\right)$ and the outlet angle on the (a) Pico-nano bubble volume and (b) mean piconano bubble size.

Maximum volume of pico-nano bubbles, $65 \%$ to $75 \%$, and minimium mean pico-nano bubble size, 150 to $240 \mathrm{~nm}$, were achieved at the medium ratio of the diameter of throat and outlet of the venture tube ( 3 to 4$)$, medium outlet angle $\left(11^{\circ}\right.$ to $\left.13^{\circ}\right)$, high inlet angle ( $26^{\circ}$ to $27^{\circ}$ ) and high ratio of the length of the throat and the diameter of throat (2.3 to 3 ).

\subsubsection{Properties of pico-nano bubbles and nanobubbles}

\subsubsection{Effect of different configurations of pico-nano bubbles, nanobubbles and}

\section{microbubbles generators on bubble size distribution}

The size distribution of pico-nano bubbles, nanobubbles and microbubbles generated by the venture tube of the optimal design and static mixer are shown in Figure 5-5. Figure 55a shows the pico-nano bubbles, nanobubbles and microbubbles generated by the static 
mixer-venturi tube which were installed in the series configuration. There are three distinct modes observed on each population frequency curve, which are $0.08 \mu \mathrm{m}, 0.7 \mu \mathrm{m}$ and $11 \mu \mathrm{m}$, respectively, representing pico-nano bubbles and nanobubbles genetated by the venture tube and microbubbles produced by static mixer. Two modes are observed in the bubble frequency curve produced by venturi tube, as shown in Figure 5-5d, because of the formation of the bubble clusters (Ata, et al., 2005), which are held together by pico-nano bubbles that attach to two or more bubbles and form stable bridges between them.

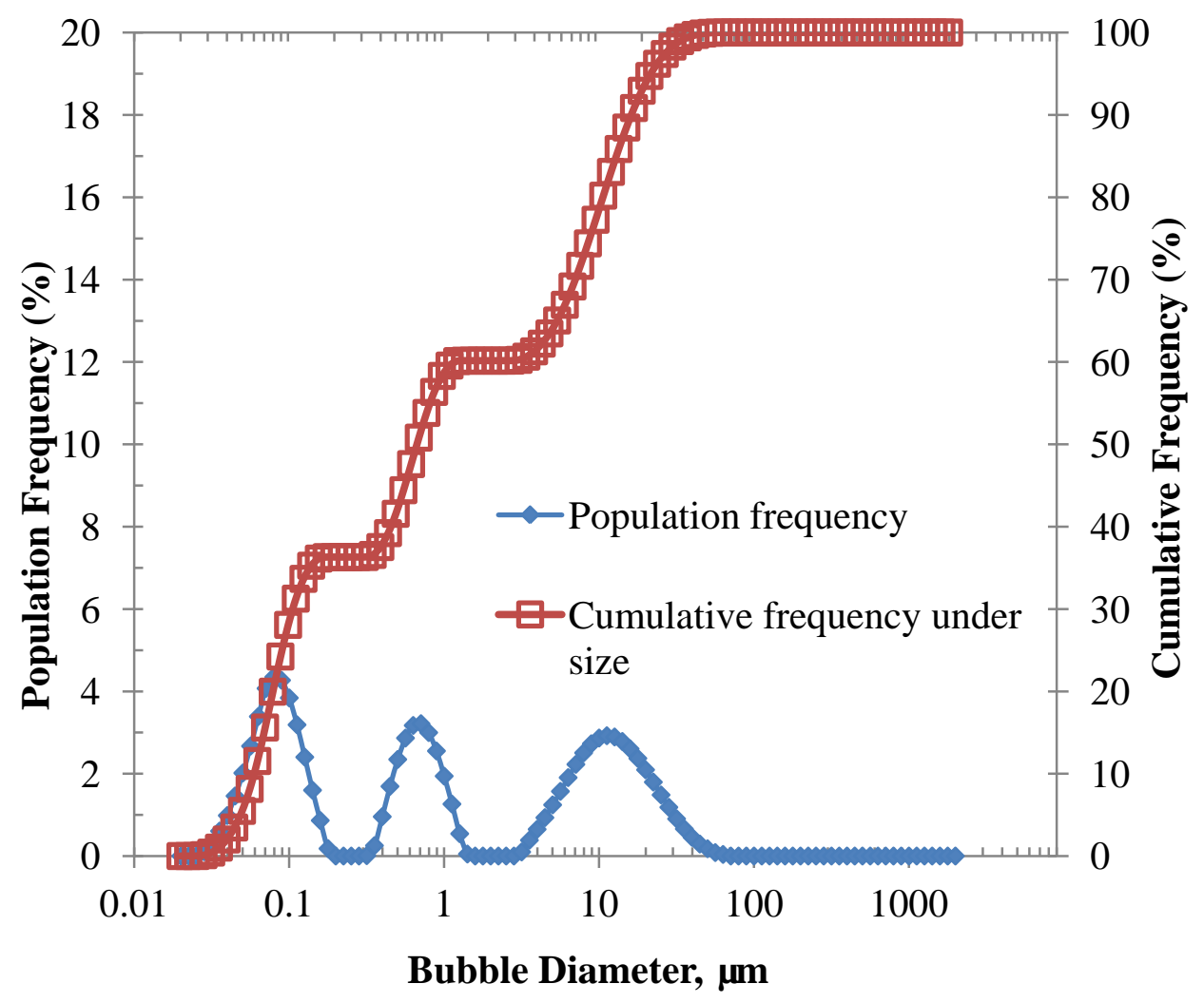

(a) By static mixer and venturi tube which were installed in the series configuration. 


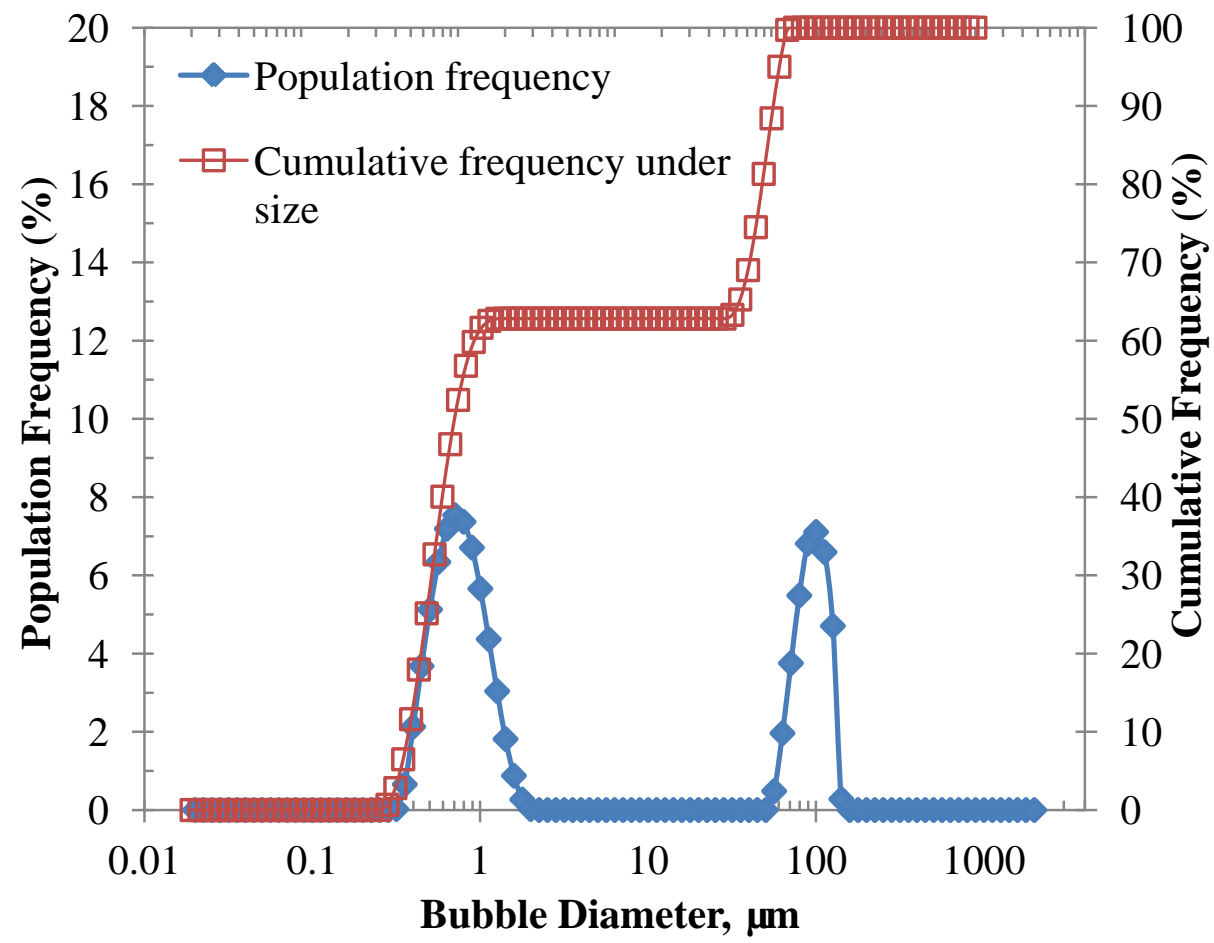

(b) By static mixer and venturi tube which were installed in the parallel configuration.

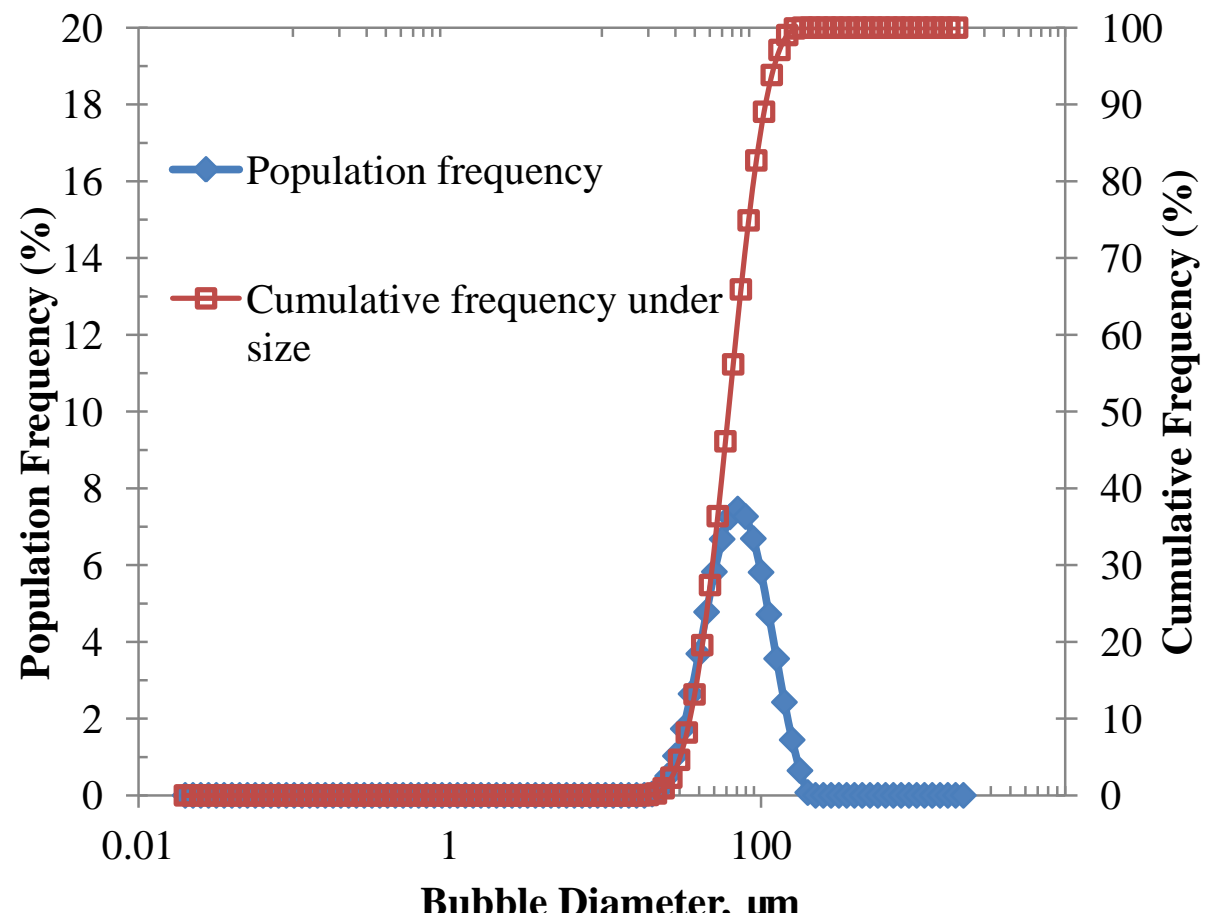

(c) By static mixer only 


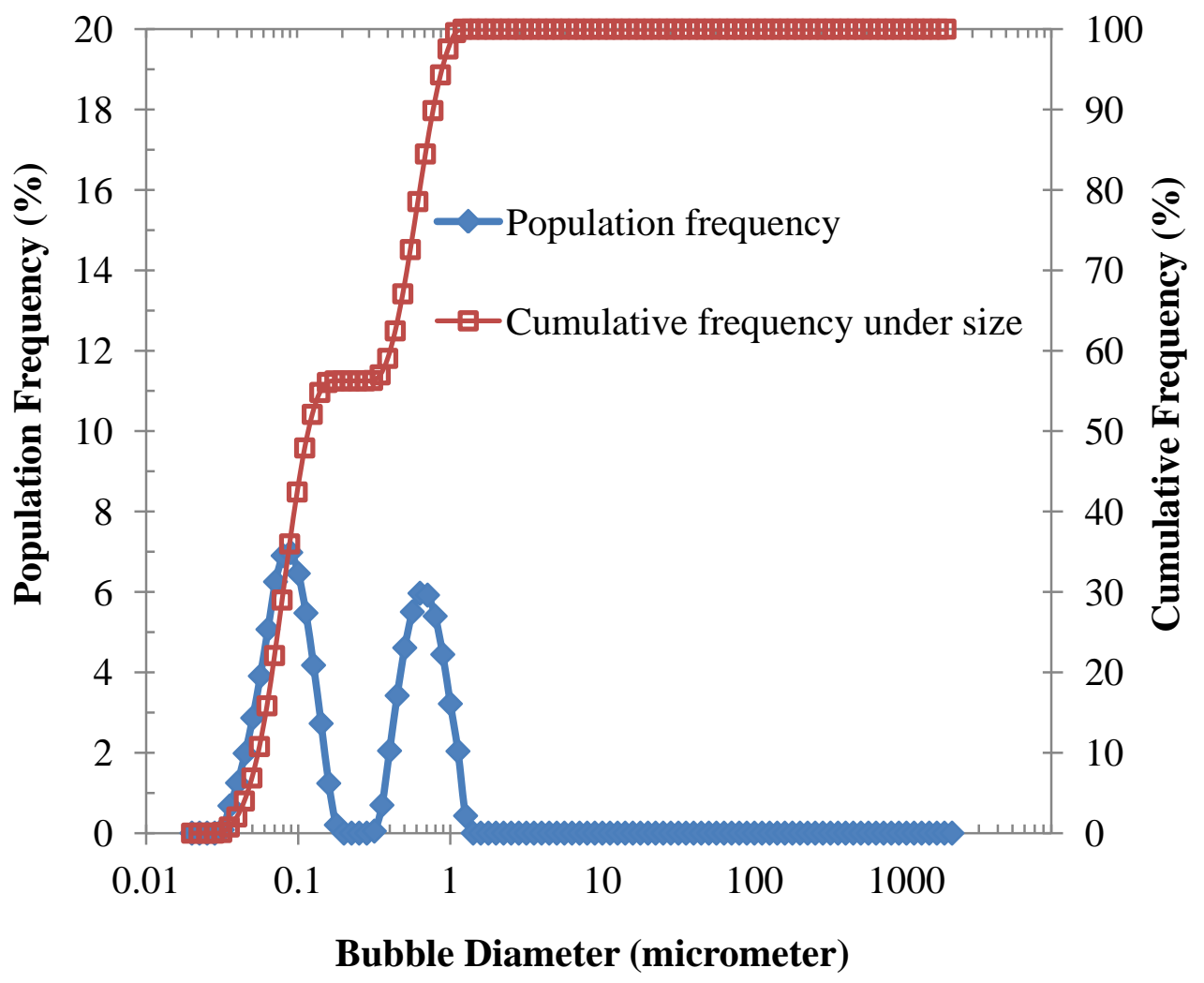

(d) By venturi tube only

Figure 5- 5 Bubbles generated by static mixer -venturi tube, static mixer only and venturi tube only with $20 \mathrm{ppm}$ MIBC.

Figure $5-5 b$ shows that the nanobubbles and microbubbles generated by static mixerventuri tube which were connected in the parallel configuration. No pico-nano bubbles are generated when the static mixer and the venturi tube are connected in parallel, this is because the flowrate through the static mixer and the venturi tube are reduced by $50 \%$ after splitting into two streams, resulting in the reduction of the pressure drop through the venturi tube and static mixer. Figure $5-5 \mathrm{c}$ shows that the bubbles generated by static mixer only, which mainly existing as microbubbles. All tests were measured after 10 minutes after the bubble generation process, in order to eliminate the effect of bubble 
rising on measurement, the pico-nano bubbles and nanobubbles solutions were recycled slowly without flowing through the venturi tube.

\subsubsection{Effect of selected frother on pico-nano bubble size distribution}

Figure 5-6 shows the size distribution of pico-nano bubbles and nanobubbles generated from air naturally dissolved in water with varying MIBC (Methyl Isobutyl Carbinol) concentration.

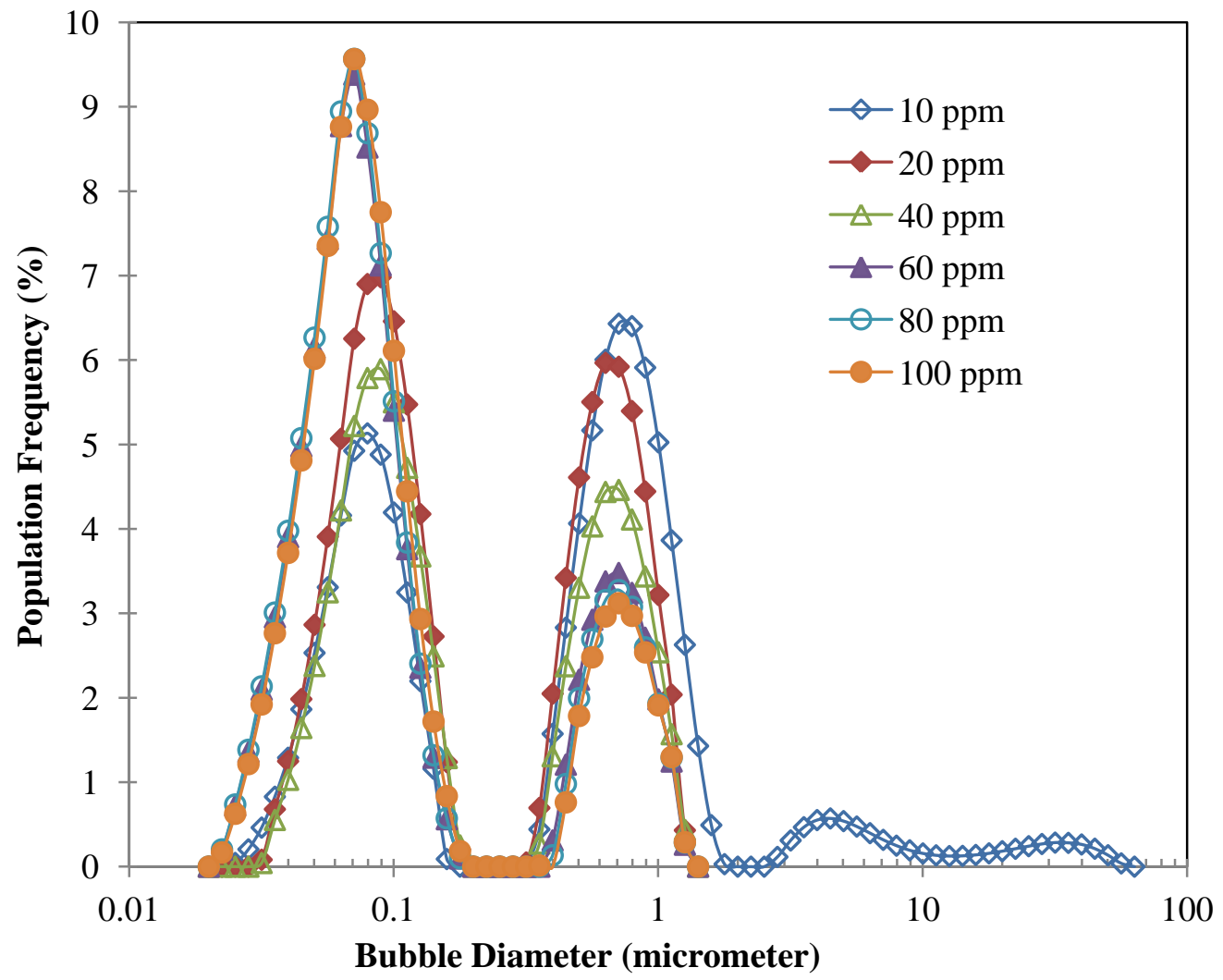

Figure 5- 6 Pico-nano bubbles generated at varying concentration of MIBC.

It can be clearly seen from Figure 5-6 that the bubble size decreases with increasing frother concentration from $10 \mathrm{ppm}$ to $100 \mathrm{ppm}$. This is because the addition of frother up 
to a given amount reduces the surface tension, $\gamma$. Fundamentally, the role of frother can be understood by the Laplace equation:

$$
r=\frac{2 \gamma}{P_{2}-P_{1}}
$$

where $\mathrm{P}_{1}, \mathrm{P}_{2}$ and $\mathrm{r}$ are the pressure inside the bubble, the pressure outside the bubble, and the radius of the bubble, respectively.

Under typical flotation conditions of frother addition, the reduction in surface tension of the liquid/vapor interface is achieved and can result in increasing in surface area and correspondingly reduction s in bubble size. Frother molecules increase the stability of the hydrated layer surrounding the bubble by absorbing on the air bubbles. The hydrophilic groups of absorbed frother molecules are directed to the liquid phase and actively interact with water molecules. This enhances the mechanical strength of the water film around the bubble and preventing its coalescence/breakup on collision with other bubbles (Finch, et al. 2008).

Figure 5-7 gives the size distribution curve for bubbles in water solution inside the testing column with 20 ppm MIBC (Methyl Isobutyl Carbinol) or TTT frother. It can be seen that both curves have two peaks. On the population frequency curve with TTT frother, two peaks are located at 0.065 and $0.7 \mu \mathrm{m}$, representing pico-nano bubbles and nanobubbles generated by the venturi tube. With frother MIBC, the modes of the piconano bubble and nanobubble size distribution are 0.08 and $0.7 \mu \mathrm{m}$, respectively. The pico-nano bubble size is smaller than the microbubble size by about three orders of magnitude. Figure 5-7 also shows that the pico-nano bubbles and nanobubbles produced with TTT frother are finer than those formed with MIBC. This is because TTT frother is 
stronger than MIBC and the surface tension reduction by TTT frother is more significant than by MIBC.

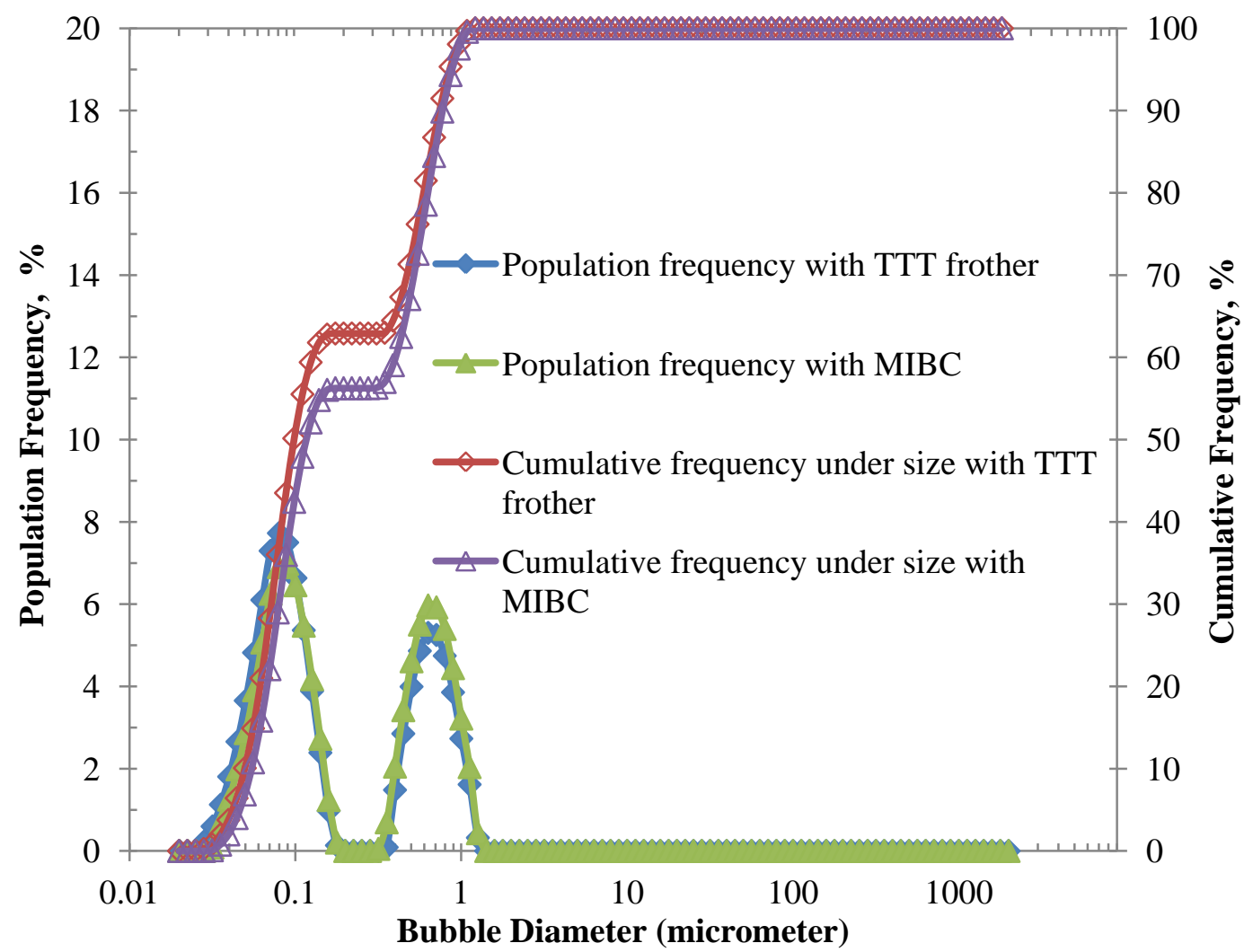

Figure 5- 7 Bubble size distribution curve in water solution with 20 ppm MIBC, and TTT frother.

\subsection{Column flotation of bituminous coal using cavitation venturi tube for pico-nano}

bubbles and nanobubbles generation

\subsubsection{Design of Experiment and Statistical Analysis Method}

\subsubsection{Six-factor three-level experimental design}

The main and interaction coefficients are evaluated and tested for significance as shown in Table 5-3. 
Table 5- 3 Estimated coefficients, t-ratios and p-values.

\begin{tabular}{|c|c|c|c|c|c|c|}
\hline \multirow[t]{2}{*}{ Term } & \multicolumn{3}{|c|}{ Combustible material recovery model } & \multicolumn{3}{|c|}{ Clean coal ash model } \\
\hline & Estimate & t Ratio & Prob. $>|t|$ & Estimate & t Ratio & Prob.>|t| \\
\hline Intercept & 95.21 & 25.55 & $<0.0001 *$ & 9.05 & 8.19 & $<0.0001 *$ \\
\hline $\mathrm{A}$ & 1.07 & 1.46 & 0.16 & -0.48 & -1.4 & 0.18 \\
\hline B & 4.73 & 4.11 & $0.0009^{*}$ & -0.006 & -2.41 & $0.03 *$ \\
\hline $\mathrm{C}$ & -0.10 & -1.23 & 0.24 & 0.03 & 1.14 & 0.27 \\
\hline $\mathrm{D}$ & -1.07 & -5.67 & $<0.0001 *$ & 2.5 & 2.53 & $0.02 *$ \\
\hline $\mathrm{E}$ & -10.18 & -6.10 & $<0.0001 *$ & -0.99 & -2.78 & $0.01 *$ \\
\hline $\mathrm{F}$ & -4.56 & -0.61 & 0.55 & 0.68 & 0.45 & 0.66 \\
\hline $\mathrm{A} \times \mathrm{B}$ & -6.00 & -1.5 & 0.15 & 0.11 & 1.37 & 0.19 \\
\hline $\mathrm{B} \times \mathrm{C}$ & 3.86 & 2.15 & 1.88 & -6.00 & -1.5 & 0.15 \\
\hline $\mathrm{C} \times \mathrm{D}$ & -0.0001 & -0.01 & 0.99 & 1.07 & 1.46 & 0.16 \\
\hline $\mathrm{D} \times \mathrm{E}$ & 0.007 & 0.03 & 0.98 & -9.08 & -0.67 & 0.51 \\
\hline$E \times F$ & -9.08 & -0.67 & 0.51 & -0.06 & -1.13 & 0.28 \\
\hline
\end{tabular}

Note: * means significant factors.

The main effects of collector dosage, Feed solids concentration and Feed rate on recovery of combustible material and clean coal ash content are significant at $95 \%$ confidence level, as indicated by the Prob. $>|t|$ values less than 0.05 when assessing the estimated coefficient. These findings indicate that feasibility of the pico-nano bubbles plays an important role in determining flotation performance, high solids concentration and feed rate would lead to the lack of pico-nanno bubbles in the flotation process, which would affect the product grade. Besides, similar to previous findings, collector dosage is also very important in determining the clean coal grade, by using optimal dosage of collector, we can get clean coal product with low ash content and high combustible material recovery. The orders of main effects are:

Feed rate $>$ Feed solids concentration $>$ Collector dosage $>$ Gas flow rate $>$ Frother dosage > Superficial wash water rate. 
As shown in Table 5-4, we split our ANOVA table into rows for Model and Error in order to examine how much error we have when we use our predictive equation, and to determine how much error has disappeared because we used our predictive equation. All major statistics analysis results in Table 5-3 show that the models for the combustible material recovery and clean coal ash models can adequately describe the effects of operating parameter on the response variables.

Based on the statistical analysis results, the reduced model in terms of the factor levels is:

Combustible Material Recovery $(\%)=95.21+1.07 \times A+4.73 \times B+(-0.1) \times C \pm(-1.07)$

$\times \mathrm{D} \pm(-10.18) \times \mathrm{E} \pm(-6.81) \times \mathrm{F}+(-6) \times \mathrm{A} \times \mathrm{B}+3.86 \times \mathrm{B} \times \mathrm{C}+(-0.0001) \times \mathrm{C} \times \mathrm{D}+0.007$

$\times \mathrm{D} \times \mathrm{E}+(-9.08) \times \mathrm{E} \times \mathrm{F}$

Clean Coal Ash $(\%)=9.05 \pm(-0.48) \times \mathrm{A} \pm(-0.006) \times \mathrm{B}+0.03 \times \mathrm{C}+(-0.99) \times \mathrm{D}+0.91 \times$

$\mathrm{E}+2.50 \times \mathrm{F}+0.11 \times \mathrm{A} \times \mathrm{B}+(-6.00) \times \mathrm{B} \times \mathrm{C}+(1.07) \times \mathrm{C} \times \mathrm{D}+(-9.08) \times \mathrm{D} \times \mathrm{E}+(-0.06)$

$\times \mathrm{E} \times \mathrm{F}$

The comparison of the observed responses and predicted responses with reduced model are shown in Figure 5-8.

Table 5- 4 ANOVA table derived for the combustible material recovery and clean coal ash models.

\begin{tabular}{|c|c|c|c|c|c|c|c|}
\hline \multicolumn{7}{|c|}{ Combustible material recovery model } \\
\hline Source & SS & DF & F value & Prob. $>$ F & $\mathrm{R}^{2}$ & $\begin{array}{c}\text { Adjusted } \\
\mathrm{R}^{2}\end{array}$ \\
\hline Model & 1179.66 & 11 & 13.36 & $<0.0001 *$ & 0.93 & 0.89 \\
\hline Error & 120.41 & 15 & \multicolumn{7}{|c|}{} \\
\hline Source & Clean coal ash model & $\mathrm{R}^{2}$ & $\begin{array}{c}\text { Adjusted } \\
\mathrm{R}^{2}\end{array}$ \\
\hline SS & DF & F value & Prob. $>\mathrm{F}$ & & 0.82 \\
\hline Error & 31.21 & 8 & 4.02 & $<0.0001 *$ & 0.89 & 0. \\
\end{tabular}

Notes: $\mathrm{DF}=$ Degree of freedom, $\mathrm{SS}=\mathrm{Sum}$ of squares. 

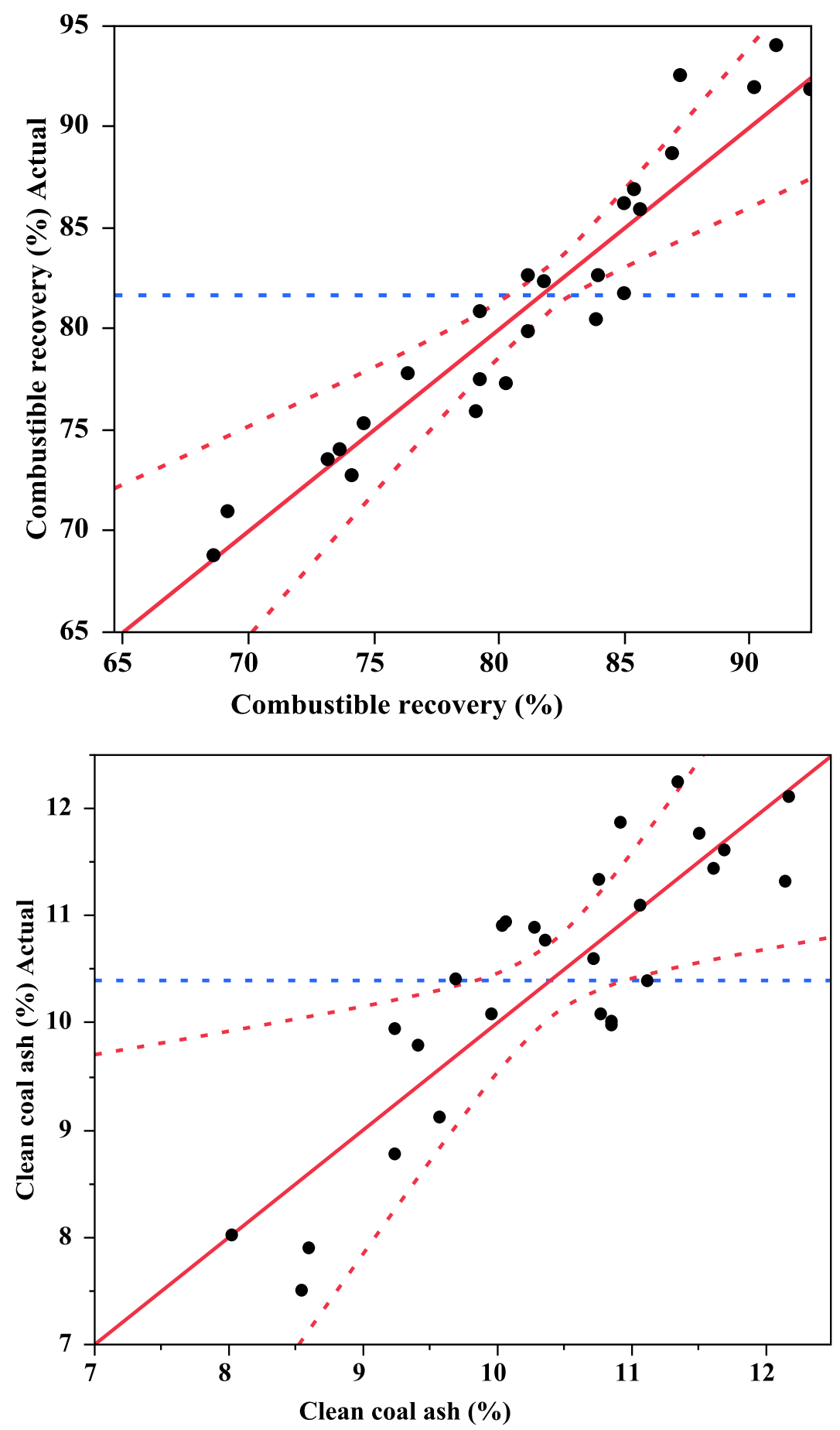

Figure 5- 8 Comparison of the observed responses and predicted responses with reduced model. 
Figure 5-9a depicts the effect of gas flow rate and collector dosages with the combustible material recovery as separation responses. The response surface and contour curves suggest that the effect of collector dosage is much more significant than gas flow rate and the area of the highest combustible efficiency was at the high level of collector dosage. The combustible material recovery increased by about $6 \%$ as the collector dosage increased from 0.5 to $1.5 \mathrm{lb} /$ ton. Figure $5-9 \mathrm{~b}$ depicts the effect of gas flow rate and collector dosages with the clean coal ash content as separation responses. It can be seen from the response surface and contour curves that the effect of collector dosage is much more significant than gas flow rate, and clean coal ash increases with increasing collector dosage. Maximum recovery was predicted at the highest collector dosage and gas flow rate while the minimum clean coal ash content is realized at the opposite end of the parameter value ranges, when gas flow rate increases from 0.5 to $2.5 \mathrm{~cm} / \mathrm{s}$, combustible material recovery increases from 78 to $79 \%, 81$ to $83 \%, 83$ to $83.5 \%$ with clean coal ash decreases from 10.5 to $10.2 \%, 11$ to $10.5 \%$ and 11.5 to $11.3 \%$, respectively at collector dosage of $0.3,0.9$ and $1.5 \mathrm{lb} /$ ton, this means that nanobubbles have more significant effect on the combustible material recovery at medium collector dosage. 


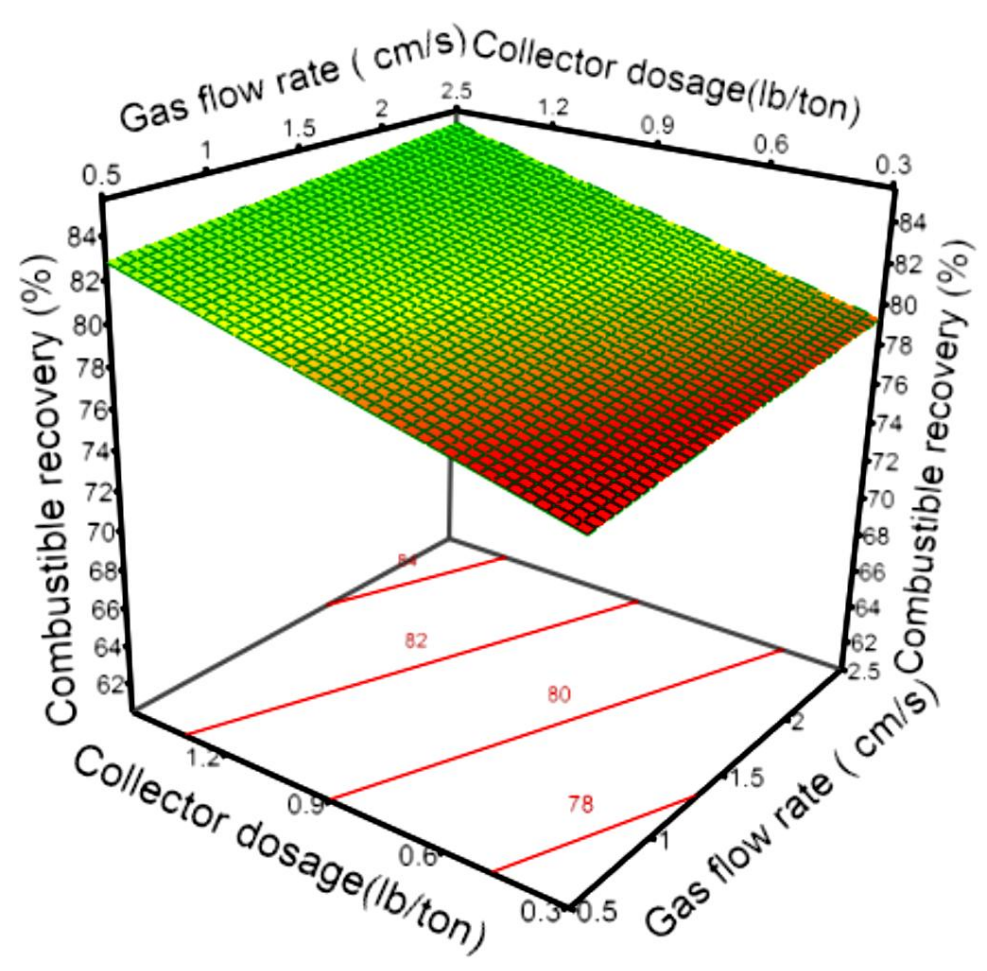

(a) Combustible material recovery.

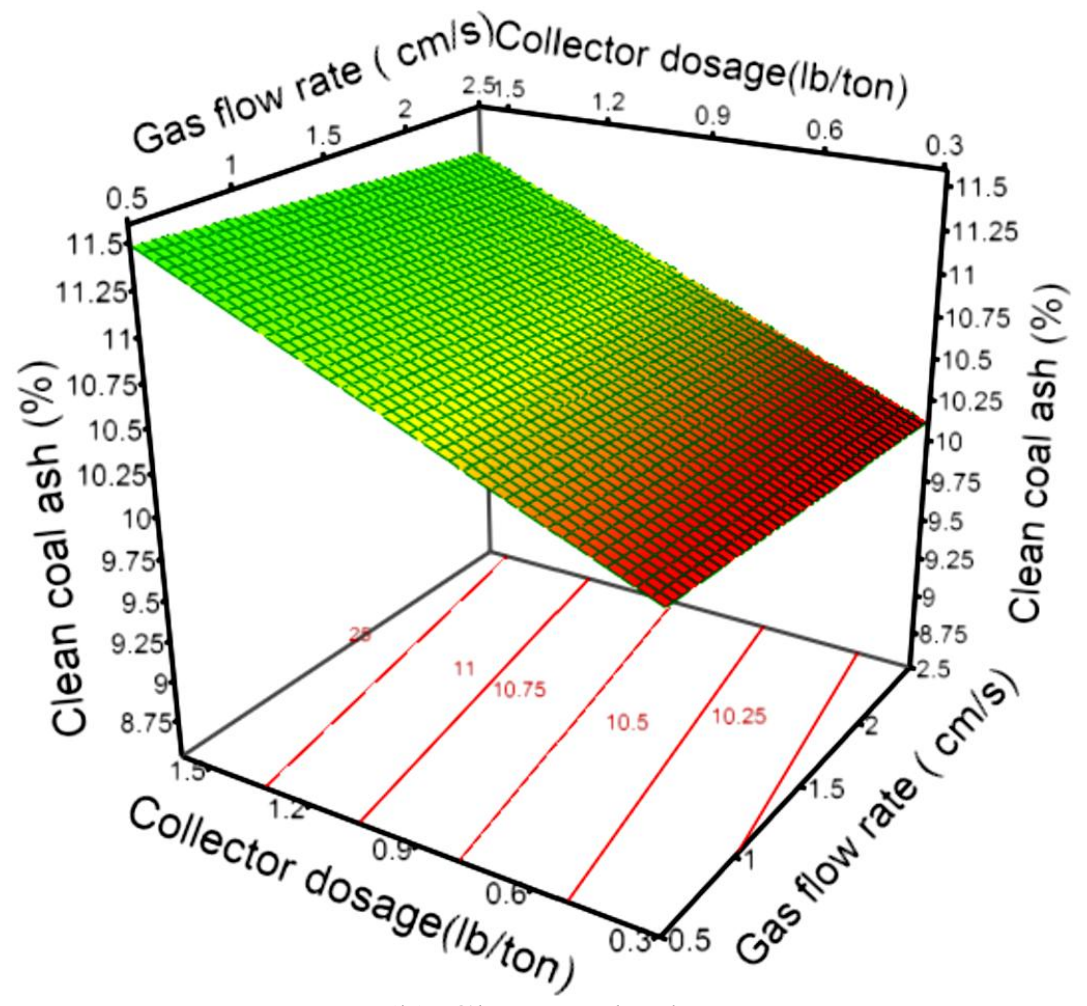

(b) Clean coal ash.

Figure 5- 9 Effect of gas flow rate and collector dosages on (a) CMR and (b) clean coal ash. 
Figure 5-10a shows the effect of gas flow rate and wash water rate with the combustible material recovery as separation responses. The response surface and contour curves suggest that the area of the highest combustible efficiency was at the low level of wash water rate. The gas flow rate had no significant effects on the combustible material recovery. The combustible material recovery increased by about $5 \%$ as the wash water rate decreased from 0.5 to $0.1 \mathrm{~cm} / \mathrm{s}$. Figure $5-10 \mathrm{~b}$ shows the effect of gas flow rate and wash water rate with clean coal ash content as separation responses. The response surface and contours suggest that the area of the lowest clean coal ash content was at the low level of wash water rate and gas flow rate. As the wash water rate increased from 0.1 to $0.5 \mathrm{~cm} / \mathrm{s}$, the clean coal ash content increased from 10.2 to $10.4 \%, 10.4$ to $10.6 \%$ and 10.7 to $10.9 \%$ at gas flow rate of $0.5 \mathrm{~cm} / \mathrm{s}, 1.5 \mathrm{~cm} / \mathrm{s}$ and $2.5 \mathrm{~cm} / \mathrm{s}$, respectively.

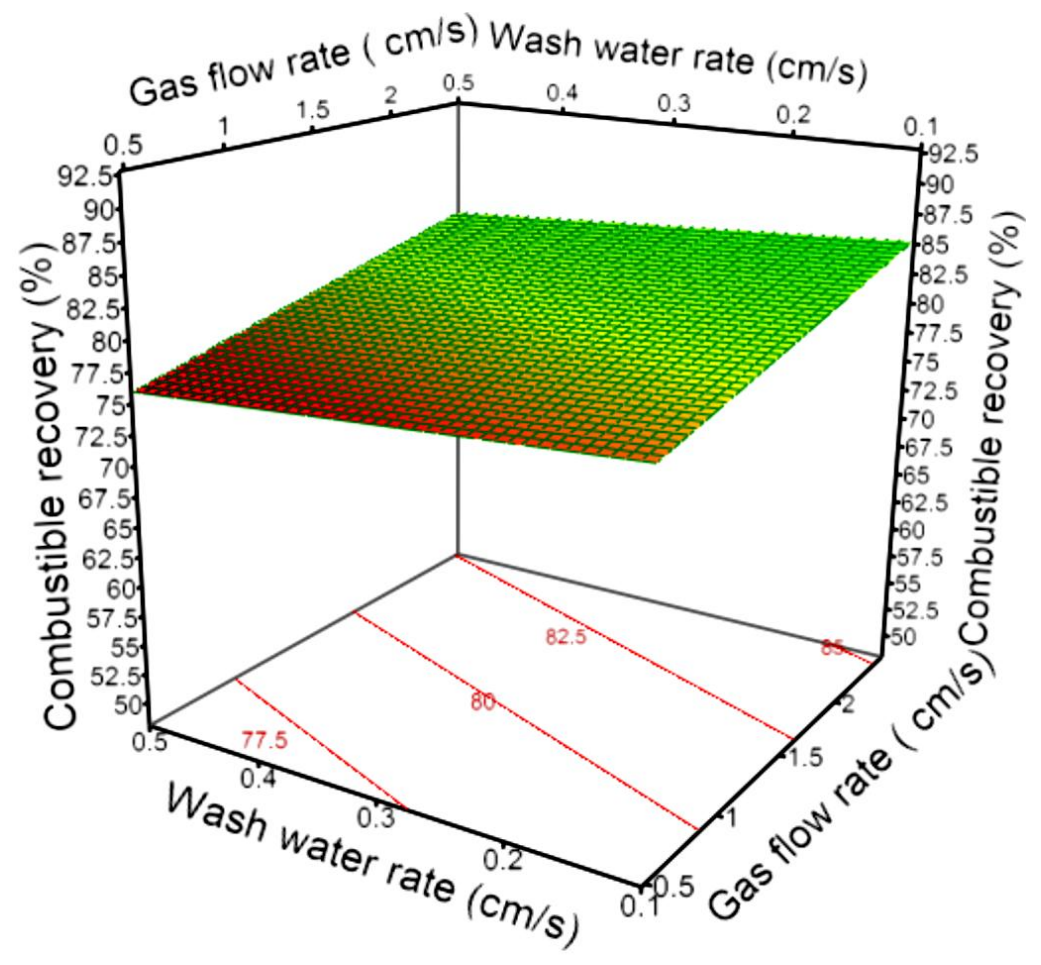

(a) Combustible material recovery. 


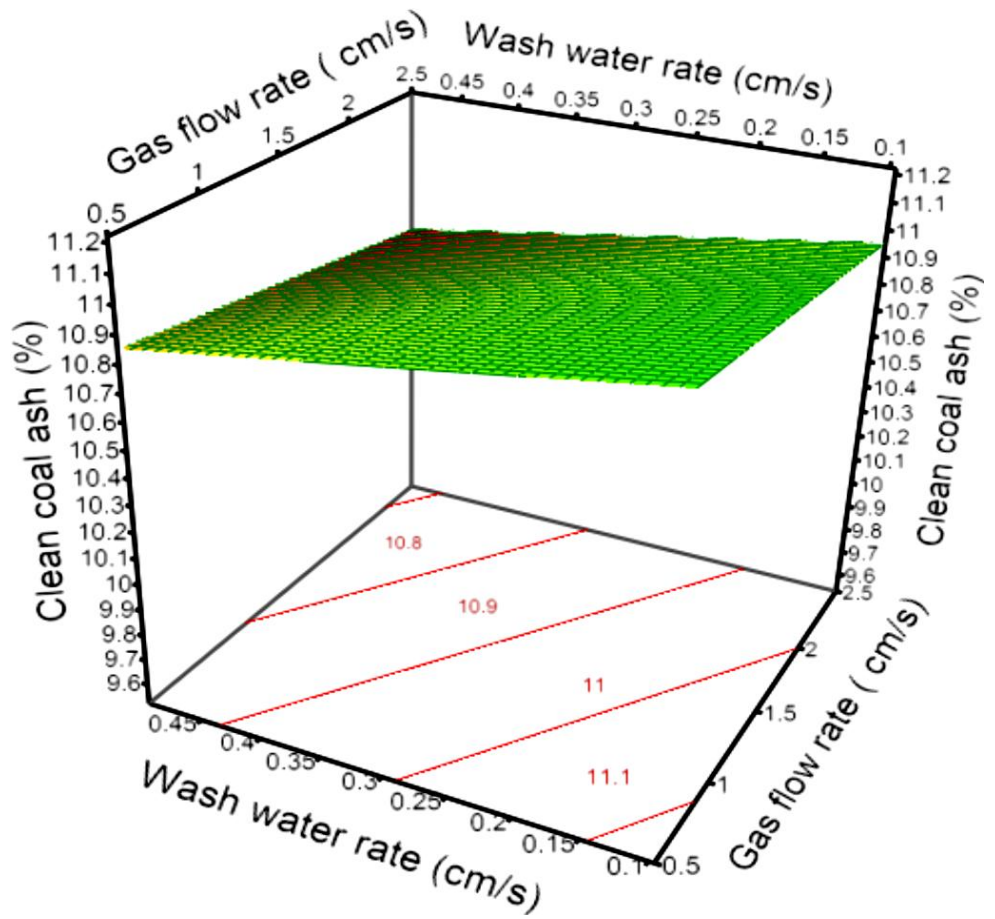

(b) Clean coal ash

Figure 5- 10 Effect of gas flow rate and wash water rate on (a) CMR and (b) clean coal ash.

Figure 5-11a shows the effect of gas flow rate and frother dosage with the combustible material recovery as separation responses. The response surface and contour curves indicate that both frother dosage and gas flow rate had no significant effect on the combustible material recovery. The combustible material recovery increased by about $1.5 \%$ as the gas flow rate increased from 0.5 to $2.5 \mathrm{~cm} / \mathrm{s}$. Figure $5-11 \mathrm{~b}$ shows that gas flow rate had little effect on the clean coal ash content comparing to the effect of frother dosage. The clean coal content increased by about $0.9 \%$ as the frother dosage increased from 5 to $40 \mathrm{ppm}$. 


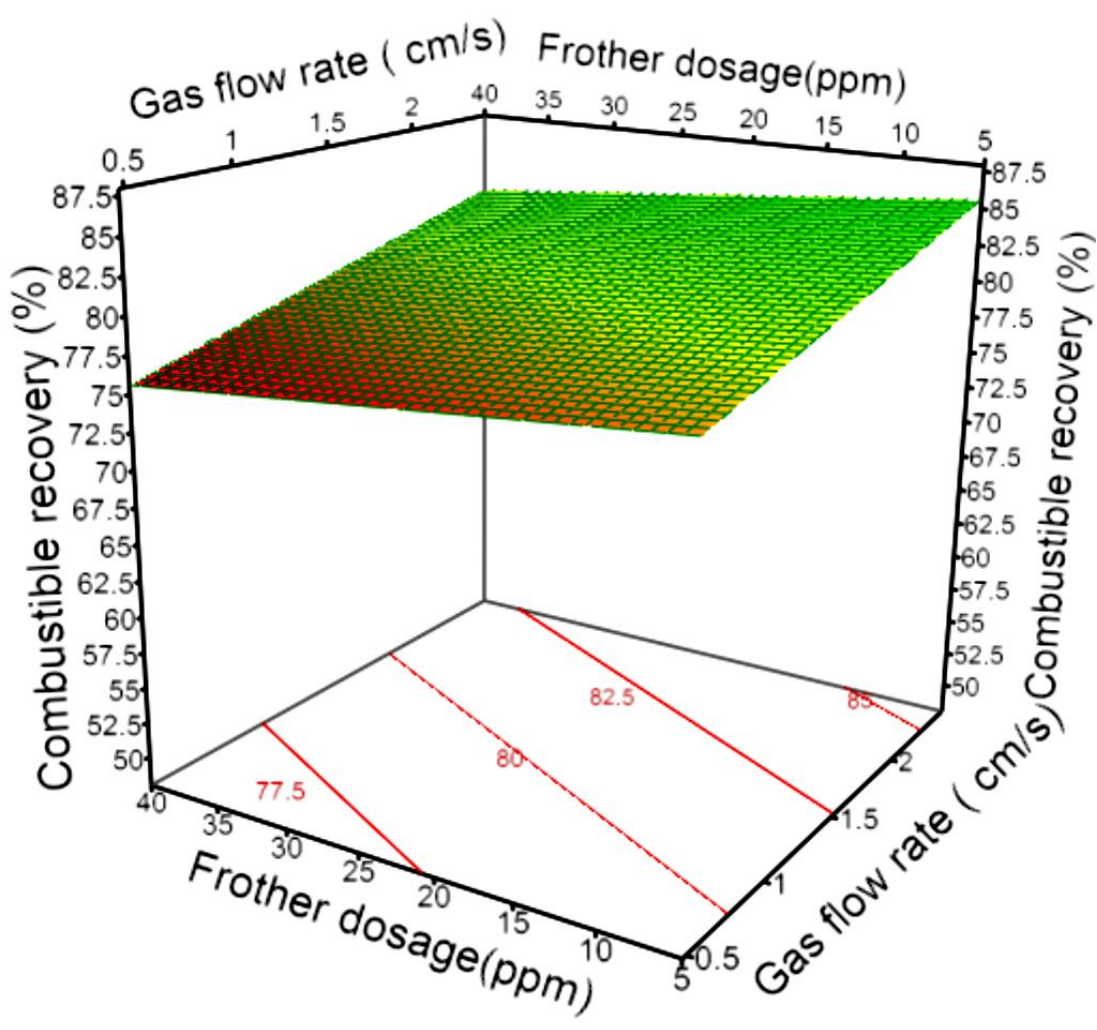

(a) Combustible material recovery.

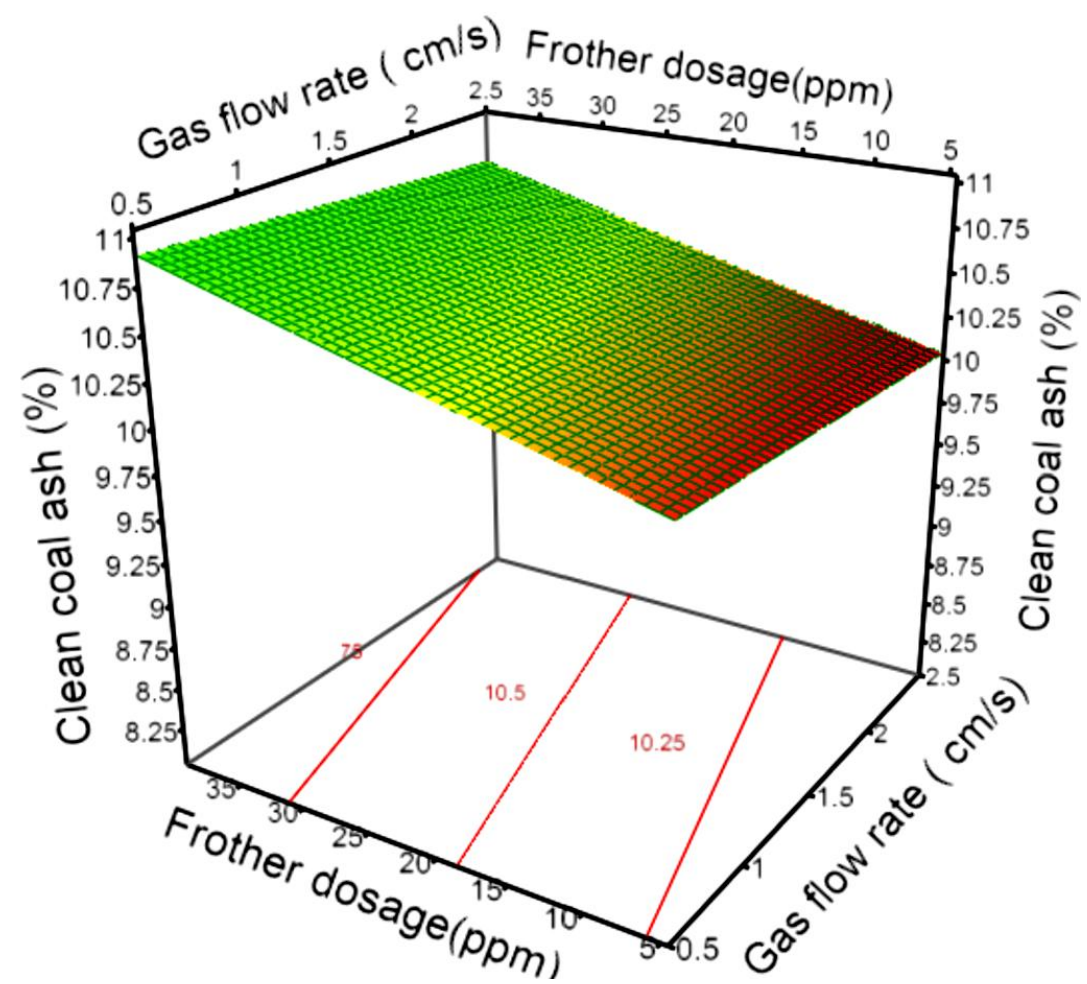

(b) Clean coal ash.

Figure 5- 11 Effect of gas flow rate and frother dosage on (a) CMR and (b) clean coal ash. 
Figure 5-12a shows the effect of gas flow rate and solids concentration with the combustible material recovery as separation responses. The response surface and contours depict that the area of the highest combustible efficiency was at the low level of solids concentration. The combustible material recovery increased by about $14 \%$ as the solids concentration decreased from 20 to $5 \%$. Figure 5-12a indicates the presence of pico-nano bubble had significant effects on the separation efficiency. Figure 5-12b shows that the area of lowest clean coal ash content was at the low level of solids concentration. The clean coal ash content increased by about $2 \%$ as the solids concentration increased from 5 to $20 \%$, while better combustible material recovery and product grade are achieved at lower solids concentration.

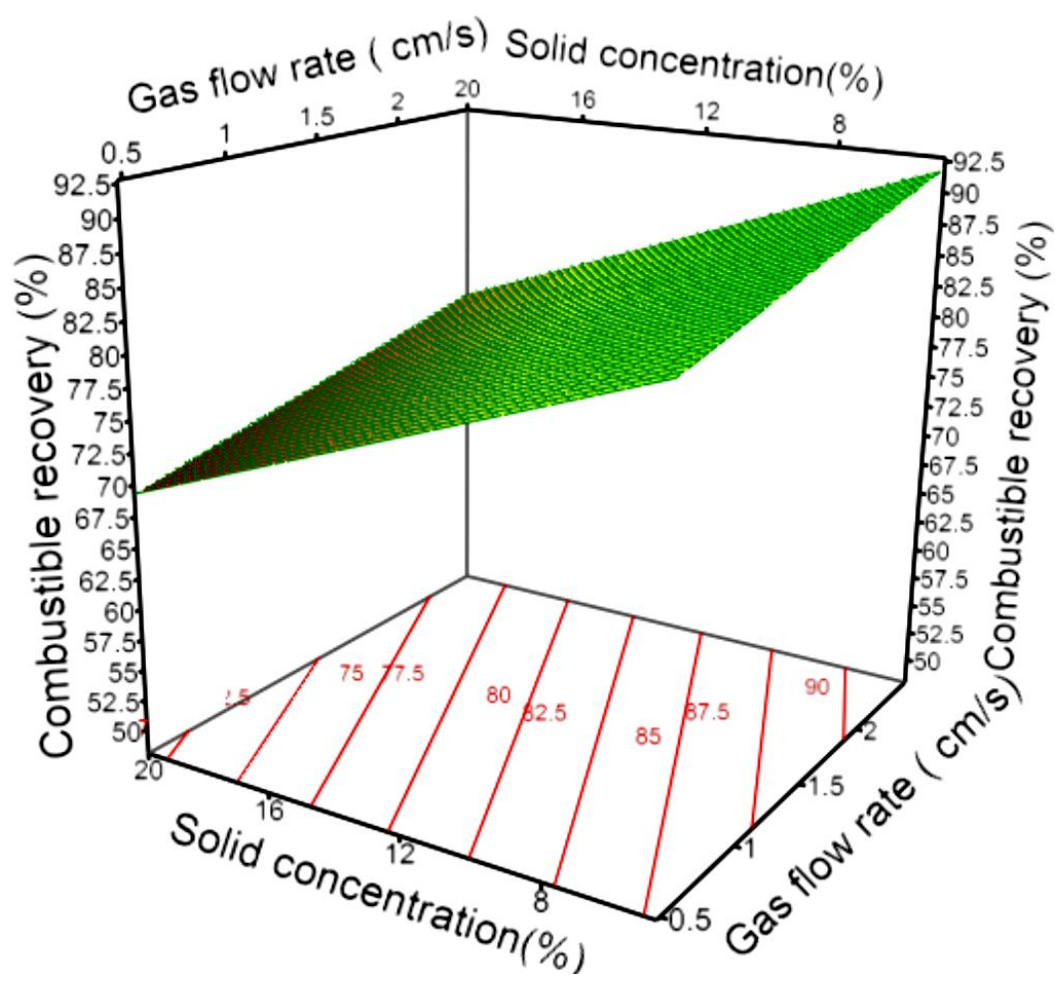

(a) Concentration on combustible material recovery. 


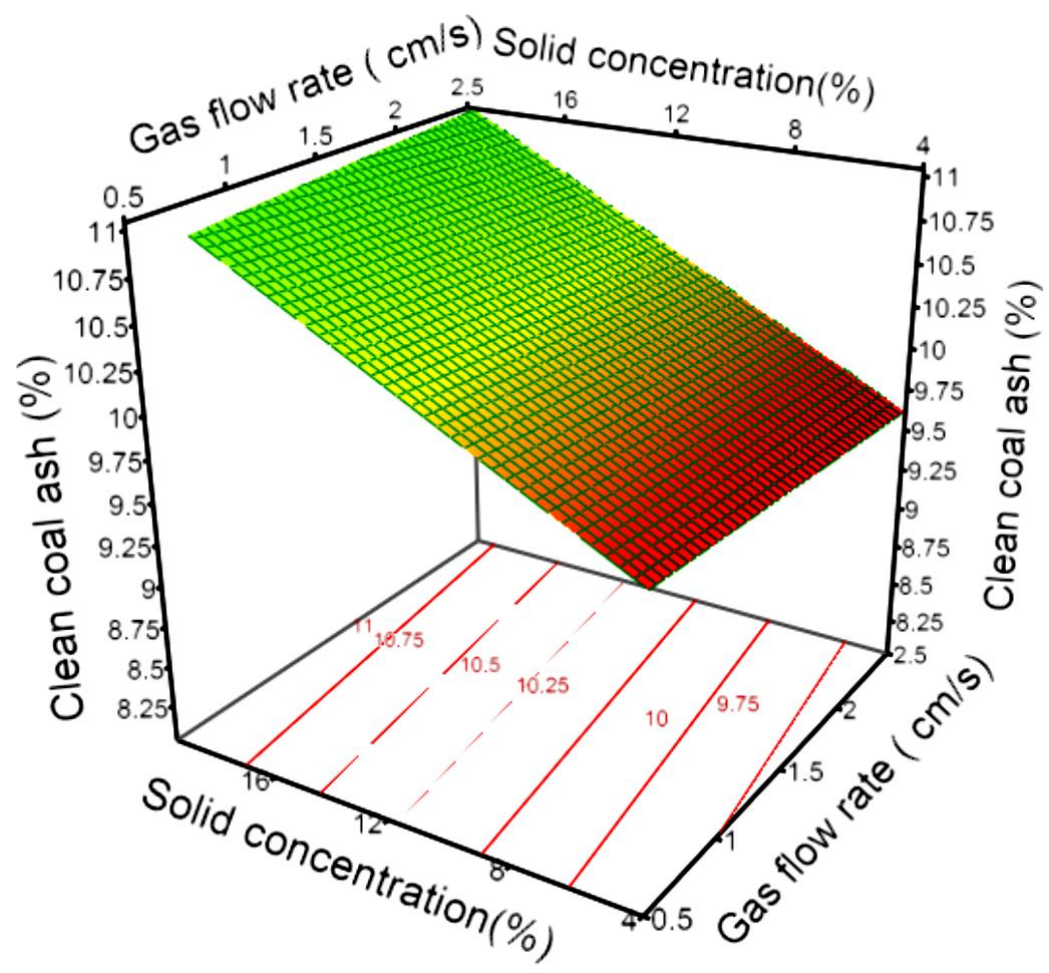

(b) Clean coal ash.

Figure 5- 12 Effect of gas flow rate and solids concentration on (a) CMR and (b) clean coal ash.

Figure 5-13a shows the effect of gas flow rate and feed rate with the combustible material recovery as separation responses. The response surface and contours depict that the area of the highest combustible efficiency was at the low level of feed rate. The combustible material recovery increased by about $8 \%$ as the feed rate decreased from 1 to $0.2 \mathrm{~cm} / \mathrm{s}$. The presence of pico-nano bubble had more significant effects on the separation efficiency. Figure 5-13b shows the effect of gas flow rate and feed rate with the clean coal ash content as separation responses. The clean coal content increases about $1 \%$ as increasing the feed rate from $0.2 \mathrm{~cm} / \mathrm{s}$ to $1 \mathrm{~cm} / \mathrm{s}$, and the gas flow rate had no significant effect on the clean coal ash, which only increased about $0.2 \%$ as decreasing gas flow rate from $2.5 \mathrm{~cm} / \mathrm{s}$ to $0.5 \mathrm{~cm} / \mathrm{s}$. Maximum recovery was predicted at the lowest feed rate, the minimum clean coal ash content is realized at same value ranges of the parameter. 


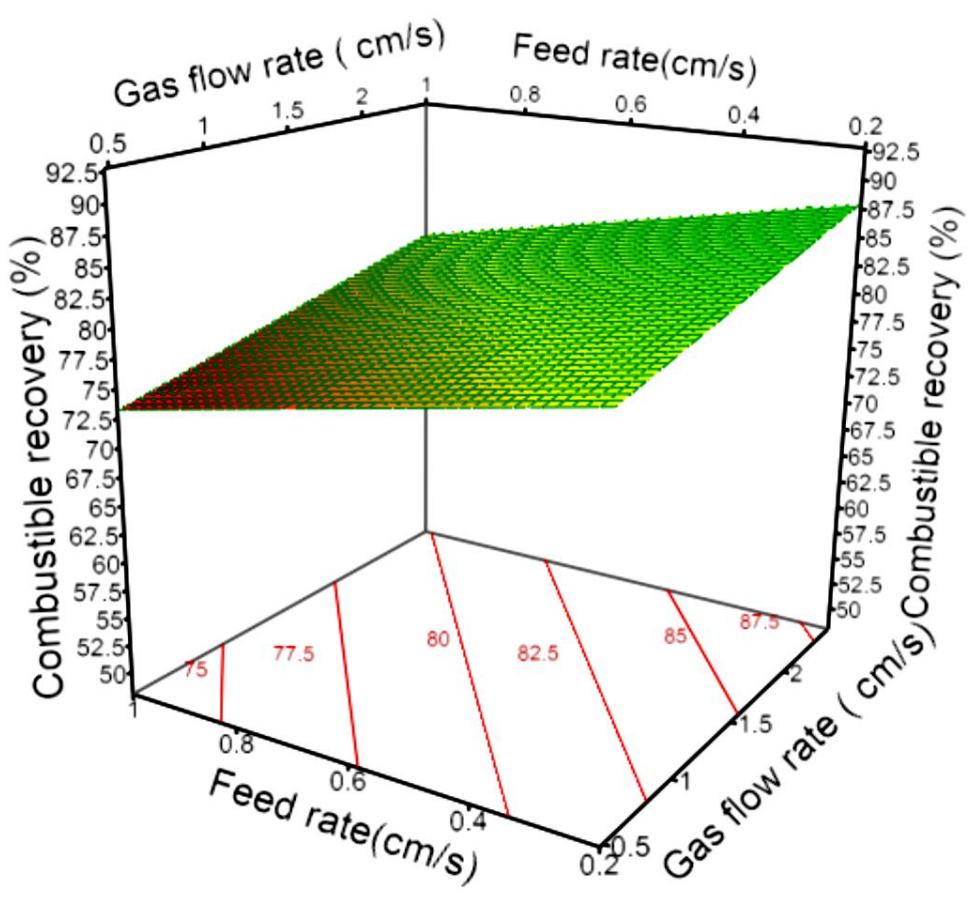

(a) Combustible material recovery.

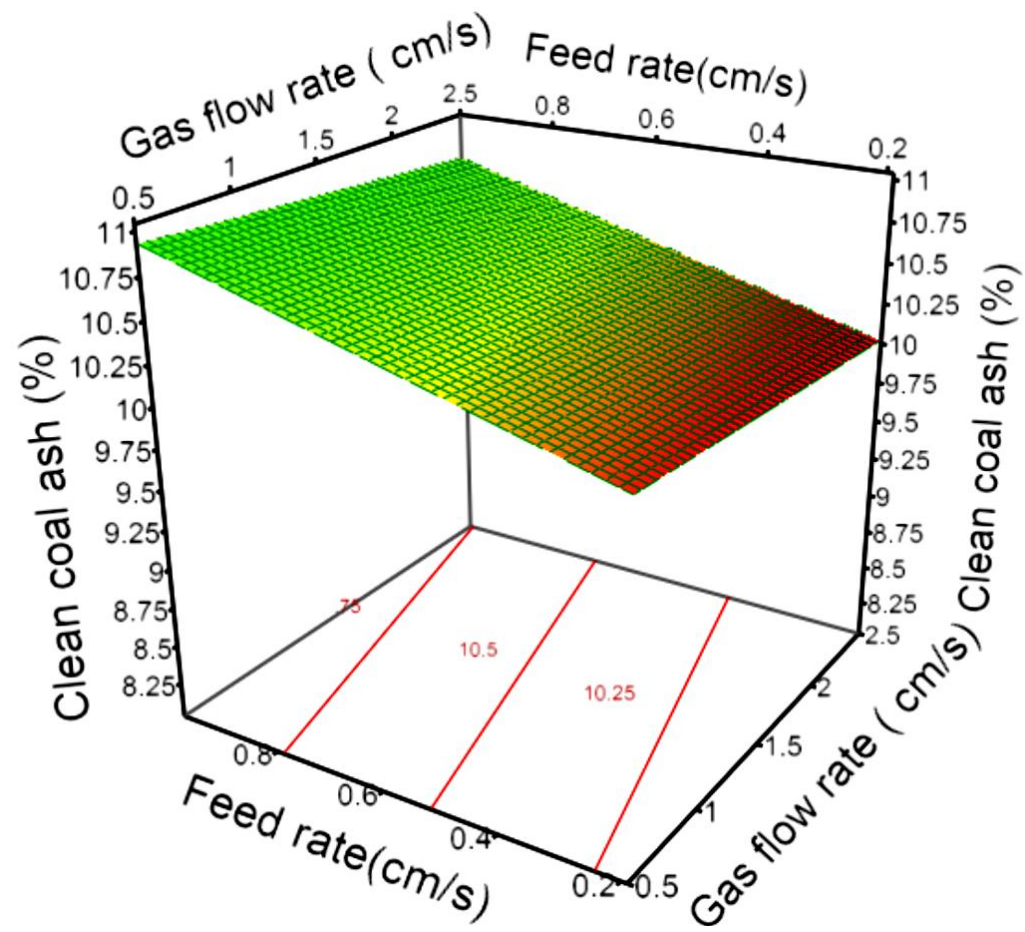

(b) Clean coal ash.

Figure 5- 13 Effect of gas flow rate and feed rate on

(a) CMR and (b) clean coal ash. 
The experimental program provided a narrow range of clean coal ash values as shown in Figure 5-14. The flotation column using pico-nano bubbles provided a reduction in ash content from $12.25 \%$ to a minimum of $7.5 \%$, while recovering $65.79 \%$ of the combustible material. The separation performances are around, some of which even significantly higher than, the theoretical best performance predicted for froth flotation (release analysis data), that is to say the presence of pico-nano bubbles enhanced flotation performance.

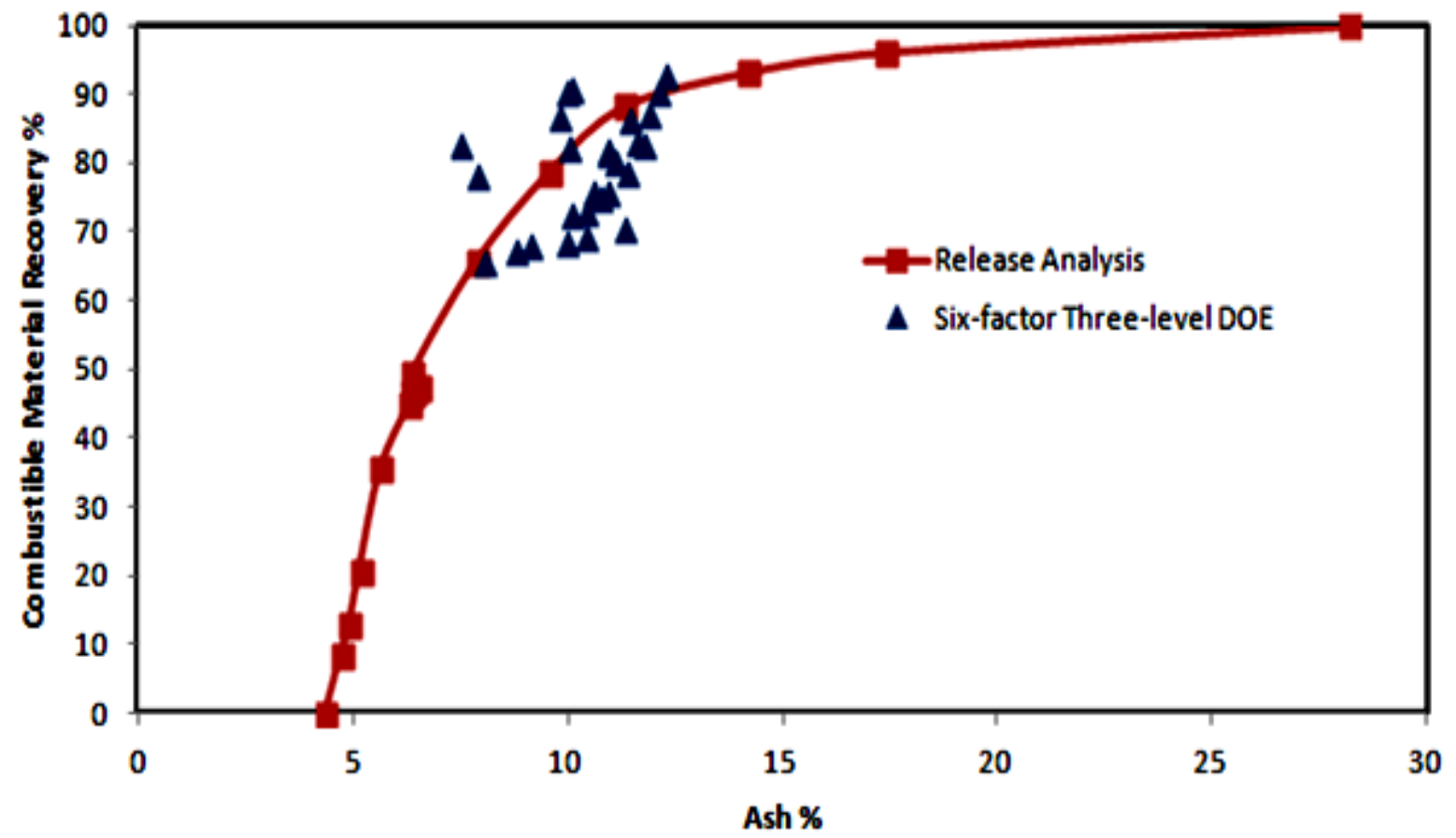

Figure 5- 14 Combustible material recovery versus clean coal ash for column flotation and release analysis flotation results. 


\subsubsection{Three-factor three-level central composite experimental design}

The statistic analysis data in Table 5-5 shows that statistically significant factors include collector dosage, feed solids concentration and feed rate. The data clearly shows the importance of feed rate in determining the combustible material recovery and clean coal ash content, as indicated by the Probability $>|t|$ values less than 0.05 when assessing the estimated coefficient.

Table 5-6 is the ANOVA for the combustible material recovery and clean coal ash models. All major statistics indicate that the models can adequately describe the operating parameters` effects on the response variables since the models do not have a significant lack of fit (the Probability $>$ F greater than 0.1). In order to improve model prediction as indicated by higher $\mathrm{R}^{2}$ and adjusted $\mathrm{R}^{2}$ values, two terms are removed (i.e. interaction between Solids concentration and feed rate (BC), and double interaction of solids concentration $\left(\mathrm{B}^{2}\right)$ ) based on lack of significance evaluation.

Table 5- 5 Estimated coefficients, t-ratios and p-values.

\begin{tabular}{|c|c|c|c|c|c|c|}
\hline \multirow{2}{*}{ Term } & \multicolumn{3}{|c|}{ Combustible material recovery } & \multicolumn{3}{c|}{ Clean Coal ash model } \\
\cline { 2 - 7 } & Estimate & $\mathrm{t}$ Ratio & Prob>|t| & Estimate & $\mathrm{t}$ Ratio & Prob>|t| \\
\hline Intercept & 83.04 & 3.83 & $0.0087^{*}$ & 24.08 & 4.70 & $0.0033^{*}$ \\
\hline $\mathrm{A}$ & -64.47 & -1.3 & 0.24 & 19.2 & 2.44 & 0.05 \\
\hline $\mathrm{B}$ & 126.49 & 1.70 & 0.14 & 12.07 & 2.03 & 0.9 \\
\hline $\mathrm{C}$ & -221 & -2.63 & $0.04^{*}$ & -2.82 & -8.25 & $0.0002^{*}$ \\
\hline $\mathrm{A} \times \mathrm{B}$ & -4.73 & -2.20 & 0.07 & 9.96 & 1.84 & 0.11 \\
\hline $\mathrm{A} \times \mathrm{C}$ & 57.08 & 1.77 & 0.13 & 22.40 & 0.92 & 0.39 \\
\hline $\mathrm{B} \times \mathrm{C}$ & 0.66 & 0.20 & 0.85 & - & - & - \\
\hline $\mathrm{A} \times \mathrm{A}$ & 73.02 & 1.95 & 0.10 & -10.20 & -1.66 & 0.15 \\
\hline $\mathrm{B} \times \mathrm{B}$ & -0.01 & -0.05 & 0.96 & - & - & - \\
\hline $\mathrm{C} \times \mathrm{C}$ & -18.48 & -1.38 & 0.22 & -19.92 & -1.26 & 0.25 \\
\hline
\end{tabular}

Note: * means significant factors. 
Table 5- 6 ANOVA table derived for the recovery and clean coal ash models derived from the results.

\begin{tabular}{|c|c|c|c|c|c|c|}
\hline $\begin{array}{c}\text { Combustible material } \\
\text { recovery model }\end{array}$ & & & & & & \\
\hline Source & SS & DF & $\begin{array}{c}\mathrm{F} \\
\text { value }\end{array}$ & $\begin{array}{l}\text { Prob. }> \\
\text { F }\end{array}$ & $\mathrm{R}^{2}$ & Adjusted $\mathrm{R}^{2}$ \\
\hline Model & $\begin{array}{c}1290.4 \\
1\end{array}$ & 9 & 4.78 & $0.04 *$ & 0.95 & 0.89 \\
\hline Lack of fit & 154.45 & 5 & 1.22 & 0.59 & & \\
\hline \multicolumn{7}{|l|}{ Clean coal ash model } \\
\hline Source & SS & DF & $\begin{array}{c}\mathrm{F} \\
\text { value }\end{array}$ & $\begin{array}{l}\text { Prob. > } \\
\text { F }\end{array}$ & $\mathrm{R}^{2}$ & Adjusted $\mathrm{R}^{2}$ \\
\hline Model & 117.25 & 7 & 8.17 & $0.0041^{*}$ & 0.93 & 0.88 \\
\hline Lack of fit & 15.44 & 7 & 2.28 & 0.47 & & \\
\hline
\end{tabular}

Note: $\mathrm{DF}=$ Degree of freedom, $\mathrm{SS}=\mathrm{Sum}$ of squares.

Based on the statistical analysis results, the reduced model in terms of the factor levels is:

Combustible Material Recovery $(\%)=83.04 \pm 64.47 \times \mathrm{A}+(-221) \times \mathrm{B}+126.49 \times \mathrm{C}+\mathrm{A} \times$ $\mathrm{B} \times(-4.73)+\mathrm{A} \times \mathrm{C} \times 57.08+\mathrm{B} \times \mathrm{C} \times 0.66+\mathrm{A} \times \mathrm{A} \times 73.02+\mathrm{B} \times \mathrm{B} \times(-0.01)+\mathrm{C} \times \mathrm{C}$ $\times(-18.48)$

Clean Coal Ash $(\%)=24.08+19.20 \times A+(-2.82) \times B+12.07 \times C+A \times B \times 9.96+A$ $\times \mathrm{C} \times 22.4+\mathrm{A} \times \mathrm{A} \times(-10.2)+\mathrm{C} \times \mathrm{C} \times(-19.92)$

Figure 5-15 indicates the effects of the feed solids concentration and the collector dosage on the combustible material recovery and clean coal ash content when the gas flow rate, frother concentration, Superficial wash water rate, and feed rate were $1.6 \mathrm{~cm} / \mathrm{s}, 20 \mathrm{ppm}, 0.2$ $\mathrm{cm} / \mathrm{s}$, and $0.2 \mathrm{~cm} / \mathrm{s}$, respectively. It can be clearly seen from the response surface and the contours of the combustible material recovery shown in Figure 5-15a that the combustible material recovery considerably decreases with increasing the feed solids concentration and slightly increases with increasing the collector dosage. At the collector 
dosage of $0.3 \mathrm{lb} / \mathrm{ton}$, the combustible material recovery increased from $75 \%$ up to $85 \%$ as the feed solids concentration decreased from 10 to $4 \%$. It can be clearly observed from the contours of the combustible material recovery shown in Figure 5-15a that when the solids concentration decreases from 10 to $4 \%$, the combustible material recovery increases from $75 \%$ to $85 \%, 65 \%$ to $87 \%$, and $74 \%$ to $93 \%$ at the collector dosages of 0.3 , 0.6 and $0.9 \mathrm{lb} / \mathrm{t}$, respectively. This means that nanobubbles have more significant effect on the combustible material recovery at the medium collector dosage than at the higher collector dosage. It can be observed from the response surface and the contours of the clean coal ash content shown in Figure 5-15b that the clean coal ash content increases with increasing the solids concentration and the collector dosage. Probably the overdosing of the collector caused a decrease in clean coal ash content at the high collector dosage and the high solids concentration. Figure 5-15b depicts that when the solids concentration increases from 4 to $10 \%$, the clean coal ash content changes from $9.0 \%$ to $10.5 \%, 11 \%$ to $10.3 \%$ and $15.0 \%$ to $9.8 \%$ at the collector dosages of $0.3,0.6$ and $0.9 \mathrm{lb} / \mathrm{t}$, respectively, the optimal operation condition would be obtained at medium collector dosage and low level of solids concentration with 85 to $90 \%$ combustible material recovery and 10 to $11 \%$ clean coal ash. 

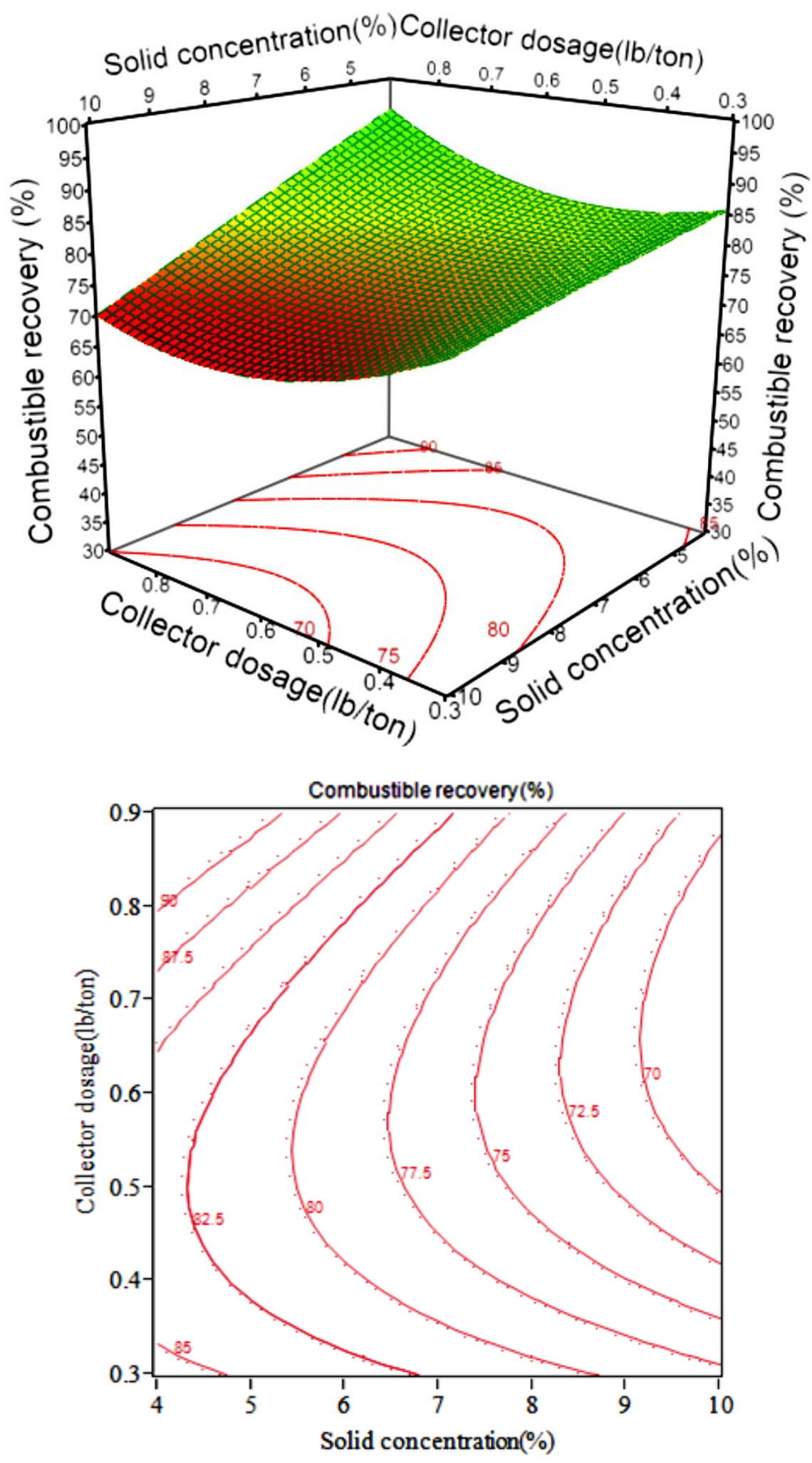

(a) Combustible material recovery. 

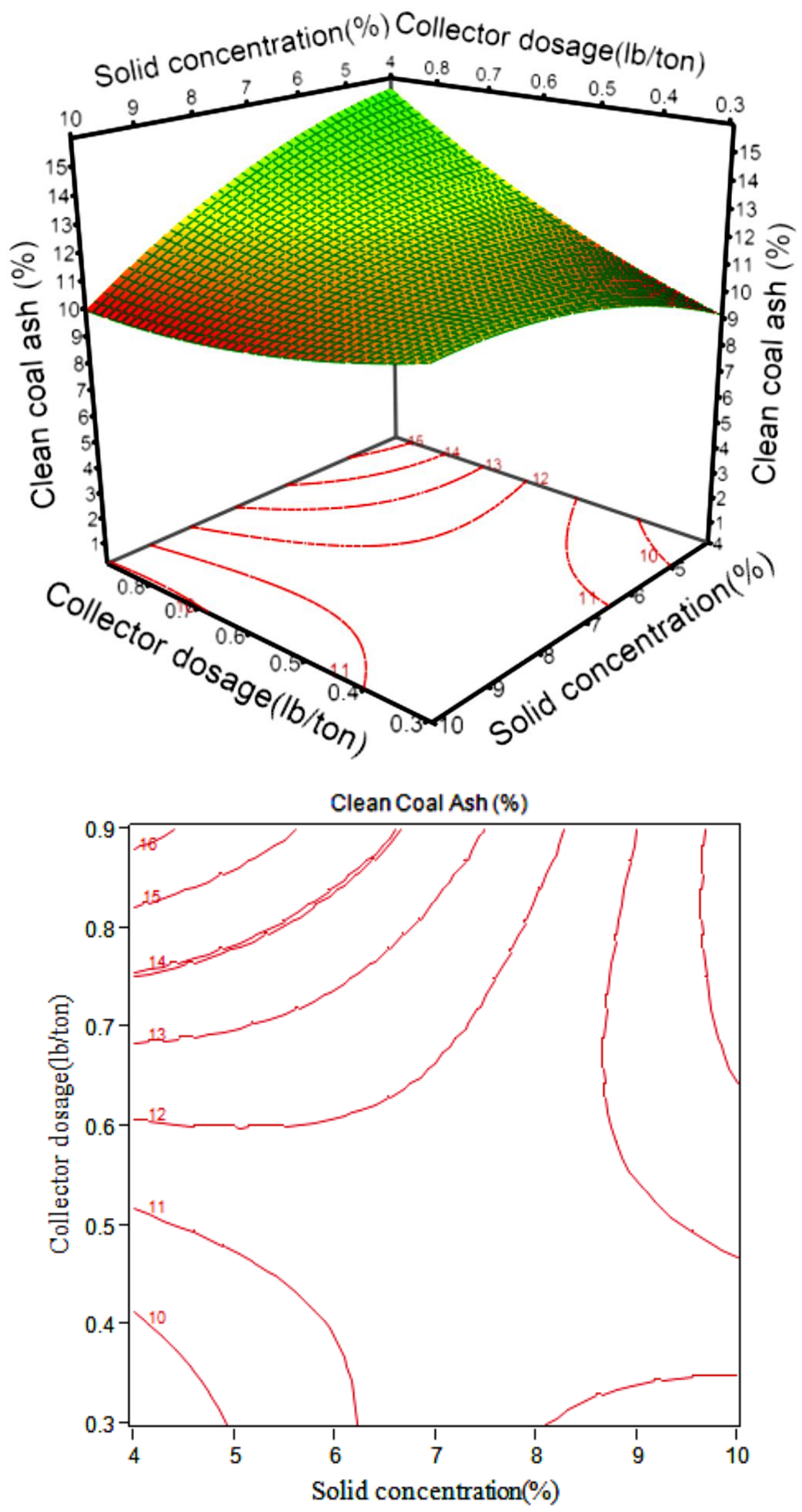

(b) Clean coal ash.

Figure 5-15 Effect of solids concentration and collector dosages on (a) CMR and (b) clean coal ash. 
Figure 5-16 shows the effects of the feed rate and the collector dosage on the combustible material recovery and clean coal ash content when the gas flow rate, frother concentration, Superficial wash water rate, and feed solids concentration are $1.6 \mathrm{~cm} / \mathrm{s}, 20 \mathrm{ppm}, 0.2 \mathrm{~cm} / \mathrm{s}$, and 7\%, respectively. It can be seen from the response surface and the contours of the clean coal ash content shown in Figure 5-16b that clean coal ash content increases with increasing the feed rate when the collector dosage ranges from $0.3 \mathrm{lb} /$ ton to $0.6 \mathrm{lb} / \mathrm{ton}$, and the decrease in clean coal ash content at high collector dosage is caused by the overdosing of the collector dosage. As can be obviously observed in Figure 5-16a, the flotation feed rate has remarkable impacts on the combustible material recovery. At a given collector dosage, the combustible material recovery significantly decreases with increasing the feed rate. While, at a given feed solids concentration, the combustible material recovery slightly increases as the collector dosage increases from $0.3 \mathrm{lb} /$ ton to $0.9 \mathrm{lb} / \mathrm{ton}$. The highest combustible material recovery was obtained at collector dosage of $0.7 \mathrm{lb} / \mathrm{ton}$ and the feed rate of about $0.4 \mathrm{~cm} / \mathrm{s}$, with clean coal ash about $10.5 \%$.

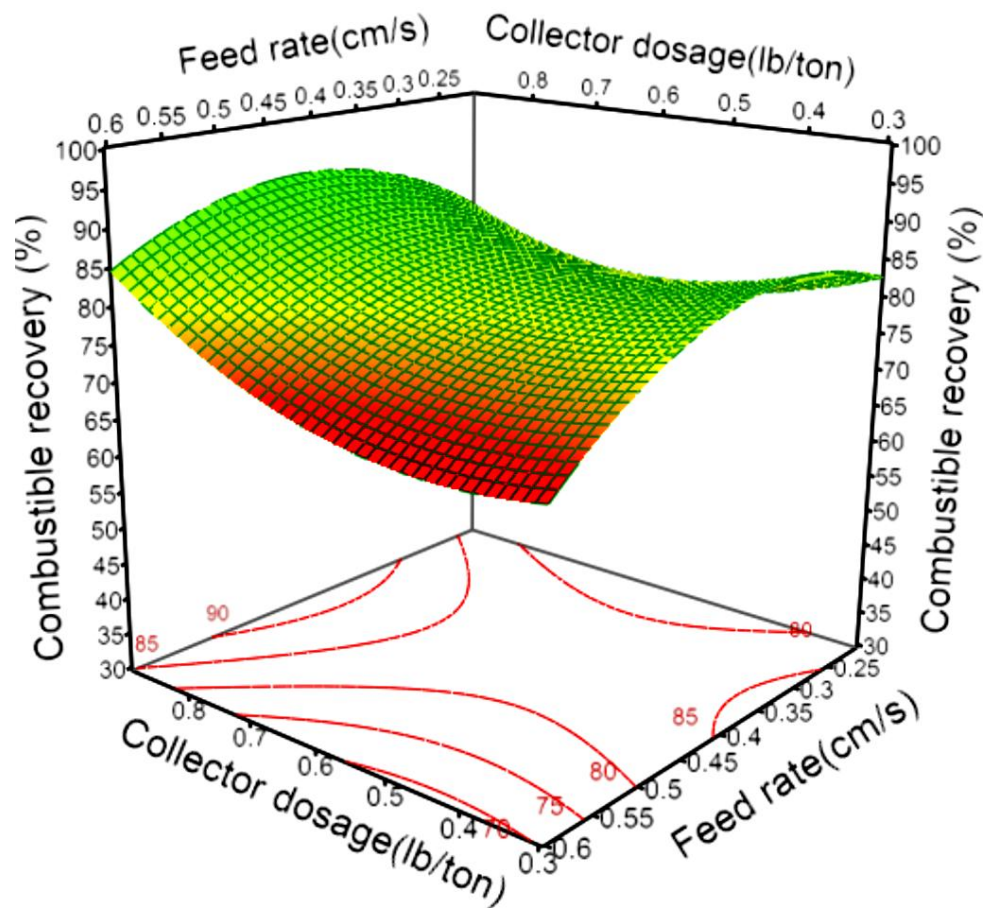




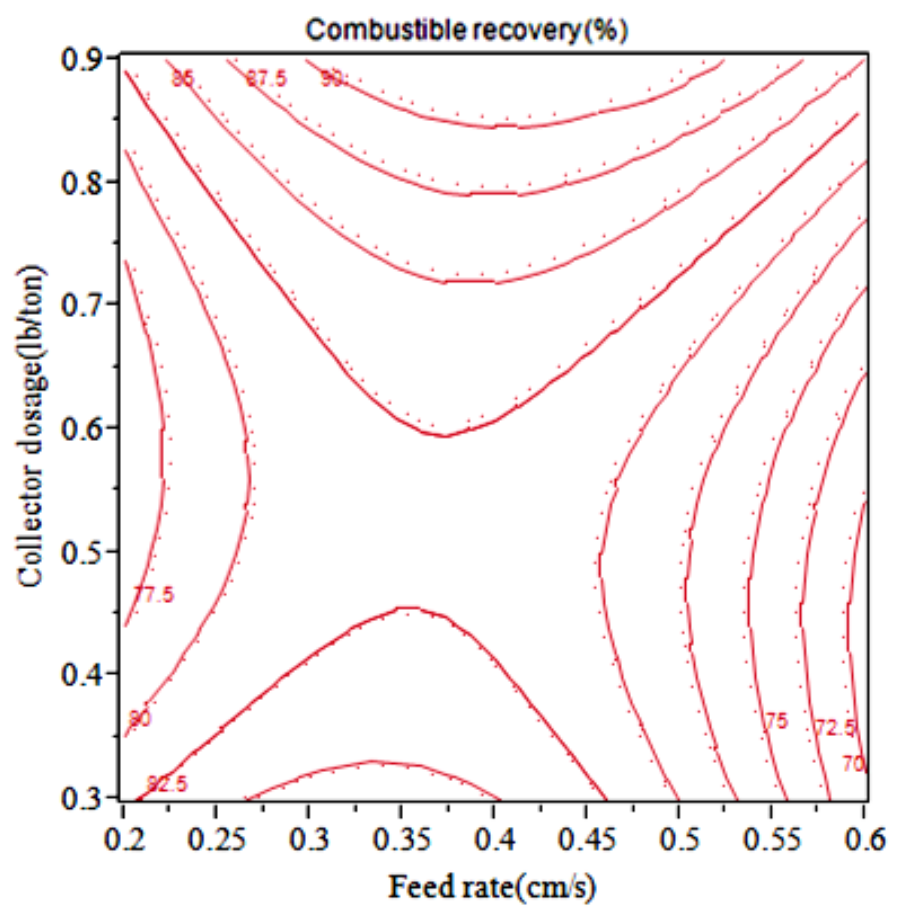

(a) Combustible material recovery.

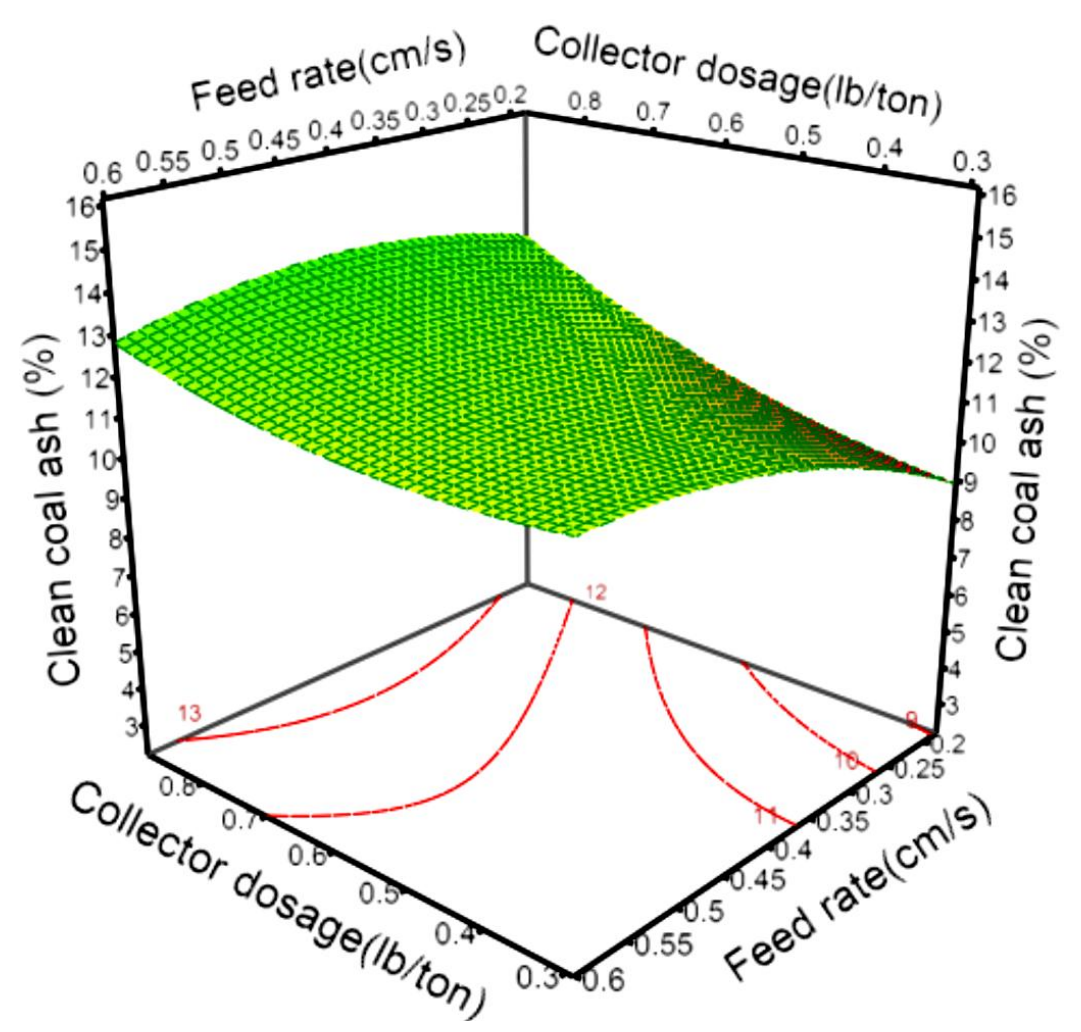




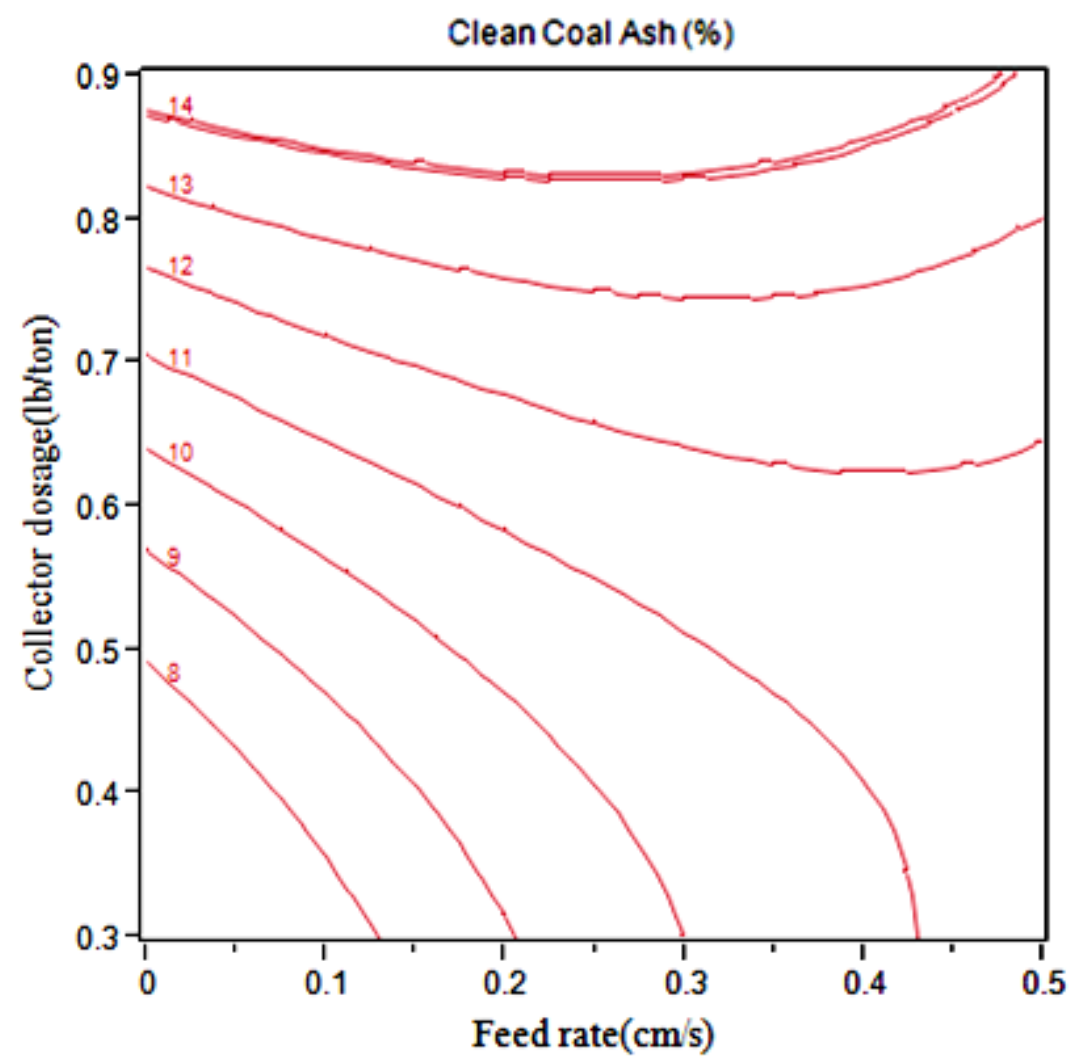

(b) Clean coal ash.

Figure 5- 16 Effect of feed rate and collector dosages on (a) CMR and (b) clean coal ash.

Figure 5-17 depicts the effects of the feed solids concentration and feed rate on the combustible material recovery and clean coal ash content when the gas flow rate, frother concentration, Superficial wash water rate, and collector dosage were $1.6 \mathrm{~cm} / \mathrm{s}, 20 \mathrm{ppm}$, $0.2 \mathrm{~cm} / \mathrm{s}$, and $0.3 \mathrm{lb} /$ ton, respectively. It can be obviously seen from Figure $5-17 \mathrm{a}$ that the combustible material recovery increases considerably with decreasing the feed rate from 0.6 to $0.4 \mathrm{~cm} / \mathrm{s}$ and slightly increases with decreasing the solids concentration. As can be seen in Figure 5-17b, the clean coal ash content increases with increasing the flotation feed rate from 0.2 to $0.6 \mathrm{~cm} / \mathrm{s}$ and decreasing the solids concentration from 10 to $4 \%$. After that, there is a slight decrease in the clean coal ash content. 

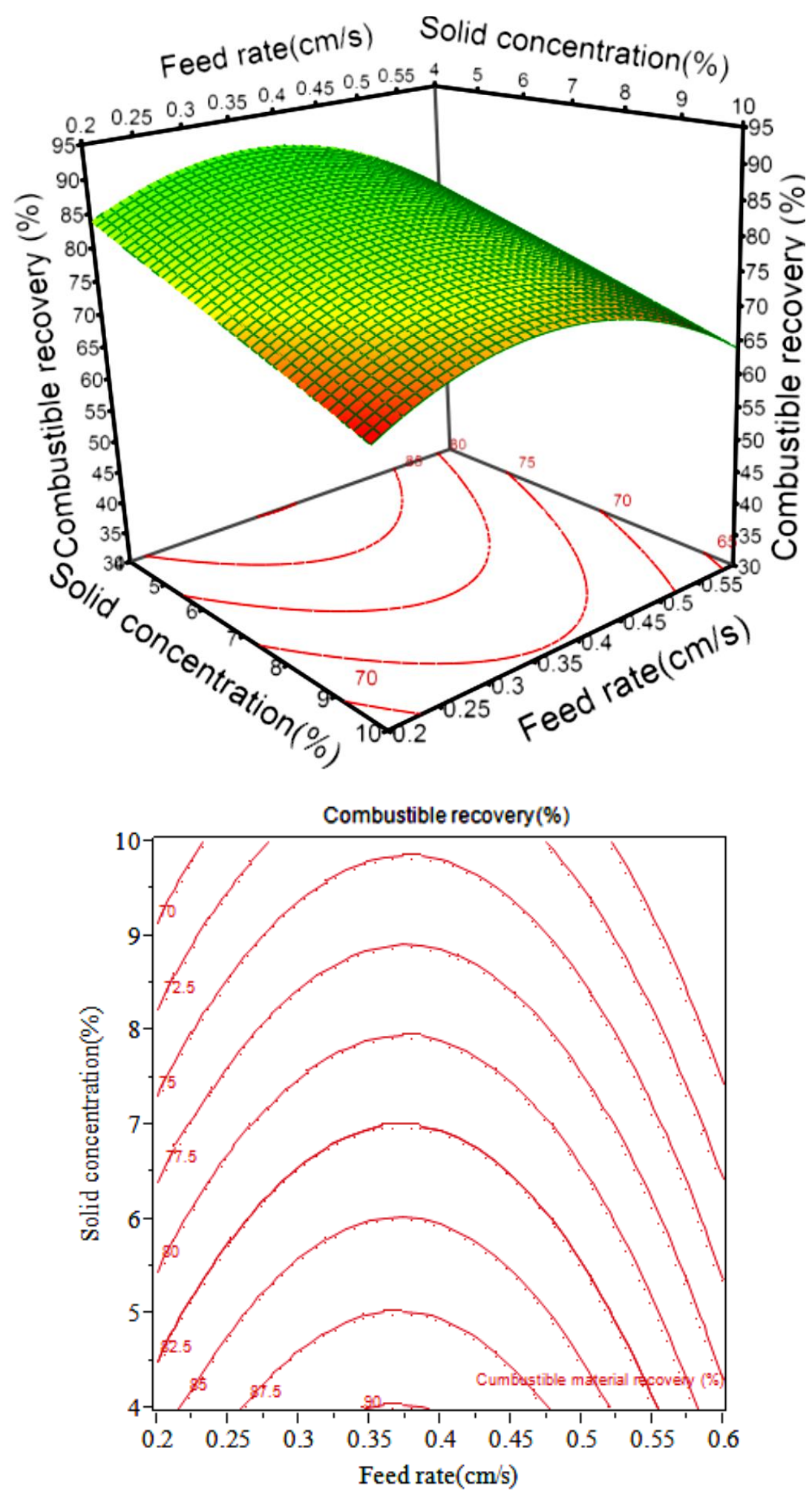

(a) Combustible material recovery. 

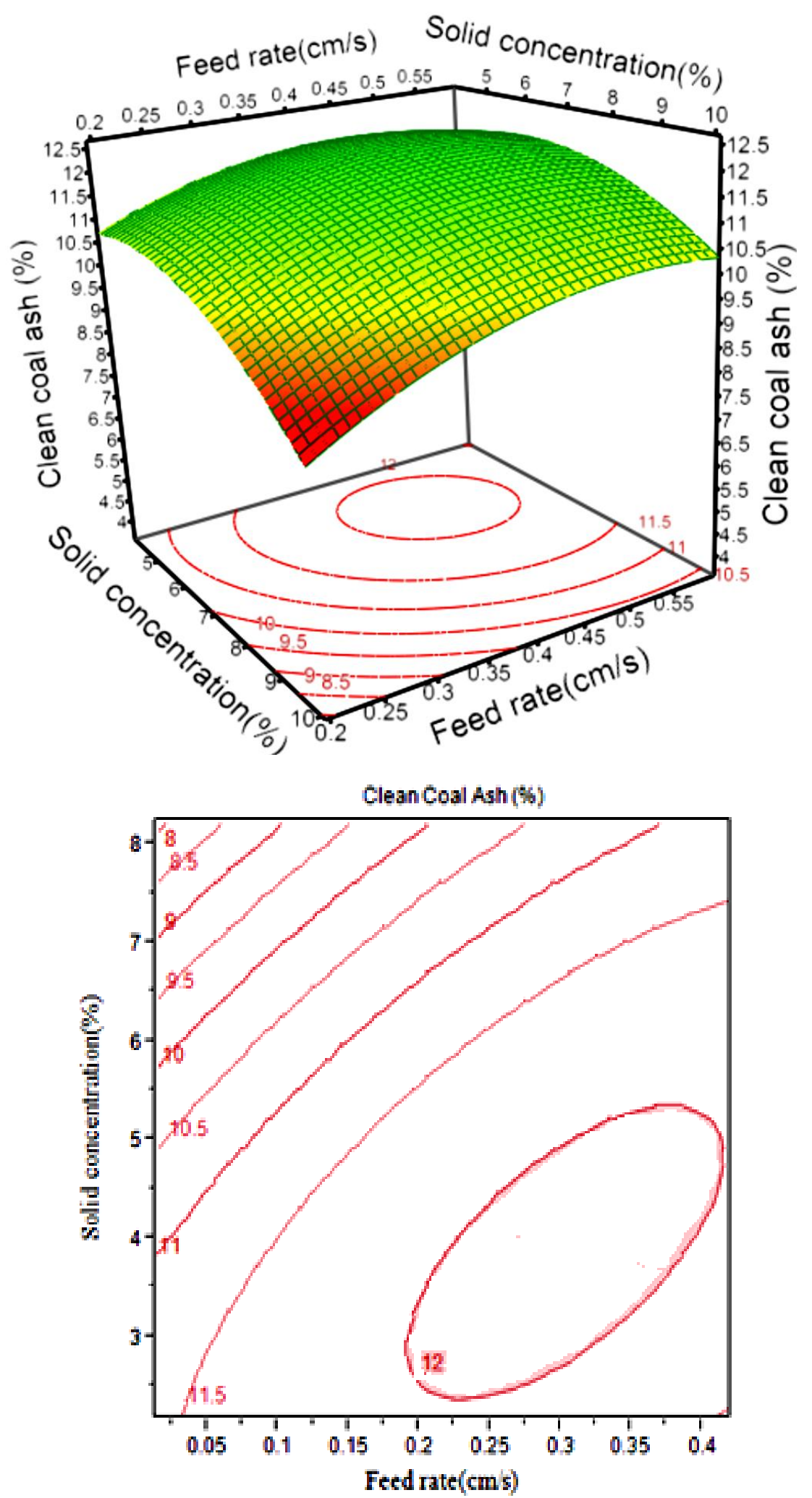

(b) Clean coal ash

Figure 5- 17 Effect of solids concentration and feed rate on (a) CMR and (b) clean coal ash. 
The experimental program provided a broad range of clean coal ash values as shown in Figure 5-18. The flotation column using pico-nano bubbles provided a reduction in ash content from $17.05 \%$ to a minimum of $7.25 \%$, while recovering $66.13 \%$ of the combustible material. The separation performances are around, some of which even significantly higher than, the theoretical best performance predicted for froth flotation (release analysis data), which means the presence of pico-nano bubbles enhanced flotation performance.

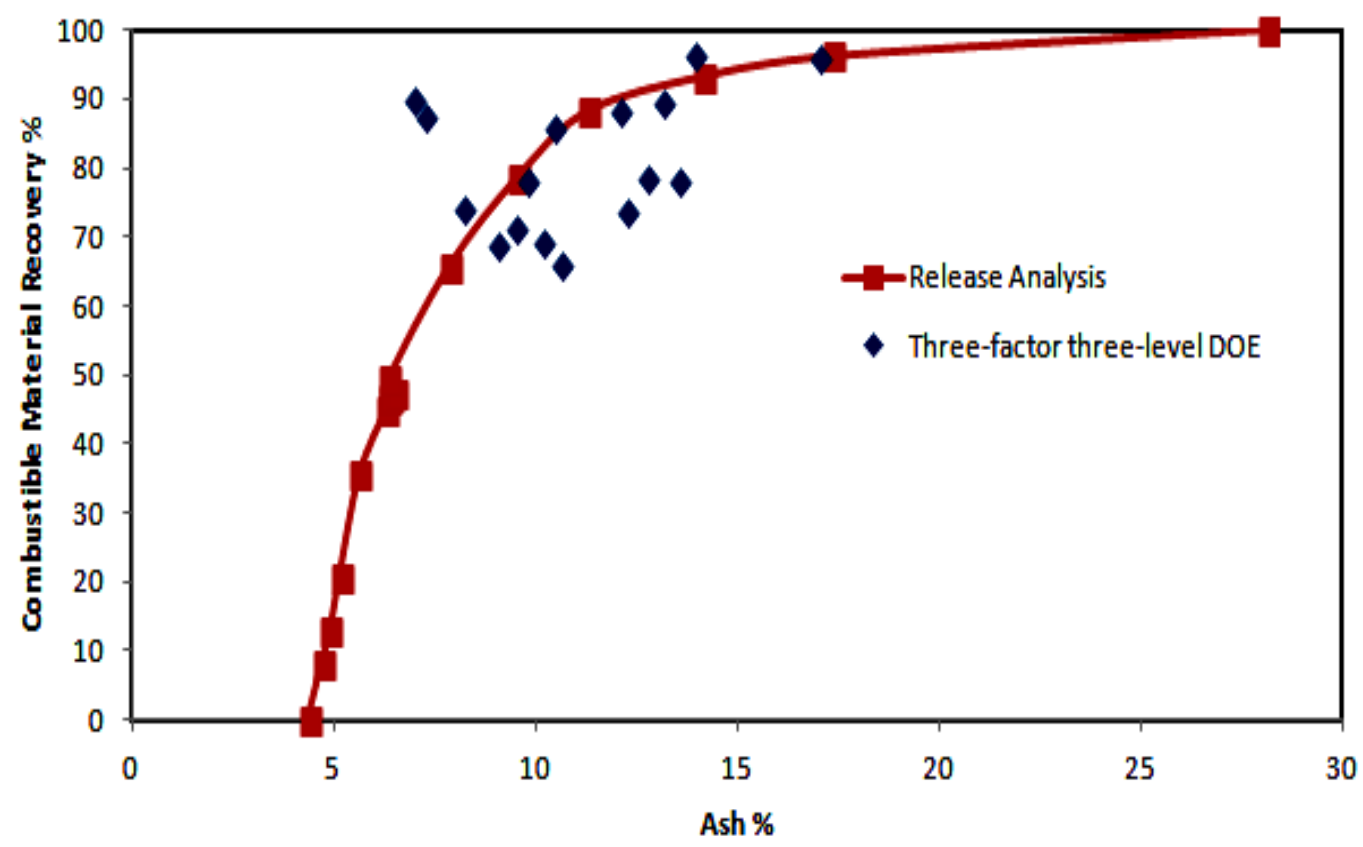

Figure 5-18 Combustible material recovery versus clean coal ash content for column flotation and release analysis flotation results. 


\subsubsection{Single factor experimental test}

The effect of collector dosage on the combustible material recovery and clean coal ash content is given in Figure 5-19. Over the tested range of collector dosage range of 0.1 to $0.9 \mathrm{lb} /$ ton feed coal, the combustible material recovery is 76 to $85 \%$, and clean coal product ash content is 7 to $14 \%$. The combustible recovery and clean coal ash content increase with increasing the collector dosage. In order to maximize the combustible recovery and minimise clean coal ash, the optimal collector dosage has been found at 0.7 lb/ton, with combustible recovery of $83.5 \%$ and clean coal ash of $9.31 \%$.

The effect of feed solid concentration in feed on the clean coal product ash content is given in Figure 5-20. It can be seen that, the clean coal product quality deteriorated as the percent of feed solid concentration increased. Figure 5-20 also shows the results of combustible material recovery as a function of solid concentration. The results indicate that the combustible recovery decreases with increasing the solid concentration. It can be due to the fact that the availability of the bubble surfaces become less as the increasing of fine coal particles surfaces when the concentration of the feed fine coal particles increase. It is noted that the clean coal product ash contents ranges from $8.15 \%$ to $11.44 \%$, and the combustible recovery ranges from $90.31 \%$ to $71.31 \%$, while the feed solid concentration ranges from $2 \%$ to $10 \%$. The optimal solid concentration is found at $3.5 \%$, with the optimal combustible recovery and clean coal ash at $89.92 \%$ and $8.15 \%$, respectively. 


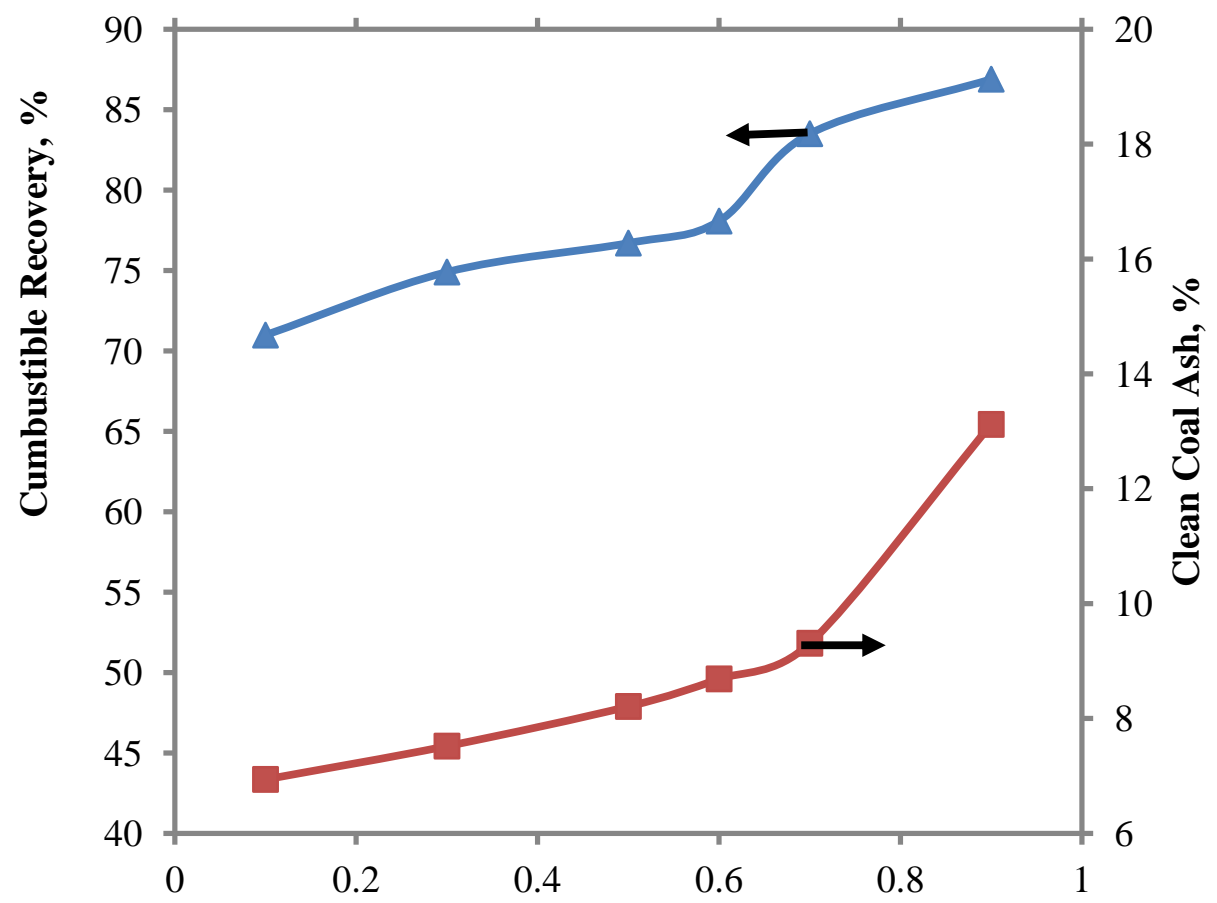

Collector Dosage, lb/ton

Figure 5- 19 Combustible material recovery and clean coal ash content as a function of collector dosage.

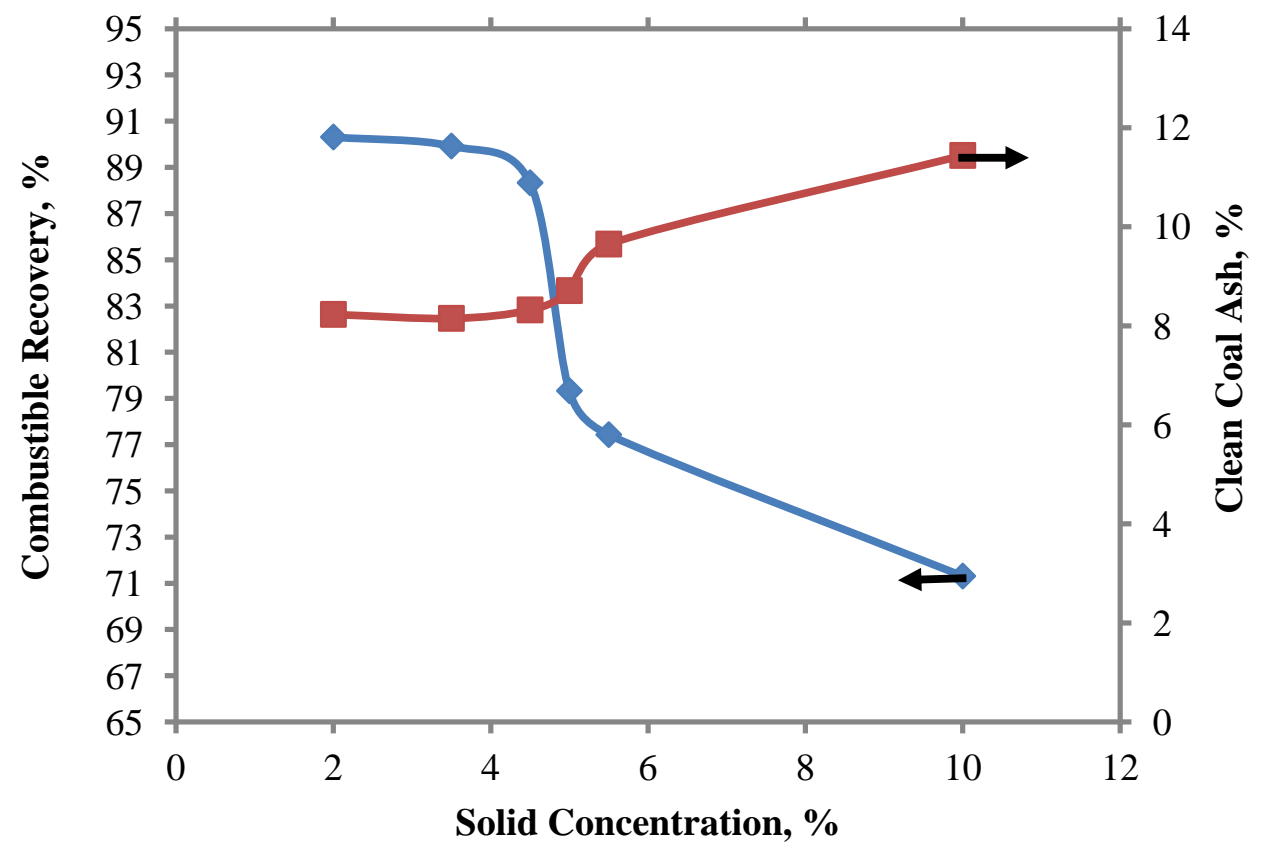

Figure 5- 20 Combustible material recovery and clean coal ash content as a function of solid concentration. 


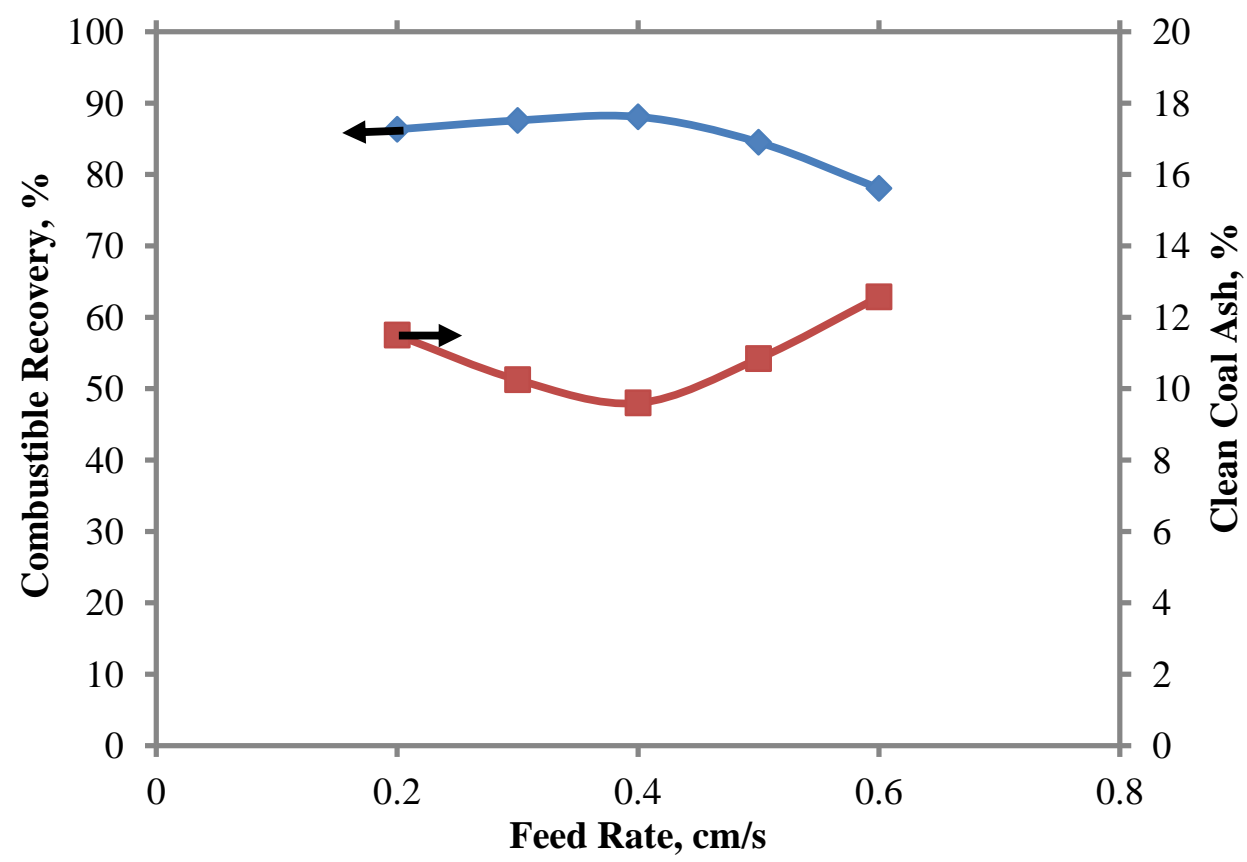

Figure 5- 21 Combustible material recovery and clean coal ash content as a function of feed rate.

Figure 5-21 shows the combustible material recovery and clean coal product ash content as a function of feed rate. Over the tested feed rate range of 0.2 to $0.5 \mathrm{~cm} / \mathrm{s}$, the combustible material recovery is $78.05 \%$ to $88.07 \%$, and clean coal product ash is $9.6 \%$ to $12.57 \%$. It can be seen from Figure 5-21 that the combustible material recovery decreases as increasing the feed rate. The clean coal ash decreases from $11.5 \%$ to $9.6 \%$ when feed rate increases from $0.2 \mathrm{~cm} / \mathrm{s}$ to $0.4 \mathrm{~cm} / \mathrm{s}$, and it increases to $12.57 \%$ as the feed rate continue increasing to $0.6 \mathrm{~cm} / \mathrm{s}$. The optimal clean coal ash content of $9.6 \%$, and highest combustible recovery of $88.07 \%$ can be achieved at the feed rate of $0.4 \mathrm{~cm} / \mathrm{s}$. 


\subsection{Effects of particle density and size distributions in coal flotation pico-nano bubbles environment}

\subsubsection{Particle size and density frequencies}

Washability data were obtained for feed coal, clean coal, and tailings of pico-nanobulle column flotation of bituminous coal. Heavy liquid, Lithium Meta-Tungstate (LMT, LMT

Liquid, LLC, ID) having $2.95 \mathrm{~g} / \mathrm{cm}^{3}$ density was diluted by de-ionized/distilled water to prepare a series of heavy mediums with various densities. The densities of the heavy medium are: $1.30,1.40,1.50,1.60,1.70,1.80,2.00,2.10$, and $2.20 \mathrm{~g} / \mathrm{cm}^{3}$. Float-sink test were conducted in a $2000 \mathrm{ml}$ squib shape separatory funnel with stopcocks. Coal slurry sample was prepared in a beaker by mixing the coal sample in a heavy medium with lowest density specified. The prepared coal slurry sample is poured into separatory funnel and let it stands for a designated time for particle separation by density. After separation, the sink particles are drained out through stopcock for filtration. The float particles remained in the sparator are poured out for filtration, drying, weighing and ash content determination. The sink particles are then used to prepared coal slurry sample by mixing with next heavier density heavy medium $\left(1.40 \mathrm{~g} / \mathrm{cm}^{3}\right)$. This process are repeated from the lowest density to the highest density of heavy medium following the sequence stated above. To obtain the accurate measurement results of the tests for fine and ultrafine particles, the solids concentrations of the slurry must be maintained at $10 \%$ by volume or lower. Pre-wetting the fine and ultrafine coal particles by heavy medium prior to the float-sink test must also be completed by gentle stirring the coal slurry sample using a glass bar for 5-10 minutes, to obtain the true float-sink separation results. 
The coal particle size and ash distributions of fine raw coal sample of Pittsburgh No. 8 seam are given in Table 3-1 and Figure 3-2. It can be seen from Figure 5-22 that, the ash contents of coal sample decrease as the particle size increases. The significant increase in ash content at finer particle size fractions can be resulted from the high clay mineral components and can be the indicative of well liberation of the sample. The fine coal sample is distributed over a wide size range as showed by $10.22 \%$ particles being larger than $250 \mu \mathrm{m}$ and $28.16 \%$ particles being finer than $45 \mu \mathrm{m}$. The feed coal ash content is 30.64\%. From Figure 5-22, the fine raw coal ash increases with increasing density, the coal is composed of macerals and ash-forming minerals, and density of ash-forming minerals are usually higher than those of the combustible matter. Also, the liberation of the intermediate-density particles, ranging from 1.5 to $1.9 \mathrm{~g} / \mathrm{cm}^{3}$, is not completely liberated (middlings), making it very difficult to separate.

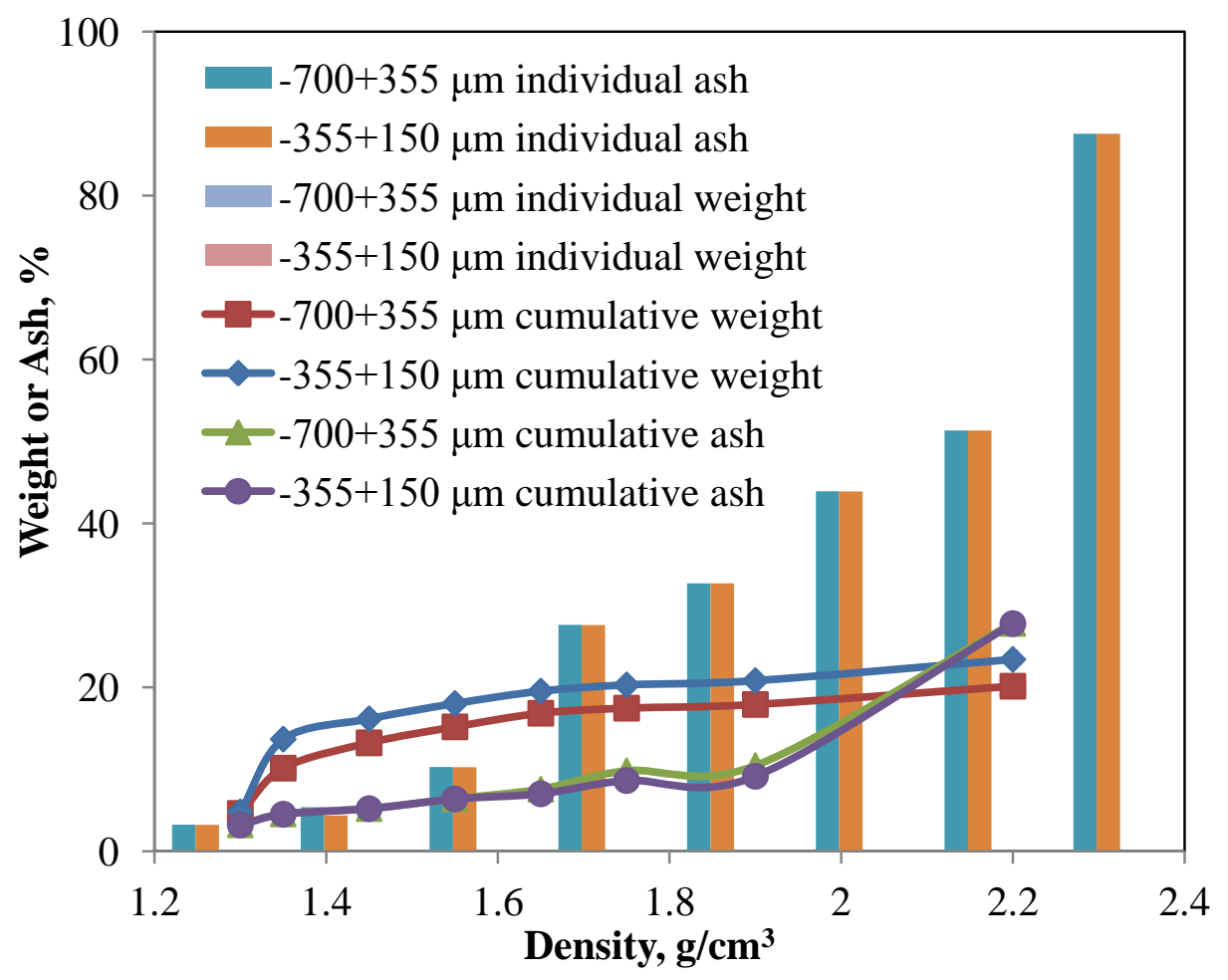

(a) $-700+355$ and $-355+150 \mu \mathrm{m}$ 


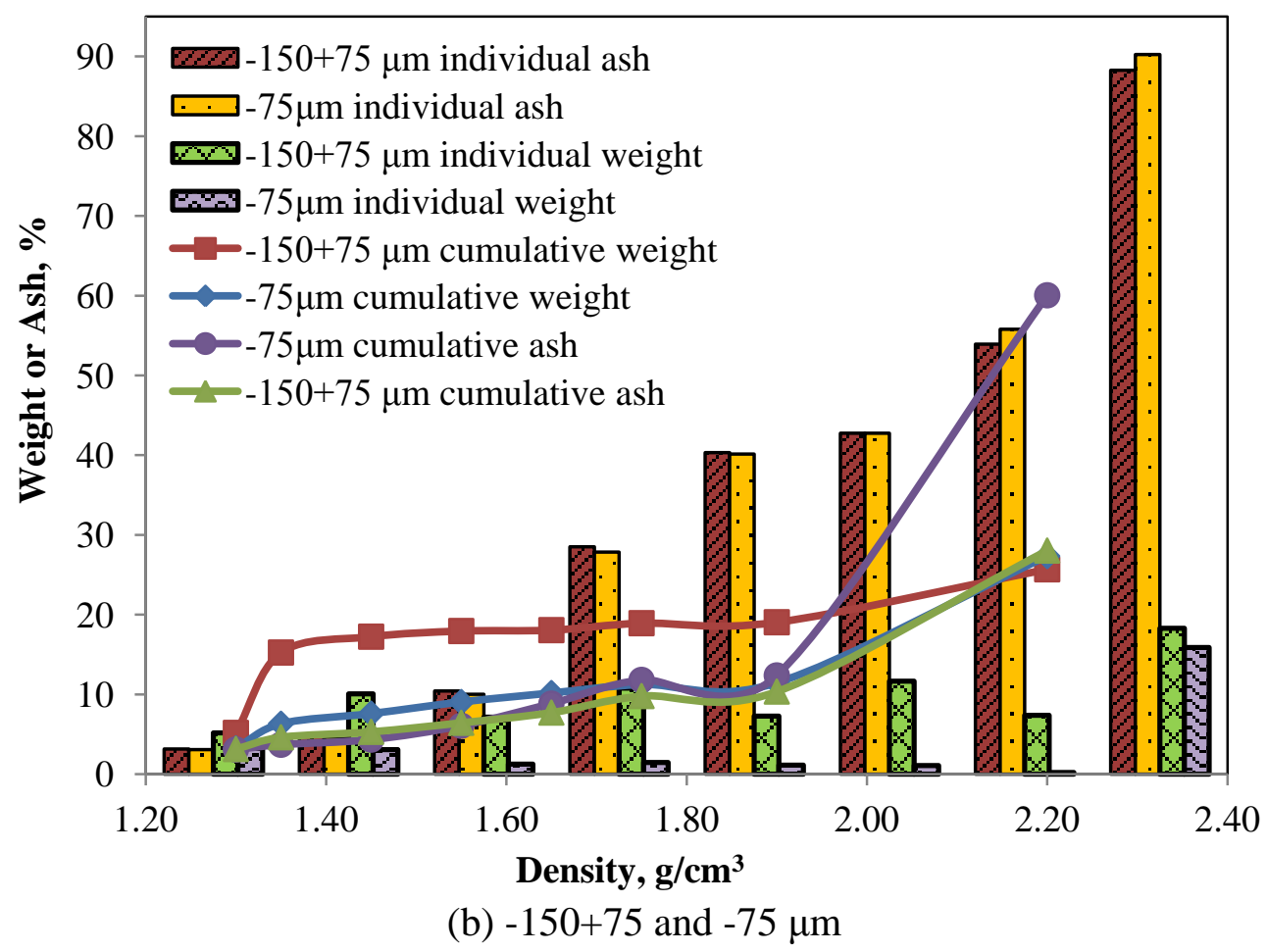

Figure 5- 22 Density and ash distributions of fine raw coal sample.

\section{3.2 Pico-nano bubble Column Flotation Test}

\subsubsection{Effect of pico-nano bubbles on flotation of coarse and ultrafine fractions of coal particles}

Figure 5-23 shows the effect of pico-nano bubbles and coal particle density on the coal flotation performance of $-700+355$ and $-75 \mu \mathrm{m}$ coal particle size ranges, respectively. The figure shows the combustible material recovery decreases significantly with increasing particle density. Since as inorganic mineral components increase, resistance to the bubble attachment increase. It has been demonstrated, organic carbonaceous components are the most amenable to bubble attachment, deceasing as the coal particle density increases. The total bubble volume or the bubble quantity required for floating a lower density coal 
particles of a given particle size is smaller than that required for floating a higher density coal particle. In other words, the increase in coal particle density (mass) of a given particle size results in a decrease of the amount of coal surface area available for bubble attachment which reduces coal particle/bubble attachment probability and increases the coal particle detachment probability. Figure 5-23 also shows that the use of pico-nano bubbles increases the combustible material recoveries with the various densities of $700+355$ and $-75 \mu \mathrm{m}$ particles. Figure 5-23(a) reveals that the presence of pico-nano bubbles increases the $-700+355 \mu \mathrm{m}$ coal particles combustible recoveries of the various density fractions: minus $1.3,1.3-1.4,1.4-1.5,1.5-1.6$, and $1.6-1.8 \mathrm{~g} / \mathrm{cm}^{3}$ by $20.1 \%, 21.9 \%$, $25.4 \%, 19.8 \%$, and $15.9 \%$, respectively. Thus, pico-nano bubbles have more effect on the medium density fractions than on the low and high density fractions. Figure 5-23(b) depicts that the presence of pico-nano bubbles increases $-75 \mu \mathrm{m}$ coal combustible material recovery of the various densities ranges: minus $1.3,1.3-1.4,1.4-1.5,1.5-1.6,1.6-$ 1.8 , and $1.8-2.0 \mathrm{~g} / \mathrm{cm}^{3}$ by $18.2 \%, 26.3 \%, 28.3 \%, 30.15 \%, 30.6 \%$ and $10.1 \%$, respectively. It can be seen from Figure 5-23 the pico-nano bubble has more effect on -75 $\mu \mathrm{m}$ ultrafine particles than the $-700+355 \mu \mathrm{m}$ coarse particles. More higher density fraction of $-75 \mu \mathrm{m}$ ultrafine particles were floated than that of $-700+355 \mu \mathrm{m}$ coarse particles.

Figure 5-24 compares the clean coal yield with and without pico-nano bubbles for the particle size ranges of $-700+355 \mu \mathrm{m}$ and $-75 \mu \mathrm{m}$ respectively. At a given clean coal product ash content, Figure 5-24 (a) shows that the presence of pico-nano bubbles increases the $-700+355 \mu \mathrm{m}$ coal particles clean coal yield by $14 \%$. Figure 5-24 (b) shows that the presence of pico-nano bubble increases the $-75 \mu \mathrm{m}$ coal particles clean coal yield by $11 \%$. Existing of pico-nano bubbles have significant effect on the clean coal yield of 
$-700+355 \mu \mathrm{m}$ coarse coal range and $-75 \mu \mathrm{m}$ fine coal range in the medium clean coal ash content than in the lower or higher product ash range.

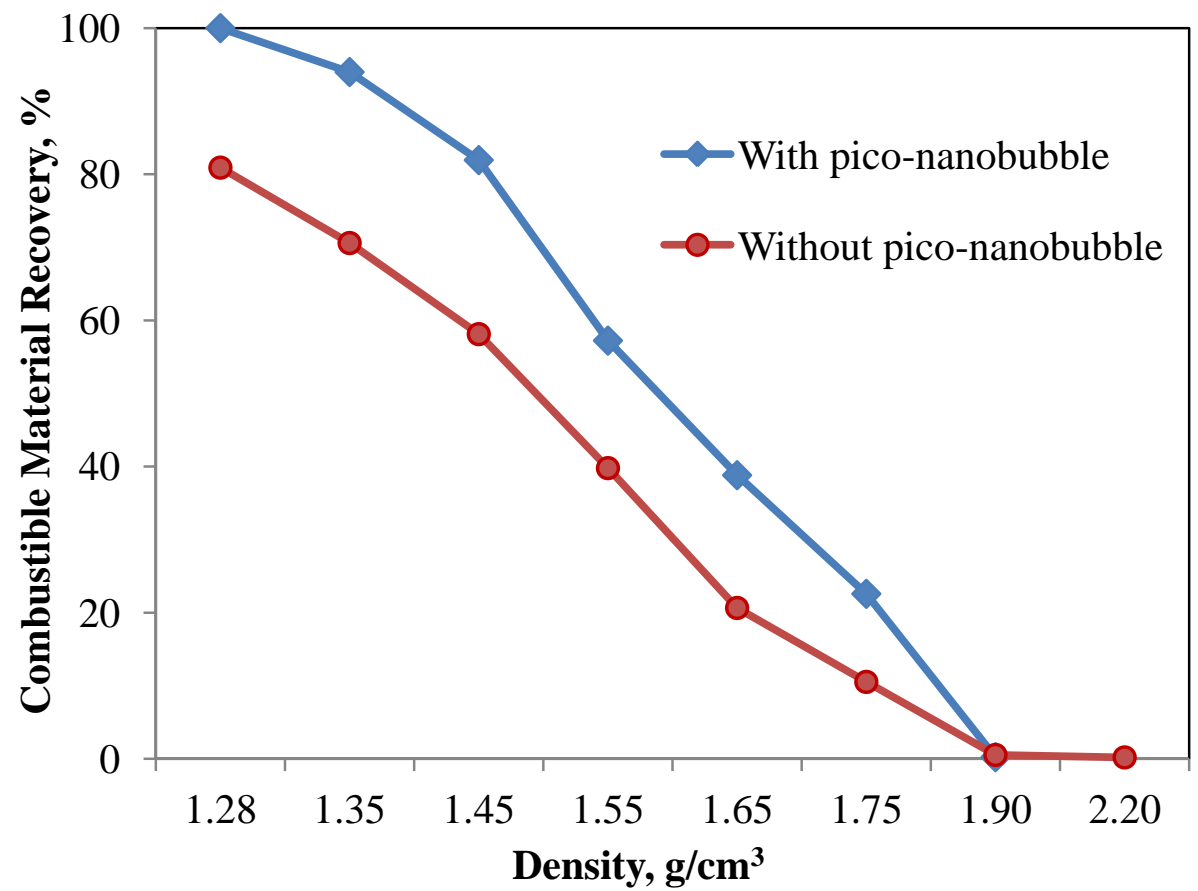

(a) $-700+355 \mu \mathrm{m}$

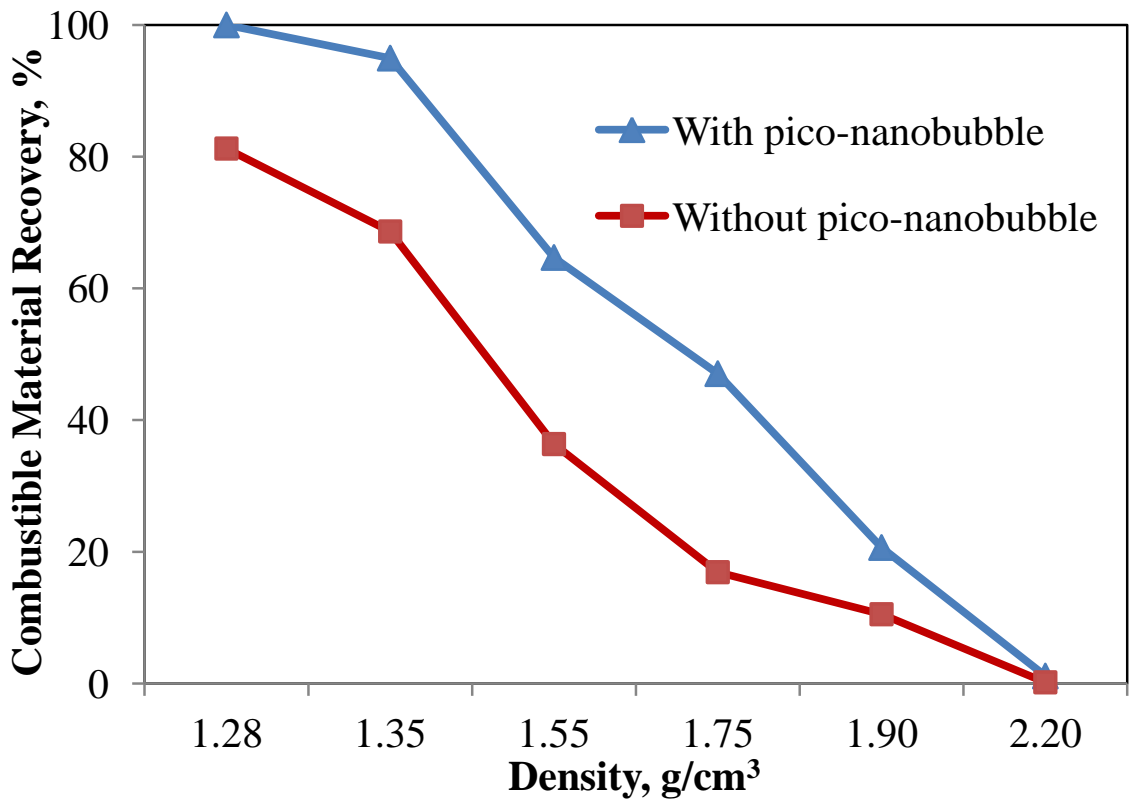

(b) $-75 \mu \mathrm{m}$

Figure 5- 23 Effect of pico-nano bubbles on coal flotation recovery. 


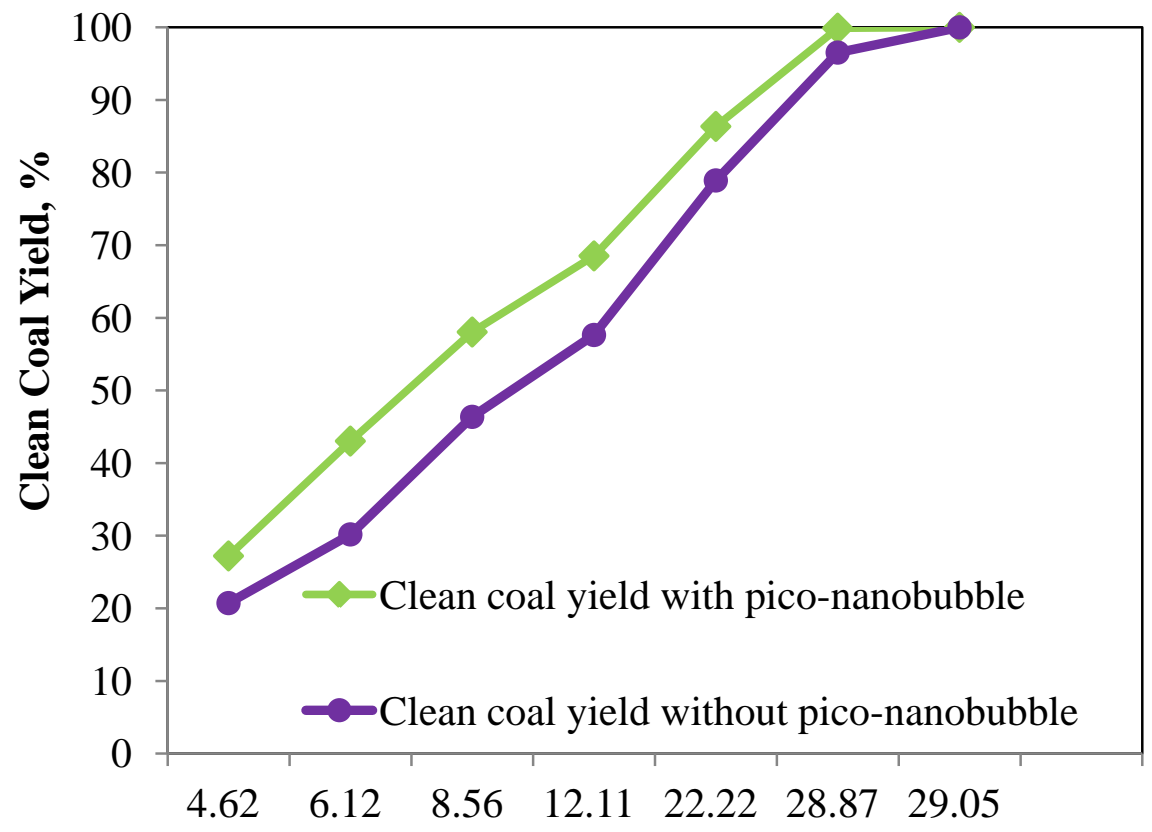

Clean Coal Ash, \%

(a) $-700+355 \mu \mathrm{m}$

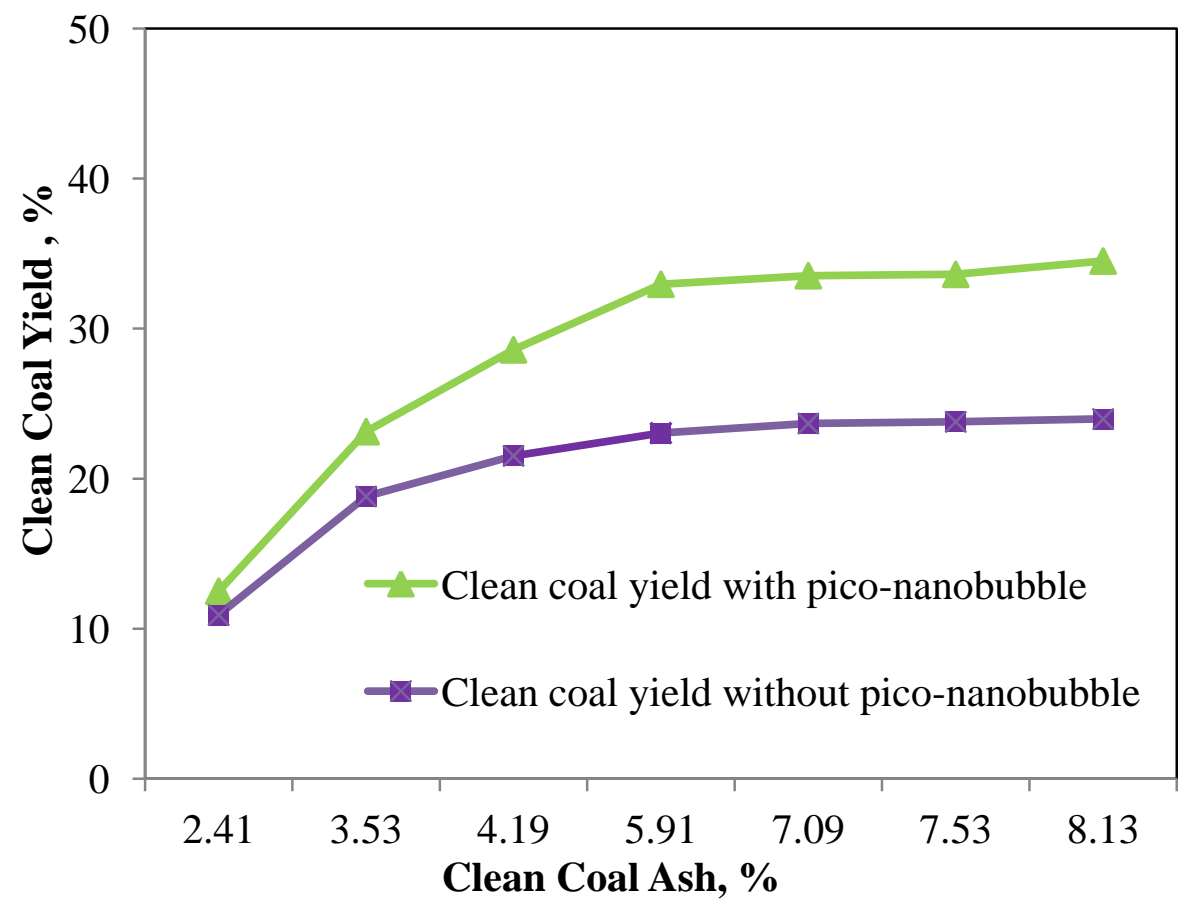

(b) $-75 \mu \mathrm{m}$

Figure 5- 24 Effect of pico-nano bubble on yield and combustible material recovery. 


\section{3. 2. 2 Effect of pico-nano bubbles on flotation particle size ranges}

Figure 5-25 reveals the effect of pico-nano bubbles on the flotation product particle size distributions of $-700+150 \mu \mathrm{m}$ and $-150 \mu \mathrm{m}$ raw coal feed in the presence and absence of pico-nano bubbles. From the cumulative particle size distribution curves in Figure 5-25 (a), the use of pico-nano bubbles increased the $-700+150 \mu \mathrm{m}$ coarse coal flotation product particle size from $250 \mu \mathrm{m}$ to $355 \mu \mathrm{m}$, which means that pico-nano bubbles greatly improved the coarse coal particle flotation recovery. Figure 5-25 (b) depicts that the presence of pico-nano bubbles decreased $-150 \mu \mathrm{m}$ fine/ultrafine coal flotation product particle size from 38 to $125 \mu \mathrm{m}$ significantly improved the fine/ultrafine coal particle flotation recovery.

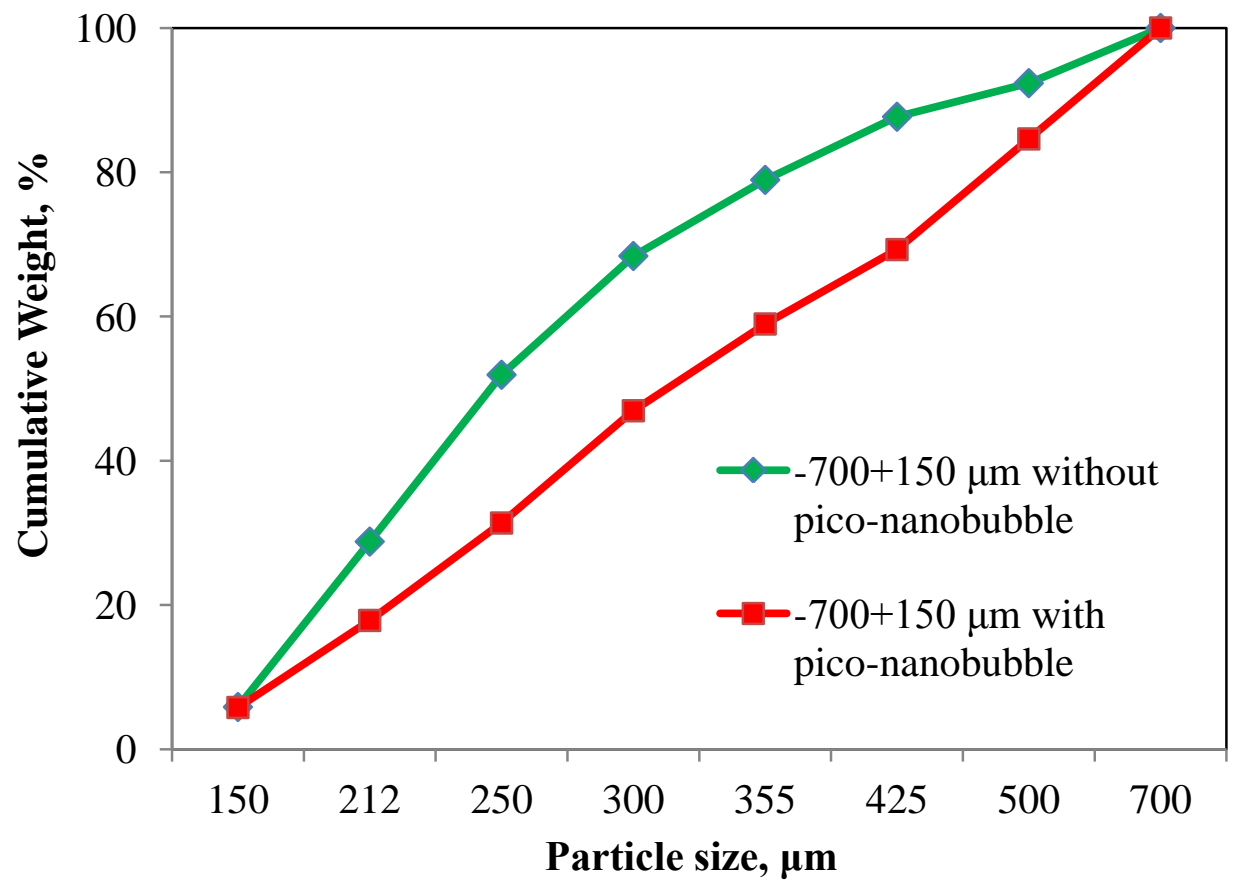

(a) $-700+150 \mu \mathrm{m}$ 


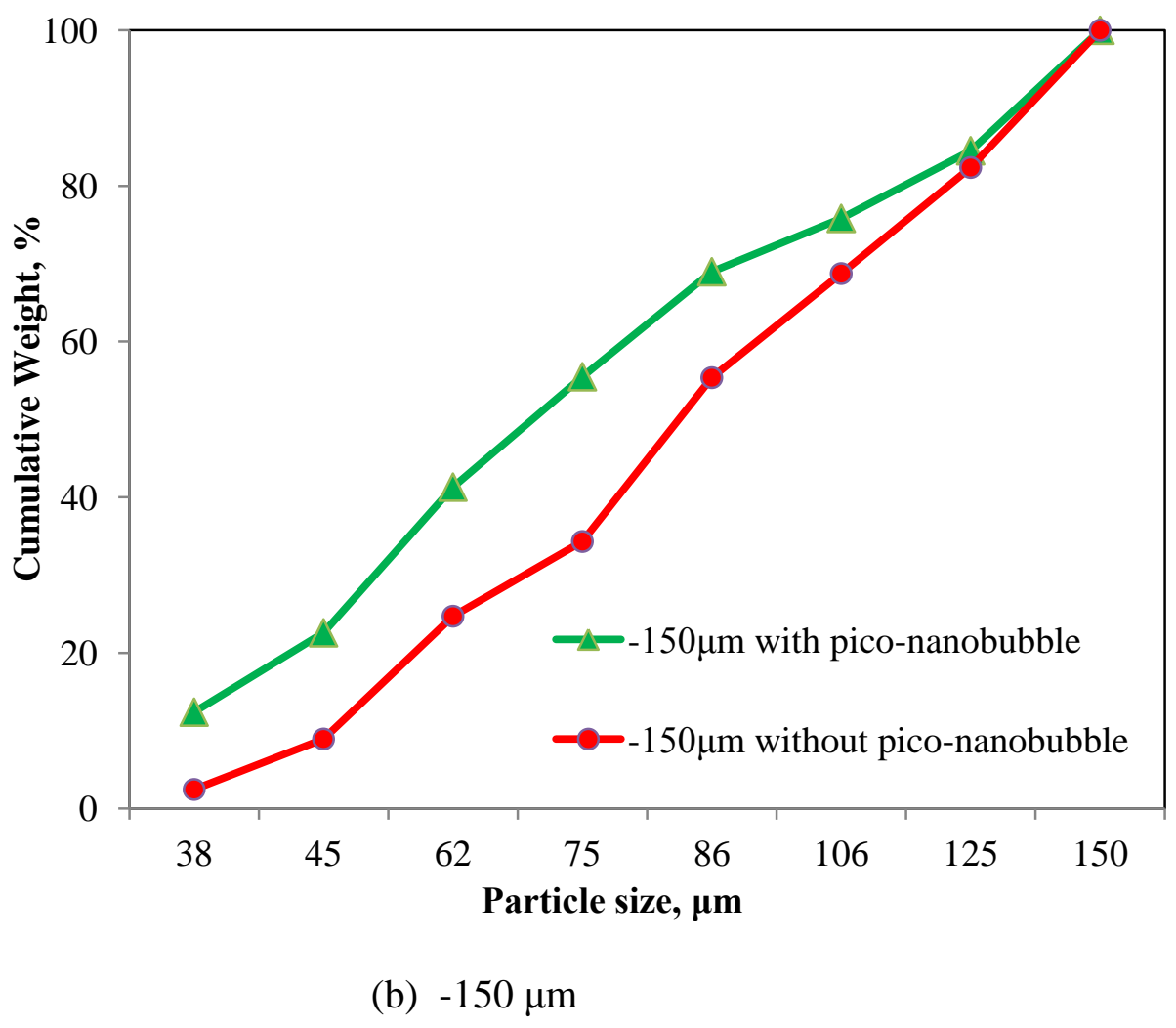

Figure 5-25 Cumulative particle size distributions of clean coal with and without pico-nano bubbles.

\subsubsection{Effect of pico-nano bubbles on flotation ash rejection}

Rejecting ash is one of the main goals in coal froth flotation. Figure 5-26 reveals the flotation ash rejection as a function of the combustible material recovery with and without pico-nano bubble for $-700+355,-355+150,-150+75$, and $-75 \mu \mathrm{m}$ size coal particles. From Figure 5-26, the flotation ash rejection without pico-nano bubble decreases rapidly with further increasing of the combustible material recovery after the combustible material recovery reaches about $75 \%, 80 \%, 90 \%$, and $90 \%$ for $-700+355$, $355+150,-150+75$, and $-75 \mu \mathrm{m}$ size ranges, respectively. The combustible material recovery at the "inflection point" is 5\%-10\% higher in the presence of pico-nano bubbles 
than in the absence of pico-nano bubbles. Figure 5-26 shows that the ash rejection of $700+355 \mu \mathrm{m}$ size coal particles is about $12.4 \%, 16.3 \%, 6.5 \%$, and $5.4 \%$ higher in the presence of pico-nano bubble than in the absence of pico-nano bubbles, at combustible material recoveries of $80 \%, 75 \%, 70 \%$, and $60 \%$, respectively. Pico-nano bubbles increase the flotation ash rejection of the $355-150 \mu \mathrm{m}$ size fraction coal particles by $15.3 \%, 11.5 \%, 6.8 \%$, and $2.7 \%$ for the combustible material recoveries of $90 \%, 75 \%$, $60 \%$, and $40 \%$, respectively. At the combustible recoveries of $95 \%, 80 \%, 70 \%$, and $50 \%$, the corresponding air rejection of $-150+75 \mu \mathrm{m}$ fraction coal particle flotation is $12.4 \%$, $7.2 \%, 4.5 \%$, and $2.1 \%$ higher with pico-nano bubbles than without pico-nano bubbles. It can be observed from the figure that, pico-nano bubbles have less effect on the ash rejection of $-75 \mu \mathrm{m}$ ultrafine coal particle flotation than that of the other three coarser size fractions. The flotation ash rejection of $-75 \mu \mathrm{m}$ ultrafine coal particles is increased by $3.4 \%, 1.5 \%$, and $1.9 \%$ at the combustible material recoveries of $84 \%, 80 \%$, and $75 \%$, respectively. This can be due to the some of the ultrafine particles of clay minerals that have been entrained and eventually floated out with the froth despite use of washing water. The use of pico-nano bubble improved the flotation ash rejection of the various size fraction coal particles. 


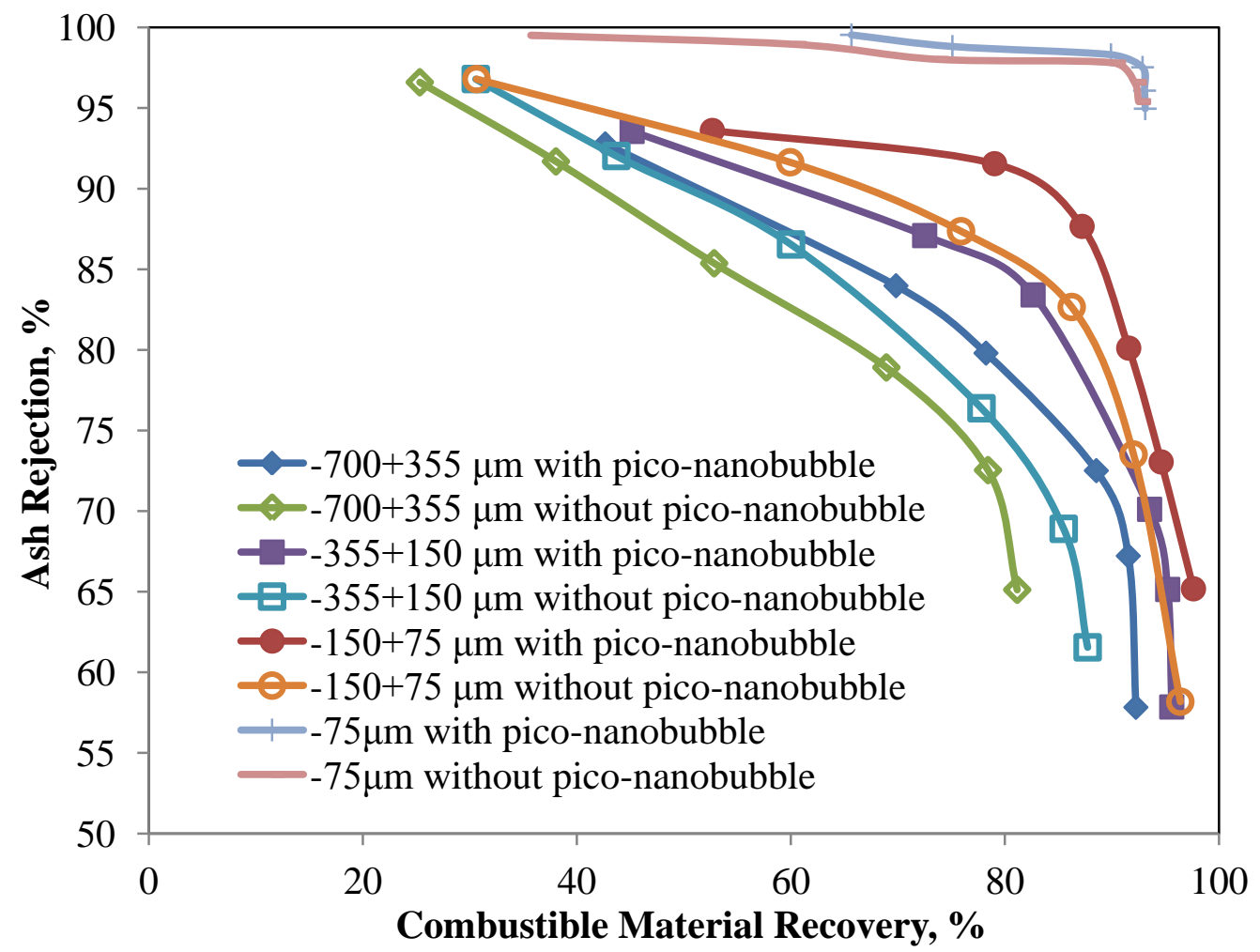

Figure 5- 26 Effect of pico-nano bubble on flotation ash rejection for various particle sizes.

\subsubsection{Effect of pico-nano bubbles on overall performance}

Figure 5-27 reveals the effect of pico-nano bubbles on the flotation product yield of four coal particle size ranges of $-700+355,-355+150,-150+75$, and $-75 \mu \mathrm{m}$. It can be observed from the figure that the effect of pico-nano bubbles on the yield of coal particle flotation decreases with decreasing feed particle size and increasing clean coal ash. Figure 5-27 (a) shows the presence of pico-nano bubbles increases the $-700+355 \mu \mathrm{m}$ coal flotation product yield by about $14.3 \%, 16.1 \%, 13.12 \%, 10.2 \%$ and the clean coal ash of $5.5 \%$, $7.5 \%, 10 \%$, and $13 \%$, respectively. The pico-nano bubbles increases the $-355+150 \mu \mathrm{m}$ clean coal yields by $14.2 \%, 10.3 \%, 10.1 \%, 7.6 \%$ and ash contents of $5.5 \%, 7.5 \%, 10 \%$, and 13\%, respectively. Figure 5-27 (b) depicts that the overall product yield of $-150+75$ 
$\mu \mathrm{m}$ particle size fraction is higher than that of $-75 \mu \mathrm{m}$ particle size fraction The flotation yield of $-150+75 \mu \mathrm{m}$ particle size fraction coal are $19.3 \%, 12.2 \%, 4.2 \%$, and $2.8 \%$ higher in the presence of pico-nano bubbles than in the absence of pico-nano bubbles at the clean coal ash of $3 \%, 4 \%, 6 \%$, and $7.5 \%$, respectively. The use of pico-nano bubbles increases $-75 \mu \mathrm{m}$ flotation yield by $2.4 \%, 8.3 \%, 12.3 \%$, and $13.2 \%$, and the clean coal ash of $3 \%, 5 \%, 7.5 \%$, and $10 \%$, respectively. It can be concluded from Figure 5-27 that the use of pico-nano bubbles increases clean coal yields at a given ash content.

Figure 5-28 (a) shows the presence of pico-nano bubble increases combustible material recovery for $-700+355 \mu \mathrm{m}$ size range of coal particles by $19.2 \%, 26.4 \%, 21.5 \%, 16.1 \%$, and clean coal ash of $5.5 \%, 7.5 \%, 10 \%$, and $13 \%$, respectively. The use of pico-nano bubble increases combustible material recovery for $-355+150 \mu \mathrm{m}$ size range of coal particle by about $23.9 \%, 21.3 \%, 19.4 \%, 11.7 \%$, and clean coal ash of $5.5 \%, 7.5 \%, 10 \%$, and 13\%, respectively. Figure 5-28 (b) shows that the combustible material recovery of $150+75 \mu \mathrm{m}$ particle size range of coal particle are $22.1 \%, 19.4 \%, 12.5 \%$, and $8.9 \%$ higher in the presence of pico-nano bubble than in the absence of pico-nano bubble, and the clean coal ash of $3 \%, 4 \%, 6 \%$, and $7.5 \%$, respectively. Pico-nano bubble increase the -75 $\mu \mathrm{m}$ coal particle combustible material recovery by $23.2 \%, 15.4 \%, 8.2 \%$, and $2.3 \%$ at the clean coal ash content of $3 \%, 5 \%, 7.5 \%$, and $10 \%$, respectively. It can be seen from the results shown above that the most significant improvement in flotation performance can be seen in the $-355+700 \mu \mathrm{m}$ coarse coal flotation. This is because the presence of piconano bubble on the coarse coal particle surfaces facilitates particle attachment to conventional-sized bubbles. 


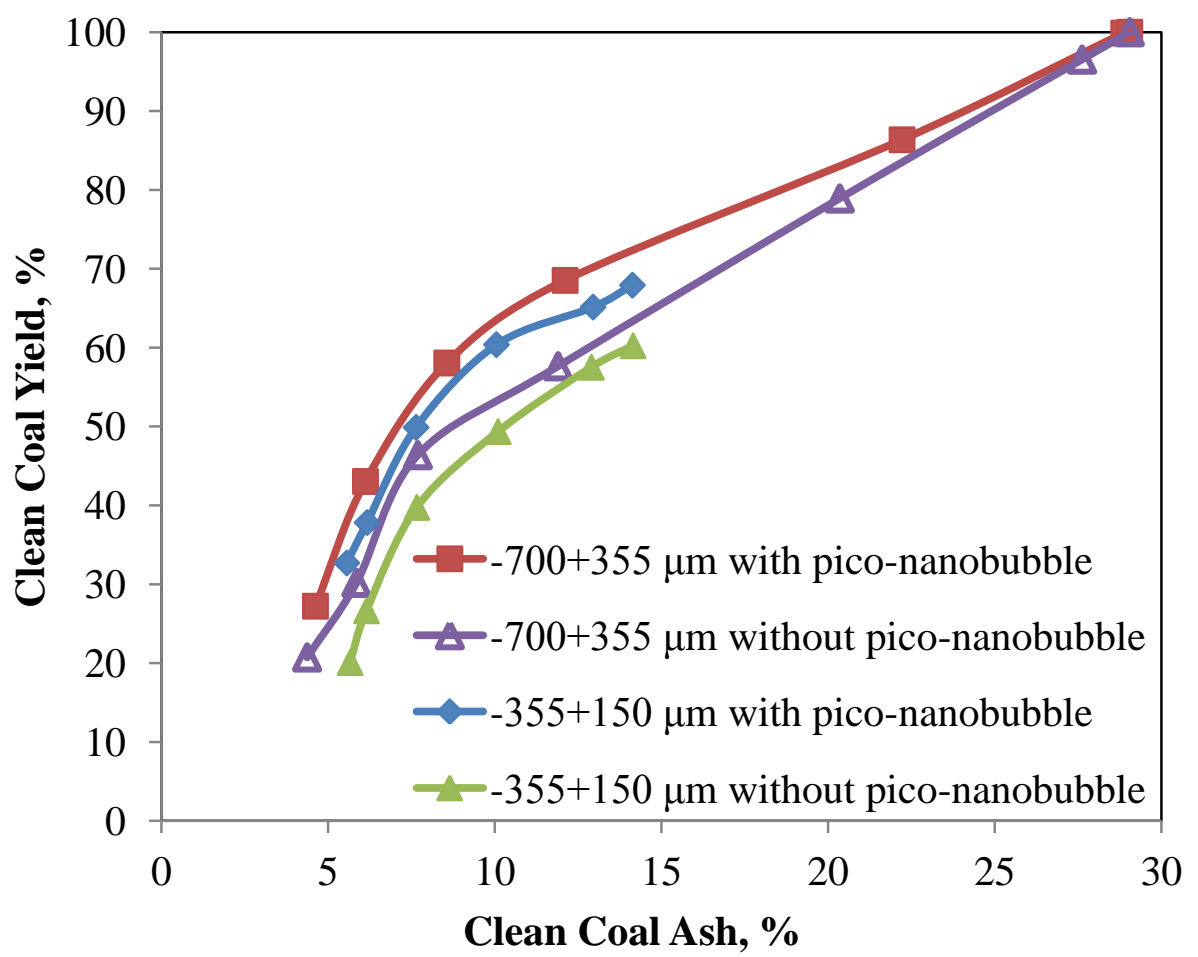

(a) $-700+355$ and $-355+150 \mu \mathrm{m}$

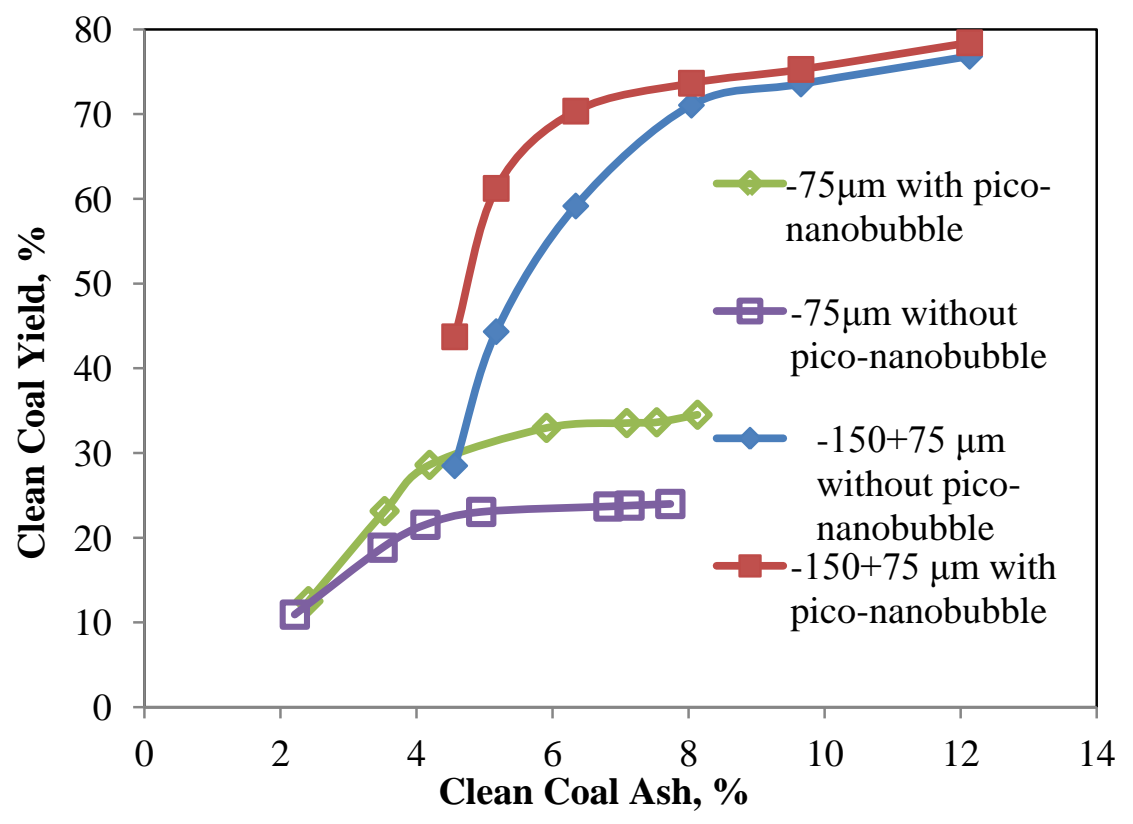

(b) $-150+75$ and $-75 \mu \mathrm{m}$

Figure 5- 27 Effect of pico-nano bubbles on flotation yield. 


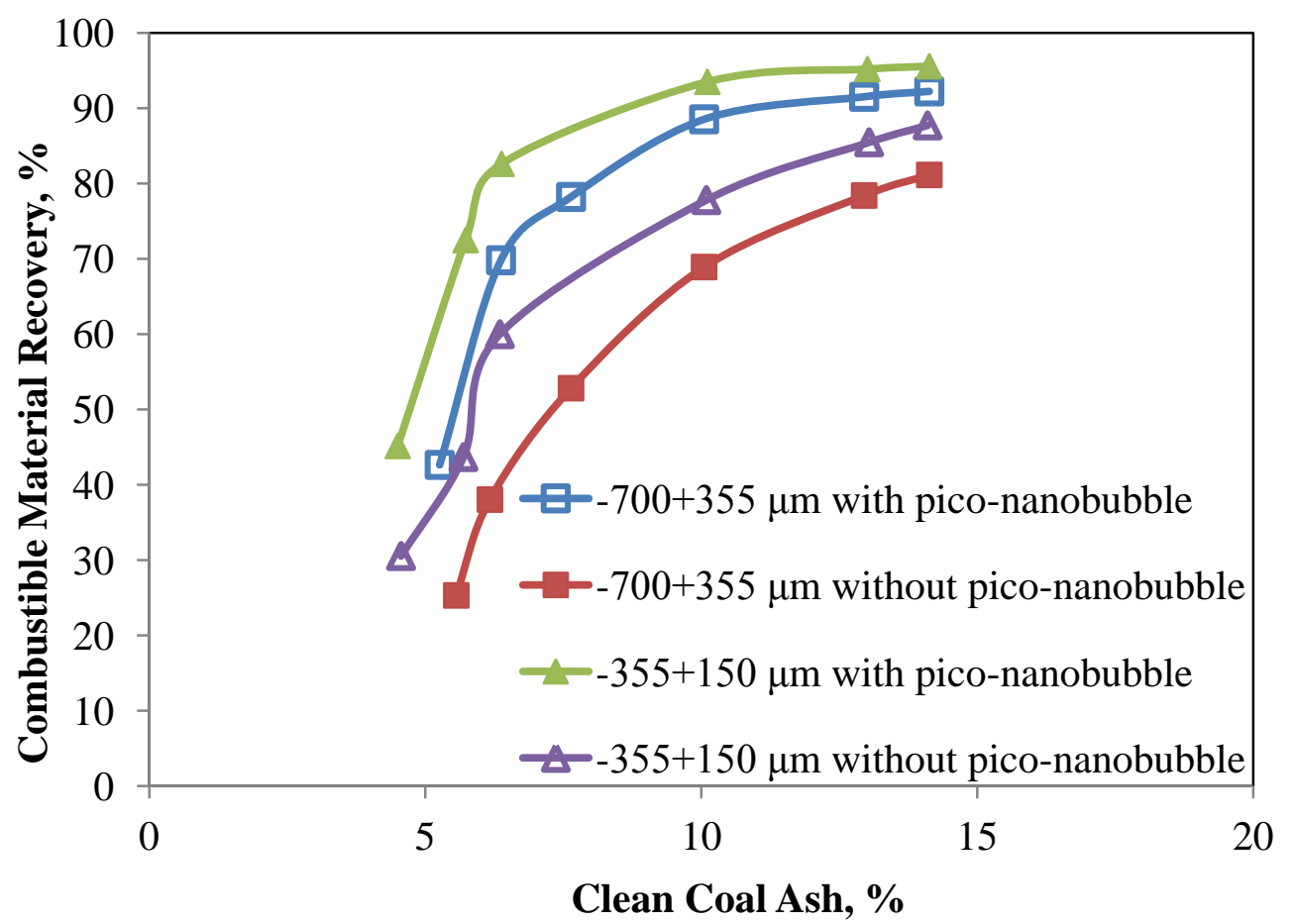

(a) $-700+355$ and $-355+150 \mu \mathrm{m}$

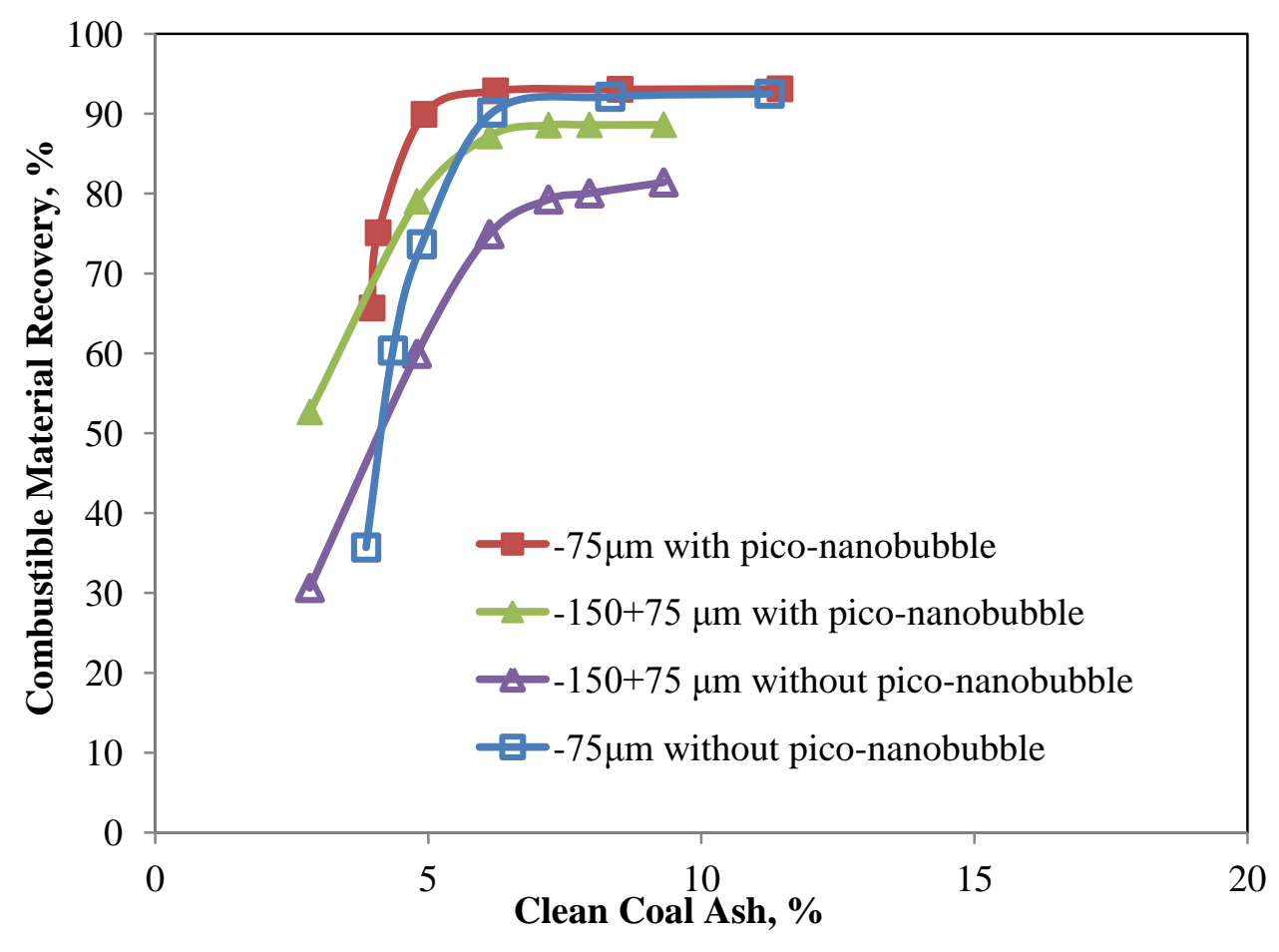

(b) $-150+75$ and $-75 \mu \mathrm{m}$

Figure 5-28 Effect of pico-nano bubble on combustible material recovery. 
The pico-nano bubble on the coarse coal particles does not have sufficient buoyancy to float the particle by themselves, but the surface of a coarse coal particle coated with piconano bubble is more hydrophobic than without pico-nano bubble. The wetting film separating the colliding convention-sized bubbles and pico-nano bubble is more unstable than the film between the convention-sized bubbles and coarse coal particles. The significant difference in diameter between the convention-sized bubble and pico-nano bubble leads to a huge differential capillary pressure, which facilitates the rupture of water films separating conventional size bubbles and pico-nano bubbles. Thus, the presence of pico-nano bubble on coal particles surfaces accelerates the water film rupture and bubble-particle collision. In other words, pico-nano bubbles on the surface of coal particle act as a secondary hydrophobizing agent to enhance the flotation rate constant.

\subsubsection{Pico-nano bubbles and nanobubbles percent effect on separation efficiency of column flotation for bituminous coal}

In order to investigate the effectiveness of pico-nano and nano bubble (bubbles smaller than $1 \mu \mathrm{m}$ ) percent in column flotation, a specially designed flotation with static mixer connected in series with the optimal designed venturi tube was developed for enhancing the recovery of ultrafine $(-45 \mu \mathrm{m})$ and coarse coal particles $(-700+355 \mu \mathrm{m})$, which are difficult to float with conventional flotation process. The column flotation tests were performed under the conditions shown in Table 5-7. MIBC is used as frother in this series of tests to adjust generation of pico-nano bubble and nano bubble percent. Various dosage of frother was used in the tests to stabilize the bubbles and adjust pico-nano and nanobubble percent to be generated. 
Table 5- 7 Column flotation test conditions for bituminous coal using optimal designed cavitation venturi tube.

\begin{tabular}{|l|l|}
\hline Feed solids percentage & $5 \% \mathrm{wt}$ \\
\hline Collector dosage & $0.7 \mathrm{lb} /$ ton Kerosene \\
\hline Feed rate & $0.4 \mathrm{~cm} / \mathrm{s}$ \\
\hline Gas flow rate & $1.6 \mathrm{~cm} / \mathrm{s}$ \\
\hline Wash water rate & $0.2 \mathrm{~cm} / \mathrm{s}$ \\
\hline
\end{tabular}

The effect of pico-nano and nano bubble percent on combustible material recovery and clean coal ash content was shown in Figure 5-29. It can be clearly seen that the combustible material recovery increases from $82 \%$ to $90 \%$ with increasing pico-nano and nano bubble percent from $65 \%$ to $83 \%$, and there is a slightly decrease of combustible material recovery after that as pico-nano and nano bubble percent increases to $100 \%$. The clean coal ash content, on the other hand, increases with increasing pico-nano and nano bubble percent. The optimal percentage of pico-nano and nano bubble is about $70 \%$, with the minimum clean coal ash content of $11.7 \%$ and maximum combustible material recovery of $86 \%$.

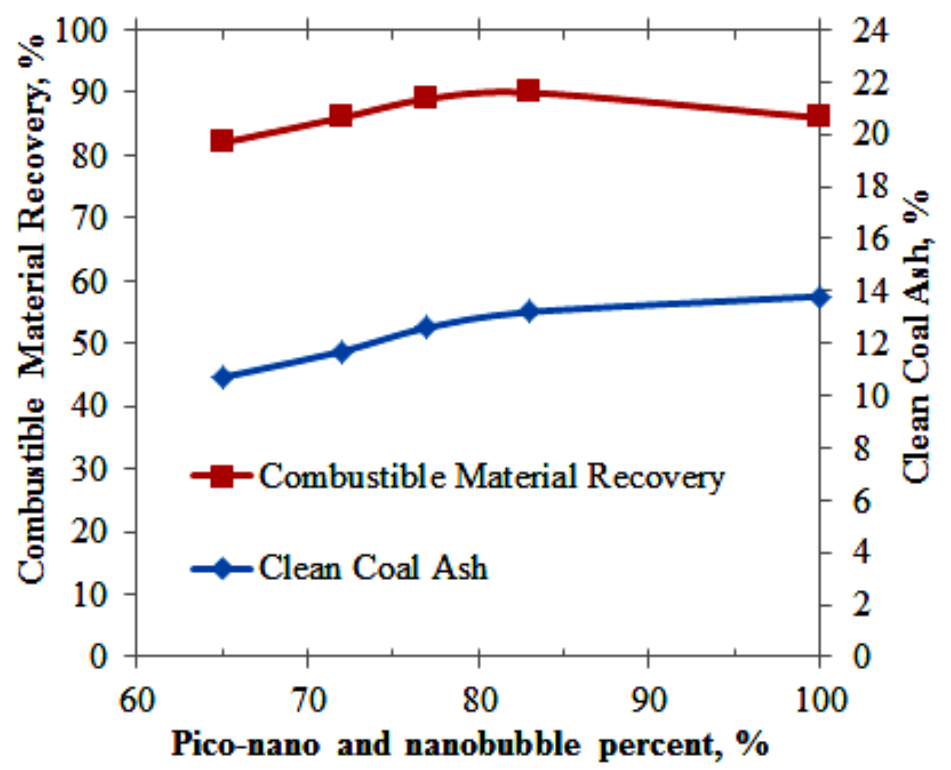

Figure 5- 29 Combustible material recovery and clean coal ash content as a function of Pico-nano and nano bubble percent. 


\subsubsection{Effect of particle size on separation efficiency and combustible material recovery}

Figure 5-30 clearly indicates that use of pico-nano bubble expanded the particle size range for effective flotation separation.

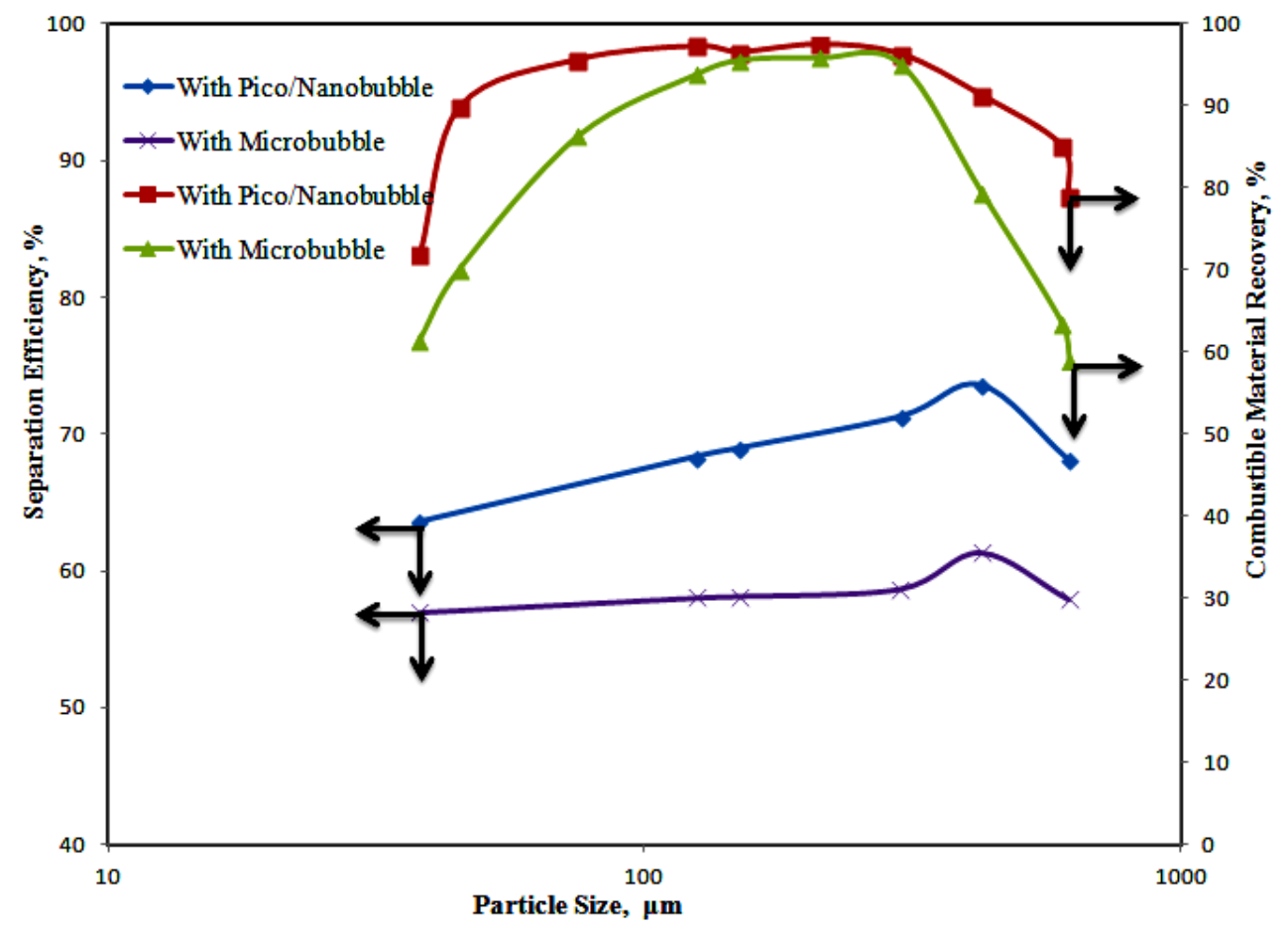

Figure 5- 30 Particle size effect on separation efficiency and combustible material recovery.

The most significant improvement in separation efficiency was observed with particles smaller than $80 \mu \mathrm{m}$ and larger than $600 \mu \mathrm{m}$. For example, separation efficiency was increased by about $10 \%$ with $30 \mu \mathrm{m}$ particles and $20 \%$ with $600 \mu \mathrm{m}$ particles. . As for the froth flotation of ultrafine particles, since the work of adhension Wa between a solid particle and water, which is $\gamma_{1}(1+\operatorname{Cos} \theta)\left(\gamma_{1}\right.$ is water surface tension and $\theta$ is contact angle), is always smaller than the work of cohension of water Wc or $2 \gamma_{1}$, the pico-nano 
and nano bubble would preferentially nucleate on the surface of ultrafine particles without collision, especially hydrophobic particles with higher contact angle $(\theta)$, which is the most important parameter in the froth flotation of ultrafine particles (Yoon, et al. 1989; Tao, et al. 2006a; Weber, et al. 1983).

Furthermore, the pico-nano and nano bubbles acts like a secondary collector on the surface of coal particles, which increases the probability of adhension and reduces the probably of detachment as a result of their lower upward velocity (Tao, et al. 2008), that's why the pico-nano and nano bubbles could improve the froth flotation efficiency. But for coarse particle froth flotation, only the presence of pico-nano and nano bubbles are not enough, and conventional sized bubbles are also needed to provide enough levitation force for the coarse particles, which are surrounded by pico-nano and nano bubbles, to be lift to the froth zone, eventually float out as product. , this also explains why there is a decrease in combustible material recovery as the pico-nano and nano bubble percent increases from $80 \%$ to $100 \%$ in Figure 5-29.

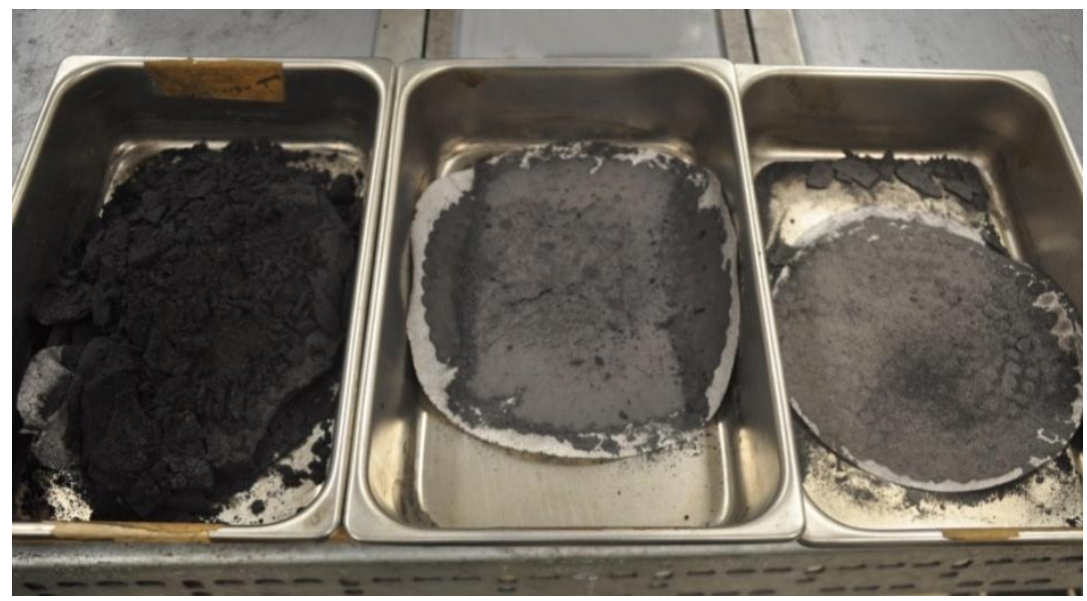

Figure 5- 31 The photo shows the clean coal (left), middlings (middle) and tailings (right) of pico-nano bubbles flotation for Pittsburgh No.8 seam coal. 
An example of the products of column flotation using pico-nano and nano bubbles is given in the Figure 5-31. The photo shows that the color change dramatically from left, the deep black color of clean coal product, to the right, which represents the tailings with the light gray color.

\subsection{Economic evaluation of the application of pico-nano bubbles in coal flotation}

The main cost of applying the pico-nano bubble into the flotation system includes the operational and capital costs. The assumptions for the economic evaluation include :

1) Assuming the average ash content of the feed is $35 \%$.

2) The flotation feed rate is 100 ton/hour.

3) $10 \%$ solid concentration of the flotation feed.

4) In order to avoid congestion and maintain the separation efficiency, 6 venturi tubes would be installed in parallel to process the recirculating tailings.

5) For the Pittsburgh No. 8 bituminous coal sample tested, the combustible material recovery improvement can be as good as $25 \%$ with column flotation. To make a conservative estimation, the recovery improvement is assumed to be $10 \%$ for industrial application.

With all those assumptions, the calculation of cost for the pico-nano bubble application would consist of the followings:

1) Venturi cost: the cost for one venturi tube is around $\$ 8,000$, assume it would last about six months, so the annual cost should be $\$ 96,000$.

2) Cavitation pump cost: Additional pump would be needed in the tailing recirculation loop, and the flow rate of the pump should be 4000 GPM or 910 $\mathrm{m}^{3} / \mathrm{h}$. A Goulds model HSU, HSUL or JCU submersible slurry pump can be used 
to meet the requirement. And the cost for this model is about $\$ 16,000$. Assume the pump would last 4 years, then the annual cost for the pump should be $\$ 4,000$.

3) Additional electricity cost: Based on our laboratory measurement, the additional energy consumption caused by the pump should be less than $4 \mathrm{kwh} /$ ton of solids is the efficiency of the pump is $60 \%$. Assume the unit price of the electricity if $\$ 0.1 / \mathrm{kwh}$, the annual cost of the electricity should be $0.1 / \mathrm{kwh} \times 4 \mathrm{kwh} / \mathrm{ton} \times 100$ ton/hour x 4320 hours/year $=\$ 172,800$.

Therefore, the total annual cost of the equipment will be: $\$ 96,000+\$ 4,000=\$ 100,000$. Consider a factor of 1.1 for the miscellaneous accessories, which include valves and flow meters, and a factor of 1.2 for the installation fees, the total capital cost becomes $\$ 132,000$. With the operational cost, the total cost for pico-nano bubble application should be $\$ 132,000+\$ 172,800=\$ 304,800$ a year.

If the flotation product of $10 \%$ clean coal ash needed to be produced, the total increase of the flotation product by using pico-nano bubble should be: 100 ton/hour x (1-35\%) x $10 \% /(1-10 \%)=7.2$ ton/hour. At current price for clean coal of about $\$ 62 /$ ton, the annual revenue by pico-nano bubble application should be: 7.2 ton/hour x 4320 hours/ year x $\$ 62 /$ ton $=\$ 1,928,448$.

Then, the net annual profit generated by pico-nano bubble application should be: $\$ 1,928,448-\$ 304,800=\$ 1,623,648$. 


\section{Chapter 6 Results and Discussions for Phosphate reverse Flotation}

\subsection{Measurement of frothability and froth stability}

\subsubsection{Effect of selected surfactant on collector frothability}

In this study, pico-nano bubbles were introduced into the flotation system to improve the flotation efficiency for coarse and fine particles. Based on previous study, it's believed that certain amount of frother is needed in order to generate and maintain pico-nano bubbles in the solution. However, in phosphate industry, fatty acid plays dual functions and works as frother and colletor for either phosphate or carbonate flotation. There is no frother applied separately to control the bubble generation. The effects of the selected frother (Methyl Isobutyl Carbinol) on the frothability of two selected fatty acid (CF413 and CF413B) were evaluated by measuring the froth height and froth lifetime at different reagent dosages.

Figure 4-1 shows the frothability of fatty acid collector (CF413 and CF413B) with selected frother (Methyl Isobutyl Carbinol) at different dosages. It can be seen that the froth height of CF413 and CF413B alone increases with reagent dosage at gas flow rate of $1.5 \mathrm{~cm} / \mathrm{s}$. And the frothability of CF413 is better than CF413B without the addition of frother (MIBC). It also can be observed from Figure 4-1 that the increase of MIBC from $5 \mathrm{ppm}$ to $15 \mathrm{ppm}$ of the fatty acid collector in the mixture results in increasing the froth height. The results show that the addition of surfactant can improve the frothability of the fatty acid collector. However, it should be noted that when MIBC is mixed with CF413 or CF413B at the dosage of $10 \mathrm{ppm}$, the frothability can be significantly improved compared to other dosages of MIBC. By adding in the frother (MIBC), the frothability difference between CF413 and CF413B has been reduced to almost negligible level when 
the dosage of MIBC is higher than $10 \mathrm{ppm}$. During this test, the overall flotation column is almost filled up with pico-nano and nanobubbles when the collector dosage is greater than $1 \mathrm{lb} /$ ton. It indicates that a large number of pico-nano bubbles and nanobubbles have been generated which would greatly increase the possibility of collision, and eventually improve the flotation separation efficiency.

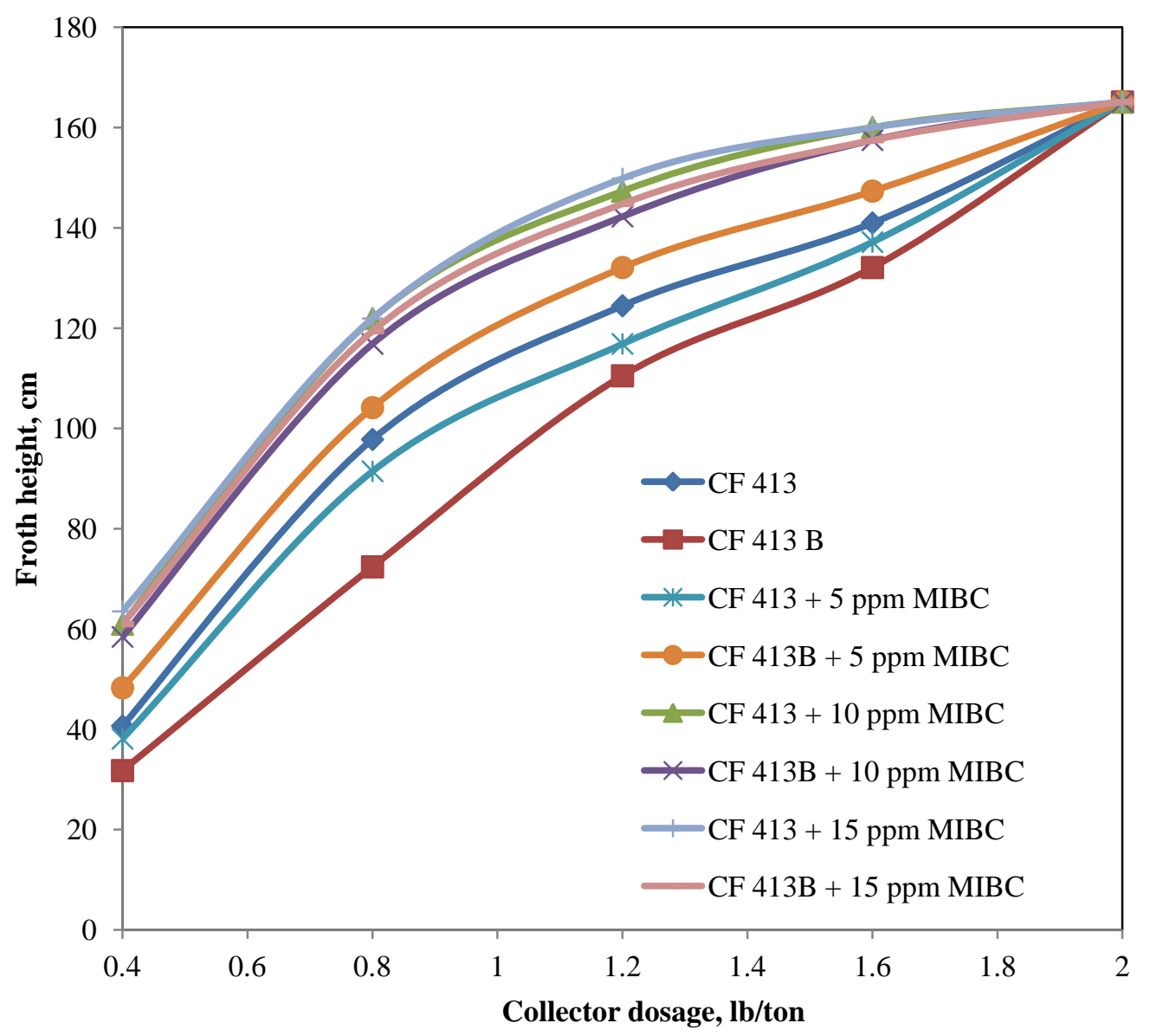

Figure 6- 1 Froth height as a function of collector dosage with different surfactants.

\subsubsection{Effect of selected surfactant on collector froth stability}

The froth lifetime as a function of collector dosage with selected surfactant is shown in

Figure 6-2. It shows that the froth lifetime increases with increasing the collector dosage. 
Without the addition of MIBC, the froth stability of CF413 is better than CF413B. With the addition of MIBC, the froth lasts longer than that without any frother. It can also be seen from Figure 6-2 that there is a significant increase of the froth lifetime when CF413 or $\mathrm{CF} 413 \mathrm{~B}$ is mixed with $\mathrm{MIBC}$ at the dosage of $10 \mathrm{ppm}$ or higher. With the increasing of the dosage of frother (MIBC), the froth lifetime difference reduces significantly, especially when the dosage of MIBC increases from $5 \mathrm{ppm}$ to $10 \mathrm{ppm}$.

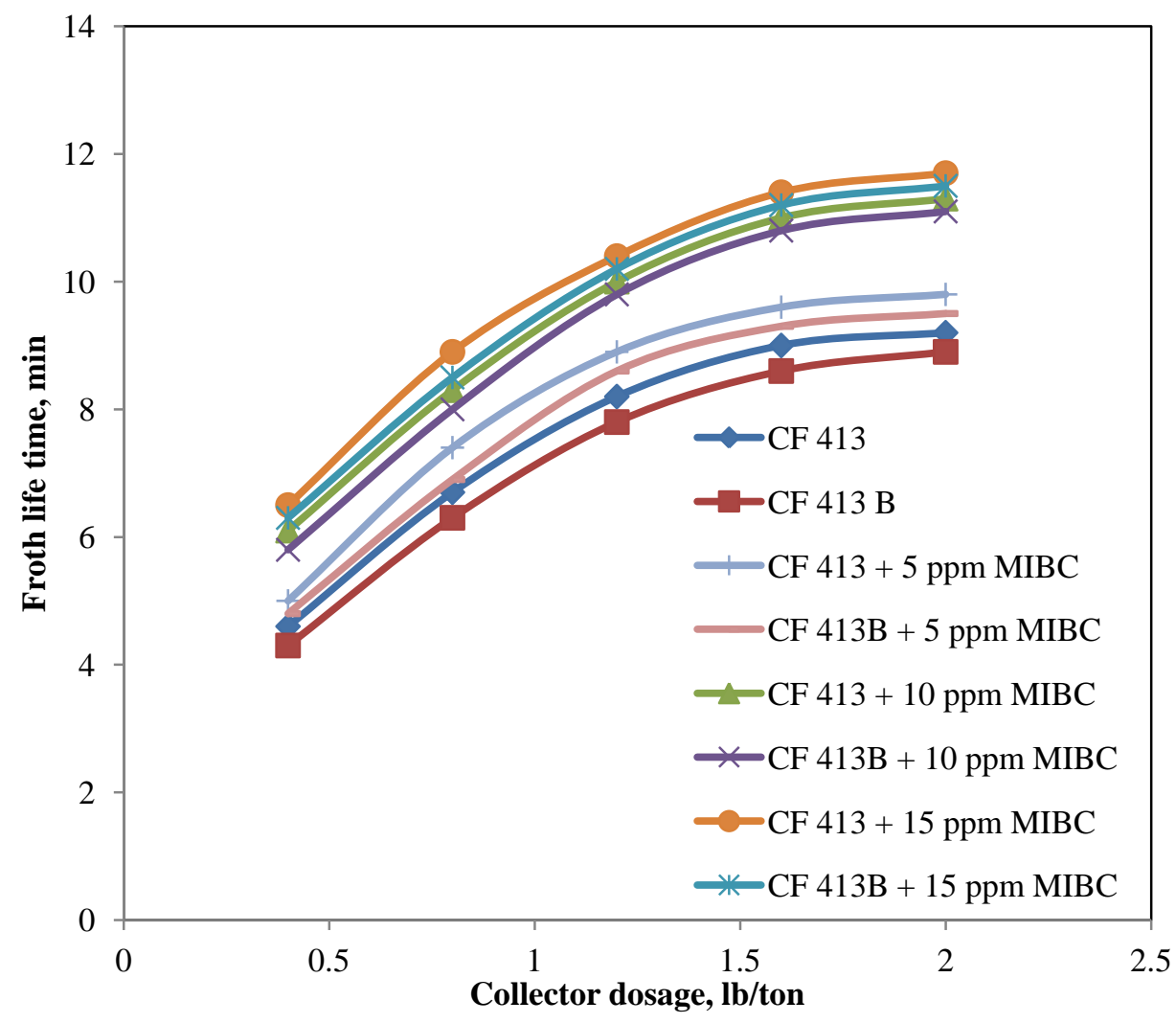

Figure 6- 2 Froth life time as a function of collector dosage with different surfactants.

\subsubsection{Effect of different collector on dolomite flotation}

In order to select better reagents for phosphate reverse flotation study, single factor experiment tests were conducted in the pico-nano bubble column flotation system by 
varying dosage of collector and collector-surfactant mixtures. Figure 6-3 shows the effect of the different collector and selected surfactant on the yield of the float in dolomite flotation.

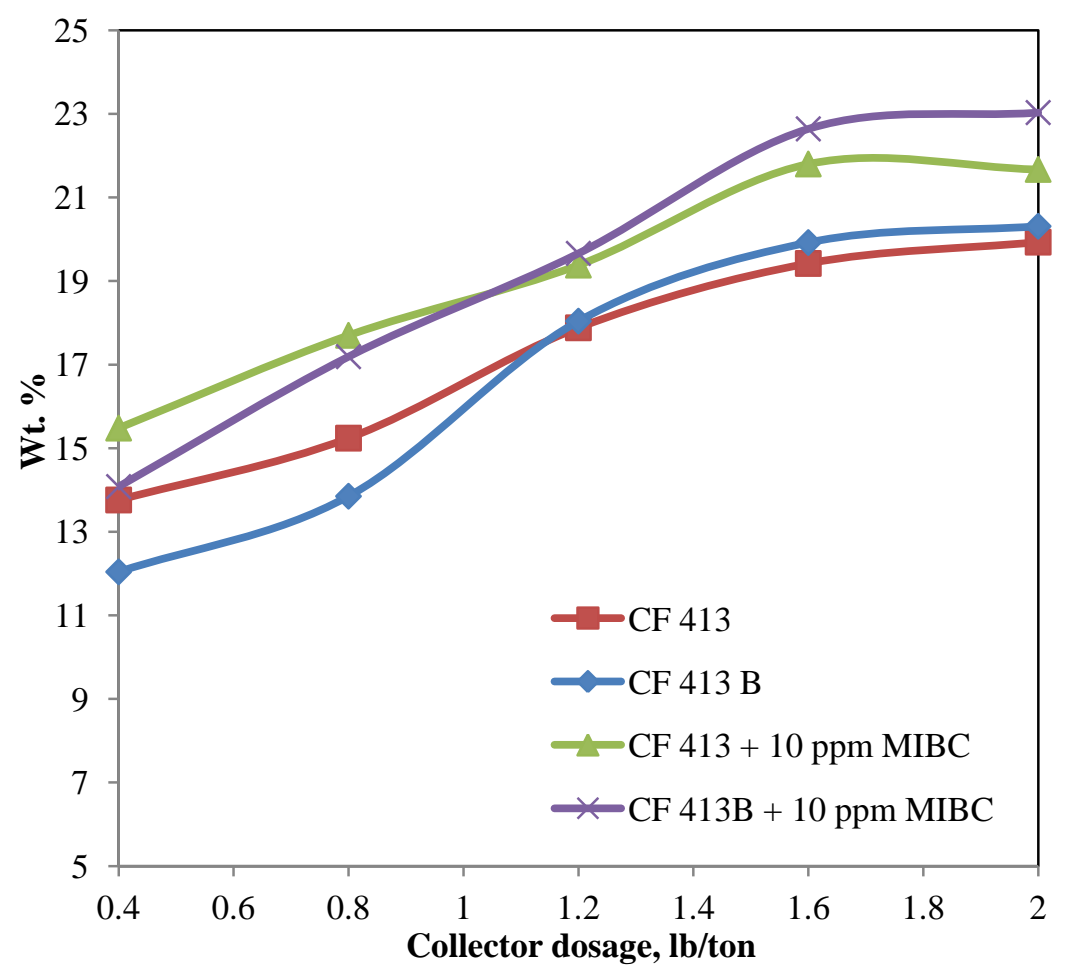

Figure 6- 3 Effect of selected surfactants on the yield of the floats using different collector with and without surfactant.

It shows that the yields for both CF413 and CF413B do not have much difference with or without surfactant when the dosages are in the range of 0.8 to $1.2 \mathrm{lb} / \mathrm{ton}$. At low collector dosage in the range of 0.4 to $0.8 \mathrm{lb} / \mathrm{ton}$, the yield has been significantly increased by using CF413 mixed with 10 ppm MIBC. However, when the collector dosage improves to high collector dosage, an opposite trend has been found. At collector dosage of $1 \mathrm{lb} / \mathrm{ton}$, the weight percentage of the floated dolomite was the same for the mixture of $10 \mathrm{ppm}$ MIBC and CF413/CF 413B. However, the yield of dolomite is significantly increased 
when the mixture dosage of CF413B with 10 ppm MIBC increases to high dosage. It indicates that $\mathrm{CF} 413$ generates more bubbles than CF413B at low collector dosages, resulting in better yield. At high collector dosage, however, the yields of floated dolomite are almost the same for CF413 and CF413B. Also, better yields can be achieved by the addition of surfactant MIBC at $10 \mathrm{ppm}$ for both CF413 and CF413B.

Figure 6-4 and Figure 6-5 show the effect of different collector and selected surfactant on the $\mathrm{MgO}$ grade and recovery in the dolomite flotation float. It can be seen from Figure 64 that the grade of $\mathrm{MgO}$ is much higher in the float when the mixture of CF413B and MIBC is used, comparing to using CF413, CF413B and mixture of CF413 and MIBC. When the collector dosage is in the range of 0.4 to $1.2 \mathrm{lb} / \mathrm{ton}$, the $\mathrm{MgO}$ grade in the float is significantly higher by CF413B and MIBC than any other collectors. When CF413 and CF413B are used alone, better grade of $\mathrm{MgO}$ in the float is obtained by using $\mathrm{CF} 413 \mathrm{~B}$ at the dosage between 0.4 to $1.3 \mathrm{lb} /$ ton. This is because CF413 generates more stable bubble than CF413B. However, as the collector dosage keeps increasing, the difference of the $\mathrm{MgO}$ grade becomes negligible by using CF413 and CF413B. Similar to previous findings that better grade of $\mathrm{MgO}$ is achieved when $10 \mathrm{ppm} \mathrm{MIBC}$ is used in the dolomite flotation.

Figure 6-5 shows the effect of different collector and selected surfactant on the $\mathrm{MgO}$ recovery in the dolomite flotation float. It can be seen from Figure 6-5 that the recovery of $\mathrm{MgO}$ increases with the increasing of collector dosage. The addition of MIBC has significant effects on the $\mathrm{MgO}$ recovery in the float. Better recovery of $\mathrm{MgO}$ is achieved by using the mixture of $\mathrm{CF} 413 \mathrm{~B}$ and $10 \mathrm{ppm}$ MIBC when the collector dosage increases to more than $0.7 \mathrm{lb} /$ ton. By using the mixture of $\mathrm{CF} 413 \mathrm{~B}$ and MIBC, about $12 \%$ or more 
dolomite can be floated at the collector dosage of $2 \mathrm{lb} /$ ton, comparing with using CF413, CF413B or the mixture of CF413 and MIBC.

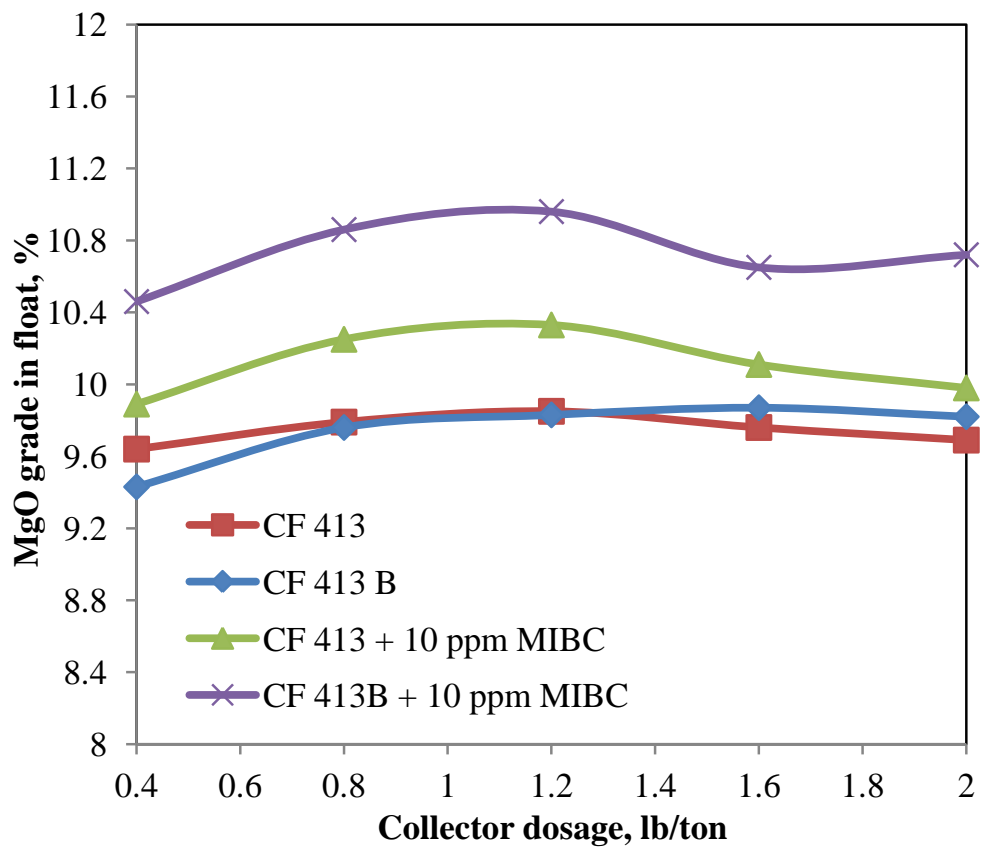

Figure 6- 4 Effect of selected surfactants on the $\mathrm{MgO}$ grade in the float using different collector with and without surfactant.

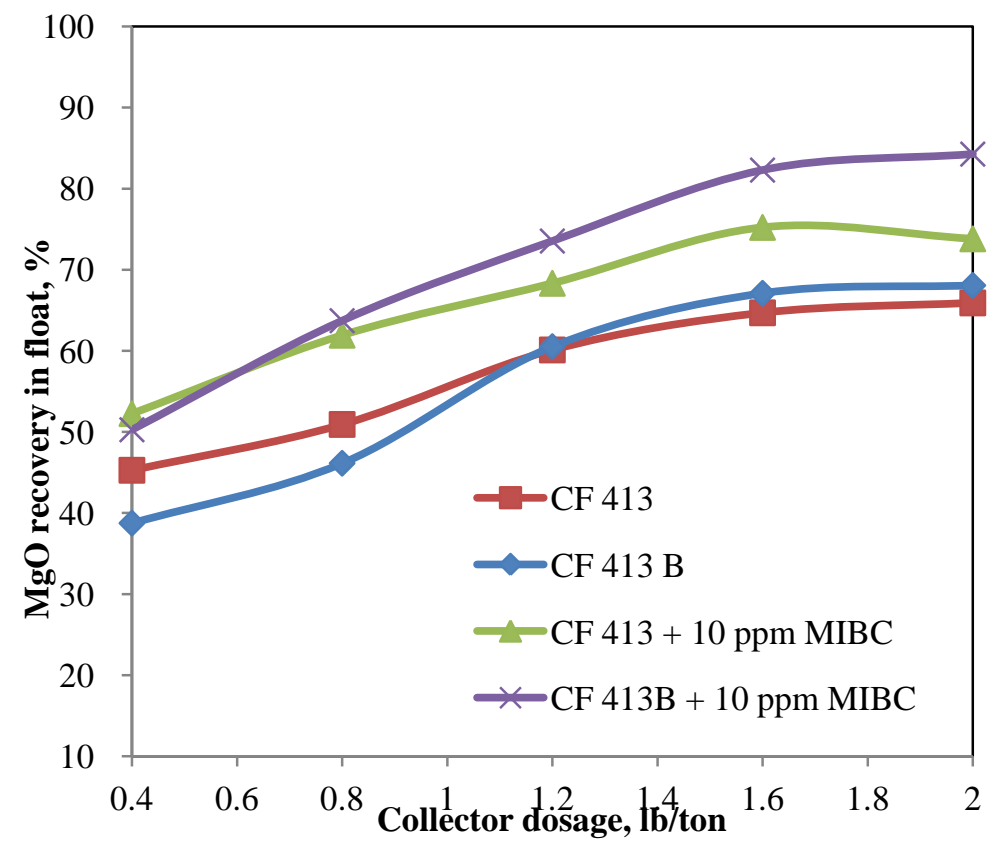

Figure 6- 5 Effect of selected surfactants on the $\mathrm{MgO}$ recovery in the float using different collector with and without surfactant. 
Figure 6-6 shows the effect of different collector and selected surfactant on the $\mathrm{P}_{2} \mathrm{O}_{5}$ grade in the dolomite flotation float. The $\mathrm{P}_{2} \mathrm{O}_{5}$ grade decreases with the increasing of collector dosage from $0.4 \mathrm{lb} /$ ton to $1.2 \mathrm{lb} /$ ton. After which the $\mathrm{P}_{2} \mathrm{O}_{5}$ grade remain essentially constant except for the mixture of CF413B/CF413 and MIBC. The product of dolomite flotation contains much lower $\mathrm{P}_{2} \mathrm{O}_{5}$ grade by using the mixture of $\mathrm{CF} 413 \mathrm{~B}$ and MIBC than using any other collectors.

Figure 6-7 shows the tendency of $\mathrm{P}_{2} \mathrm{O}_{5}$ loss in the dolomite flotation float with and without surfactant. At collector dosage less than $1.4 \mathrm{lb} /$ ton, $\mathrm{P}_{2} \mathrm{O}_{5}$ loss is higher by using CF413. It should be noted that CF413 improves the selectivity in dolomite flotation, however, it has little effect on the collecting ability. When the mixture of CF413B and MIBC is used, the float of dolomite flotation contains less $\mathrm{P}_{2} \mathrm{O}_{5}$, resulting in less $\mathrm{P}_{2} \mathrm{O}_{5}$ loss in the tailings.

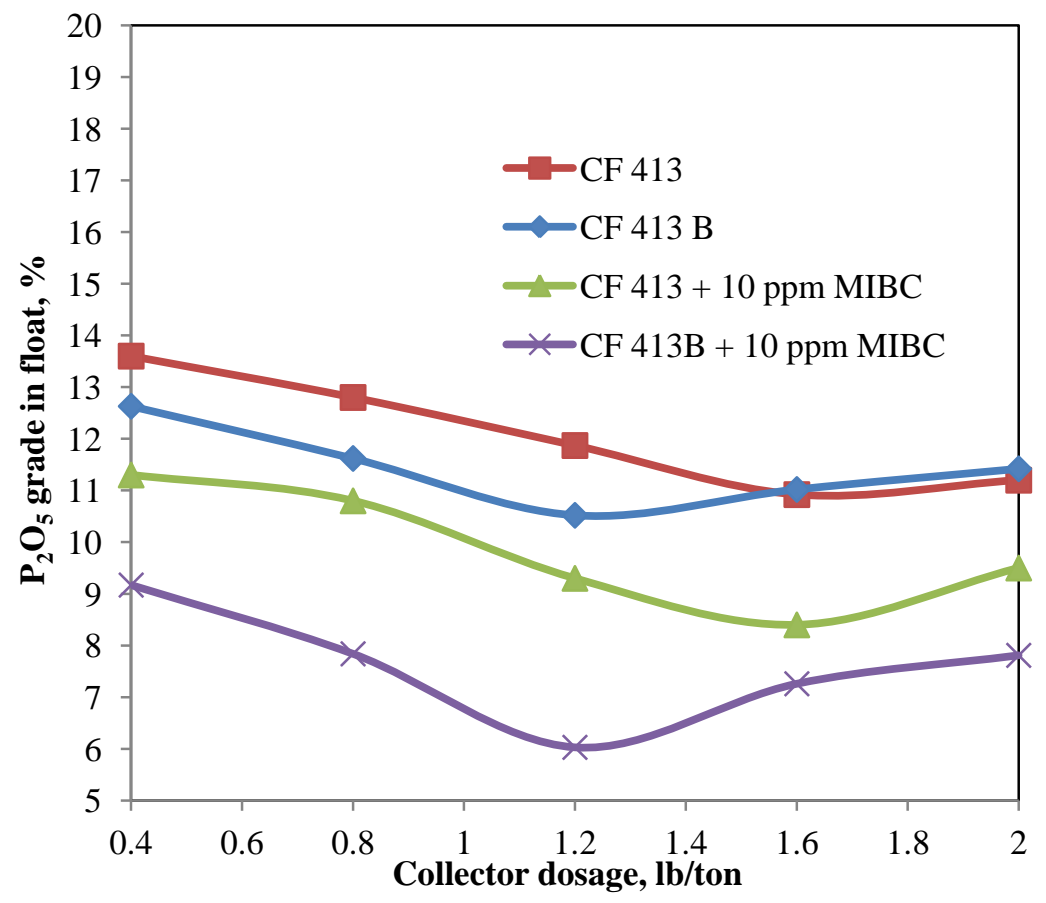

Figure 6- 6 Effect of selected surfactants on the $\mathrm{P}_{2} \mathrm{O}_{5}$ grade in the float using different collector with and without surfactant. 


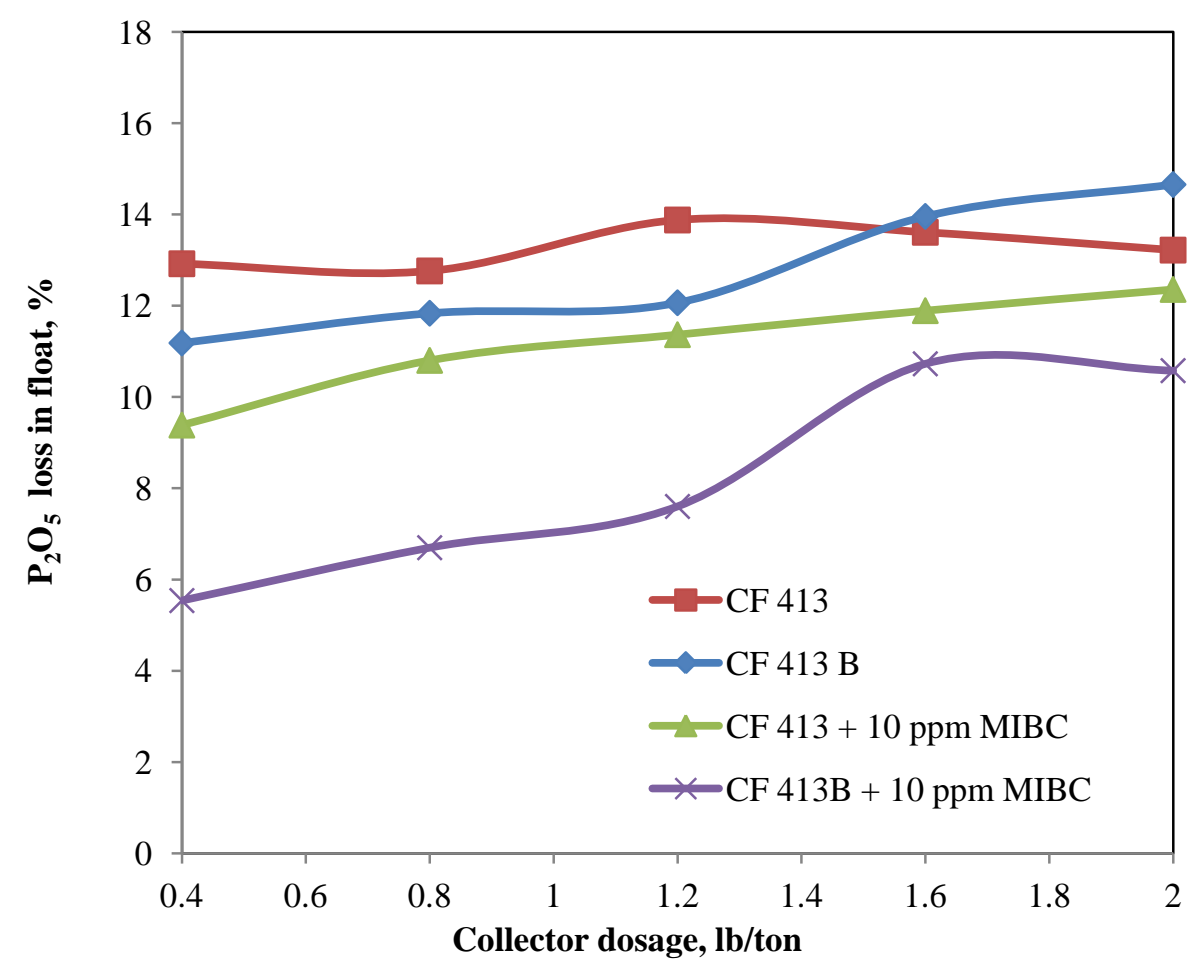

Figure 6- 7 Effect of selected surfactants on the $\mathrm{P}_{2} \mathrm{O}_{5}$ loss in the float using different collector with and without surfactant.

Figure 6-8 shows the effect of different collector and selected surfactant on the $\mathrm{MgO}$ grade in the dolomite flotation sink. It can be seen from the curves that $\mathrm{MgO}$ grade decreases with increasing the collector dosage. At collector dosage less than $0.8 \mathrm{lb} / \mathrm{ton}$, the lowest grade of $\mathrm{MgO}$ in the tailings is obtained by using the mixture of CF413 and MIBC. As the collector dosage keeps increasing from 0.8 to $1.6 \mathrm{lb} /$ ton, the $\mathrm{MgO}$ grade in the tailings decreases significantly and reduces to the lowest grade of $\mathrm{MgO}$ by using the mixture of CF413B and MIBC. When the collector dosage is higher than $1.6 \mathrm{lb} /$ ton, all the curves level off. It implies that there is no significant effect on $\mathrm{MgO}$ grade by further increasing the collector doage above this dosage. 


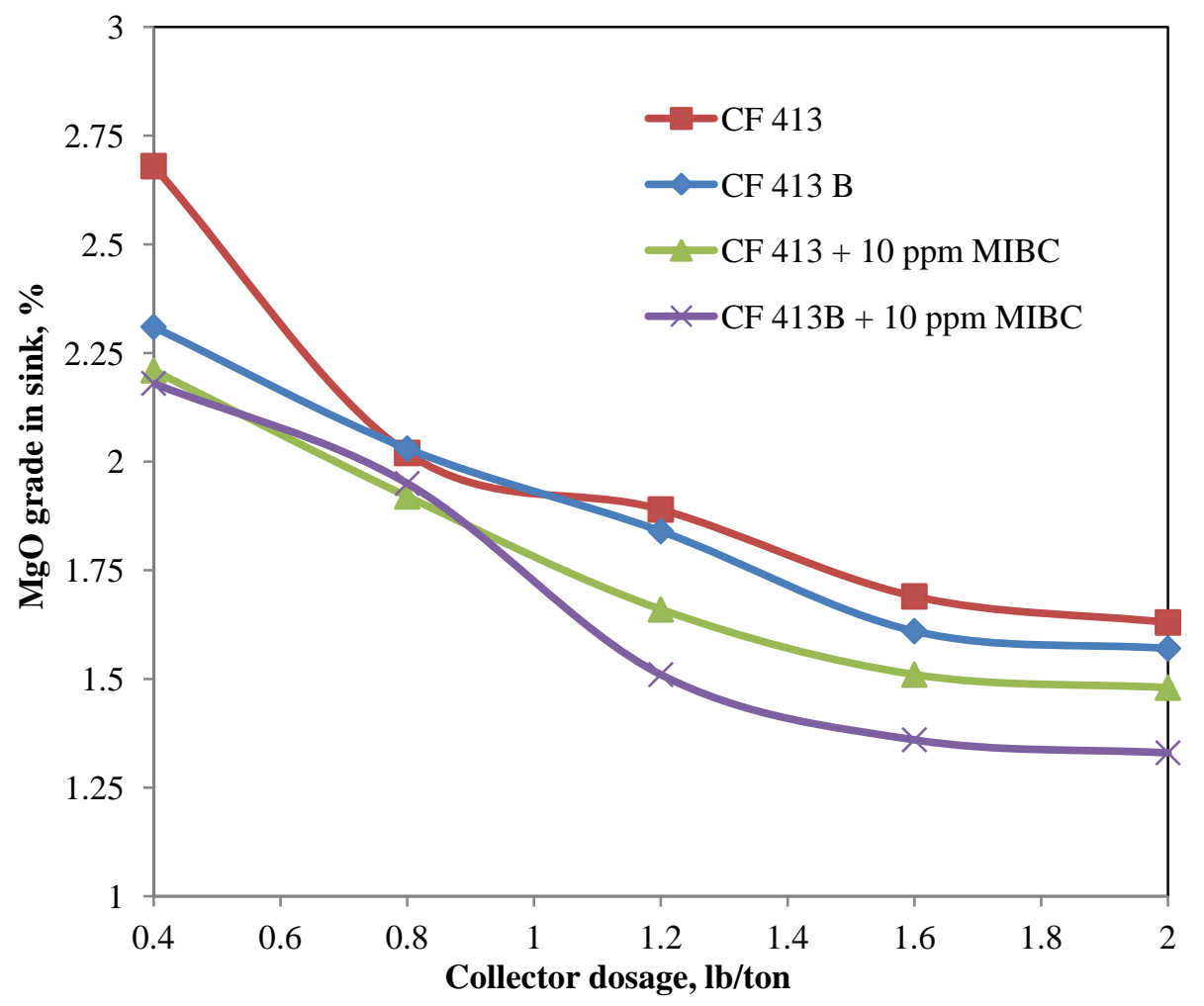

Figure 6- 8 Effect of selected surfactants on the $\mathrm{MgO}$ grade in the sink using different collector with and without surfactant.

Figure 6-9 shows the effect of different collector and selected surfactant on the $\mathrm{MgO}$ recovery in the dolomite flotation sink. There is a general trend that $\mathrm{MgO}$ recovery in the sink decreases with increasing the collector dosage for all the collectors with or without MIBC. As the collector dosage keeps increasing, the $\mathrm{MgO}$ recovery in the tailings decreases significantly and reduces to the lowest recovery of $\mathrm{MgO}$ when the mixture of CF413B and MIBC is used. It can be seen from the figure that the significance of the collector with or without MIBC in improving dolomite flotation is in the order as follows: Mixture of CF413B and MIBC > Mixture of CF413 and MIBC > CF413 > CF413B. 


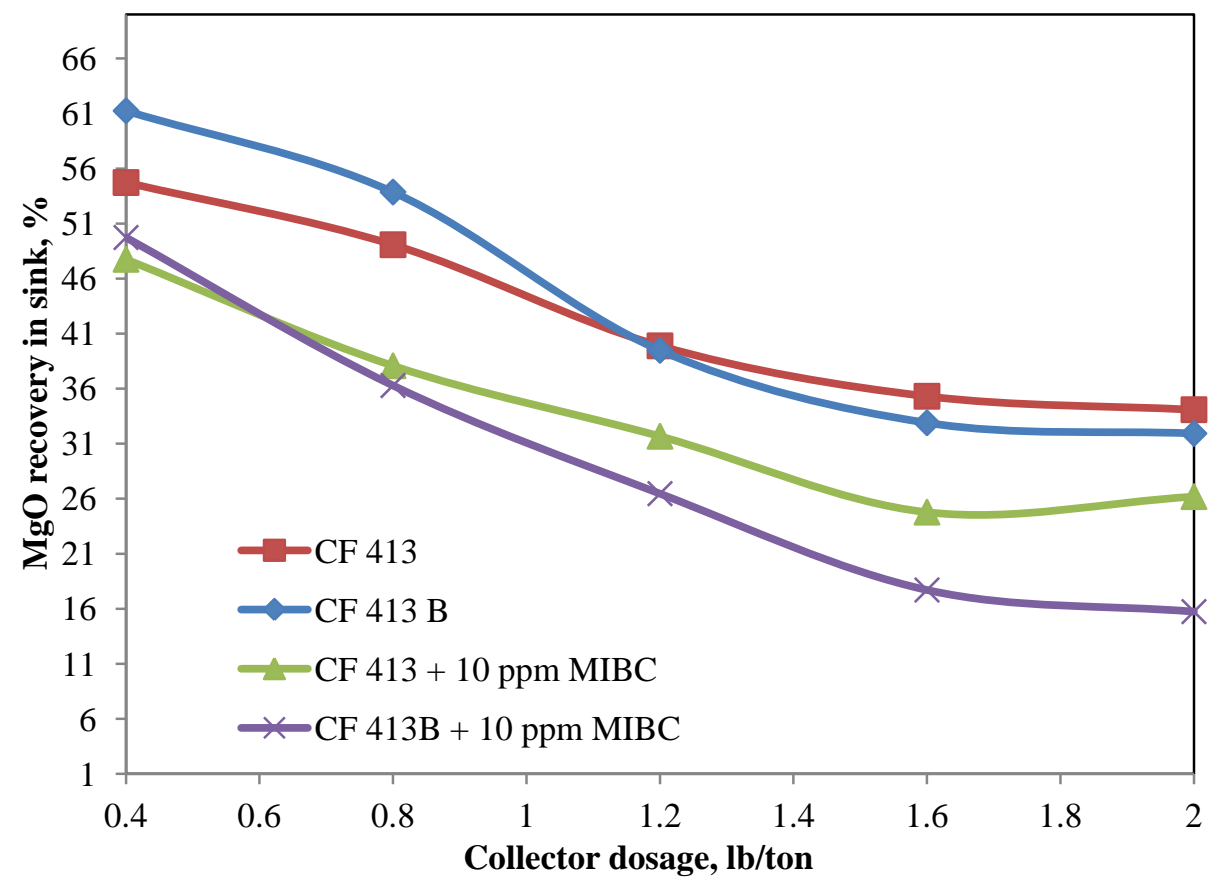

Figure 6- 9 Effect of selected surfactants on the $\mathrm{MgO}$ recovery in the sink using different collector with and without surfactant.

\subsection{Design of Experiment and Statistical Analysis Method}

\subsubsection{Seven-factor two-level fractional factorial experimental design}

The operation parameters for pico-nanbubble column flotation being tested include $\mathrm{pH}$, collector dosage, frother dosage, feed rate, feed solid percentage, air flow rate and wash water flow rate. The experiment designs method is described in section 4.3.8. The main factors are evaluated and tested for significance as shown in Table 6-1. The main effects of collector dosage, frother dosage, feed rate, solids concentration and $\mathrm{pH}$ on SIp index are more significant than gas flow rate and superficial wash water rate, which is similar to previous findings. The orders of main effects are:

Collector dosage $>$ Frother dosage $>\mathrm{pH}>$ Feed solids concentration $>$ Feed rate $>$ Gas flow rate $>$ Superficial wash water rate. 
Table 6- 1 Estimated coefficients, t-ratios and p-values.

\begin{tabular}{|c|c|c|c|}
\hline \multirow{2}{*}{ Term } & \multicolumn{3}{|c|}{ SIp model } \\
\cline { 2 - 4 } & Estimate & $\begin{array}{c}\text { Pseudo } \\
\text { t-Ratio }\end{array}$ & $\begin{array}{c}\text { Pseudo } \\
\text { p-Value }\end{array}$ \\
\hline Intercept & 63.935 & - & - \\
\hline A & 3.825 & 5.02 & $0.0270^{*}$ \\
\hline B & 2.39 & 3.14 & 0.0723 \\
\hline C & 0.5075 & 0.67 & 0.5649 \\
\hline D & -0.9375 & -1.23 & 0.3277 \\
\hline E & -3.9975 & -5.25 & $0.0245^{*}$ \\
\hline F & -0.3 & -0.39 & 0.7267 \\
\hline G & -0.1425 & -0.19 & 0.8666 \\
\hline
\end{tabular}

Note: * means significant factors.

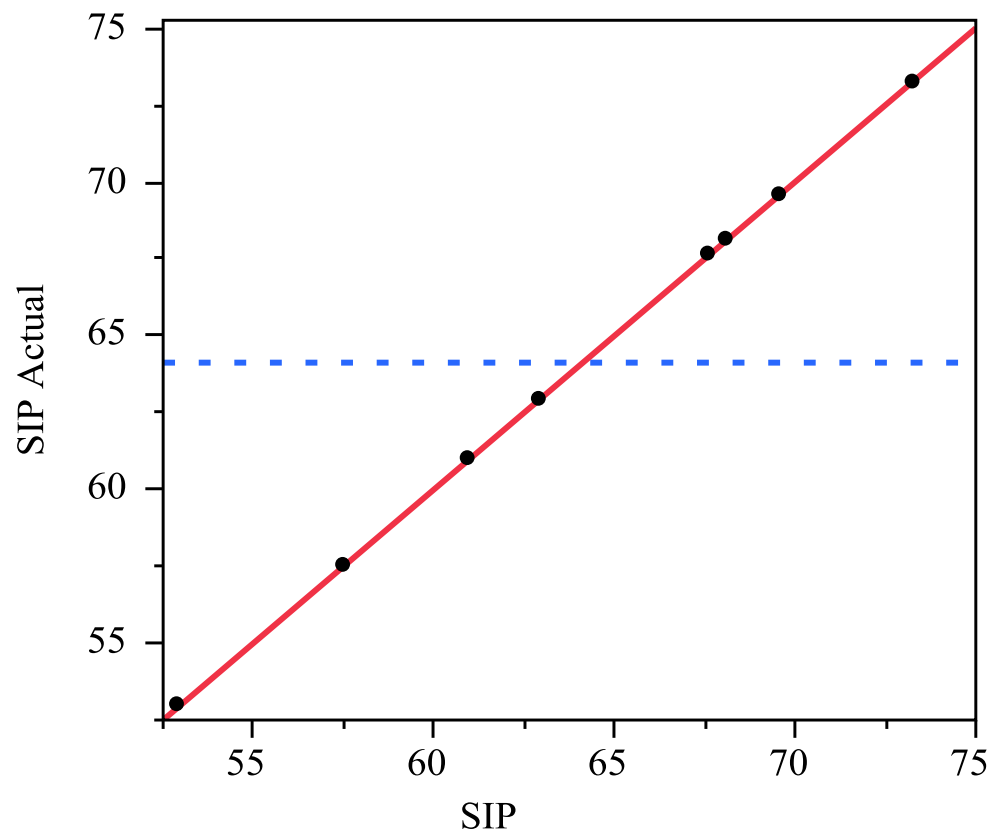

Figure 6- 10 Comparison of the observed responses and predicted responses.

Based on the statistical analysis results, the reduced model in terms of the factor levels is:

SIp Index $(\%)=63.935 \pm 3.825 \times \mathrm{A} \pm 2.39 \times \mathrm{B} \pm 0.5075 \times \mathrm{C} \pm(-0.9375) \times \mathrm{D} \pm(-3.9975)$

$$
\times \mathrm{E} \pm(-0.3) \times \mathrm{F} \pm(-0.1425) \times \mathrm{G}
$$


The comparison of the observed responses and predicted responses with reduced model are shown in Figure 6-10. It shows that the model for SIp index can adequately describe the effects of operating parameter on the response variables.

Figure 6-11 depicts the effect of $\mathrm{pH}$ and collector dosages with SIp index as separation responses. The response surface suggests that the effect of collector dosage is more significant than $\mathrm{pH}$ and the area of the highest SIp index value was at the low level of collector dosage and $\mathrm{pH}$ value. The SIp index decreased by about $6 \%$ as the collector dosage increased from 1.5 to $2.0 \mathrm{lb} / \mathrm{ton}$. Also, the selectivity index decreased sharply with the increase of $\mathrm{pH}$ value.

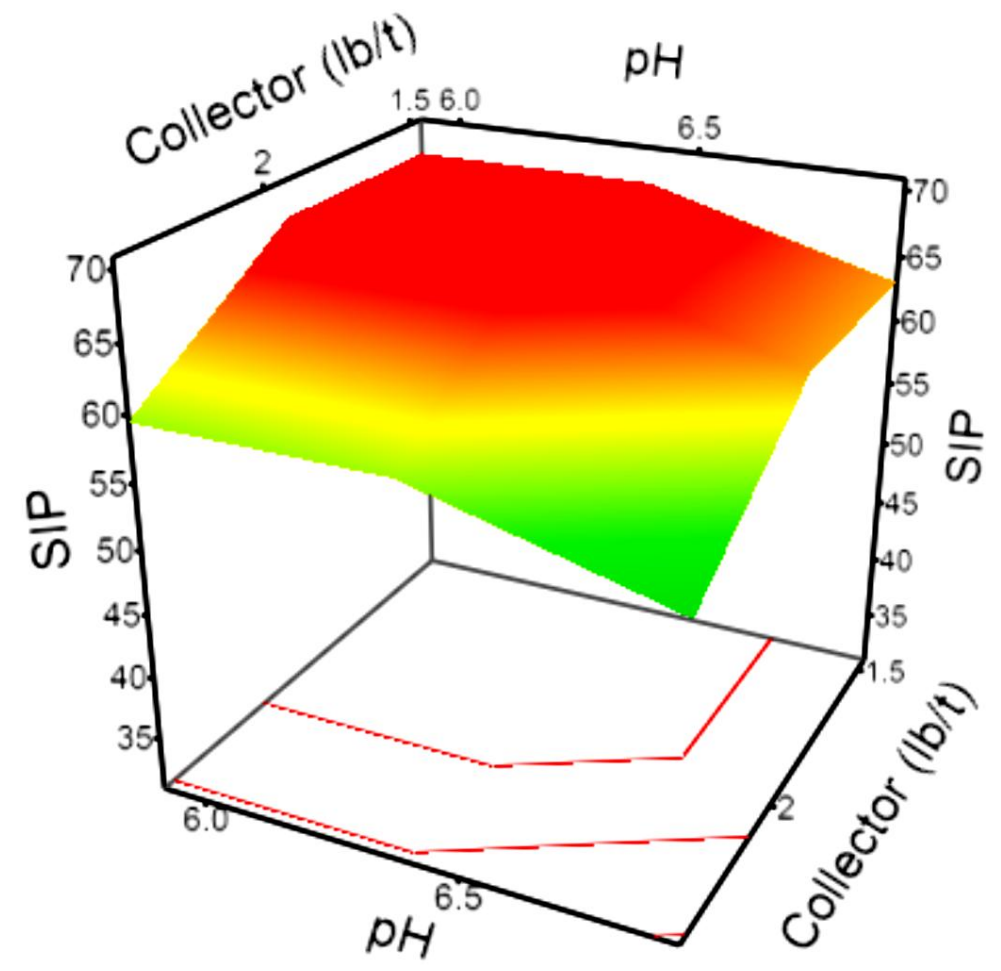

Figure 6- 11 Effect of $\mathrm{pH}$ and collector dosages on SIp index.

Figure 6-12 depicts the effect of feed rate and collector dosages with SIp index as separation responses. The response surface suggests that the area of the highest SIP index 
was at the low level of feed rate. The SIp index increased by about $2 \%$ as the feed rate decreased from 0.4 to $0.3 \mathrm{~cm} / \mathrm{s}$.

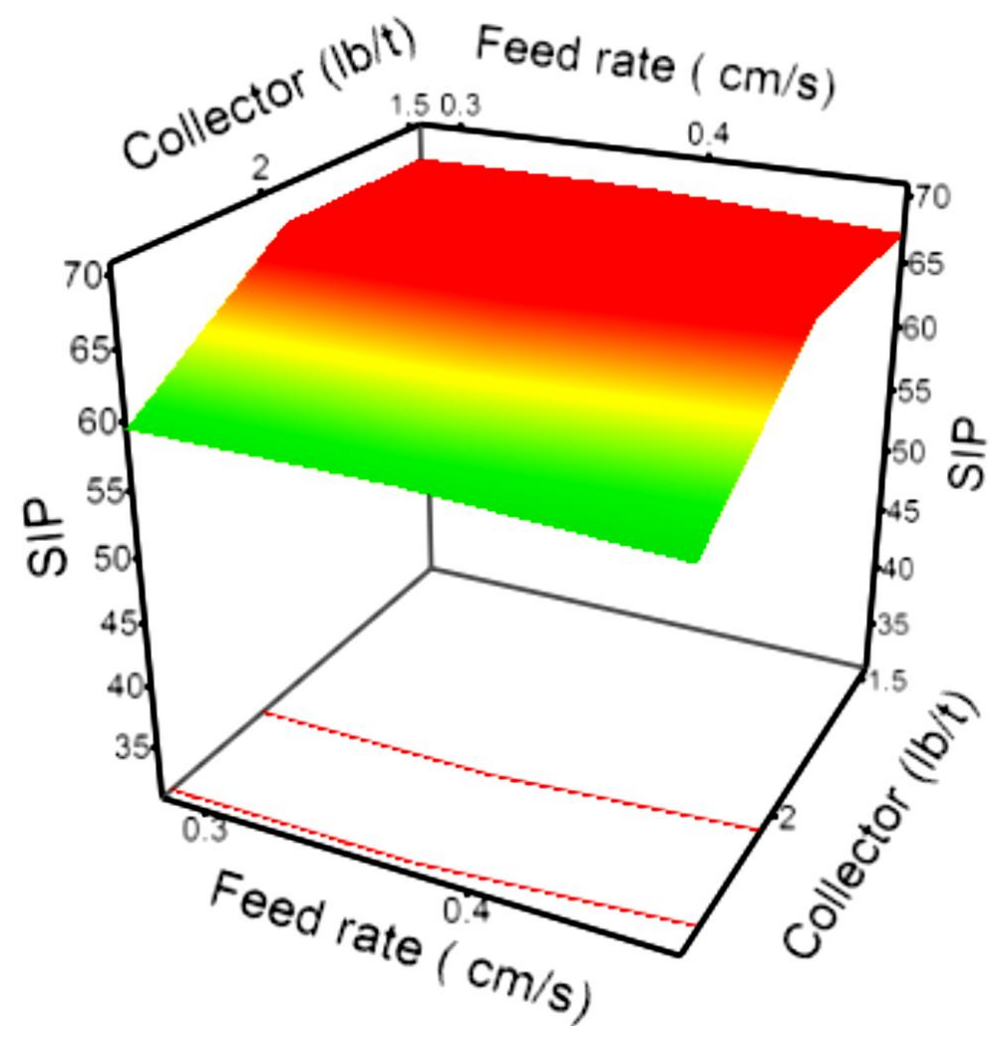

Figure 6- 12 Effect of feed rate and collector dosages on SIp index.

Figure 6-13 depicts the effect of feed solid concentration and collector dosages with SIp index as separation responses. The response surface depicts that the area of the highest SIp index was obtained at the high level of solids concentration. The SIp index increased by about $5 \%$ as the solids concentration increased from 15 to $20 \%$ at high level of collector dosage, and the SIp index increasement reduced to about $2 \%$ at low level of collector dosage. However, the SIp index was much higher at low level of collector dosage than which at high level. 


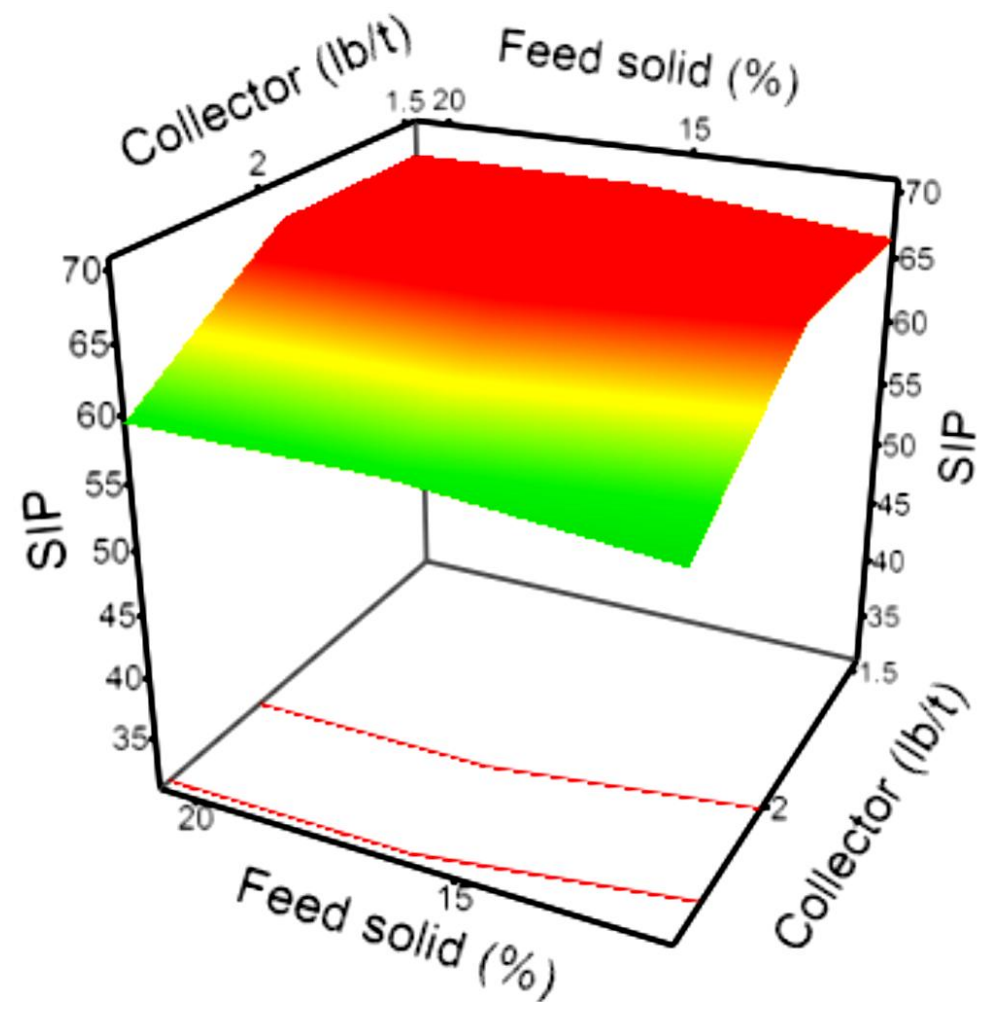

Figure 6- 13 Effect of feed solid concentration and collector dosages on SIp index.

Figure 6-14 depicts the effect of frother dosages and collector dosages with SIp index as separation responses. The SIp index increased by about $7 \%$ as the frother dosages increased from 4 to $7 \mathrm{ppm}$. It is not surprising to find that the best separation selectivity index is observed at high level of frother dosage. In order to maintain the pico-nano bubbles in the solution, certain amount of frother must be applied. According to the results, $4 \mathrm{ppm}$ of frother is not enough to reduce the surface tension and keep the generated pico-nano buble in the solution. So, for the next step of design of experiment, the frother dosages should be increased. 


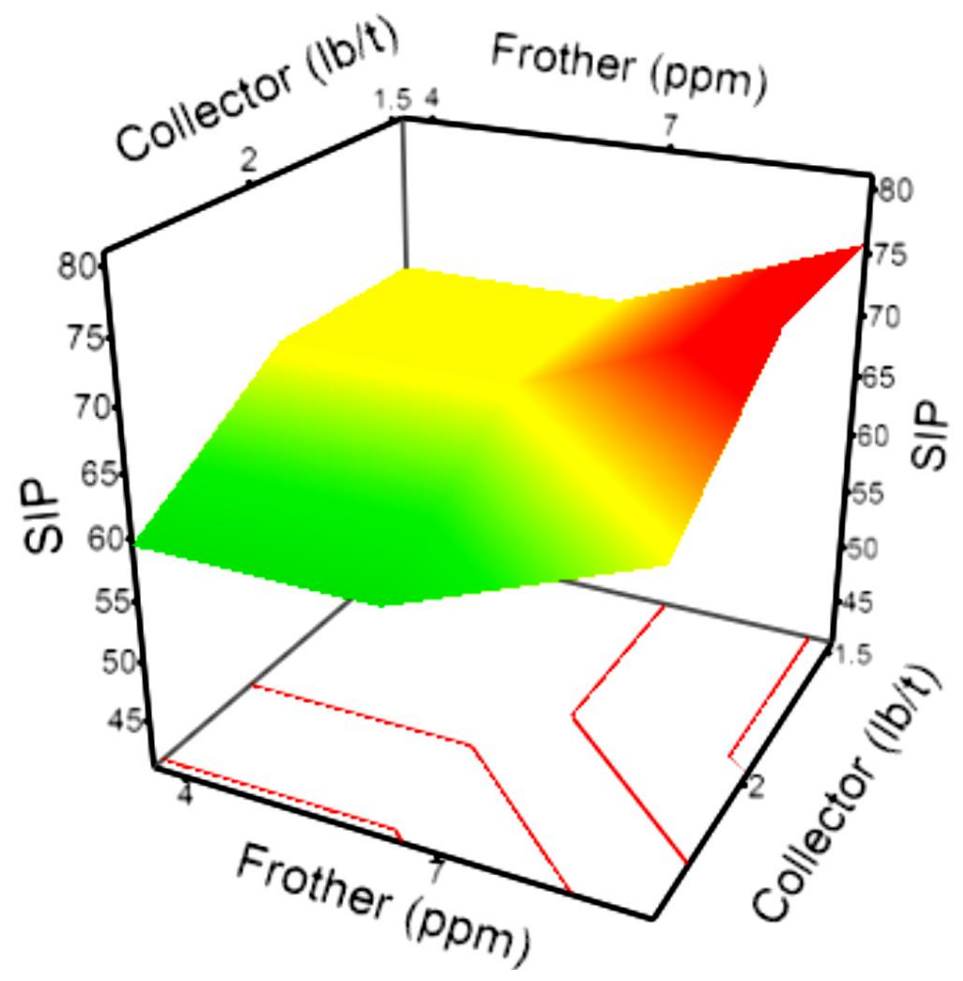

Figure 6- 14 Effect of frother dosages and collector dosages on SIp index.

Figure 6-15 and 6-16 depict the effect of air flow rate, wash water rate and collector dosages with SIp index as separation responses. The response surface suggests that The gas flow rate and wash water rate had no significant effects on the separation selectivity (SIp ) index. The separation selectivity index barely changes according to wash water rate and air flow rate. So, for the next step of design of experiment, these two factors can be eliminated and keep them constant during the test. 


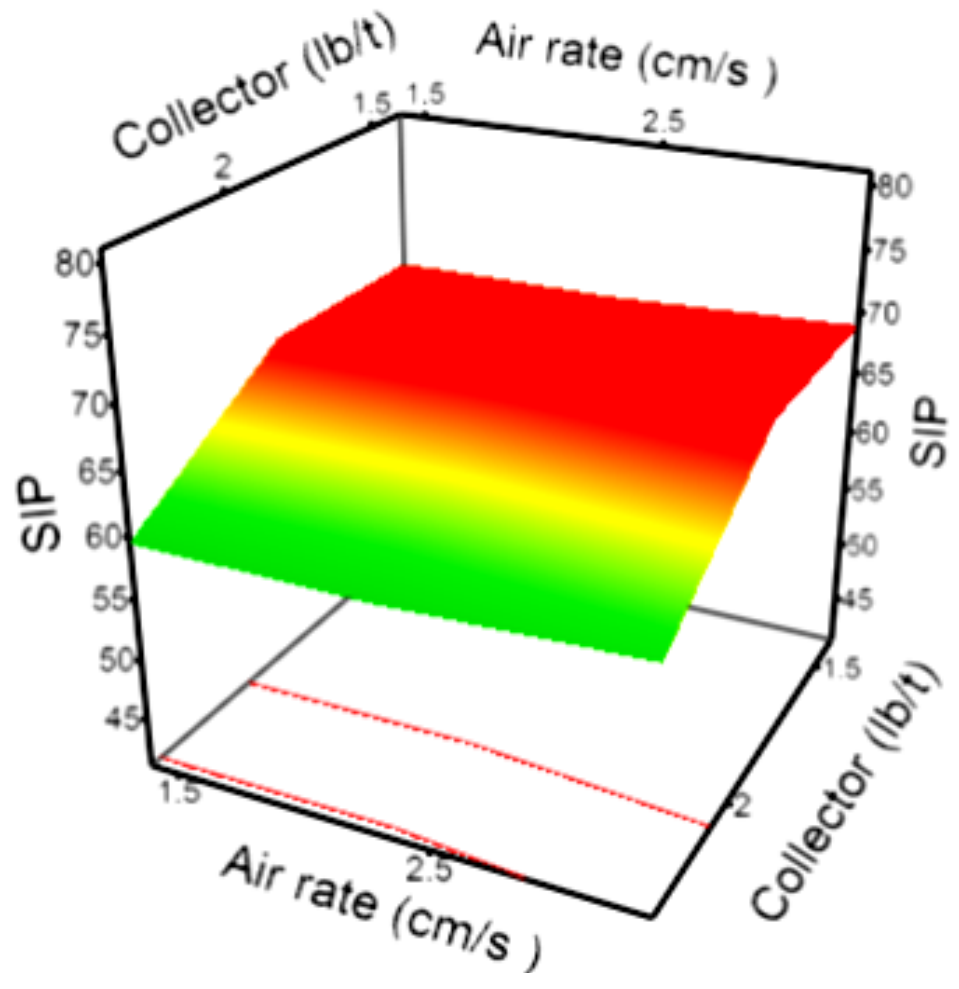

Figure 6- 15 Effect of gas flow rate and collector dosages on SIp index.

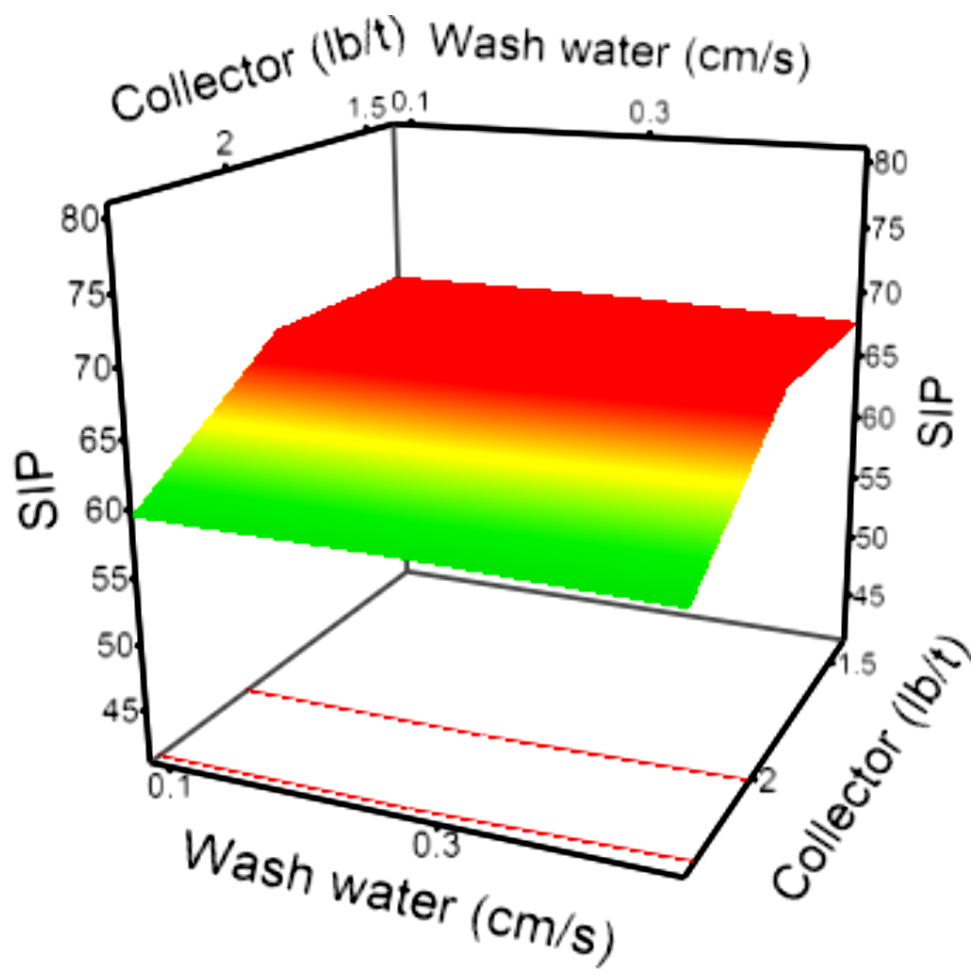

Figure 6- 16 Effect of wash water flow rate and collector dosages on SIp index. 
The significance of each factor can also be calculated by multiplying each column of plus and minus signs in the original experimental design shown in Table 4-10, adding them up and then dividing by [( No. of runs)/2]. For example, the significance of collector dosage, $\mathrm{E}_{\mathrm{c}}$, in fractional factorial design can be calculated as follows:

$$
\begin{aligned}
\mathrm{E}_{\mathrm{c}} & =\left(\mathrm{SI}_{1}-\mathrm{SI}_{2}-\mathrm{SI}_{3}+\mathrm{SI}_{4}+\mathrm{SI}_{5}-\mathrm{SI}_{6}-\mathrm{SI}_{7}+\mathrm{SI}_{8}\right) /(8 / 2) \\
& =(68.1-69.38-67.44+52.85+61.99-72.26-61.96+57.5) / 4 \\
& =-7.65
\end{aligned}
$$

Table 6-2 shows the significance of the each factor using SIp index as response surface in factorial factor design. Due to minimum runs were conducted, only the main effects can be estimated. It can be seen from table 6-2 that five factors are more significant because the estimates effect values are relatively large.

Table 6- 2 Main Effects of the Factors for Factorial Design.

\begin{tabular}{|l|c|}
\hline \multicolumn{1}{|c|}{ Factors } & Effect \\
\hline Collector dosage & -7.65 \\
\hline $\mathrm{pH}$ & -4.78 \\
\hline Feed rate & -1.02 \\
\hline Feed solid concentration & 1.87 \\
\hline Frother dosage & 7.99 \\
\hline Air flow rate & 0.60 \\
\hline Wash water rate & 0.29 \\
\hline
\end{tabular}

The significance of the main effects are as follows:

(1) Effect of collector dosage: The low level of collector dosage yields an effect of SIp value 7.65 higher than the high level of collector dosage. This effect is relatively larger than others. It means collector dosage should be decreased. 
(2) Effect of $\mathrm{pH}$ : The low level of $\mathrm{pH}$ value yields an effect of SIp value 4.78 higher than the high level of $\mathrm{pH}$ value. It indicates that the $\mathrm{pH}$ value should be decreased for next set of experiment.

(3) Effect of feed rate: $0.3 \mathrm{~cm} / \mathrm{s}$ feed rate yields an effect of SIp value 1.02 higher than a feed rate of $0.4 \mathrm{~cm} / \mathrm{s}$. It shows that the feed rate should be decreased.

(4) Effect of feed solid concentration: 20\% feed solid concentration yields an effect of SIp value 1.87 higher than $15 \%$ feed solid concentration. It indicates that the feed solid concentration should be increased further.

(5) Effect of frother dosage: 7 ppm frother dosage yields an effect of SIp value 7.99 higher than the frother dosage of $4 \mathrm{ppm}$. This effect is the largest relatively to others. It means that the frother dosage should be further increased for next set of experiment.

(6) Effect of air flow rate: $2.5 \mathrm{~cm} / \mathrm{s}$ air flow rate yields an effect of SIp value similar to that of $1.5 \mathrm{~cm} / \mathrm{s}$ air flow rate. There is no significant effect when the air flow rate is changing from $1.5 \mathrm{~cm} / \mathrm{s}$ to $2.5 \mathrm{~cm} / \mathrm{s}$.

(7) Effect of wash water rate: $0.1 \mathrm{~cm} / \mathrm{s}$ wash water rate yields an effect of SIp value close to that of $0.3 \mathrm{~cm} / \mathrm{s}$ wash water rate. There is no much difference when the wash water rate changed from $0.1 \mathrm{~cm} / \mathrm{s}$ to $0.3 \mathrm{~cm} / \mathrm{s}$.

The analysis results from the graphical method and the calculation results are almost the same. Based on the first stage fractional factorial design, step-two experiment was conducted by selecting the most significant factors, including collector dosage, frother dosage, $\mathrm{pH}$ value, feed solid concentration and feed rate. 


\subsubsection{Five-factor two-level fractional factorial experimental design}

The statistic analysis data in Table 6-3 shows that statistically significant factors include $\mathrm{pH}$, collector dosage, frother dosage, feed solids concentration and feed rate. The data clearly shows the importance of $\mathrm{pH}$ in determining SIp, as indicated by the Probability > $|t|$ values less than 0.0378 when assessing the estimated coefficient. The orders of main effects are:

$\mathrm{pH}>$ Collector dosage $>$ Frother dosage $>$ Feed rate $>$ Feed solids concentration.

Table 6- 3 Estimated coefficients, t-ratios and p-values.

\begin{tabular}{|c|c|c|c|}
\hline \multirow{2}{*}{ Term } & \multicolumn{3}{|c|}{ SIp model } \\
\cline { 2 - 4 } & Estimate & t Ratio & Prob $>|\mathrm{t}|$ \\
\hline Intercept & 68.815 & 177.49 & $<0.0001^{*}$ \\
\hline A & 1.9375 & 5.00 & $0.0378^{*}$ \\
\hline B & -1.4925 & -3.85 & 0.0613 \\
\hline C & -0.7575 & -1.95 & 0.1899 \\
\hline D & 0.255 & 0.66 & 0.5783 \\
\hline E & -0.9325 & -2.41 & 0.1380 \\
\hline
\end{tabular}

Note: * means significant factors.

Table 6-4 shows the analysis of variance (ANOVA). DF is the degree of freedom, SS is the sum of squares and MS is the mean square. The F-statistic also known as the F-ratio, is a measure for the strength of the regression. The F-ratios are calculated by comparing the model mean square (MSR) with the error mean square (MSE), F = MSR / MSE = ( SSR /1)/(s2e). Here MSR is the predicted mean-suqared-anomaly and MSE is the meansquared-error. A strong relationship between responses and independent parameters gives a high F-ratio.

Table 6- 4 ANOVA table with SIp index as responses.

\begin{tabular}{|c|c|c|c|c|}
\hline Source & DF & SS & MS & F- Ratio \\
\hline Model & 5 & 59.9188 & 11.9838 & 9.9657 \\
\hline Error & 2 & 2.4050 & 1.2025 & Prob. $>$ F \\
\hline C. Total & 7 & 62.3238 & --- & 0.0937 \\
\hline
\end{tabular}


Based on the statistical analysis results, the reduced model in terms of the factor levels is: SIp index $(\%)=68.815 \pm 1.9375 \times \mathrm{A} \pm-1.4925) \times \mathrm{B} \pm(-0.7575) \times \mathrm{C} \pm \mathrm{D} \times 0.255 \pm \mathrm{E} \times$

The coefficient of determination $\left(\mathrm{R}^{2}\right)$ is other measures for expressing the goodness-of-fit of the regression model. $\mathrm{R}^{2}$ is 1 for a perfect regression and zero for a completely useless fit (no correlation between responses and independent parameters). The comparison of the observed responses and predicted responses are shown in Figure 6-17. The coefficient of determination $\left(\mathrm{R}^{2}\right)$ for this test is 0.96 , which shows that the model for SIp index can adequately describe the effects of operating parameter on the response variables.

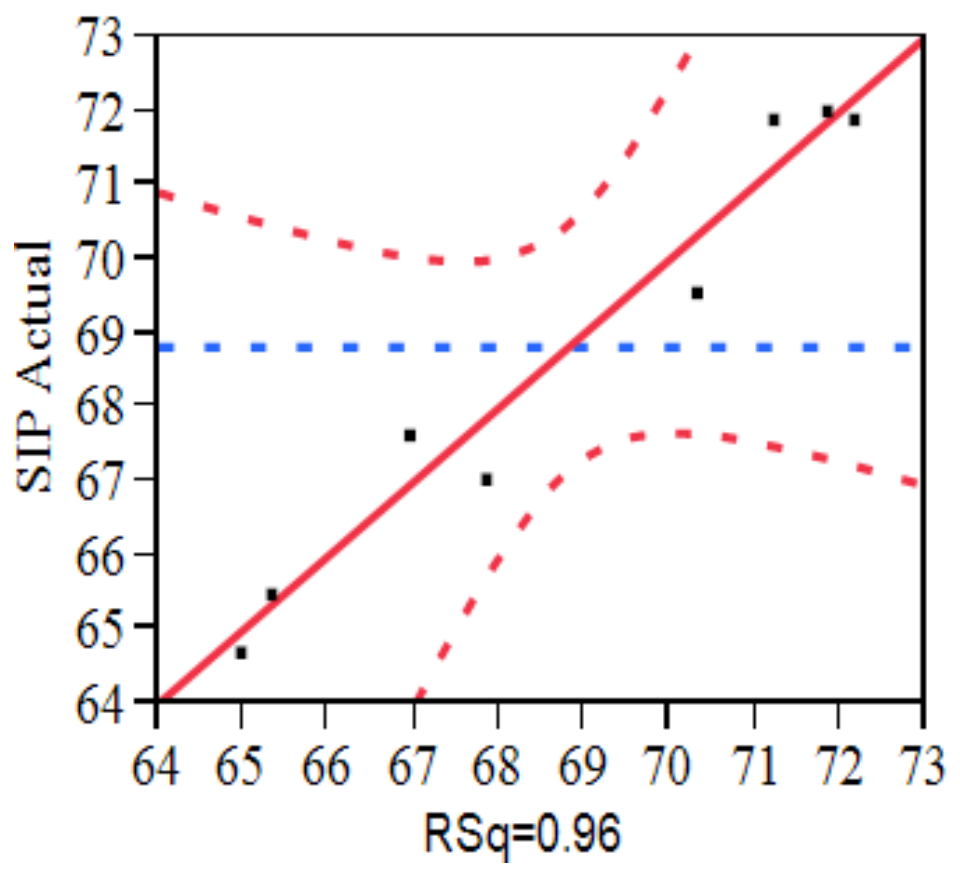

Figure 6- 17 Comparison of the observed responses and predicted responses.

Figure 6-18 depicts the effect of $\mathrm{pH}$ and feed rate with SIp index as separation responses. The response surface suggests that the effect of $\mathrm{pH}$ is more significant than feed rate and the area of the highest SIp index value was obtained at the high level of feed rate and low 
level of $\mathrm{pH}$ value. The SIp index decreased by about 3.5\% as the $\mathrm{pH}$ increased from 5.5 to 6.0. However, the selectivity index increased with the increase of feed rate value.

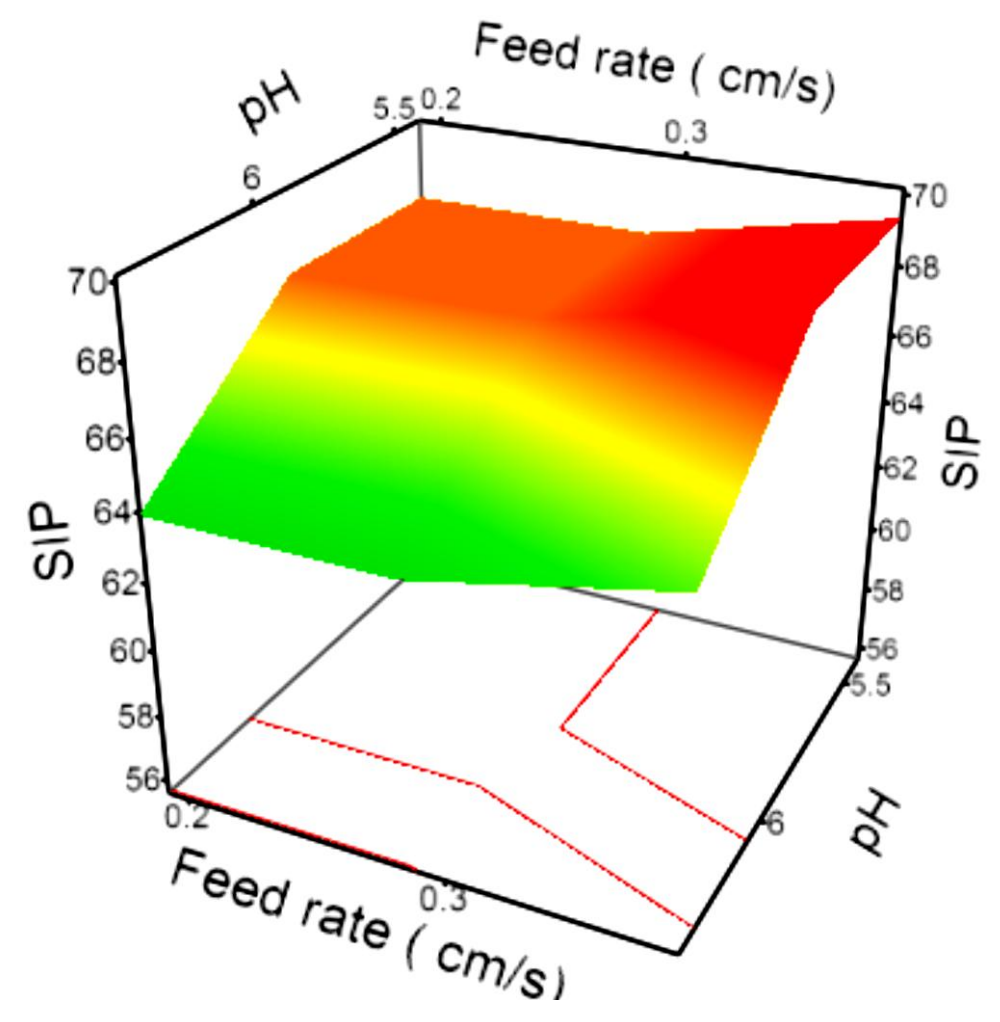

Figure 6- 18 Effect of $\mathrm{pH}$ and feed rate on SIp index.

Figure 6-19 depicts the effect of frother dosages and $\mathrm{pH}$ with SIp index as separation responses. the area of the highest SIp index value was achieved at the low level of frother dosage and low level of $\mathrm{pH}$ value. The SIp index decreased by about $1.5 \%$ as the frother dosages increased from 7 to $10 \mathrm{ppm}$. This is because the overdose of the frother deteriorates the selectivity of the pico-nano bubbles flotation by generating too many bubbles in the flotation system. In order to maintain the selectivity of pico-nano bubble in the flotation system, low level of frother dosage should be used. 


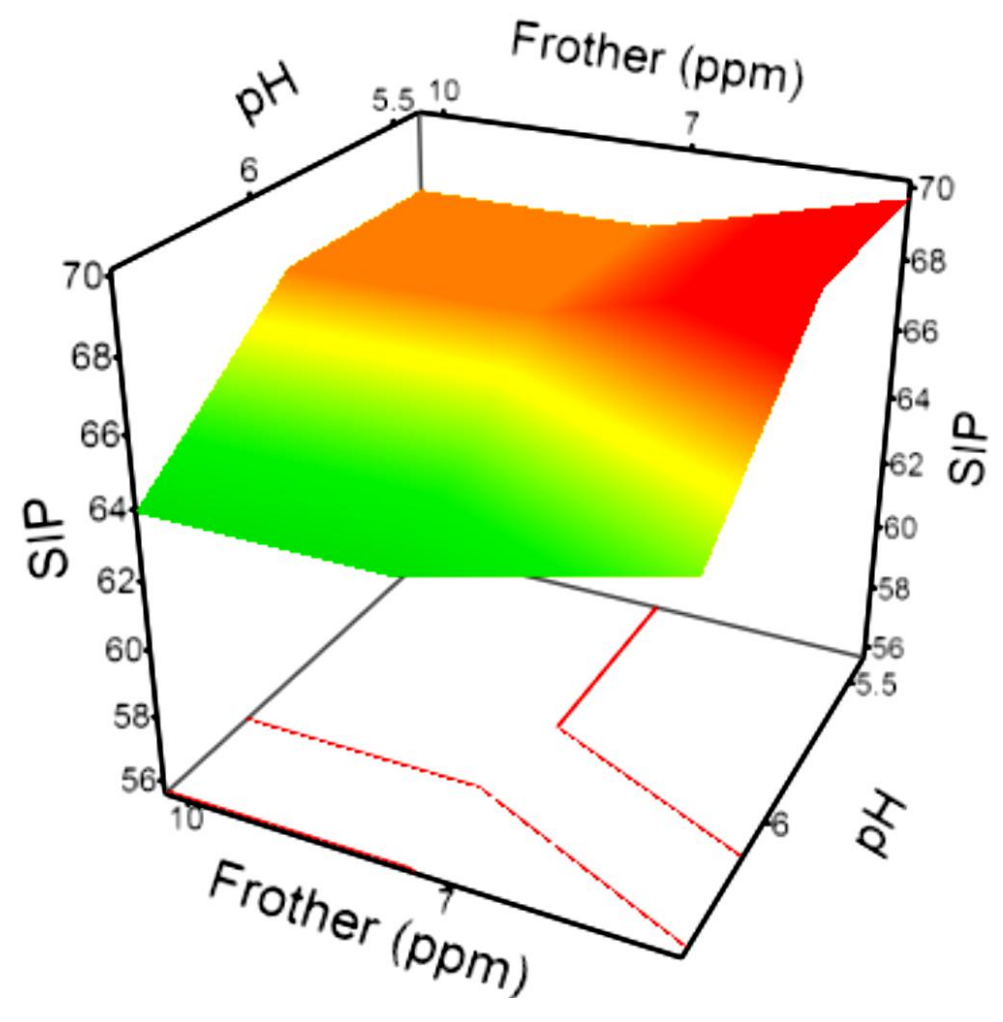

Figure 6- 19 Effect of frother dosage and pH on SIp index.

Figure 6-20 depicts the effect of collector dosage and $\mathrm{pH}$ with SIp index as separation responses. The response surface depicts that the area of the highest SIp index was obtained at the high level of collector dosage. The SIp index increased by about $4.5 \%$ as the collector dosage increased from 1 to $1.5 \mathrm{lb} /$ ton at low level of $\mathrm{pH}$ value, and the SIp index increasement reduced to about $3 \%$ at high level of $\mathrm{pH}$ value. However, the SIp index was much higher at low level of $\mathrm{pH}$ value than which at high level. 


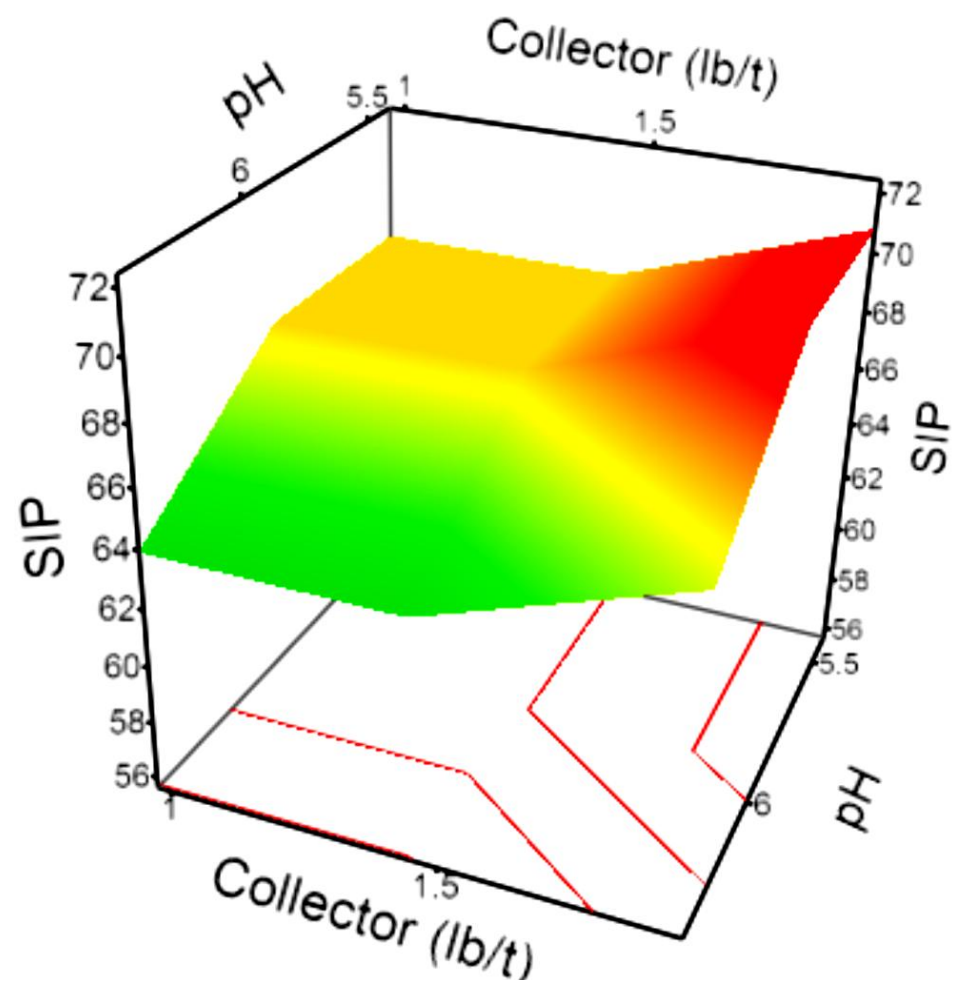

Figure 6- 20 Effect of collector dosages and $\mathrm{pH}$ on SIp index.

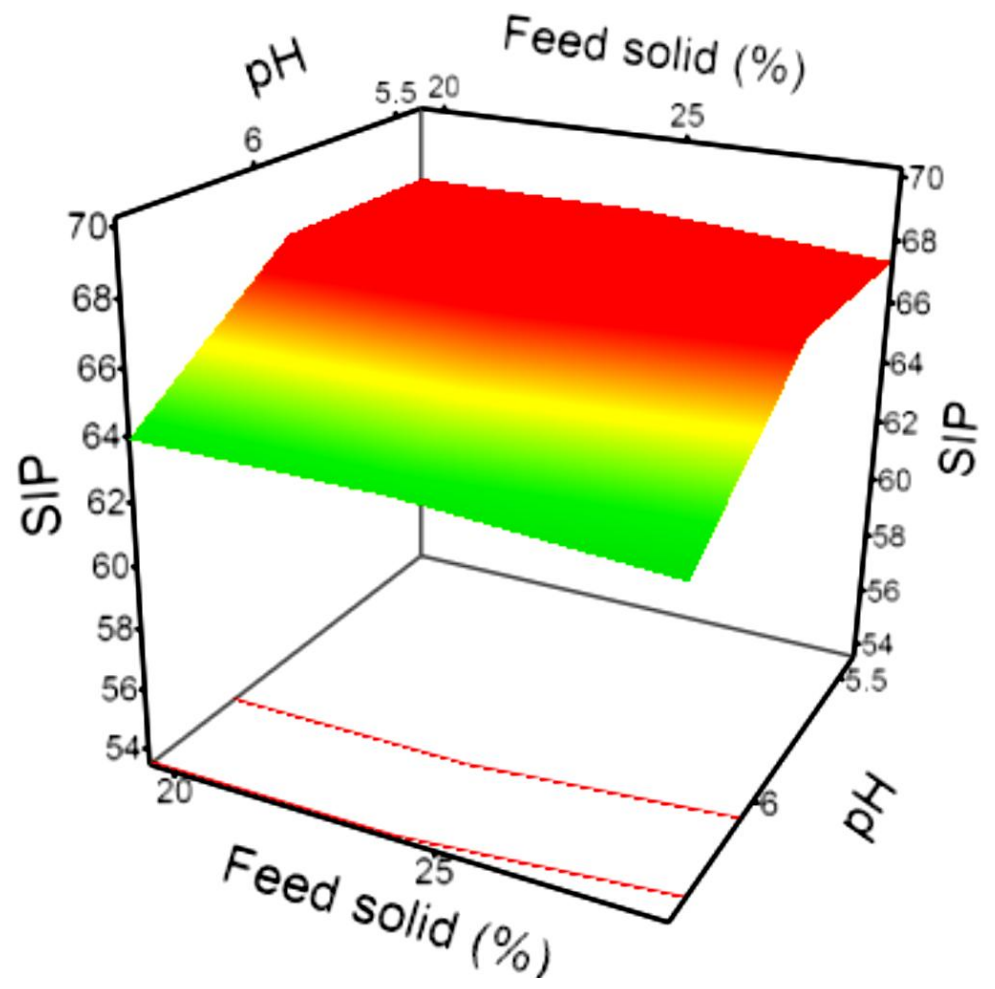

Figure 6- 21 Effect of feed solid concentration and pH on SIp index. 
Figure 6-21 depicts the effect of feed solids concentration and $\mathrm{pH}$ value with SIp index as separation responses. The response surface suggests that the feed solids concentration had no significant effects on the separation selectivity (SIp) index. The separation selectivity index (SIp) barely changes when the feed solids concentration is changing.

Table 6-5 shows the significance of the each factor using SIp index as response surface in factorial factor design. The results of main effects from step-two are much smaller than those of step-one experiment. It can be seen from table 6-5 that two factors, $\mathrm{pH}$ value and collector dosage, are more significant because the estimates effect values are relatively larger.

Table 6- 5 Main Effects of the Factors for Factorial Design.

\begin{tabular}{|l|c|}
\hline \multicolumn{1}{|c|}{ Factors } & Effect \\
\hline Collector dosage & 2.99 \\
\hline $\mathrm{pH}$ & -3.87 \\
\hline Feed rate & 1.52 \\
\hline Feed solid concentration & -0.51 \\
\hline Frother dosage & -1.87 \\
\hline
\end{tabular}

The significance of the main effects are as follows:

(1) Effect of collector dosage: The high level of collector dosage yields an effect of SIp value 2.99 higher than the low level of collector dosage. This effect is relatively larger than others. It means collector dosage should be increased.

(2) Effect of $\mathrm{pH}$ : The low level of $\mathrm{pH}$ value yields an effect of SIp value 3.87 higher than the high level of $\mathrm{pH}$ value. This effect is the largest relatively to others. It indicates that the $\mathrm{pH}$ value should be decreased for next set of experiment. 
(3) Effect of feed rate: $0.3 \mathrm{~cm} / \mathrm{s}$ feed rate yields an effect of SIp value 1.52 higher than a feed rate of $0.2 \mathrm{~cm} / \mathrm{s}$.

(4) Effect of feed solid concentration: $20 \%$ feed solid concentration yields an effect of SIp value 0.51 higher than $25 \%$ feed solid concentration. It indicates that the feed solid concentration should be increased further. There is no much difference when the wash water rate changed from $20 \%$ to $25 \%$.

(5) Effect of frother dosage: 7 ppm frother doosage yields an effect of SIp value 7.99 higher than the frother dosage of $10 \mathrm{ppm}$. It means that the frother dosage should be further increased for next set of experiment.

The analysis results from the graphical method and the calculation results are almost the same. Based on the second stage fractional factorial design, the optimum operation conditions could be achieved at high level of collector, within 1 and 2 lb/ton, low level of $\mathrm{pH}$, around 5.5, high level of feed rate, $0.3 \mathrm{~cm} / \mathrm{s}$, low level of feed solid concentration, $20 \%$, and low level of frother dosage, 7 ppm. Besides, the less significant factors of air flow rate should be set at $1.5 \mathrm{~cm} / \mathrm{s}$, and the wash water rate should be set at $0.1 \mathrm{~cm} / \mathrm{s}$.

\subsubsection{Single factor experimental test}

In order to refine the optimum operation conditions, single factor experiments are conducted based on the results from two stages of design of experiment. The factors being tested are $\mathrm{pH}$ and collector dosage, while the other factors are fixed as follows:

Feed rate $0.3 \mathrm{~cm} / \mathrm{s}$, feed solid concentration $20 \%$, frother dosage $7 \mathrm{ppm}$, air flow rate 1.5 $\mathrm{cm} / \mathrm{s}$, and the wash water rate $0.1 \mathrm{~cm} / \mathrm{s}$. 


\subsubsection{Collector dosage effect}

The effect of collector dosage on the combustible material recovery and clean coal ash content is given in Figure 6-22. It can be seen that, the $\mathrm{MgO}$ product quality deteriorated as the collector dosage increased. Figure 6-22 also shows the results of $\mathrm{MgO}$ recovery as a function of collector dosage. The results indicate that the $\mathrm{MgO}$ recovery increases with increasing the collector dosage. It is noted that the $\mathrm{MgO}$ grade in the sink decreases from $1.3 \%$ to $0.94 \%$, and the $\mathrm{MgO}$ recovery in the float increases from $68.26 \%$ to $81.17 \%$, while the collector dosage increases from $1 \mathrm{lb} /$ ton to $1.8 \mathrm{lb} /$ ton. No significantly increasing in $\mathrm{MgO}$ grade and recovery as the collector dosage keeps increasing from 1.8 to 2.0. The optimal collector dosage is found at $1.8 \mathrm{lb} /$ ton, with the optimal $\mathrm{MgO}$ grade and recovery at $0.94 \%$ and $81.17 \%$, respectively.

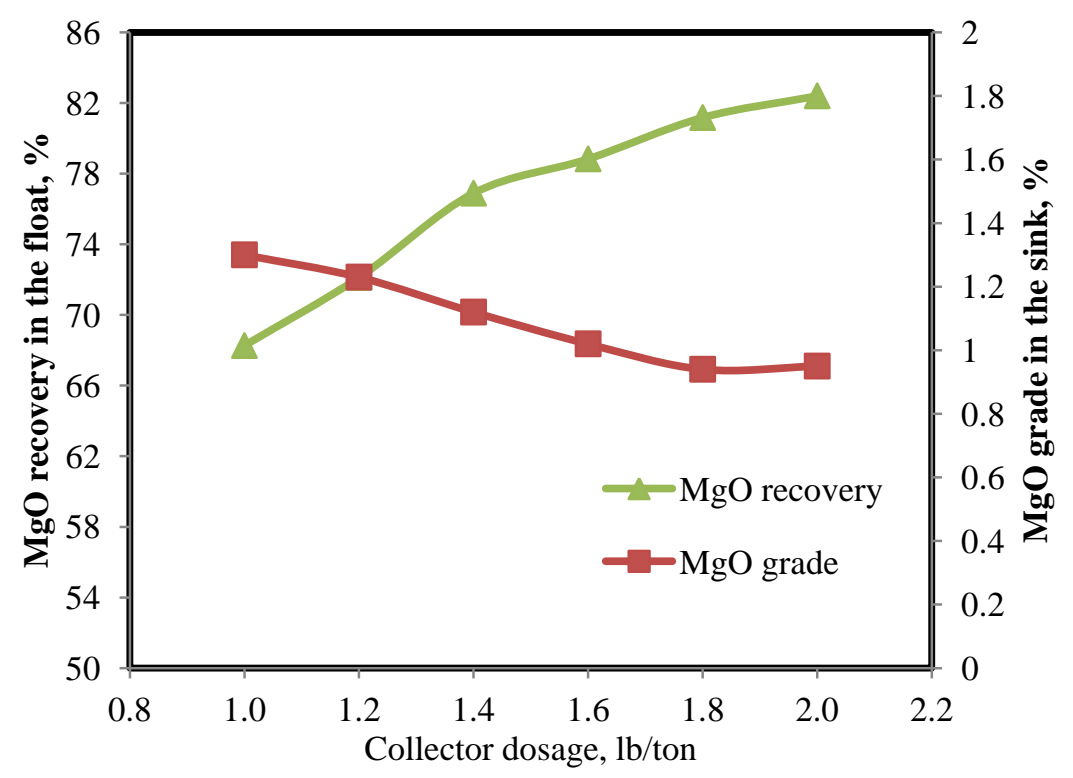

Figure 6- $22 \mathrm{MgO}$ grade in the sink and $\mathrm{MgO}$ recovery in the dolomite flotation float as a function of collector dosage. 
The effects of collector dosage on the $\mathrm{P}_{2} \mathrm{O}_{5}$ grade and recovery in the dolomite flotation sink and the separation selectivity index (SIp) are given in Figure 6-23. Over the tested range of collector dosage range of 1.0 to $2.0 \mathrm{lb} /$ ton, $\mathrm{P}_{2} \mathrm{O}_{5}$ recovery is $89.61 \%$ to $91.80 \%$, $\mathrm{P}_{2} \mathrm{O}_{5}$ grade is $28.82 \%$ to $29.89 \%$ and separation selectivity index content is 66.06 to 74.02 . The $\mathrm{P}_{2} \mathrm{O}_{5}$ grade and separation selectivity index increase as the collector dosage increases from $1.0 \mathrm{lb} /$ ton to $1.8 \mathrm{lb} /$ ton. The SIp keeps almost level during this collector dosage range. As the collector dosage keeps increasing from $1.8 \mathrm{lb} /$ ton to $2.0 \mathrm{lb} / \mathrm{ton}$, the $\mathrm{P}_{2} \mathrm{O}_{5}$ recovery and SIp decreases while the $\mathrm{P}_{2} \mathrm{O}_{5}$ grade keeps unchanged. In order to maximize the separation selectivity index, $\mathrm{P}_{2} \mathrm{O}_{5}$ grade and $\mathrm{P}_{2} \mathrm{O}_{5}$ recovery, the optimal collector dosage has been found at $1.8 \mathrm{lb} /$ ton, with $\mathrm{SIp}$ of $74.02 \%, \mathrm{P}_{2} \mathrm{O}_{5}$ grade of $29.89 \%$ and $\mathrm{P}_{2} \mathrm{O}_{5}$ recovery of $91.20 \%$.

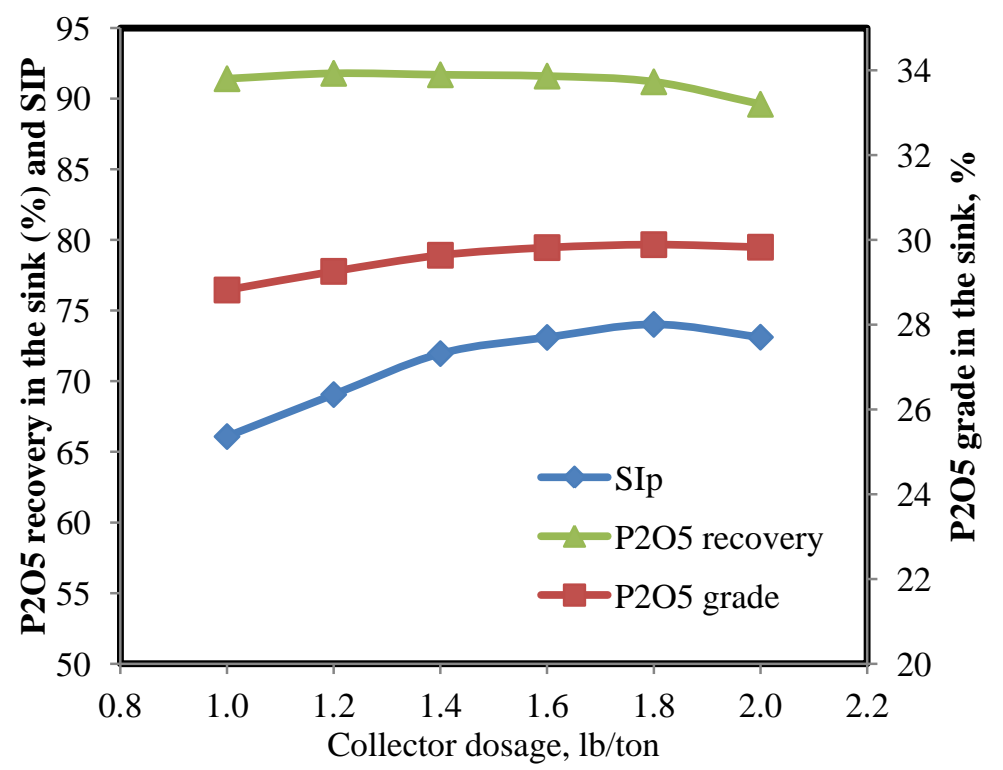

Figure 6- $23 \mathrm{P}_{2} \mathrm{O}_{5}$ grade and recovery in the dolomite flotation sink and the separation selectivity index as a function of collector dosage. 


\subsubsection{2 pH effect}

The optimum $\mathrm{pH}$ for dolomite flotation should be around 5.5 according to previous experiments, which is similar to the findings reported by Somasundaran et al. (1987). Figure 6-24 presents the $\mathrm{MgO}$ grade in the sink and $\mathrm{MgO}$ recovery in the dolomite flotation float as a function of $\mathrm{pH}$. It shows that both $\mathrm{MgO}$ grade and recovery deteriorate with the increase of flotation $\mathrm{pH}$. At $\mathrm{pH} 5.0, \mathrm{MgO}$ grade in the sink is $1.23 \%$. When the $\mathrm{pH}$ is increased from 5.0 to $5.4, \mathrm{MgO}$ grade is decreased to $0.98 \%$. However, the $\mathrm{MgO}$ recovery almost keeps constant at $76.4 \%$ within this $\mathrm{pH}$ range. It drops to $71.48 \%$ as the $\mathrm{pH}$ increases to 5.7. In order to maximize the $\mathrm{MgO}$ recovery and minimize the $\mathrm{MgO}$ grade in the sink as well, the optimal value for $\mathrm{pH}$ should be fixed at 5.4.

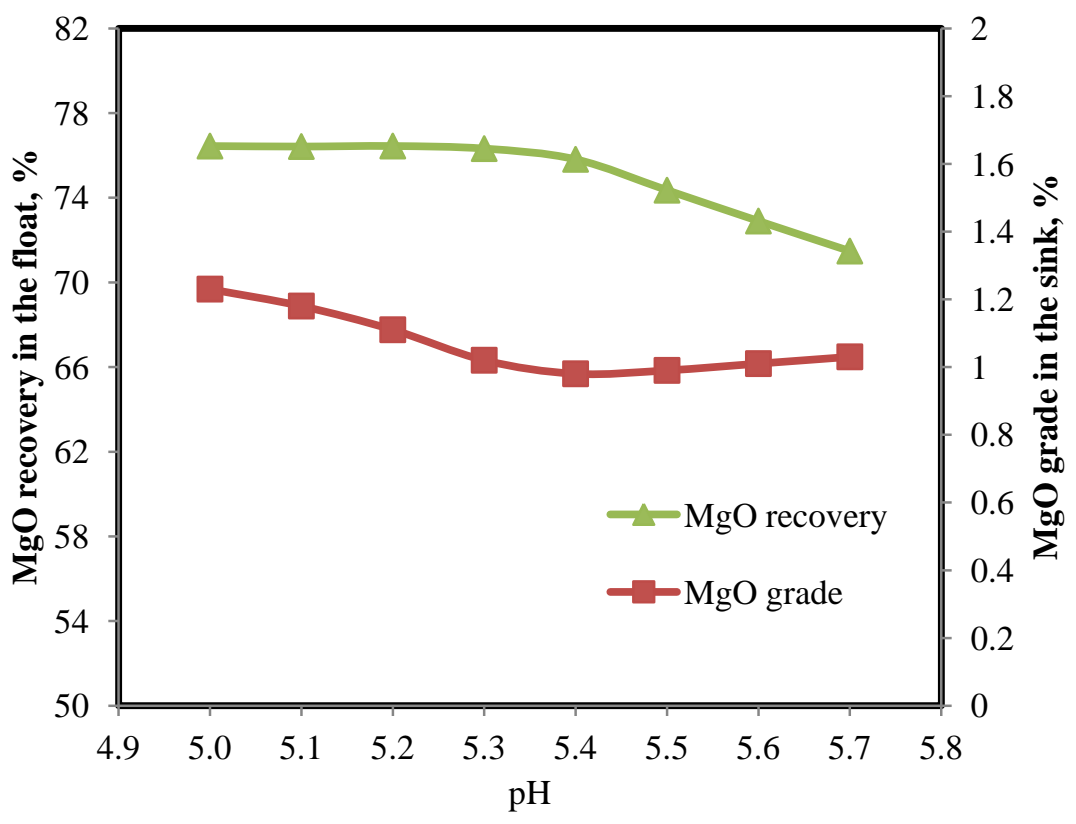

Figure 6- $24 \mathrm{MgO}$ grade in the sink and $\mathrm{MgO}$ recovery in the dolomite flotation float as a function of $\mathrm{pH}$. 
$\mathrm{P}_{2} \mathrm{O}_{5}$ grade and recovery in the dolomite flotation sink and the separation selectivity index as a function of $\mathrm{pH}$ is given in Figure 6-25. It can be seen that, $\mathrm{P}_{2} \mathrm{O}_{5}$ grade and recovery, as well as the separation selectivity index (SIP), increase as the dosage of collector increases. It is noted that the SIp increases from $65.46 \%$ to $72.73 \%, \mathrm{P}_{2} \mathrm{O}_{5}$ recovery ranges from $86.83 \%$ to $92.86 \%$ and $\mathrm{P}_{2} \mathrm{O}_{5}$ grade also increases from $28.08 \%$ to 29.86\%, while the $\mathrm{pH}$ increases from 5.0 to 5.4. As the $\mathrm{pH}$ keeps increasing, the SIp decreases, however, the $\mathrm{P}_{2} \mathrm{O}_{5}$ grade and recovery keeps almost unchanged. The optimal $\mathrm{pH}$ is found at 5.4, with the optimal separation selectivity index, $\mathrm{P}_{2} \mathrm{O}_{5}$ recovery and grade at $72.73 \%, 92.86 \%$ and $29.86 \%$, respectively.

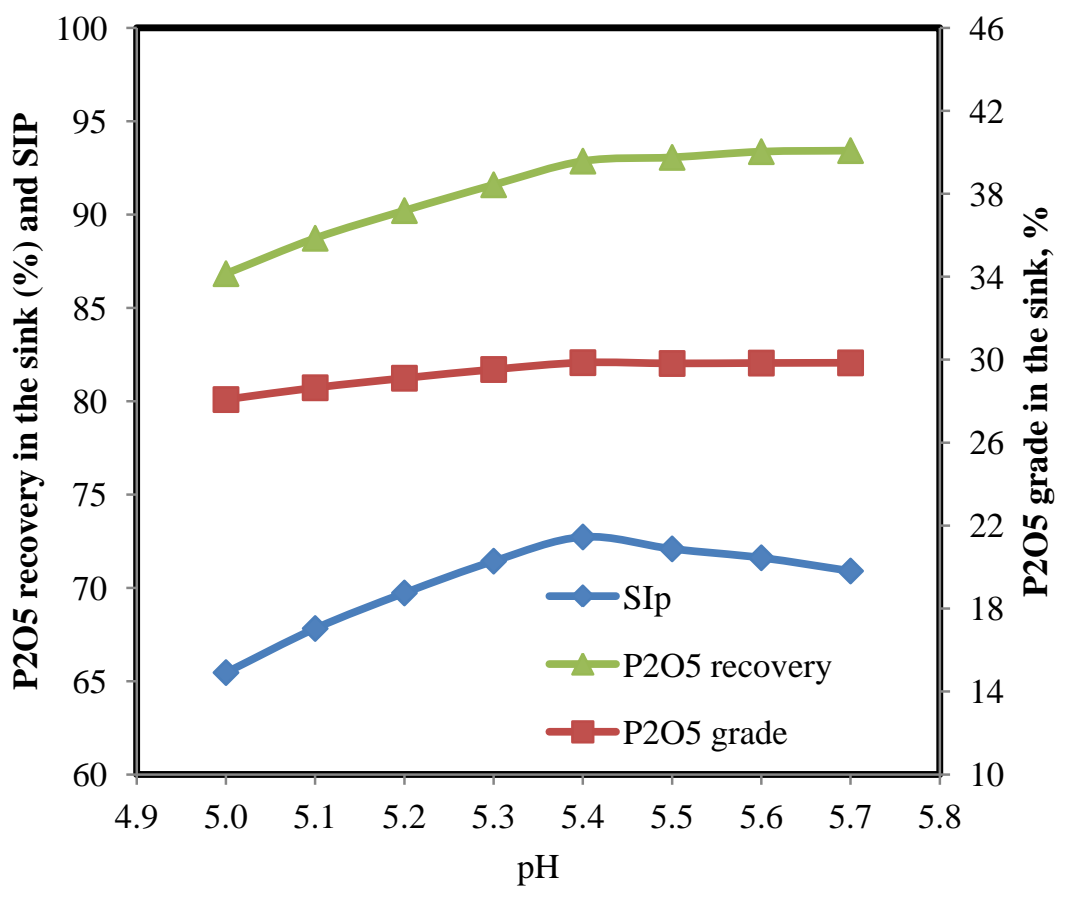

Figure 6- $25 \mathrm{P}_{2} \mathrm{O}_{5}$ grade and recovery in the dolomite flotation sink and the separation selectivity index as a function of $\mathrm{pH}$. 


\subsubsection{Amine flotation to remove silica impurity}

Under the operation conditions of $\mathrm{pH} 5.4$, collector dosage $1.8 \mathrm{lb} /$ ton of feed, feed rate $0.3 \mathrm{~cm} / \mathrm{s}$, feed solid concentration $20 \%$, frother dosage $7 \mathrm{ppm}$, air flow rate $1.5 \mathrm{~cm} / \mathrm{s}$, and the wash water rate $0.1 \mathrm{~cm} / \mathrm{s}$. The underflow of column or mechanical cell flotation after dolomite flotation is collected for silica amine flotation. The procedure is described in section 4.3.9. Three column flotation tests are conducted with and without pico-nano bubble flotation column/ regular mechanical cell and the underflow of the flotation is collected for silica flotation tests in order to compare the difference of the test results with and without pico-nano bubble. The amine flotation is carried out by using CA 1250 of $1 \mathrm{lb} /$ ton and Kerosene of $0.2 \mathrm{lb} /$ ton as collector. The material balance is given in Table 6-6. It can be seen that, in the presence of pico-nano bubble, more dolomite has been removed in the float of dolomite flotation, reducing the $\mathrm{MgO}$ content in the final phosphate concentrate. The final composite phosphate concentrate contains $33.15 \%$ $\mathrm{P}_{2} \mathrm{O}_{5}, 0.87 \% \mathrm{MgO}$ and $4.25 \%$ acid insoluble with the overall $\mathrm{P}_{2} \mathrm{O}_{5}$ recovery of $93.76 \%$ when Pico-nano bubble flotation column is used. In the absence of pico-nano bubble, the product of column flotation would only produce the composite phosphate concentrate with $27.86 \%$ of $\mathrm{P}_{2} \mathrm{O}_{5}, 1.55 \% \mathrm{MgO}$ and $5.00 \%$ acid insoluble with the overall $\mathrm{P}_{2} \mathrm{O}_{5}$ recovery of $82.68 \%$. Also, the product of mechanical cell flotation is not as good as that of pico-nano bubble column flotation. The test results indicate that the separation selectivity of dolomite flotation has been greatly improved by introducing pico-nano bubble into flotation system. 
Table 6- 6 Material balance of dolomite flotation followed by silica amine flotation.

\begin{tabular}{|c|c|c|c|c|c|c|c|c|}
\hline \multirow{2}{*}{ Condition } & \multirow{2}{*}{ Product } & \multirow{2}{*}{ Wt., \% } & \multicolumn{3}{|c|}{ Grade, \% } & \multicolumn{3}{|c|}{ Recovery, $\%$} \\
\hline & & & $\mathrm{P}_{2} \mathrm{O}_{5}$ & $\mathrm{Mg}$ & A.I. & $\mathrm{P}_{2} \mathrm{O}_{5}$ & $\mathrm{MgO}$ & A.I. \\
\hline \multirow{6}{*}{$\begin{array}{l}\text { With pico-nano bubble flotation } \\
\text { column for dolomite flotation }\end{array}$} & Dolomite float & 19.13 & 6.90 & 13.98 & 8.25 & 5.24 & 81.03 & 11.66 \\
\hline & silica float & 9.65 & 2.61 & 0.04 & 92.53 & 1.00 & 0.12 & 65.98 \\
\hline & $\operatorname{sink}$ & 58.35 & 33.88 & 0.85 & 3.59 & 78.50 & 15.03 & 15.48 \\
\hline & -38 um fines & 12.87 & 29.86 & 0.98 & 7.23 & 15.26 & 3.82 & 6.88 \\
\hline & Composite conc. & 71.22 & 33.15 & 0.87 & 4.25 & 93.76 & 18.85 & 22.36 \\
\hline & Head & 100.00 & 25.18 & 3.30 & 13.53 & 100.00 & 100.00 & 100.00 \\
\hline \multirow{6}{*}{$\begin{array}{l}\text { Without pico-nano bubble flotation } \\
\text { column for dolomite flotation }\end{array}$} & Dolomite float & 18.13 & 21.92 & 12.35 & 10.59 & 15.90 & 66.61 & 14.11 \\
\hline & silica float & 9.86 & 3.61 & 0.07 & 82.03 & 1.42 & 0.21 & 59.43 \\
\hline & $\operatorname{sink}$ & 58.99 & 28.88 & 1.52 & 4.29 & 68.16 & 26.68 & 18.59 \\
\hline & -38 um fines & 13.02 & 27.86 & 1.68 & 8.23 & 14.51 & 6.51 & 7.87 \\
\hline & Composite conc. & 72.01 & 28.70 & 1.55 & 5.00 & 82.68 & 33.18 & 26.47 \\
\hline & Head & 100.00 & 24.99 & 3.36 & 13.61 & 100.00 & 100.00 & 100.00 \\
\hline \multirow{6}{*}{$\begin{array}{l}\text { Without pico-nano bubble mechanical } \\
\text { cell for dolomite flotation }\end{array}$} & Dolomite float & 13.13 & 28.92 & 13.58 & 12.72 & 15.18 & 53.57 & 12.30 \\
\hline & silica float & 8.85 & 4.05 & 0.11 & 78.53 & 1.43 & 0.29 & 51.20 \\
\hline & $\operatorname{sink}$ & 67.15 & 26.88 & 1.95 & 5.78 & 72.15 & 39.34 & 28.60 \\
\hline & - 38 um fines & 10.87 & 25.86 & 2.08 & 9.86 & 11.24 & 6.79 & 7.90 \\
\hline & Composite conc. & 78.02 & 26.74 & 1.97 & 6.35 & 83.39 & 46.14 & 36.49 \\
\hline & Head & 100.00 & 25.02 & 3.33 & 13.57 & 100.00 & 100.00 & 100.00 \\
\hline
\end{tabular}




\subsubsection{Correlation between grade and recovery}

The relationship between $\mathrm{P}_{2} \mathrm{O}_{5}$ grade and $\mathrm{P}_{2} \mathrm{O}_{5}$ recovery are plotted in Figure 6-26. It shows that the phosphate concentrate with much higher $\mathrm{P}_{2} \mathrm{O}_{5}$ recovery is obtained at the same $\mathrm{P}_{2} \mathrm{O}_{5}$ grade. Both the $\mathrm{P}_{2} \mathrm{O}_{5}$ grade and $\mathrm{P}_{2} \mathrm{O}_{5}$ recovery have been greatly improved in the presence of pico-nano bubbles. Not only the collecting ability but also the selectivity of dolomite flotation has been improved significantly by using pico-nano bubble in the flotation system. It acts as a secondary collector, bridging between hydrophobic and conventional bubbles, which can significantly improve the flotation recovery of hydrophobic particles by increasing the probability of collision and attachment, reducing the probability of detachment at the meanwhile.

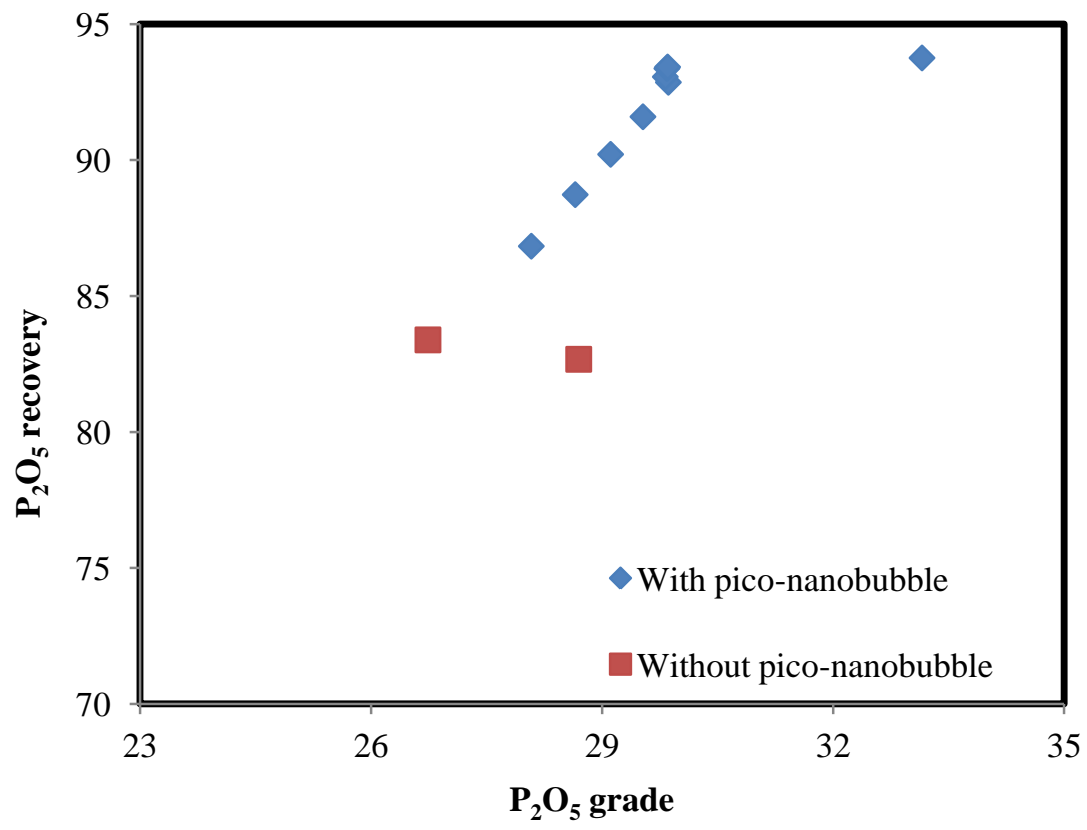

Figure 6- 26 Relationship between $\mathrm{P}_{2} \mathrm{O}_{5}$ grade and $\mathrm{P}_{2} \mathrm{O}_{5}$ recovery in the sink product of dolomite flotation. 


\subsubsection{Effect of pico-nano bubbles on $\mathrm{P}_{2} \mathrm{O}_{5}$ recovery of varying sizes}

The effect of pico-nanobubles on the flotation recovery of different size phosphate particles of different sizes are shown in Figure 6-27. The data indicates that pico-nano bubbles not only improved the flotation recovery of all phosphate particles but also increased the corresponding product grade. The flotation recovery increases from 5\% up to $14 \%$ as the particles size increases from $75 \mu \mathrm{m}$ to $700 \mu \mathrm{m}$, which indicates that piconano bubbles have more significant effect on coarser phosphate particles than on finer particles.

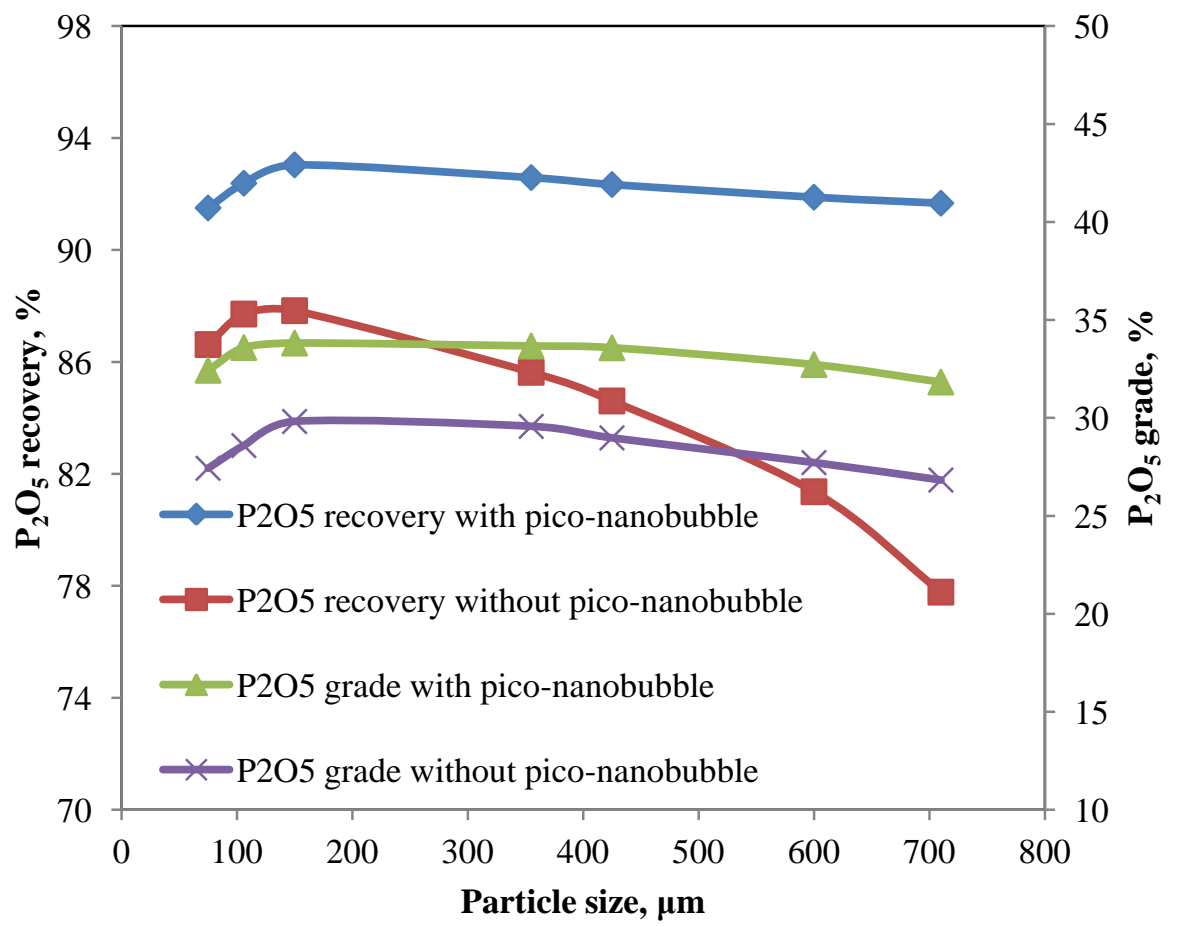

Figure 6- $27 \mathrm{P}_{2} \mathrm{O}_{5}$ grade and recovery in the dolomite flotation sink and the separation selectivity index as a function of particle size.

Figure 6-28 - 6-29 show $\mathrm{P}_{2} \mathrm{O}_{5}$ recovery as a function of $\mathrm{P}_{2} \mathrm{O}_{5}$ grade for $-700+150 \mu \mathrm{m}$ and - $150 \mu \mathrm{m}$ phosphate particles, respectively. The $\mathrm{P}_{2} \mathrm{O}_{5}$ content in flotation product of all size fractions in the presence of pico-nano bubbles are much higher than that in the 
sbsence of pico-nano bubbles. It can be seen from the figures that the flotation recovery of $\mathrm{P}_{2} \mathrm{O}_{5}$ has been greatly improved, meanwhile, the grade of the flotation product has been significantly increased with pico-nano bubbles.

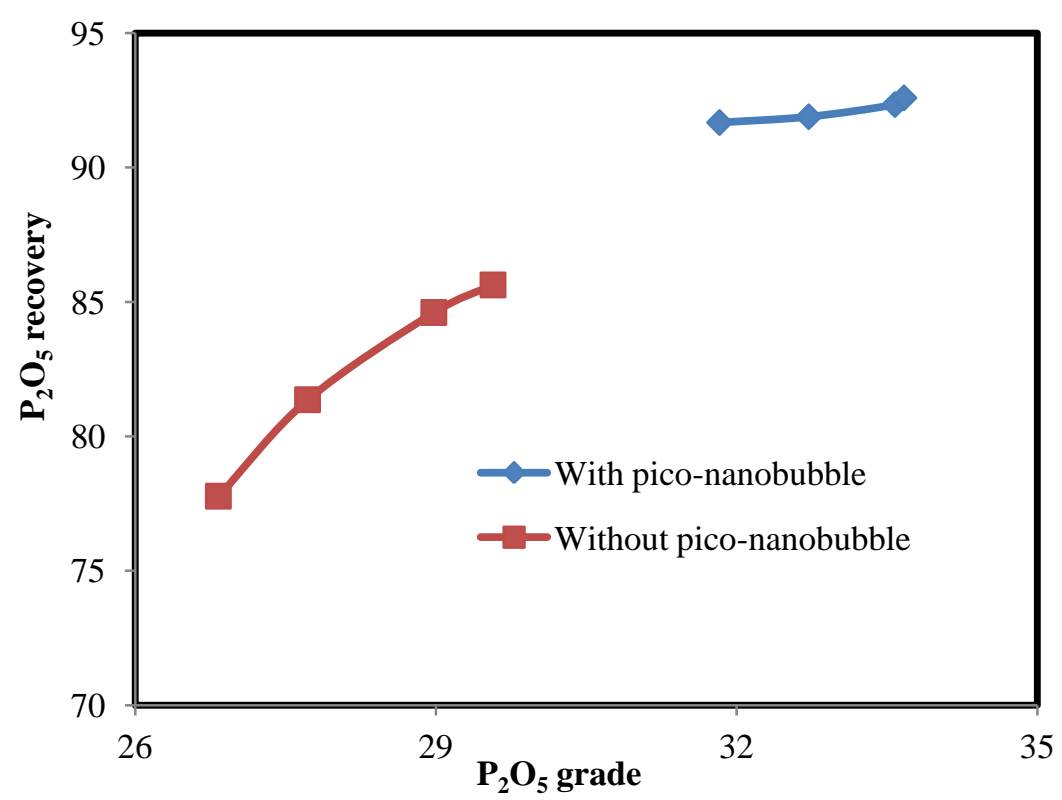

Figure 6- $28 \mathrm{P}_{2} \mathrm{O}_{5}$ grade vs. $\mathrm{P}_{2} \mathrm{O}_{5}$ recovery for $-700+150 \mu \mathrm{m}$ phosphate particles with and without pico-nano bubbles.

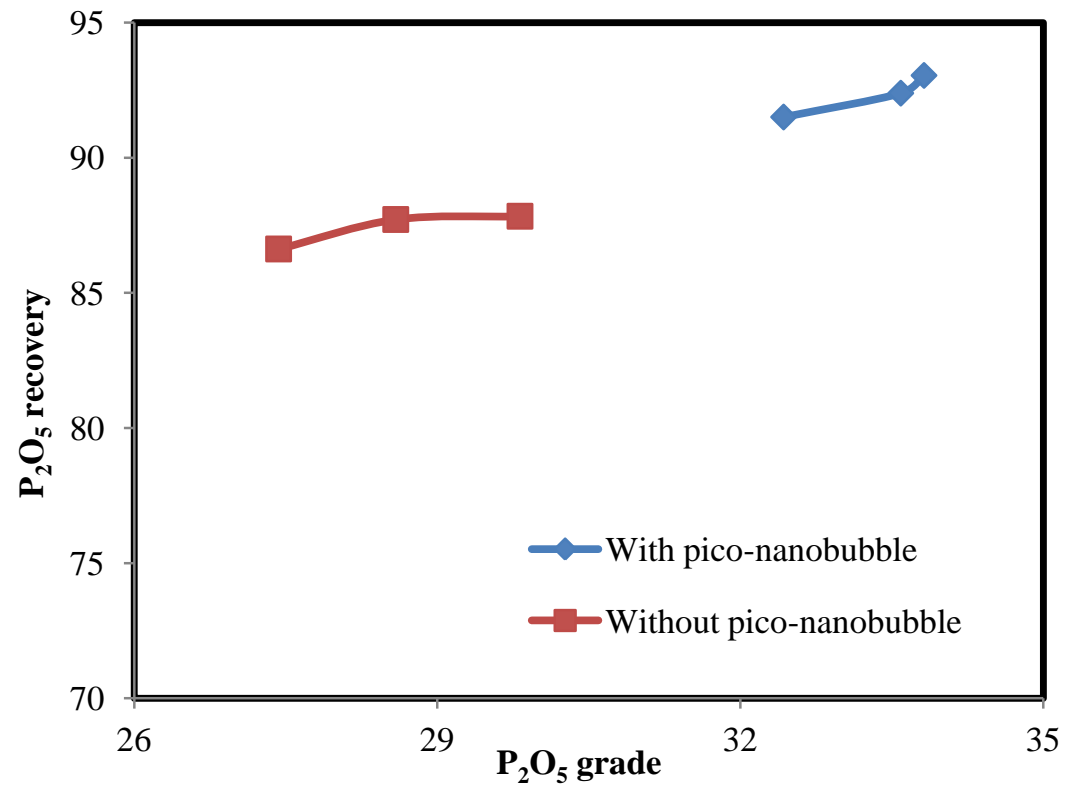

Figure 6- $29 \mathrm{P}_{2} \mathrm{O}_{5}$ grade vs. $\mathrm{P}_{2} \mathrm{O}_{5}$ recovery for $-150 \mu \mathrm{m}$ phosphate particles with and without pico-nano bubbles. 


\subsection{Economic evaluation of pico-nano bubble enhanced phosphate reverse flotation}

The main cost of applying the pico-nano bubble into the phosphate reverse flotation system includes the operational and capital costs. The assumptions for the economic evaluation include:

1) Assuming the $\mathrm{P}_{2} \mathrm{O}_{5}$ of the feed is $25 \%$.

2) The flotation feed rate is 100 ton/hour.

3) $20 \%$ solid concentration of the flotation feed.

4) In order to avoid congestion and maintain the separation efficiency, 8 venturi tubes would be installed in parallel to process the recirculating tailings.

5) Based on the tests results, the $\mathrm{P}_{2} \mathrm{O}_{5}$ recovery improvement can be as good as $15 \%$ with column flotation. To make a conservative estimation, the recovery improvement is assumed to be $5 \%$ for industrial application.

Similar to the calculation for the application of pico-nano bubbles in coal flotation, the total cost for the application of pico-nano bubbles in phosphate reverse flotation system should be $\$ 347,040$ a year.

If the flotation product of $30 \% \mathrm{P}_{2} \mathrm{O}_{5}$ grade needed to be produced, the total increase of the flotation product by using pico-nano bubble should be : 100 ton/hour $\times 25 \%$ x 5\%/30\% = 4.2 ton/hour. At current price for phosphate rock of about $\$ 108 /$ ton, the annual revenue by pico-nano bubble application should be: 4.2 ton/hour $\mathrm{x} 4320$ hours/ year $\mathrm{x} \$ 108 /$ ton $=$ $\$ 1,959,552$.

Then, the net profit generated by pico-nano bubble application should be: $\$ 1,959,552$ $\$ 347,040=\$ 1,612,512$. 


\section{Chapter 7 Conclusions}

The recovery improvement of coal flotation and phosphate reverse flotation demonstrated that pico-nano bubbles would significantly improve the flotation recovery of hydrophobic particles by increasing the probability of collision and attachment and reducing the probability of detachment.

The following conclusions can be drawn based on the experimental results and findings presented and discussed for the application of pico-nano bubbles in coal flotation.

1) Flotation efficiency of fine to coarser coal has been enhanced in the presence of piconano and nano bubbles. Maximum volume of pico-nano bubbles, $65 \%$ to $75 \%$, and minimum mean pico-nano bubble size, 150 to $240 \mathrm{~nm}$, were achieved at the medium ratio of the diameter of throat and outlet of the venture tube (3 to 4), medium outlet angle $\left(11^{\circ}\right.$ to $\left.13^{\circ}\right)$, high inlet angle $\left(26^{\circ}\right.$ to $\left.27^{\circ}\right)$ and high ratio of the length of the throat and the diameter of throat (2.3 to 3 ). The optimal percentage of pico-nano bubbles and nano bubbles is about $70 \%$, which produces maximum combustible material recovery of $86 \%$ and clean coal ash content of $11.7 \%$.

2) Use of pico-nano bubbles in column flotation, the maximum combustible recovery of 85 to $90 \%$ and minimum clean coal ash of 9.5 to $11 \%$ are achieved at solids concentration of $4 \%$, collector dosage of $0.7 \mathrm{lb} / \mathrm{tom}$, feed rate of $0.4 \mathrm{~cm} / \mathrm{s}$, the gas flow rate of $1.6 \mathrm{~cm} / \mathrm{s}$, frother concentration of $20 \mathrm{ppm}$, superficial wash water rate of $0.2 \mathrm{~cm} / \mathrm{s}$, and feed rate of $0.2 \mathrm{~cm} / \mathrm{s}$ from $29.6 \%$ ash content of Pittsburgh No. 8 seam coal. At a given flotation combustible material recovery, more than half of the 
collector can be saved by using pico-nano bubbles in the column flotation. The frother dosage is also reduced up to one half of the dosage.

3) The column flotation using pico-nano bubles is capable of extending to float minus $75 \mu \mathrm{m}$ and 300-700 $\mu \mathrm{m}$ particle size ranges more effectively than column flotation with conventional sparger devices. Use of pico-nano bubbles in the flotation column, remarkably increases the combustible material recoveries for coarse fractions, $700+325 \mu \mathrm{m}$, and ultrafines fraction, $-75 \mu \mathrm{m}$. The presence of pico-nano bubbles enhances the effective separation density of 1.40 to $1.60 \mathrm{~g} / \mathrm{cm}^{3}$. The presence of piconano bubbles also has more considerable effect on minus $75 \mu \mathrm{m}$ fine fraction than on $-700+355 \mu \mathrm{m}$ coarse fraction. More high density particles of minus $75 \mu \mathrm{m}$ fraction were floated than that of $-700+355 \mu \mathrm{m}$ coarse particles. The presence of pico-nano bubble has more considerable effects on improvement of combustible material recovery than on that of flotation yield, especially for the $-75 \mu \mathrm{m}$ ultrafines and ultrafines fractions.

4) The use of pico-nano bubble increases combustible material recovery at the "inflection point" of the curve of flotation ash rejection versus combustible material recovery of varying size by $5 \%-10 \%$.

5) The economic analysis demonstrates that the application of pico-nano bubbles in coal flotation is economically feasible. For a coal preparation plant with 100 ton/hour feed rate, the annual profit of $\$ 1.62$ million can be achieved with the application of piconano bubbles.

The following conclusions can be drawn for the application of pico-nano bubbles in phosphate reverse flotation. 
1) The froth stability of CF413 is better than CF413B without the addition of MIBC. With the addition of MIBC, the froth lasts longer than that without any frother. There is a significant increase of the froth lifetime when CF413 or CF 413B is mixed with MIBC at the dosage of $10 \mathrm{ppm}$ or higher. With the increasing of the dosage of frother (MIBC), the froth lifetime difference reduces significantly, especially when the dosage of MIBC increases from $5 \mathrm{ppm}$ to $10 \mathrm{ppm}$.

2) The addition of surfactant can improve the frothability of the fatty acid collector. When MIBC is mixed with $\mathrm{CF} 413$ or $\mathrm{CF} 413 \mathrm{~B}$ at the dosage of $10 \mathrm{ppm}$, the frothability can be significantly improved compared to other dosages of MIBC. By adding in the frother (MIBC), the frothability difference between CF413 and CF413B has been reduced to almost negligible level when the dosage of MIBC is higher than 10 ppm.

3) $\mathrm{CF} 413$ generates more bubbles than $\mathrm{CF} 413 \mathrm{~B}$ at low collector dosages, resulting in better yield. At high collector dosage, however, the yields of floated dolomite are almost the same for CF413 and CF413B. Also, better yields can be achieved by the addition of surfactant MIBC at $10 \mathrm{ppm}$ for both $\mathrm{CF} 413$ and CF413B. The significance of the collector with or without MIBC in improving dolomite flotation is in the order as follows:

Mixture of CF413B and MIBC > Mixture of CF413 and MIBC > CF413 > CF413B.

4) The optimum operation conditions could be achieved at high level of collector, within $1.8 \mathrm{lb} / \mathrm{ton}$, low level of $\mathrm{pH}$, around 5.4 , high level of feed rate, $0.3 \mathrm{~cm} / \mathrm{s}$, low level of feed solid concentration, 20\%, and low level of frother dosage, 7 ppm. Besides, the less significant factors of air flow rate should be set at $1.5 \mathrm{~cm} / \mathrm{s}$, and the wash water 
rate should be set at $0.1 \mathrm{~cm} / \mathrm{s}$ with the optimal separation selectivity index, $\mathrm{P}_{2} \mathrm{O}_{5}$ recovery and grade at $72.73 \%, 92.86 \%$ and $29.86 \%$, respectively.

5) The final composite phosphate concentrate contains $33.15 \% \mathrm{P}_{2} \mathrm{O}_{5}, 0.87 \% \mathrm{MgO}$ and 4.25\% acid insoluble with the overall $\mathrm{P}_{2} \mathrm{O}_{5}$ recovery of $93.76 \%$ when Pico-nano bubble flotation column is used. In the absence of pico-nano bubble, the product of column flotation would only produce the composite phosphate concentrate with $28.70 \%$ of $\mathrm{P}_{2} \mathrm{O}_{5}, 1.55 \% \mathrm{MgO}$ and $5.00 \%$ acid insoluble with the overall $\mathrm{P}_{2} \mathrm{O}_{5}$ recovery of $82.68 \%$. The product of mechanical cell flotation is also not as good as that of piconano bubble column flotation. The separation selectivity of dolomite flotation has been greatly improved by introducing pico-nano bubble into flotation system.

6) Both the $\mathrm{P}_{2} \mathrm{O}_{5}$ grade and $\mathrm{P}_{2} \mathrm{O}_{5}$ recovery have been greatly improved in the presence of pico-nano bubbles. Not only the collecting ability but also the selectivity of dolomite flotation has been improved significantly by using pico-nano bubble in the flotation system. It acts as a secondary collector, bridging between hydrophobic and conventional bubbles, which can significantly improve the flotation recovery of hydrophobic particles by increasing the probability of collision and attachment, reducing the probability of detachment at the meanwhile.

7) Pico-nano bubbles not only improved the flotation recovery of all phosphate particles but also increased the corresponding product grade. The flotation recovery increases from $5 \%$ up to $14 \%$ as the particles size increases from $75 \mu \mathrm{m}$ to $700 \mu \mathrm{m}$, which indicates that pico-nano bubbles have more significant effect on coarser phosphate particles than on finer particles. 
8) The $\mathrm{P}_{2} \mathrm{O}_{5}$ content in flotation product of all size fractions, $-700+150 \mu \mathrm{m}$ and $-150 \mu \mathrm{m}$, in the presence of pico-nano bubbles are much higher than that in the sbsence of piconano bubbles. The flotation recovery of $\mathrm{P}_{2} \mathrm{O}_{5}$ has been greatly improved, and the grade of the flotation product has been significantly increased in the presence of piconano bubbles as well.

9) The economic analysis demonstrates that the application of pico-nano bubbles in phosphate reverse flotation is economically feasible. For a phosphate processing plant with 100 ton/hour feed rate, the annual profit of $\$ 1.61$ million can be achieved with the application of pico-nano bubbles. 


\section{Chapter 8 Recommendations for Future Work}

The results obtained from the present investigation showed that pico-nano bubbles significantly improved phosphate and coal separation performance. It also demonstrated the potential of improving the flotation recovery of coarse phosphate and coal by using pico-nano bubbles in the flotation system. However, additional research work in the following areas is recommended for the successful application of the pico-nano bubbles in the flotation industry:

1) The design of cavitation venturi tube has been investigated in this study. It is only discussed the significant of different designs from the construction point of view. In order to better understand the generation of pico-nano bubbles, more fundamental studies that associated with the hydrodynamic conditions of the pico-nano bubbles' generation should be further studied. Computational fluid dynamics (CFD) should be introduced to help with the simulation of the generation of pico-nano bubbles under different hydrodynamic conditions, which will provide useful information on the formation of pico-nano bubbles during the hydrodynamic cavitation process.

2) In order to verify the test results obtained from the laboratory scale flotation column, a pilot and industrial scale column with pico-nano bubbles cavitation venturi tube should be fabricated and tested. 
3) In this study, phosphate and coal were selected as the materials being tested with pico-nano bubbles flotation column. It is recommended that more minerals, including metallic and non-metallic minerals, should be tested in the future.

4) Pico-nano bubbles should be applied to other flotation equipment, not only in open flotation column.

5) A detailed technical performance and economic feasibility study should be performed using the data generated from the pilot and industrial scale testing program. 


\section{References}

Anazia, I., and Hanna, J., 1988, "Innovative process for beneficiation of dolomite phosphate ores”, Int. J. Miner. Process., Vol.23, No.3-4, pp.311-314.

Amelunxen, R.L., 1993. The contact cell: a future generation of flotation machines. Engineering and Mining Journal (April), pp. 36-37.

Ata, S., Jameson, G. J., 2005. "The Formation of bubble clusters in flotation cells", Int. J. Miner. Process., Vol. 76, pp. 123-139.

Attalla, M., Chao, C., and Nicol, S.K., 2000, "The role of cavitation in coal flotation", In: Pro.of the 8th Australian Coal preparation Conference, Port Stephens, 12-16 November. Australian Coal Preparation Society, pp. 337-350.

Bahr, A., Imhof, R.M., Ludke, H., 1985, “Application and sizing of a pneumatic flotation cell”, Min.Proc.Congress, Cannes, France.

Banisi, S., Finch, J. A., and Laplante, A. R., 1995, "Effect of solid particles on gas holdup in flotation columns-I. measurement", Chem. Engng Sci., Vol. 50 No. 14, pp. 2329-2334.

BP Statistical Review of World Energy, 2012.

Brennen, C.E., 1995, “Cavitation and Bubble Dynamics”, Oxford Univ. Press, New York.

Carr, M.W., Hillman, A.R., and Lubetkin, S.D., 1995, "Nucleation rate dispersion in bubble evolution kinetics”, J. Colloid. Interf. Sci., Vol. 169, pp. 135-142.

Cheng, T. W., and Holtham, P. N., 1995, "The particle detachment process in flotation", Minerals Engineering, Vol. 8, No. 8, pp. 883-891.

Cleric, C., 1984, "Flotation of a phosphate rock with carbonate-quartz gangue", Reagents in the Mineral Industry, Jones, M.J. and Oblatt, R., eds., IMM, London, pp. 221-225.

Crozier. R.D., 1992, "Flotation: theory, reagents and ore testing", Oxford, New York, Pergamon.

Dean, R.B., 1944, The formation of bubbles. J. Appl. Sci., Vol. 15, pp. 446-451.

Deglon, D.A., Sawyerr, F., O’Connor, C.T., 1999, “A model to relate the flotation rate constant and the bubble surface area flux in mechanical flotation cells", Miner. Eng., Vol. 12, No. 6, pp. $599-608$. 
Derjaguin, B.V., S.S. Dukhin, and N.N. Rulyov, 1984, "Kinetic theory of flotation of small particles", Surface and Colloid Science, Vol. 13, pp. 71-113.

Didenko, Y.T., and Suslick, K.S., 2002, "The energy efficiency of formation of photons, radicals and ions during single-bubble cavitation”, Nature, Vol. 418 (July), pp. 394-397.

Duan, J., Fornasiero, D., and Ralston, J., 2003, "Calculation of the flotation rate constant of chalcopyrite particles in an ore”, Int'l. J. Miner. Process., Vol. 72, pp. 227-237.

Dupre, V., Ponasse, M., Aurelle, Y., Secq, A., 1998, "Bubble formation by water release in nozzles - I. Mechanisms”, Water Research, Vol.32, No. 8, pp. 2491-2497.

Dzienisiewicz, J., Pryor, E.J., 1950, “An investigation into the action of air in froth flotation”, Trans. IMM, London, Vol.59, pp. 455-491.

Edzwald, J.K., 1995, "Principles and applications of dissolved air flotation", Water Sci. Technol., Vol. 31, No.3, pp. 1-23.

El-Shall, , H., Cheng, Y.H., Abdel-Khalek, N.A. and Gupta, S., 1999, “ A parametric study of column flotation of florida phosphates", Beneficiation of Phosphates: "Advance in research and practice", Zhang, P., El-Shall, H., Wiegel, R., eds., SME, Littleton, CO., pp.75-86.

El-Shall, H., 2001, "Bubble generation, design, modeling and optimization of novel flotation columns for phosphate beneficiation", Final Report to Florida Institute of Phosphate Research, FIPR, Publication No.02-111-175.

Falutsu, M., 1994, "Column flotation froth characteristics-stability of the bubble-particle system”, Int'l. J. Miner. Process., Vol. 40 , pp. 225- 243.

Fan, M., 2008, "Picobubble enhanced flotation of coarse phosphate particles" (Ph.D. dissertation), Kentucky: University of Kentucky.

Fan, M., Tao, D., Honaker, R. Q., and Luo, Z., 2010a, "Nanobubble generation and its applications in froth flotation (part II): fundamental study and theoretical analysis", Mining Sci. \& Tech., Vol. 20, No. 2, pp. 0159-0177.

Fan, M., Tao, D., Honaker, R. Q., and Luo, Z., 2010b, "Nanobubble generation and its applications in froth flotation (part IV): mechanical cells and specially designed column flotation of coal", Mining Sci. \& Tech., Vol. 20, No. 4, pp. 0641-0671.

Feng, D., and Aldrich, C.,1999, "Effect of particle size on flotation performance of complex sulfide ores", Minerals Engineering, Vol. 12, pp. 721-731. 
Finch, J. A. and Dobby, G. S., 1991, "Column flotation: a selected review- 1", Int. J. Min. Proc., Vol. 33, pp. 343-354.

Finch, J. A., Nesset, J. E., Acuna, C., 2008, "Role of frother on bubble production and behaviour in flotation”, Minerals Engineering, Vol. 21, pp. 949-957.

Flanngingan, D.J., and suslick, K.S., 2005, "Plasma formation and temperature measurement during single-bubble cavitation”, Nature, Vol. 434 (March), pp. 52-55.

Flynn, H.G., 1964, "Physics of acoustic cavitation in liquids", In: Mason, W.P. (Ed.), Physical Acoustics, Principles and Methods, part B, vol. 1. Academic Press, New York, pp. 57-172.

Gerth, W.A., Hemmingsen, E.A., 1980, "Heterogeneous nucleation of bubbles at solid surfaces in gas-supersaturate aqueous solutions”, J. Colloids Interf. Sci. 74, pp. 80-89.

Gochin, R.J., and Solari, J.A., 1983, "Dissolved air flotation for recovery of fine cassiterite", Transactions of the Institute of Mining and Metallurgy, Sect. C 92, C52-58.

Gogate, P.R., and Pandit, A.B., 2001, "Hydrodynamic cavitation reactors: a state of the art review", Reviews in Chemical Engineering, Vol. 17, No. 1, pp. 1-85.

Gontijo, C., Fornasiero, D., and Ralston, J., 2007, "The limits of fine and coarse particle flotation”, Can. J. Chem. Eng., Vol. 85, pp. 739-747.

Grainer-Allen, T.J.N., 1970, "Bubble generation in froth flotation machines", Trans. IMM, London, C15-C22.

Gu, Z. X., 2002, "Fine particle flotation for florida dolomitic phosphate pebbles" (Master thesis), West Virginia: West Virginia University.

Gu, Z. X., Gao, Z. Z., and Hwang C. L., 1999a, "Development of new technology for beneficiation of florida dolomitic phosphate resources", Final report submitted to Florida Institute of Phosphate Research, publication No. 02-129-167.

Gu, Z. X., Gao, Z. Z., and Zheng S. B., 1999b, "Beneficiation of florida dolomitic phosphate pebble with a fine particle flotation process", Beneficiation of Phsphate: "Advance in research and practice”, Zhang, P., El-Shall, H., Wiegel, R., eds., SME, Littleton, CO., pp. $155-162$.

Gurr, T.M., 2001, "Industrial minerals 2000- phosphate rock”, Mining Engineering, Vol.53, No.6, pp. 51-52. 
Hampton, M. A., and Nguyen, A. V., 2010, "Nanobubbles and the nanobubble bridging capillary force", Advances in Colloid and Interface Sci., Vol. 154 No. 1, pp. 30-55.

Harrison, S. T. L., and Pandit, A. B., 1992,'The disruption of microbial cells by hydrodynamic cavitation", $9^{\text {th }}$ International Biotechnology Symposium, Washington, DC.

Hart, G., Morgan, S., and Bramall, N., 2002, "Generation of pico bubbles in flotation feed a means to reduce collector use", Proceedings of Ninth Australian Coal Preparation Conference, Yeppoon, pp. 136-148.

Harvey, E.N., McElroy, W.D., and Whiteley, A.H., 1947, "Cavity formation in water", J. Appl. Phys., Vol. 18, pp. 162-172.

Hemmingsen, E.A., 1975, “Cavitation in gas-supersaturated solutions”, J. Appl. Phys., Vol. 46, pp. 213- 218.

Hemmingsen, E.A., 1977, "Spontaneous formation of bubbles in gas-supersaturated water", Nature, Vol. 267 (May), pp. 141-142.

Hemmingsen, E.A., 1978, "Effects of surfactants and electrolytes on the nucleation of bubbles in gas-supersaturated solutions", Z. Naturforsch. Vol. 33, pp. 164-171.

Hemmingsen, E.A., Hemmingsen, B.B., 1990, "Bubble formation properties of hydrophobic particles in water and cells of Tetrahymena", Undersea Biomed. Res., Vol. 17, pp. 67-78.

Hernainz, F., Calero, M. and Blazquez, G., 2004, "Flotation of low-grade phosphate ore", Advanced powder technology, Vol. 15, No. 4, pp. 421-433.

Houot, R., 1982, "Benificiation of phosphate ores through flotation: review of industrial applications and potencial developments", Intl. J. of mineral Process., Vol. 9, pp.353-384.

Hu, H., Zhou, Z.A., Xu, Zhenghe, and Finch, J.A., 1998, "Numerical and experimental study of a cavitation tube”, Metallurgical and Materials Trans. B., Vol. 29, pp. 911-917.

IEA ( International Energy Agency) Coal Information, 2012.

International Standard, ISO 5167-4: 2003 (E), 2003, Measurement of fluid flow by means of pressure differential devices inserted in circular cross-section conduits running full - Part 4: Venturi tubes. First ed. Geneva, Switzerland.

Ityokumbul, M. T., 1993, "Maximum gas velocity in column flotation", Minerals Engng, Vol. 6, pp. 1279-1286. 
Jackson, M.L., 1994, "Energy effects in bubble nucleation”, I\&EC Research, Vol. 33, No. 4, pp. 929-933.

Jackson, M.L. and Collins, W., 1964, "Scale-Up of a venturi aerator", Ind. Eng. Chem. Process Des. Dev.,Vol.3, No.4, pp. 386-393.

Jameson, GJ, 1988, “A new concept in flotation column design”, Column '88 Proceedings of an International Symposium on Column Flotation, SME, Phoenix Az, 1988. Sastry, KV, ed., pp. 281-289.

JMP, Version 7. SAS Institute Inc., Cary, NC, 1989-2007.

Jordan, C. E. and Susko, F. J., 1992, "Rapid flotation using a modified bubble-injected hydrocyclone and a shallow-depth froth separator for improved flotation kinetics", Minerais Eng., Vol.5, pp. 1239-1257.

King R. P., 1982, "Flotation of fine particles, in principles of flotation (R. P. King,ed.)", South African Institute of Mining and Metallurgy, Johannesburg, pp. 217-219.

Kirchberg, H., and Topfer, E., 1964, “The mineralization of air bubbles in flotation”, Proc. 7th Int'1. Min. Processing Congress, N. A. Arbiter, ed., pp. 157-168.

Klassen, V.I., and Mokrousov, V.A., 1963, "An Introduction to the Theory of Flotation", Butterworths, London.

Knapp, R.T., Daily, J.W., Hammitt, F.G., 1970, “Cavitation”, McGraw-Hill, New York.

Krasowska, M., Zawala, J., and Malysa, K., 2009, “Air at hydrophobic surfaces and kinetics of three phase contact formation", Advances in Colloid and Interface Sci., Vol. 147-148, pp. 155-169.

Lawendy, T.A.B., and McClellan, G.H., 1993, "Flotation of dolomitic and calcareous phosphate ores", 1993, Beneficiation of Phosphates: Theory and Practise, El-Shall, H., Moudgil, B., Wiegel, R., eds., SME, Littleton, CO., pp.231-244.

Luttrell, G. H., and Yoon, R.-H., 1992, "A hydrodynamic model for bubble-particle attachment”, J. Colloid Interface Sci, Vol. 154, pp. 129-137.

McNamara III, W.B., Didenko, Y.T., Suslick, K.S., 1999, "Sonoluminescence temperatures during multi-bubble cavitation”, Nature 401 (October), pp. 772-775.

Momber, A.W., 2004, “Aggregate liberation from concrete by flow cavitation", Int'l. J. Miner. Process., Vol. 74, pp. 177-187. 
Moudgil, B. M., and Somasundaran, P., 1986, "Advances in phosphate beneficiation", Advances in Mineral Processing, Arbiter Symposium, SME, pp.426.

Muganda, S., Zanin, M., and Grano, S. R., 2010, "Influence of particle size and contact angle on the flotation of chalcopyrite in a laboratory batch flotation cell", Int'1. J. Miner. Process., Vol. 98, pp. 150-162.

Nicol, S.K., Engel, M.D., Teh, K.C., 1986, "Fine particle flotation in an acoustic field". Int'l. J. Miner. Process., Vol. 17, pp. 143-150.

Nomura, Y., Uesawa, S., Kaneko, A., and Abe, Y., 2011 "Study on bubble breakup mechanism in a venturi tube", Proceedings of the ASME-JSME-KSME 2011 Joint Fluids Engineering Conference, Japan, pp. 2527-2534.

Pease, D.C., Blinks, L.R., 1947, "Cavitation from solid surfaces in the absence of gas nuclei”, J. Phys. Colloid Chem, Vol.51, pp. 556-567.

Peng, F. F. and Xiong, Y., 2012, "Flotation of fine coal using cavitation venturi tube for pico and nanobubble generation to improve collision/attachment", Int'l. Pittsburgh Coal Conference, Pittsburgh, PA, October 15-18, 2012.

Peng, F. F., and Xiong, Y., 2013, "Pico-Nano Bubble Flotation Using Static Mixer-Venturi Tube For Pittsburgh No. 8 Seam Coal", Preprint, 2013 SME Annual Meeting, Denver, CO, Feb. 24-27.

Piantadosi, C., Jasieniak, M., Skinner, W. M., and Smart, R. S. C., 2000, "Statistical comparison of surface species in flotation concentrates and tails from ToF-SIMS evidence", Minerals Engineering, Vol. 13, pp. 1377-1394.

Ponasse, M., Dupre, V., Aurelle, Y., Secq, A., 1998, "Bubble formation by water release in nozzle-II. Influence of various parameters on bubble size", Water Research, Vol. 32, No.8, pp. 2498-2506.

Prozorov, T., Prozorov, R., and Suslick, K.S., 2004, "High velocity interparticle collisions driven by ultrasound”, J. Am. Chem. Soc., Vol. 126, pp. 13890-13891.

RaDEN, D.J., 1979, “Current problems in beneficiation of phosphate fines”, In:Beneficiation of Mineral Fines- Problems and Research Needs, Somasundaran, P., and Arbiter, N., eds., AIME, pp.79-93.

Ralston, J., Dukhin, S.S., 1999, "The interaction between particles and bubbles", Colloids and Surfaces, Vol.151, No.1, pp. 3-14. 
Ralston, J., Fornasiero, D., Hayes, R., 1999 a, "Bubble-particle attachment and detachment in flotation”, Int'l. J. Miner. Process., Vol56, No. 1-4, pp. 133-164.

Randolph, J. M., 1997, "Characterizing flotation response: a theoretical and experimental comparison of techniques", Master Thesis, Virginia Polytechnic Institute and State University, VA.

Rao, D.V., 1979, "Flotation of low grade phosphate ore”, Int. Symp. on Resources Eng. And Tech., Jan. 8-11, pp.1-7.

Rees, A. J., Rodmail, D. 1. and label, T. F., 1980a, "Dissolved air flotation for solid/ liquid separation", J. Separ. Proc. Technol., Vol. 1, No.3, pp. 19-23.

Rees, A.J., Rodman, D.J. and label, T.F., 1980b, "Evaluation of dissolved air tlotation saturator performance", Technical Report TR 143, Water Research Centre, Report TM 106.

Ross, D., 1976, “Cavitation”, Pergamon Press, New York, pp. 203-251.

Rykaart, E.M., Haarhoff, J., 1995, "Behavior of air injection nozzles in dissolved air flotation”, Wat. Sci. Tech., Vol. 31, No. 3, pp. 25-35.

Sahu, K.K., Hazama, Y., Ishihara, K.N., 2006, "Gushing in canned beer: the effect of ultrasonic vibration”, J. Colloid Interface Sci., Vol. 302, pp. 356-362.

Schubert, H., 2005, "Nanobubbles, hydrophobic effect, heterocoagulation and hydrodynamics in flotation”, Int. J. Miner. Process.. Vol. 78, pp. 11-21.

Senthikumar, P., Pandit, A.B., 1999, "Modelling hydrodynamic cavitation", Chem. Eng. Tech., Vol.22, No.12, pp. 1017-1027.

Sis, H. and Chander, S., 2003, "Improving froth characteristics and flotation recovery of phosphate ores with nonionic surfactants", Minerals Engineering, Vol. 16, No. 7, pp. 587-595.

Somasundaran, P., Xiao, L., and Viswanathan, K.V., 1987, "Interactions between dissolved mineral species and surfactants in the fracolite/dolomite flotation", Proceedings of International Symposium organized by Central-South University of Technology and Technical University of Clausthal, Changsha, China, Sept. 21-24.

Soubiran, J., and Sherwood, J. D., 2000, "Bubble motion in a potential flow within a venturi”, International Journal of Multiphase Flow, Vol.26, pp. 1771-1796. 
Taggart, A.F., 1927, “Handbook of Ore Dressing”, John Wiley \& Sons, New York, pp. 945.

Takahashi, T., Miyahara, T., Mochizuki, H., 1979, "Fundamental study of bubble formation in dissolved air flotation", J. Chem. Eng. Japan, Vol. 12, No. 4, pp. 275-280.

Tao, D., 2004, "Role of bubble size in flotation of coarse and fine particles - a review", Separation Sci. Technol., Vol. 39, pp. 741-760.

Tao, D., Fan, M., Honaker, R., Parekh, B.K., 2006a, "Picobubble enhanced flotation of coarse phosphate particles", In: Proceedings of the Twenty-Third International Mineral Processing Congress, Istanbul, Turkey, pp. 3-8.

Tao, D., Honaker, R., Parakh, B.K., Fan, M., 2006b, "Development of picobubble flotation for enhanced recovery of coarse phosphate particles", Final report for Florida Institute of Phosphate Research, FIPR Contract \#02-02-154R.

Tao, Y., Liu, J., Yu, S., Tao, D., 2006c, "Picobubble enhanced fine coal flotation", Separation Science and Technology, Vol.41, No.16, pp. 3597-3607.

Tao, D., Yu, S., Zhou, X.H., Honaker, R. Q., Parekh, B. K., 2008, "Picobubble column flotation of fine coal," International Journal of Coal Preparation and Utilization, Vol. 28, pp. 1-14.

Trahar W. J. and Warren L. J., 1976, "The floatability of very fine particles-a review", International Journal of Mineral Processing, Vol. 3, pp. 103-131.

Tustsumi, A., Nieh, J.-Y., and Fan, L.-S., 1991, "Particle wettability effect on bubble wake dynamics in gas-liquid-solid fluidization", Chem. Engng Sci. Vol. 46, pp. 23812384 .

U.S. Energy Information Administration Form EIA-7A, Coal Production and Preparation Report, and U.S. Department of Labor, Mine Safety and Health Administration Form 7000-2, Quarterly Mine Employment and Coal Production Report, 2012.

U.S. Geological Survey, Mineral Commodity Summaries, January 2013.

Walstra, P., 1989, "Principles of foam formation and stability", In: Wilson, A.J. (Ed.), Foams: Physics Chemistry and Structure. Springer-Verlag, Berlin Heidelberg.

Weber M. E. and Paddock D., 1983, "Interceptional and Gravitational Collision Efficiencies for Single Collectors at Intermediate Reynolds Numbers", J. Colloid. Interface Sci., Vol. 94, pp. 328-335. 
Westwater, J.W., 1964, "Measurement of bubble growth during mass transfer", In: Davis, R., Ed., Cavitation in Real Liquids. Elsevier Publishing Company, Amsterdam, pp. 34-54.

Wiegel R., 1999, "Phosphate rock beneficiation practice in florida", Beneficiation of Phosphates: "Advance in research and practice", Zhang, P., El-Shall, H., Wiegel, R., eds., SME, Littleton, CO., pp.271-5.

Wu, T.Y., 1969, "Cavity flow analysis: a review of the state of knowledge", In: Robertson, J.M., Wislicenus, G.F. (Eds.), Cavitation State of Knowledge, ASME, New York, pp. 106-137.

Xu, M., Finch, J. A., and Uribe-Salas, A., 1991, "Maximum gas and bubble surface rates in flotation columns", Int. J. Miner. Process., Vol. 32, pp. 233-250.

Xu, M., Quinn, P., and Stratton-Crawly, R., 1996, “A feed-line aerated flotation colum, Part 1: Batch and continuous test work", Minerals Engineering, Vol. 9, No. 5, pp. 499-508.

Xu, Z., Choung, J., Sun, W., Cui, Z., 2006, "Visualization of fine bubbles and their role in fine particle flotation", In: 38th Annual Canadian Mineral Processors Operators Conference, Ottawa, January 17-19.

Yalcin, T., Byers, A., Ughadpaga, K., 2002, "Dissolved gas method of generating bubbles for potential use in ore flotation", Mineral Processing and Extractive Metallurgy Review, Vol. 27, pp. 181-197.

Yalcin, T., Byers, A., 2006, "Dissolved gas flotation in mineral processing", Mineral Processing and Extractive Metallurgy Review, Vol. 27, pp. 1-11.

Yianatos, J. B., Finch, J. A., Dobby, G. S., and Xu, M., 1988, "Bubble size estimation in a bubble swarm”, J. Coll. Int. Sci., Vol. 126 No.1, pp. 37-44.

Yoon, R.-H., 2000, "The role of hydrodynamic and surface forces in bubble-particle interaction”, Inter. J. Miner. Process., Vol. 58, pp. 128-143.

Yoon. R. H.. Adel. G. T. and Luttrell. G. H., 1988. V.S. patent appl. no. 5761008, "A process and apparatus for separating fine particles by microbubble flotation together with a process and apparatus for generation of microbubbles".

Yoon, R.-H., and Luttrell, G. H., 1989, "The effect of bubble size on fine particle flotation", Miner Process Extr Metall Rev, Vol. 5, pp. 101-122.

Young, F.R., 1989, “Cavitation”, McGraw-Hill Book Company, London. 
Yount, D.E., Kunkle, T.D., 1975, "Gas nucleation in the vicinity of solid hydrophobic spheres", J. Appl. Phys., Vol.46, No. 10, pp. 4484-4486.

Yount, D.E., and Strauss, R.H., 1976, "Bubble formation in gelatin: a model for decompression sickness", J. Appl. Phys., Vol. 47, No. 11, pp. 5081-5089.

Zhang, J., 1995, "Phosphate beneficiation-challenges and opportunities", In: Misra M., editor. Separation processes: heavy metals, ions and minerals: proceedings of a symposium; Las Vegas, NV, Warrendale (PA): The Minerals, Metals \& Materials Society, pp. 167-183.

Zhang, P., Yu, Y. and Bogan, M., 1997, "Challenging the Crago double float process. II amine-fatty acid flotation of siliceous phosphates”, Minerals Engineering, Vol. 10, No. 9, pp. 983-94.

Zhou, Z.A., Xu, Zhenghe, Finch, J.A., 1995, "Fundamental study of cavitation in flotation", In: XIX International Mineral Processing Congress, vol. 3. San Francisco, pp. 93-97.

Zhou, Z.A., Xu, Zhenghe, Finch, J.A., 1996a, "Effect of gas nuclei on hydrophobic coagulation", J. Colloid. Interface Sci. 179, pp. 311-314.

Zhou, Z.A., Xu, Zhenghe, Finch, J.A., Liu, Q., 1996b, "Effect of gas nuclei on the filtration of fine particles with different surface properties", Colloids \& Surfaces, Vol.113, pp. 6777.

Zhou, Z. A., Hu, H., Xu, Zhenghe, and Finch, J.A., Rao, S.R., 1997a, "Role of hydrodynamic cavitation in fine particle flotation", Int'l. J. Miner. Process., Vol. 51, pp. 139-149.

Zhou, Z.A., Langlois, R., Xu, Zhenghe, Finch, J.A., Agnew, R., 1997b, "In-plant testing of a hydrodynamic reactor in flotation", In: Finch, J.A., Rao, S.R., Huang, L.M. (Eds.), Processing of Complex Ores. CIM, Sudbury, Canada, pp. 185-193.

Zhou, Z.A., Xu, Zhenghe, and Finch, J.A., 1998, "Effect of surface properties of solids on dynamic bubble formation in gas-supersaturated systems", Ind. Eng. Chem. Res., vol. 37, pp. 1998-2004.

Zhou, Z.A., Xu, Zhenghe, and Finch, J.A., 1999, "Generation of small bubbles by hydrodynamic cavitation”, Trans. IMM, Vol. 108, pp. 55-58.

Zhou, Z.A., Chow, R.S., Su, N., 2005, "Spontaneous bubble nucleation on bitumen surfaces”, Report for CONRAD Extraction Technology Group, Alberta Research Council. 
Zhou, Z.A., Chow, R.S., 2006, "Effect of shear on bitumen-bubble attachment in model systems", Final Report for CONRAD Bitumen Production Technical Group, Alberta Research Council.

Zhou, Z. A., Hu, H., Xu, Zhenghe, and Finch, J.A., Rao, S.R., 1997, "Role of hydrodynamic cavitation in fine particle flotation", Int. J. Miner. Process, Vol. 51, pp. 139-149.

Zhou, Z. A., Xu, Z. H., Finch, J. A., Masliyah, J. H., and Chow, R. S., 2009, “On the role of cavitation in particle collection in flotation - A critical review II", Minerals Engineering, Vol. 22, pp. 419-433. 


\section{Appendix A}

Effect of different designs of cavitation venturi tube on bubble

distribution data 
Table A- 1 Results of four-factor three-level experimental design of venturi tube design tests.

\begin{tabular}{|c|c|c|c|c|c|c|}
\hline Run & $\mathrm{D}_{\mathrm{in}} / \mathrm{D}_{\mathrm{t}}$ & $\mathrm{L}_{\mathrm{t}} / \mathrm{D}_{\mathrm{t}}$ & Inlet Angle & Outlet Angle & $\begin{array}{c}\text { Pico-nano bubble } \\
\text { Volume }(\%)\end{array}$ & $\begin{array}{c}\text { Mean Pico-nano bubble } \\
\text { Size }(\mathrm{nm})\end{array}$ \\
\hline 1 & 2 & 1 & 27 & 16 & 60.15 & 112.21 \\
\hline 2 & 6 & 1 & 27 & 16 & 0.94 & 723.83 \\
\hline 3 & 2 & 3 & 15 & 16 & 28.38 & 520.74 \\
\hline 4 & 6 & 1 & 15 & 16 & 33.92 & 764.50 \\
\hline 5 & 6 & 3 & 15 & 8 & 37.77 & 630.88 \\
\hline 6 & 6 & 1 & 27 & 8 & 28.30 & 657.50 \\
\hline 7 & 2 & 2 & 21 & 12 & 62.81 & 291.00 \\
\hline 8 & 4 & 2 & 21 & 12 & 70.65 & 181.73 \\
\hline 9 & 2 & 3 & 15 & 8 & 0.58 & 941.88 \\
\hline 10 & 4 & 2 & 21 & 12 & 73.68 & 175.00 \\
\hline 11 & 4 & 3 & 21 & 12 & 94.89 & 23.50 \\
\hline 12 & 6 & 2 & 21 & 12 & 44.68 & 543.65 \\
\hline 13 & 2 & 1 & 15 & 16 & 32.74 & 648.90 \\
\hline
\end{tabular}




\begin{tabular}{|c|c|c|c|c|c|c|}
\hline 14 & 2 & 3 & 27 & 16 & 82.76 & 20.20 \\
\hline 15 & 4 & 1 & 21 & 12 & 80.23 & 130.20 \\
\hline 16 & 6 & 1 & 15 & 8 & 21.73 & 935.50 \\
\hline 17 & 4 & 2 & 27 & 12 & 74.58 & 72.50 \\
\hline 18 & 2 & 1 & 27 & 8 & 78.92 & 10.28 \\
\hline 19 & 4 & 2 & 21 & 8 & 56.25 & 588.59 \\
\hline 20 & 6 & 3 & 15 & 16 & 49.60 & 240.00 \\
\hline 21 & 6 & 3 & 27 & 8 & 68.06 & 268.98 \\
\hline 22 & 4 & 2 & 21 & 16 & 50.23 & 488.90 \\
\hline 23 & 6 & 3 & 27 & 16 & 65.17 & 112.50 \\
\hline 24 & 2 & 3 & 27 & 8 & 91.15 & 68.50 \\
\hline 25 & 2 & 1 & 15 & 8 & 27.75 & 826.00 \\
\hline 26 & 4 & 2 & 15 & 12 & 44.68 & 579.58 \\
\hline
\end{tabular}




\section{Appendix B}

Application of pico-nano bubbles in coal flotation data 
Table B- 1 Results of six-factor three-level experimental design for column flotation using pico-nano bubbles.

\begin{tabular}{|c|c|c|c|c|c|c|c|c|}
\hline Run & $\begin{array}{l}\text { Gas flow } \\
\text { rate }(\mathrm{cm} / \mathrm{s})\end{array}$ & $\begin{array}{l}\text { Collector } \\
\text { dosage } \\
\text { (lb/ton) }\end{array}$ & $\begin{array}{c}\text { Frother } \\
\text { dosage } \\
(\mathrm{ppm})\end{array}$ & $\begin{array}{c}\text { Solids } \\
\text { concentration } \\
(\%)\end{array}$ & $\begin{array}{l}\text { Feed rate } \\
(\mathrm{cm} / \mathrm{s})\end{array}$ & $\begin{array}{l}\text { Wash water } \\
\text { rate }(\mathrm{cm} / \mathrm{s})\end{array}$ & $\begin{array}{c}\text { Clean coal } \\
\text { Ash }(\%)\end{array}$ & CMR (\%) \\
\hline 1 & 1.5 & 1.5 & 5 & 10 & 1 & 0.1 & 10.08 & 79.86 \\
\hline 2 & 0.5 & 0.9 & 20 & 10 & 1 & 0.5 & 11.43 & 72.77 \\
\hline 3 & 2.5 & 0.9 & 5 & 20 & 1 & 0.3 & 11.76 & 73.97 \\
\hline 4 & 2.5 & 1.5 & 20 & 5 & 0.6 & 0.1 & 8.01 & 91.79 \\
\hline 5 & 1.5 & 0.3 & 20 & 20 & 0.6 & 0.5 & 11.31 & 70.92 \\
\hline 6 & 2.5 & 0.9 & 5 & 20 & 0.6 & 0.1 & 10.89 & 75.93 \\
\hline 7 & 2.5 & 0.9 & 5 & 20 & 0.2 & 0.5 & 10.00 & 82.59 \\
\hline 8 & 2.5 & 1.5 & 20 & 5 & 1 & 0.3 & 7.89 & 88.65 \\
\hline 9 & 0.5 & 1.5 & 40 & 20 & 1 & 0.5 & 11.60 & 73.47 \\
\hline 10 & 0.5 & 0.3 & 5 & 5 & 0.6 & 0.3 & 9.78 & 86.93 \\
\hline 11 & 1.5 & 1.5 & 5 & 10 & 0.6 & 0.5 & 10.76 & 82.31 \\
\hline 12 & 1.5 & 0.9 & 40 & 5 & 1 & 0.1 & 10.59 & 86.18 \\
\hline 13 & 0.5 & 0.3 & 5 & 5 & 0.2 & 0.1 & 7.50 & 91.97 \\
\hline
\end{tabular}




\begin{tabular}{|c|c|c|c|c|c|c|c|c|}
\hline 14 & 0.5 & 1.5 & 40 & 20 & 0.6 & 0.3 & 11.33 & 80.84 \\
\hline 15 & 2.5 & 1.5 & 20 & 5 & 0.2 & 0.5 & 9.94 & 90.88 \\
\hline 16 & 0.5 & 1.5 & 40 & 20 & 0.2 & 0.1 & 8.77 & 82.66 \\
\hline 17 & 1.5 & 0.9 & 40 & 5 & 0.6 & 0.5 & 12.25 & 85.91 \\
\hline 18 & 1.5 & 1.5 & 5 & 10 & 0.2 & 0.3 & 9.11 & 92.51 \\
\hline 19 & 1.5 & 0.3 & 20 & 20 & 0.2 & 0.3 & 11.86 & 75.29 \\
\hline 20 & 0.5 & 0.9 & 20 & 10 & 0.6 & 0.3 & 10.38 & 77.27 \\
\hline 21 & 2.5 & 0.3 & 40 & 10 & 0.6 & 0.1 & 10.93 & 82.32 \\
\hline 22 & 0.5 & 0.3 & 5 & 5 & 1 & 0.5 & 10.40 & 77.45 \\
\hline 23 & 2.5 & 0.3 & 40 & 10 & 1 & 0.3 & 9.97 & 77.75 \\
\hline 24 & 1.5 & 0.9 & 40 & 5 & 0.2 & 0.3 & 10.07 & 94.04 \\
\hline 25 & 1.5 & 0.3 & 20 & 20 & 1 & 0.1 & 12.10 & 68.79 \\
\hline 26 & 2.5 & 0.3 & 40 & 10 & 0.2 & 0.5 & 11.09 & 80.45 \\
\hline 27 & 0.5 & 0.9 & 20 & 10 & 0.2 & 0.1 & 10.90 & 81.78 \\
\hline
\end{tabular}


Table B- 2 Results of three-factor three-level central composite design for column flotation using pico-nano bubbles.

\begin{tabular}{|c|c|c|c|c|c|}
\hline Run & $\begin{array}{c}\text { Collector dosage } \\
\text { (lb/ton) }\end{array}$ & $\begin{array}{l}\text { Solids concentration } \\
\qquad(\%)\end{array}$ & Feed rate $(\mathrm{cm} / \mathrm{s})$ & Clean coal Ash $(\%)$ & $\mathrm{CMR}(\%)$ \\
\hline 1 & 0.3 & 4 & 0.2 & 7.25 & 87.66 \\
\hline 2 & 0.9 & 4 & 0.6 & 13.94 & 96.43 \\
\hline 3 & 0.6 & 7 & 0.2 & 9.02 & 69.05 \\
\hline 4 & 0.6 & 7 & 0.4 & 12.74 & 78.76 \\
\hline 5 & 0.9 & 10 & 0.2 & 8.20 & 74.24 \\
\hline 6 & 0.9 & 4 & 0.2 & 17.05 & 96.20 \\
\hline 7 & 0.3 & 7 & 0.4 & 12.06 & 88.21 \\
\hline 8 & 0.3 & 4 & 0.6 & 10.16 & 69.45 \\
\hline 9 & 0.6 & 10 & 0.4 & 12.27 & 73.83 \\
\hline 10 & 0.6 & 7 & 0.6 & 13.52 & 78.04 \\
\hline 11 & 0.9 & 7 & 0.4 & 13.13 & 89.75 \\
\hline 12 & 0.3 & 10 & 0.2 & 9.79 & 78.02 \\
\hline 13 & 0.3 & 10 & 0.6 & 10.60 & 66.13 \\
\hline 14 & 0.9 & 10 & 0.6 & 9.47 & 71.31 \\
\hline 15 & 0.6 & 4 & 0.4 & 9.98 & 90.68 \\
\hline 16 & 0.6 & 7 & 0.4 & 10.45 & 85.89 \\
\hline
\end{tabular}


Table B- 3 Effect of collector dosage on clean coal and combustible material recovery.

\begin{tabular}{|c|c|c|c|}
\hline Kerosene, lb/ton & Clean Coal Ash, \% & Combustible Recovery, \% & Clean Coal Yield, \% \\
\hline 0.1 & 6.94 & 70.98 & 57.17 \\
\hline 0.3 & 7.52 & 74.9 & 59.91 \\
\hline 0.5 & 8.21 & 76.7 & 60.03 \\
\hline 0.6 & 8.69 & 78.07 & 64.85 \\
\hline 0.7 & 9.31 & 83.5 & 64.97 \\
\hline 0.9 & 13.12 & 86.89 & 72.38 \\
\hline
\end{tabular}

Table B- 4 Effect of solid Concentration on clean coal and combustible material recovery.

\begin{tabular}{|c|c|c|c|}
\hline Solid Concentration, \% & Reject Ash, \% & Combustible Recovery, \% & Clean Coal Yield, \% \\
\hline 2 & 64.68 & 90.31 & 79.36 \\
\hline 3.5 & 65.98 & 89.92 & 69.5 \\
\hline 4.5 & 70.78 & 88.33 & 64.85 \\
\hline 5 & 75.71 & 79.33 & 60.28 \\
\hline 5.5 & 77.45 & 77.43 & 55.62 \\
\hline 10 & 79.44 & 71.31 & \\
\hline
\end{tabular}


Table B- 5 Effect of feed rate on clean coal and combustible material recovery.

\begin{tabular}{|c|c|c|}
\hline Feed Rate, \% & Combustible Recovery, \% & Clean Coal Ash, \% \\
\hline 0.2 & 86.32 & 11.5 \\
\hline 0.3 & 87.56 & 10.25 \\
\hline 0.4 & 88.07 & 9.6 \\
\hline 0.5 & 84.51 & 10.84 \\
\hline 0.6 & 78.05 & 12.57 \\
\hline
\end{tabular}

Table B- 6 Effect of pico-nano bubbles and coal particle density on the coal flotation performance.

\begin{tabular}{|c|c|c|c|c|}
\hline \multirow{2}{*}{ Density } & \multicolumn{2}{|c|}{$-700+355 \mu \mathrm{m}$} & \multicolumn{2}{c|}{$-75 \mu \mathrm{m}$} \\
\cline { 2 - 5 } & With pico-nano bubble & Without pico-nano bubble & With pico-nano bubble & Without pico-nano bubble \\
\cline { 2 - 5 } & CMR & CMR & CMR & 81.23 \\
\hline 1.28 & 100 & 80.91 & 94.96 & 68.64 \\
\hline 1.35 & 94.00 & 70.59 & 64.69 & 36.36 \\
\hline 1.55 & 57.23 & 39.78 & 47.05 & 16.9 \\
\hline 1.75 & 22.57 & 10.52 & 20.65 & 10.52 \\
\hline 1.90 & 0.21 & 0.52 & 1.14 & 0.18 \\
\hline
\end{tabular}


Table B- 7 Density and ash distributions of fine raw coal sample

\begin{tabular}{|c|c|c|c|c|c|c|c|c|c|c|c|c|}
\hline \multirow{3}{*}{$\begin{array}{c}\text { Specific } \\
\text { gravity }\end{array}$} & \multicolumn{3}{|c|}{$700-355 \mu \mathrm{m}$} & \multicolumn{3}{|c|}{$355-150 \mu \mathrm{m}$} & \multicolumn{3}{|c|}{$150-75 \mu \mathrm{m}$} & \multicolumn{3}{|c|}{$75-0 \mu \mathrm{m}$} \\
\hline & \multicolumn{2}{|c|}{ Individual } & \multirow{2}{*}{$\begin{array}{c}\text { Cumulative } \\
\text { Ash, \% }\end{array}$} & \multicolumn{2}{|c|}{ Individual } & \multirow{2}{*}{$\begin{array}{c}\text { Cumulative } \\
\text { Ash, \% }\end{array}$} & \multicolumn{2}{|c|}{ Individual } & \multirow{2}{*}{$\begin{array}{c}\text { Cumulative } \\
\text { Ash, \% }\end{array}$} & \multicolumn{2}{|c|}{ Individual } & \multirow{2}{*}{$\begin{array}{c}\text { Cumulative } \\
\text { Ash, \% }\end{array}$} \\
\hline & $\begin{array}{c}\mathrm{Wt} \\
\%\end{array}$ & Ash, \% & & $\mathrm{Wt}, \%$ & $\begin{array}{c}\text { Ash, } \\
\%\end{array}$ & & $\mathrm{Wt}, \%$ & $\begin{array}{c}\text { Ash, } \\
\%\end{array}$ & & $\mathrm{Wt}, \%$ & $\begin{array}{c}\text { Ash, } \\
\%\end{array}$ & \\
\hline 1.3 & 4.63 & 3.24 & 3.24 & 4.82 & 3.22 & 3.21 & 5.17 & 3.15 & 3.15 & 3.24 & 3.08 & 3.08 \\
\hline 1.35 & 10.15 & 5.38 & 4.57 & 13.69 & 4.36 & 4.53 & 15.25 & 4.75 & 4.63 & 6.32 & 4.63 & 3.69 \\
\hline 1.45 & 13.24 & 10.29 & 5.22 & 16.17 & 10.27 & 5.2 & 17.24 & 10.42 & 5.31 & 7.59 & 10.03 & 4.33 \\
\hline 1.55 & 15.19 & 27.62 & 6.41 & 18.04 & 27.6 & 6.39 & 17.95 & 28.52 & 6.44 & 9.05 & 27.84 & 6.07 \\
\hline 1.65 & 16.85 & 32.69 & 7.59 & 19.55 & 32.7 & 7.02 & 18.06 & 40.33 & 7.72 & 10.17 & 40.14 & 8.84 \\
\hline 1.75 & 17.47 & 43.92 & 9.83 & 20.31 & 43.91 & 8.64 & 18.93 & 42.76 & 9.79 & 11.24 & 42.75 & 11.82 \\
\hline 1.9 & 17.92 & 51.36 & 10.46 & 20.83 & 51.34 & 9.16 & 19.05 & 53.92 & 10.36 & 11.46 & 55.8 & 12.38 \\
\hline 2.2 & 20.15 & 87.54 & 27.81 & 23.42 & 87.55 & 27.78 & 25.69 & 88.28 & 28.04 & 27.34 & 90.25 & 60.05 \\
\hline
\end{tabular}


Table B- 8 Effect of pico-nano bubble on yield and combustible material recovery.

\begin{tabular}{|c|c|c|c|c|c|c|c|}
\hline \multicolumn{4}{|c|}{$-700+355 \mu \mathrm{m}$} & \multicolumn{4}{|c|}{$-75 \mu \mathrm{m}$} \\
\hline \multicolumn{2}{|c|}{ With pico-nano bubble } & \multicolumn{2}{|c|}{ Without pico-nano bubble } & \multicolumn{2}{|c|}{ With pico-nano bubble } & \multicolumn{2}{|c|}{ Without pico-nano bubble } \\
\hline $\begin{array}{c}\text { Clean coal } \\
\text { yield, \% }\end{array}$ & $\begin{array}{c}\text { Clean coal } \\
\text { ash, } \%\end{array}$ & $\begin{array}{c}\text { Clean coal } \\
\text { yield, \% }\end{array}$ & $\begin{array}{c}\text { Clean coal } \\
\text { ash, } \%\end{array}$ & $\begin{array}{l}\text { Clean coal } \\
\text { yield, \% }\end{array}$ & $\begin{array}{c}\text { Clean coal } \\
\text { ash, } \%\end{array}$ & $\begin{array}{c}\text { Clean coal } \\
\text { yield, \% }\end{array}$ & $\begin{array}{c}\text { Clean coal } \\
\text { ash, } \%\end{array}$ \\
\hline 20.72 & 4.37 & 27.21 & 4.41 & 12.51 & 2.41 & 10.92 & 2.21 \\
\hline 30.18 & 5.85 & 43.03 & 5.90 & 23.14 & 3.53 & 18.82 & 3.50 \\
\hline 46.37 & 7.69 & 58.05 & 7.71 & 28.59 & 4.19 & 21.52 & 4.13 \\
\hline 57.64 & 11.90 & 68.53 & 11.95 & 32.96 & 5.91 & 23.04 & 4.95 \\
\hline 78.92 & 20.35 & 86.36 & 20.28 & 33.53 & 7.09 & 23.68 & 6.82 \\
\hline 96.53 & 27.62 & 99.89 & 27.84 & 33.62 & 7.53 & 23.79 & 7.13 \\
\hline 100.00 & 29.05 & 100.00 & 29.45 & 34.51 & 8.13 & 23.98 & 7.73 \\
\hline
\end{tabular}


Table B- 9 Effect of pico-nano bubbles on the flotation product particle size distributions of $-700+150 \mu \mathrm{m}$ and $-150 \mu \mathrm{m}$ raw coal feed in the presence and absence of pico-nano bubbles.

\begin{tabular}{|c|c|c|c|}
\hline \multirow{2}{*}{\multicolumn{2}{|c|}{ Size, $\mu \mathrm{m}$}} & Without pico-nano bubble & With pico-nano bubble \\
\hline & & Cumulative wt, $\%$ & Cumulative wt, $\%$ \\
\hline \multirow{8}{*}{$-700+150$} & 150 & 5.86 & 5.79 \\
\hline & 212 & 28.79 & 17.86 \\
\hline & 250 & 51.92 & 31.37 \\
\hline & 300 & 68.39 & 46.93 \\
\hline & 355 & 78.94 & 58.96 \\
\hline & 425 & 87.69 & 69.28 \\
\hline & 500 & 92.35 & 84.62 \\
\hline & 700 & 100 & 100 \\
\hline \multicolumn{2}{|c|}{ Size, $\mu \mathrm{m}$} & Cumulative weight & Cumulative weight \\
\hline \multirow{8}{*}{-150} & 38 & 2.45 & 12.38 \\
\hline & 45 & 8.93 & 22.58 \\
\hline & 62 & 24.71 & 41.3 \\
\hline & 75 & 34.31 & 55.48 \\
\hline & 86 & 55.36 & 68.97 \\
\hline & 106 & 68.74 & 75.83 \\
\hline & 125 & 82.37 & 84.52 \\
\hline & 150 & 100 & 100 \\
\hline
\end{tabular}


Table B- 10 Effect of pico-nano bubble on flotation ash rejection for various particle sizes.

\begin{tabular}{|c|c|c|c|c|c|c|c|}
\hline \multicolumn{4}{|c|}{$150-75 \mu \mathrm{m}$} & \multicolumn{4}{|c|}{$700-355 \mu \mathrm{m}$} \\
\hline \multicolumn{2}{|c|}{ Without pico-nano bubble } & \multicolumn{2}{|c|}{ With pico-nano bubble } & \multicolumn{2}{|c|}{ Without pico-nano bubble } & \multicolumn{2}{|c|}{ With pico-nano bubble } \\
\hline CMR, \% & Ash Rejection, $\%$ & CMR, \% & Ash Rejection, \% & Ash Rejection, \% & CMR, \% & CMR, \% & Ash Rejection, \% \\
\hline 96.8 & 30.62 & 52.66 & 93.61 & 96.6 & 25.32 & 42.65 & 92.78 \\
\hline 91.64 & 59.93 & 79.03 & 91.55 & 91.69 & 38.04 & 69.82 & 83.98 \\
\hline 87.36 & 75.9 & 87.21 & 87.66 & 85.37 & 52.83 & 78.23 & 79.8 \\
\hline 82.66 & 86.24 & 91.57 & 80.11 & 78.91 & 68.92 & 88.54 & 72.51 \\
\hline 73.51 & 92.02 & 94.6 & 73.05 & 72.54 & 78.42 & 91.53 & 67.22 \\
\hline 58.18 & 96.39 & 97.62 & 65.18 & 65.12 & 81.15 & 92.24 & 57.83 \\
\hline \multicolumn{4}{|c|}{$75-0 \mu \mathrm{m}$} & \multicolumn{4}{|c|}{$355-150 \mu \mathrm{m}$} \\
\hline \multicolumn{2}{|c|}{ Without pico-nano bubble } & \multicolumn{2}{|c|}{ With pico-nano bubble } & \multicolumn{2}{|c|}{ Without pico-nano bubble } & \multicolumn{2}{|c|}{ With pico-nano bubble } \\
\hline $\mathrm{CMR}, \%$ & Ash Rejection, \% & CMR, \% & Ash Rejection, \% & Ash Rejection, \% & CMR, \% & $\mathrm{CMR}, \%$ & Ash Rejection, \% \\
\hline 99.51 & 35.69 & 65.66 & 99.54 & 96.8 & 30.55 & 45.16 & 93.55 \\
\hline 98.95 & 60.34 & 75.09 & 98.82 & 92.03 & 43.69 & 72.5 & 87.09 \\
\hline 98.02 & 73.64 & 89.91 & 98.31 & 86.54 & 60.01 & 82.63 & 83.41 \\
\hline 97.8 & 90.14 & 92.86 & 97.53 & 76.38 & 77.81 & 93.52 & 70.11 \\
\hline 96.6 & 92.11 & 93.05 & 96.08 & 68.9 & 85.49 & 95.21 & 65.14 \\
\hline 95.4 & 92.49 & 93.11 & 94.96 & 61.55 & 87.73 & 95.59 & 57.85 \\
\hline
\end{tabular}


Table B- 11 Effect of pico-nano bubbles on flotation yield.

\begin{tabular}{|c|c|c|c|c|c|c|c|}
\hline \multicolumn{4}{|c|}{$-355+150 \mu \mathrm{m}$} & \multicolumn{4}{|c|}{$-150+75 \mu \mathrm{m}$} \\
\hline \multicolumn{2}{|c|}{ Without pico-nano bubble } & \multicolumn{2}{|c|}{ With pico-nano bubble } & \multicolumn{2}{|c|}{ Without pico-nano bubble } & \multicolumn{2}{|c|}{ With pico-nano bubble } \\
\hline $\begin{array}{c}\text { Clean coal } \\
\text { ash, } \%\end{array}$ & $\begin{array}{c}\text { Clean coal } \\
\text { yield, \% }\end{array}$ & $\begin{array}{c}\text { Clean coal } \\
\text { yield, \% }\end{array}$ & $\begin{array}{c}\text { Clean coal } \\
\text { ash, } \%\end{array}$ & $\begin{array}{c}\text { Clean coal } \\
\text { ash, } \%\end{array}$ & $\begin{array}{c}\text { Clean coal } \\
\text { yield, \% }\end{array}$ & $\begin{array}{c}\text { Clean coal } \\
\text { yield, \% }\end{array}$ & $\begin{array}{c}\text { Clean coal } \\
\text { ash, } \%\end{array}$ \\
\hline 5.56 & 32.69 & 20.07 & 5.66 & 4.56 & 43.71 & 28.49 & 4.59 \\
\hline 6.17 & 37.82 & 26.63 & 6.15 & 5.17 & 61.23 & 44.32 & 5.37 \\
\hline 7.64 & 49.89 & 39.74 & 7.66 & 6.34 & 70.35 & 59.15 & 6.3 \\
\hline 10.05 & 60.38 & 49.36 & 10.1 & 8.04 & 73.64 & 71.05 & 8.14 \\
\hline 12.95 & 65.14 & 57.51 & 12.9 & 9.65 & 75.27 & 73.55 & 9.68 \\
\hline 14.13 & 67.92 & 60.24 & 14.15 & 12.13 & 78.42 & 76.82 & 12.23 \\
\hline \multicolumn{4}{|c|}{$-700+355 \mu \mathrm{m}$} & \multicolumn{4}{|c|}{$-75 \mu \mathrm{m}$} \\
\hline \multicolumn{2}{|c|}{ Without pico-nano bubble } & \multicolumn{2}{|c|}{ With pico-nano bubble } & \multicolumn{2}{|c|}{ Without pico-nano bubble } & \multicolumn{2}{|c|}{ With pico-nano bubble } \\
\hline $\begin{array}{c}\text { Clean coal } \\
\text { ash, } \%\end{array}$ & $\begin{array}{c}\text { Clean coal } \\
\text { yield, } \%\end{array}$ & $\begin{array}{c}\text { Clean coal } \\
\text { yield, } \%\end{array}$ & $\begin{array}{c}\text { Clean coal } \\
\text { ash, } \%\end{array}$ & $\begin{array}{c}\text { Clean coal } \\
\text { ash, } \%\end{array}$ & $\begin{array}{c}\text { Clean coal } \\
\text { yield, } \%\end{array}$ & $\begin{array}{c}\text { Clean coal } \\
\text { ash, } \%\end{array}$ & $\begin{array}{c}\text { Clean coal } \\
\text { yield, \% }\end{array}$ \\
\hline 4.62 & 27.21 & 4.37 & 20.72 & 2.41 & 12.51 & 2.21 & 10.92 \\
\hline 6.12 & 43.03 & 5.85 & 30.18 & 3.53 & 23.14 & 3.50 & 18.82 \\
\hline 8.56 & 58.05 & 7.69 & 46.37 & 4.19 & 28.59 & 4.13 & 21.52 \\
\hline 12.11 & 68.53 & 11.90 & 57.64 & 5.91 & 32.96 & 4.95 & 23.04 \\
\hline 22.22 & 86.36 & 20.35 & 78.92 & 7.09 & 33.53 & 6.82 & 23.68 \\
\hline 28.87 & 99.89 & 27.62 & 96.53 & 7.53 & 33.62 & 7.13 & 23.79 \\
\hline 29.05 & 100.00 & 29.05 & 100.00 & 8.13 & 34.51 & 7.73 & 23.98 \\
\hline
\end{tabular}


Table B- 12 Effect of pico-nano bubble on combustible material recovery.

\begin{tabular}{|c|c|c|c|c|c|c|c|}
\hline \multicolumn{4}{|c|}{$700-355 \mu \mathrm{m}$} & \multicolumn{4}{|c|}{$150-75 \mu \mathrm{m}$} \\
\hline \multicolumn{2}{|c|}{ Without pico-nano bubble } & \multicolumn{2}{|c|}{ With pico-nano bubble } & \multicolumn{2}{|c|}{ Without pico-nano bubble } & \multicolumn{2}{|c|}{ With pico-nano bubble } \\
\hline Clean coal ash, $\%$ & CMR, \% & $\mathrm{CMR}, \%$ & Clean coal ash, $\%$ & Clean coal ash, $\%$ & $\mathrm{CMR}, \%$ & CMR, \% & Clean coal ash, $\%$ \\
\hline 5.56 & 25.32 & 42.65 & 5.26 & 2.83 & 30.62 & 52.66 & 2.83 \\
\hline 6.17 & 38.04 & 69.82 & 6.37 & 4.79 & 59.93 & 79.03 & 4.82 \\
\hline 7.64 & 52.83 & 78.23 & 7.64 & 6.12 & 74.9 & 87.21 & 6.02 \\
\hline 10.05 & 68.92 & 88.54 & 10.05 & 7.2 & 79.24 & 88.57 & 7.2 \\
\hline 12.95 & 78.42 & 91.53 & 12.95 & 7.95 & 80.02 & 88.6 & 7.98 \\
\hline 14.13 & 81.15 & 92.24 & 14.13 & 9.31 & 81.39 & 88.62 & 9.29 \\
\hline \multicolumn{4}{|c|}{$355-150 \mu \mathrm{m}$} & \multicolumn{4}{|c|}{$75-0 \mu \mathrm{m}$} \\
\hline \multicolumn{2}{|c|}{ Without pico-nano bubble } & \multicolumn{2}{|c|}{ With pico-nano bubble } & \multicolumn{2}{|c|}{ Without pico-nano bubble } & \multicolumn{2}{|c|}{ With pico-nano bubble } \\
\hline Clean coal ash, $\%$ & CMR, \% & CMR, $\%$ & Clean coal ash, $\%$ & Clean coal ash, $\%$ & CMR, $\%$ & CMR, \% & Clean coal ash, $\%$ \\
\hline 4.56 & 30.55 & 45.16 & 4.5 & 3.86 & 35.69 & 65.66 & 3.97 \\
\hline 5.69 & 43.69 & 72.5 & 5.73 & 4.35 & 60.34 & 75.09 & 4.08 \\
\hline 6.35 & 60.01 & 82.63 & 6.38 & 4.88 & 73.64 & 89.91 & 4.92 \\
\hline 10.09 & 77.81 & 93.52 & 10.11 & 6.17 & 90.14 & 92.86 & 6.23 \\
\hline 13.04 & 85.49 & 95.21 & 13.01 & 8.33 & 92.11 & 93.05 & 8.51 \\
\hline 14.1 & 87.73 & 95.59 & 14.13 & 11.25 & 92.49 & 93.11 & 11.44 \\
\hline
\end{tabular}


Table B- 13 Particle size effect on separation efficiency and combustible material recovery with pico-nano bubbles.

\begin{tabular}{|c|c|c|c|c|c|c|c|c|c|}
\hline \multicolumn{10}{|c|}{ With Pico-nano bubbles } \\
\hline \multirow{2}{*}{\multicolumn{2}{|c|}{ Size Range, $\mu \mathrm{m}$}} & \multicolumn{2}{|c|}{ Yield, \% } & \multicolumn{3}{|c|}{ Ash, $\%$} & \multirow{3}{*}{$\begin{array}{c}\text { CMR, \% } \\
79.09\end{array}$} & \multirow{3}{*}{$\begin{array}{c}\text { Ash Rejection, \% } \\
89.00\end{array}$} & \multirow{3}{*}{$\begin{array}{c}\text { Separation Efficiency, \% } \\
68.09\end{array}$} \\
\hline & & \multirow{2}{*}{$\begin{array}{c}\text { Clean Coal } \\
52.19\end{array}$} & \multirow{2}{*}{$\begin{array}{c}\text { Tailing } \\
47.81\end{array}$} & \multirow{2}{*}{$\begin{array}{l}\text { Feed } \\
39.50\end{array}$} & \multirow{2}{*}{\begin{tabular}{|c|} 
Clean Coal \\
8.33
\end{tabular}} & \multirow{2}{*}{$\frac{\text { Tailing }}{73.54}$} & & & \\
\hline$>$ & 600 & & & & & & & & \\
\hline 425 & 600 & 60.73 & 39.27 & 35.82 & 9.95 & 75.83 & 85.21 & 83.14 & 68.35 \\
\hline 300 & 425 & 68.88 & 31.12 & 31.04 & 8.56 & 80.81 & 91.34 & 81.01 & 72.35 \\
\hline 212 & 300 & 83.14 & 16.86 & 18.31 & 5.32 & 82.37 & 96.36 & 75.86 & 72.22 \\
\hline 90 & 212 & 88.70 & 11.30 & 14.12 & 5.34 & 83.00 & 97.76 & 66.45 & 64.21 \\
\hline 45 & 90 & 92.47 & 7.53 & 9.58 & 5.22 & 63.20 & 96.94 & 49.65 & 46.59 \\
\hline 0 & 45 & 71.22 & 28.78 & 29.06 & 10.48 & 75.04 & 89.87 & 74.31 & 64.18 \\
\hline & & & & & Withou & Pico-nar & o bubbles & & \\
\hline Size P & um & Yield, & & & Ash, \% & & CMP of & $\Delta$ ch Paiontion of & Sanaration Efficioncy of \\
\hline SIZE K & $g, \mu \mathrm{II}$ & Clean Coal & Tailing & Feed & Clean Coal & Tailing & CNIK, $\%$ & Asn кејесtion, $\%$ & 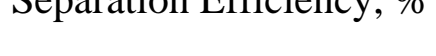 \\
\hline$>$ & 600 & 38.23 & 61.77 & 40.40 & 5.46 & 62.03 & 60.64 & 94.83 & 55.47 \\
\hline 425 & 600 & 39.66 & 60.34 & 41.09 & 5.67 & 64.37 & 63.51 & 94.52 & 58.03 \\
\hline 300 & 425 & 60.61 & 39.39 & 31.63 & 10.36 & 64.37 & 79.47 & 80.15 & 59.62 \\
\hline 212 & 300 & 85.73 & 14.27 & 15.71 & 6.50 & 71.05 & 95.10 & 64.53 & 59.63 \\
\hline 90 & 212 & 92.92 & 7.08 & 9.25 & 5.76 & 54.92 & 96.48 & 42.08 & 38.56 \\
\hline 45 & 90 & 78.38 & 21.62 & 13.88 & 5.15 & 45.55 & 86.33 & 70.94 & 57.27 \\
\hline 0 & 45 & 50.42 & 49.58 & 34.53 & 9.09 & 60.39 & 70.01 & 86.72 & 56.73 \\
\hline
\end{tabular}




\section{Appendix C}

Application of pico-nano bubbles in phosphate reverse flotation data 
Table C- 1 Effect of CF 413 B on dolomite flotation.

\begin{tabular}{|c|c|c|c|c|c|c|c|c|}
\hline \multirow{2}{*}{ Reagent } & \multirow{2}{*}{ Dosage, lb/ton } & \multirow{2}{*}{ Product } & \multirow{2}{*}{$\mathrm{Wt}, \%$} & \multicolumn{2}{|c|}{ Grade, \% } & \multicolumn{2}{|c|}{ Recovery, \% } & \multirow{2}{*}{ SI } \\
\hline & & & & $\mathrm{P}_{2} \mathrm{O}_{5}$ & $\mathrm{MgO}$ & $\mathrm{P}_{2} \mathrm{O}_{5}$ & $\mathrm{MgO}$ & \\
\hline \multirow{15}{*}{ CF $413 \mathrm{~B}$} & \multirow{3}{*}{0.4} & Float & 12.04 & 12.63 & 9.43 & 11.18 & 38.75 & \multirow{3}{*}{41.97} \\
\hline & & Sink & 87.96 & 25.9 & 2.31 & 88.82 & 61.25 & \\
\hline & & Feed & 100 & 24.30 & 3.17 & 100.00 & 100.00 & \\
\hline & \multirow{3}{*}{0.8} & Float & 13.85 & 12.63 & 9.76 & 11.83 & 46.14 & \multirow{3}{*}{46.96} \\
\hline & & Sink & 86.15 & 25.9 & 2.03 & 88.17 & 53.86 & \\
\hline & & Feed & 100 & 24.06 & 3.10 & 100.00 & 100.00 & \\
\hline & \multirow{3}{*}{1.2} & Float & 18.04 & 10.52 & 9.83 & 12.06 & 60.52 & \multirow{3}{*}{57.07} \\
\hline & & Sink & 81.96 & 27.52 & 1.84 & 87.94 & 39.48 & \\
\hline & & Feed & 100 & 24.45 & 3.28 & 100.00 & 100.00 & \\
\hline & \multirow{3}{*}{1.6} & Float & 19.92 & 11.02 & 9.87 & 13.96 & 67.10 & \multirow{3}{*}{59.17} \\
\hline & & Sink & 80.08 & 27.56 & 1.61 & 86.04 & 32.90 & \\
\hline & & Feed & 100 & 24.27 & 3.26 & 100.00 & 100.00 & \\
\hline & \multirow{3}{*}{2} & Float & 20.31 & 11.42 & 9.82 & 14.66 & 68.07 & \multirow{3}{*}{58.98} \\
\hline & & Sink & 79.69 & 27.47 & 1.57 & 85.34 & 31.93 & \\
\hline & & Feed & 100 & 24.21 & 3.25 & 100.00 & 100.00 & \\
\hline
\end{tabular}


Table C- 2 Effect of CF 413 on dolomite flotation.

\begin{tabular}{|c|c|c|c|c|c|c|c|c|}
\hline \multirow{2}{*}{ Reagent } & \multirow{2}{*}{$\begin{array}{c}\text { Dosage, } \\
\text { lb/ton }\end{array}$} & \multirow{2}{*}{ Product } & \multirow{2}{*}{$\mathrm{Wt}, \%$} & \multicolumn{2}{|c|}{ Grade, \% } & \multicolumn{2}{|c|}{ Recovery, \% } & \multirow{2}{*}{ SI } \\
\hline & & & & $\mathrm{P}_{2} \mathrm{O}_{5}$ & $\mathrm{MgO}$ & $\mathrm{P}_{2} \mathrm{O}_{5}$ & $\mathrm{MgO}$ & \\
\hline \multirow{15}{*}{ CF 413} & \multirow{3}{*}{0.4} & Float & 13.76 & 13.6 & 7.64 & 12.92 & 45.27 & \multirow{3}{*}{45.02} \\
\hline & & Sink & 86.24 & 25.8 & 2.68 & 87.08 & 54.73 & \\
\hline & & Feed & 100 & 24.12 & 3.36 & 100.00 & 100.00 & \\
\hline & \multirow{3}{*}{0.8} & Float & 15.24 & 12.8 & 9.79 & 12.76 & 50.92 & \multirow{3}{*}{49.41} \\
\hline & & Sink & 84.76 & 26.4 & 2.02 & 87.24 & 49.08 & \\
\hline & & Feed & 100 & 24.33 & 3.20 & 100.00 & 100.00 & \\
\hline & \multirow{3}{*}{1.2} & Float & 17.88 & 11.87 & 9.85 & 13.88 & 60.11 & \multirow{3}{*}{54.54} \\
\hline & & Sink & 82.12 & 26.9 & 1.89 & 86.12 & 39.89 & \\
\hline & & Feed & 100 & 24.21 & 3.31 & 100.00 & 100.00 & \\
\hline & \multirow{3}{*}{1.6} & Float & 19.42 & 10.92 & 9.76 & 13.61 & 64.69 & \multirow{3}{*}{58.06} \\
\hline & & Sink & 80.58 & 27.5 & 1.69 & 86.39 & 35.31 & \\
\hline & & Feed & 100 & 24.28 & 3.26 & 100.00 & 100.00 & \\
\hline & \multirow{3}{*}{2} & Float & 19.93 & 11.2 & 9.69 & 13.22 & 65.91 & \multirow{3}{*}{59.42} \\
\hline & & Sink & 80.07 & 27.8 & 1.63 & 86.78 & 34.09 & \\
\hline & & Feed & 100 & 24.49 & 3.24 & 100.00 & 100.00 & \\
\hline
\end{tabular}


Table C- 3 Effect of the mixture of CF 413 and MIBC on dolomite flotation.

\begin{tabular}{|c|c|c|c|c|c|c|c|c|}
\hline \multirow{2}{*}{ Reagent } & \multirow{2}{*}{$\begin{array}{c}\text { Dosage, } \\
\text { lb/ton }\end{array}$} & \multirow{2}{*}{$\begin{array}{l}\operatorname{Pr} \\
\text { oduct }\end{array}$} & \multirow{2}{*}{$\mathrm{Wt}, \%$} & \multicolumn{2}{|c|}{ Grade, $\%$} & \multicolumn{2}{|c|}{ Recovery, \% } & \multirow{2}{*}{ SI } \\
\hline & & & & $\mathrm{P}_{2} \mathrm{O}_{5}$ & $\mathrm{MgO}$ & $\mathrm{P}_{2} \mathrm{O}$ & $\mathrm{MgO}$ & \\
\hline \multirow{15}{*}{$\begin{array}{c}\text { CF } 413 \\
+ \\
10 \text { ppm MIBC }\end{array}$} & \multirow{3}{*}{0.4} & Float & 15.48 & 11.3 & 9.89 & 9.38 & 52.25 & \multirow{3}{*}{54.47} \\
\hline & & Sink & 84.52 & 27.5 & 2.21 & 90.62 & 47.75 & \\
\hline & & Feed & 100 & 24.99 & 3.40 & 100.00 & 100.00 & \\
\hline & \multirow{3}{*}{0.8} & Float & 17.7 & 10.8 & 10.25 & 10.80 & 61.92 & \multirow{3}{*}{59.34} \\
\hline & & Sink & 82.3 & 27.8 & 1.92 & 89.20 & 38.08 & \\
\hline & & Feed & 100 & 24.79 & 3.39 & 100.00 & 100.00 & \\
\hline & \multirow{3}{*}{1.2} & Float & 19.38 & 9.3 & 10.33 & 11.37 & 68.33 & \multirow{3}{*}{62.89} \\
\hline & & Sink & 80.62 & 28.2 & 1.66 & 88.63 & 31.67 & \\
\hline & & Feed & 100 & 24.54 & 3.34 & 100.00 & 100.00 & \\
\hline & \multirow{3}{*}{1.6} & Float & 21.8 & 8.4 & 10.11 & 11.89 & 75.22 & \multirow{3}{*}{66.93} \\
\hline & & Sink & 78.2 & 28.9 & 1.51 & 88.11 & 24.78 & \\
\hline & & Feed & 100 & 24.43 & 3.38 & 100.00 & 100.00 & \\
\hline & \multirow{3}{*}{2} & Float & 21.67 & 9.5 & 9.98 & 12.36 & 73.81 & \multirow{3}{*}{65.53} \\
\hline & & Sink & 78.33 & 28.7 & 1.48 & 87.64 & 26.19 & \\
\hline & & Feed & 100 & 24.54 & 3.32 & 100.00 & 100.00 & \\
\hline
\end{tabular}


Table C- 4 Effect of the mixture of CF 413B and MIBC on dolomite flotation.

\begin{tabular}{|c|c|c|c|c|c|c|c|c|}
\hline \multirow{2}{*}{ Reagent } & \multirow{2}{*}{$\begin{array}{c}\text { Dosage, } \\
\text { lb/ton }\end{array}$} & \multirow{2}{*}{ Product } & \multirow{2}{*}{$\mathrm{Wt}, \%$} & \multicolumn{2}{|c|}{ Grade, $\%$} & \multicolumn{2}{|c|}{ Recovery, \% } & \multirow{2}{*}{ SI } \\
\hline & & & & $\mathrm{P}_{2} \mathrm{O}_{5}$ & $\mathrm{MgO}$ & $\mathrm{P}_{2} \mathrm{O}_{5}$ & $\mathrm{MgO}$ & \\
\hline \multirow{15}{*}{$\begin{array}{c}\text { CF 413B } \\
+ \\
10 \text { ppm MIBC }\end{array}$} & \multirow{3}{*}{0.4} & Float & 14.08 & 9.17 & 10.46 & 5.54 & 50.27 & \multirow{3}{*}{57.53} \\
\hline & & Sink & 85.92 & 28.2 & 2.18 & 94.46 & 49.73 & \\
\hline & & Feed & 100 & 25.52 & 3.35 & 100.00 & 100.00 & \\
\hline & \multirow{3}{*}{0.8} & Float & 17.19 & 7.84 & 9.86 & 6.70 & 63.71 & \multirow{3}{*}{65.35} \\
\hline & & Sink & 82.81 & 28.9 & 1.95 & 93.30 & 36.29 & \\
\hline & & Feed & 100 & 25.28 & 3.31 & 100.00 & 100.00 & \\
\hline & \multirow{3}{*}{1.2} & Float & 19.66 & 6.03 & 10.76 & 7.60 & 73.54 & \multirow{3}{*}{70.66} \\
\hline & & Sink & 80.34 & 29.5 & 1.51 & 92.40 & 26.46 & \\
\hline & & Feed & 100 & 24.89 & 3.33 & 100.00 & 100.00 & \\
\hline & \multirow{3}{*}{1.6} & Float & 22.64 & 7.26 & 10.25 & 10.73 & 82.29 & \multirow{3}{*}{72.48} \\
\hline & & Sink & 77.36 & 29.6 & 1.36 & 89.27 & 17.71 & \\
\hline & & Feed & 100 & 24.54 & 3.37 & 100.00 & 100.00 & \\
\hline & \multirow{3}{*}{2} & Float & 23.03 & 7.81 & 9.72 & 10.58 & 84.26 & \multirow{3}{*}{73.85} \\
\hline & & Sink & 76.97 & 29.8 & 1.33 & 89.42 & 15.74 & \\
\hline & & Feed & 100 & 24.74 & 3.26 & 100.00 & 100.00 & \\
\hline
\end{tabular}


Table C- 5 Results of seven-factor two-level fractional factorial experimental design.

\begin{tabular}{|c|c|c|c|c|c|c|c|}
\hline \multirow{2}{*}{ Run } & \multirow{2}{*}{ Product } & \multirow{2}{*}{$\mathrm{Wt}, \%$} & \multicolumn{2}{|c|}{ Grade, \% } & \multicolumn{2}{|c|}{ Recovery, \% } & \multirow{2}{*}{ SI } \\
\hline & & & $\mathrm{P}_{2} \mathrm{O}_{5}$ & $\mathrm{MgO}$ & $\mathrm{P}_{2} \mathrm{O}_{5}$ & $\mathrm{MgO}$ & \\
\hline \multirow{3}{*}{1} & Float & 18.78 & 7.83 & 10.94 & 7.86 & 70.12 & \multirow{3}{*}{68.10} \\
\hline & Sink & 81.22 & 29.1 & 1.59 & 92.14 & 29.88 & \\
\hline & Feed & 100 & 25.11 & 3.35 & 100.00 & 100.00 & \\
\hline \multirow{3}{*}{2} & Float & 20.1 & 7.83 & 10.94 & 9.35 & 75.05 & \multirow{3}{*}{69.38} \\
\hline & Sink & 79.9 & 29.1 & 1.39 & 90.65 & 24.95 & \\
\hline & Feed & 100 & 24.82 & 3.31 & 100.00 & 100.00 & \\
\hline \multirow{3}{*}{3} & Float & 19.56 & 7.84 & 10.88 & 9.68 & 72.63 & \multirow{3}{*}{67.44} \\
\hline & Sink & 80.44 & 28.8 & 1.48 & 90.32 & 27.37 & \\
\hline & Feed & 100 & 24.70 & 3.32 & 100.00 & 100.00 & \\
\hline \multirow{3}{*}{4} & Float & 11.62 & 7.59 & 16.43 & 3.87 & 41.36 & \multirow{3}{*}{52.85} \\
\hline & Sink & 88.38 & 27.9 & 1.41 & 96.13 & 58.64 & \\
\hline & Feed & 100 & 25.54 & 3.16 & 100.00 & 100.00 & \\
\hline \multirow{3}{*}{5} & Float & 16.37 & 8.02 & 12.77 & 6.43 & 57.94 & \multirow{3}{*}{61.99} \\
\hline & Sink & 83.63 & 28.7 & 1.35 & 93.57 & 42.06 & \\
\hline & Feed & 100 & 25.31 & 3.22 & 100.00 & 100.00 & \\
\hline \multirow{3}{*}{6} & Float & 20.19 & 8.91 & 11.04 & 7.59 & 76.07 & \multirow{3}{*}{72.26} \\
\hline & Sink & 79.81 & 29.7 & 1.37 & 92.41 & 23.93 & \\
\hline & Feed & 100 & 25.50 & 3.32 & 100.00 & 100.00 & \\
\hline \multirow{3}{*}{7} & Float & 16.34 & 8.02 & 12.37 & 6.39 & 57.83 & \multirow{3}{*}{61.96} \\
\hline & Sink & 83.66 & 28.7 & 1.45 & 93.61 & 42.17 & \\
\hline & Feed & 100 & 25.32 & 3.23 & 100.00 & 100.00 & \\
\hline \multirow{3}{*}{8} & Float & 13.32 & 7.85 & 14.98 & 3.69 & 47.05 & \multirow{3}{*}{57.50} \\
\hline & Sink & 86.68 & 28.5 & 1.33 & 96.31 & 52.95 & \\
\hline & Feed & 100 & 25.75 & 3.15 & 100.00 & 100.00 & \\
\hline
\end{tabular}


Table C- 6 Results of five-factor two-level fractional factorial experimental design.

\begin{tabular}{|c|c|c|c|c|c|c|c|}
\hline \multirow{2}{*}{ Run } & \multirow{2}{*}{ Product } & \multirow{2}{*}{$\mathrm{Wt}, \%$} & \multicolumn{2}{|c|}{ Grade, $\%$} & \multicolumn{2}{|c|}{ Recovery, \% } & \multirow{2}{*}{ SI } \\
\hline & & & $\mathrm{P}_{2} \mathrm{O}_{5}$ & $\mathrm{MgO}$ & $\mathrm{P}_{2} \mathrm{O}_{5}$ & $\mathrm{MgO}$ & \\
\hline \multirow{3}{*}{1} & Float & 20.61 & 6.79 & 11.05 & 8.57 & 77.73 & \multirow{3}{*}{72.03} \\
\hline & Sink & 79.39 & 29.54 & 1.17 & 91.43 & 22.27 & \\
\hline & Feed & 100 & 24.85 & 3.21 & 100.00 & 100.00 & \\
\hline \multirow{3}{*}{2} & Float & 18.84 & 6.84 & 13.12 & 5.49 & 71.50 & \multirow{3}{*}{71.95} \\
\hline & Sink & 81.16 & 29.87 & 1.04 & 94.51 & 28.50 & \\
\hline & Feed & 100 & 25.53 & 3.32 & 100.00 & 100.00 & \\
\hline \multirow{3}{*}{3} & Float & 18.81 & 7.52 & 12.25 & 8.27 & 70.30 & \multirow{3}{*}{67.68} \\
\hline & Sink & 81.19 & 28.98 & 1.2 & 91.73 & 29.70 & \\
\hline & Feed & 100 & 24.94 & 3.28 & 100.00 & 100.00 & \\
\hline \multirow{3}{*}{4} & Float & 20.85 & 7.03 & 11.87 & 10.39 & 77.35 & \multirow{3}{*}{69.57} \\
\hline & Sink & 79.15 & 29.04 & 1.12 & 89.61 & 22.65 & \\
\hline & Feed & 100 & 24.45 & 3.36 & 100.00 & 100.00 & \\
\hline \multirow{3}{*}{5} & Float & 16.62 & 6.95 & 13.68 & 6.17 & 61.67 & \multirow{3}{*}{64.74} \\
\hline & Sink & 83.38 & 28.97 & 1.15 & 93.83 & 38.33 & \\
\hline & Feed & 100 & 25.31 & 3.23 & 100.00 & 100.00 & \\
\hline \multirow{3}{*}{6} & Float & 19.71 & 6.73 & 12.09 & 7.06 & 74.60 & \multirow{3}{*}{71.95} \\
\hline & Sink & 80.29 & 29.69 & 1.03 & 92.94 & 25.40 & \\
\hline & Feed & 100 & 25.16 & 3.21 & 100.00 & 100.00 & \\
\hline \multirow{3}{*}{7} & Float & 17.85 & 6.59 & 13.54 & 6.99 & 64.21 & \multirow{3}{*}{65.52} \\
\hline & Sink & 82.15 & 29.04 & 0.98 & 93.01 & 35.79 & \\
\hline & Feed & 100 & 25.03 & 3.22 & 100.00 & 100.00 & \\
\hline \multirow{3}{*}{8} & Float & 18.91 & 7.12 & 11.82 & 8.57 & 69.83 & \multirow{3}{*}{67.08} \\
\hline & Sink & 81.09 & 28.92 & 1.18 & 91.43 & 30.17 & \\
\hline & Feed & 100 & 24.80 & 3.19 & 100.00 & 100.00 & \\
\hline
\end{tabular}


Table C- 7 Effect of $\mathrm{pH}$ on dolomite flotation.

\begin{tabular}{|c|c|c|c|c|c|c|c|}
\hline \multirow{2}{*}{$\mathrm{pH}$} & \multirow{2}{*}{ Product } & \multirow{2}{*}{$\mathrm{Wt}, \%$} & \multicolumn{2}{|c|}{ Grade, \% } & \multicolumn{2}{|c|}{ Recovery, \% } & \multirow{2}{*}{ SI } \\
\hline & & & $\mathrm{P}_{2} \mathrm{O}_{5}$ & $\mathrm{MgO}$ & $\mathrm{P}_{2} \mathrm{O}_{5}$ & $\mathrm{MgO}$ & \\
\hline \multirow{3}{*}{5} & Float & 20.68 & 6.63 & 10.83 & 13.17 & 76.44 & \multirow{3}{*}{65.46} \\
\hline & Sink & 79.32 & 28.48 & 1.23 & 86.83 & 23.56 & \\
\hline & Feed & 100 & 23.96 & 3.22 & 100.00 & 100.00 & \\
\hline \multirow{3}{*}{5.1} & Float & 20.56 & 6.68 & 10.89 & 11.27 & 76.42 & \multirow{3}{*}{67.83} \\
\hline & Sink & 79.44 & 28.65 & 1.18 & 88.73 & 23.58 & \\
\hline & Feed & 100 & 24.13 & 3.18 & 100.00 & 100.00 & \\
\hline \multirow{3}{*}{5.2} & Float & 20.51 & 6.73 & 10.92 & 9.79 & 76.44 & \multirow{3}{*}{69.73} \\
\hline & Sink & 79.49 & 29.11 & 1.11 & 90.21 & 23.56 & \\
\hline & Feed & 100 & 24.52 & 3.12 & 100.00 & 100.00 & \\
\hline \multirow{3}{*}{5.3} & Float & 20.44 & 6.77 & 11.94 & 8.41 & 76.32 & \multirow{3}{*}{71.43} \\
\hline & Sink & 79.56 & 29.53 & 1.02 & 91.59 & 23.68 & \\
\hline & Feed & 100 & 24.88 & 3.25 & 100.00 & 100.00 & \\
\hline \multirow{3}{*}{5.4} & Float & 20.23 & 6.81 & 11.98 & 7.14 & 75.81 & \multirow{3}{*}{72.73} \\
\hline & Sink & 79.77 & 29.86 & 0.98 & 92.86 & 24.19 & \\
\hline & Feed & 100 & 25.20 & 3.21 & 100.00 & 100.00 & \\
\hline \multirow{3}{*}{5.5} & Float & 19.95 & 6.92 & 11.92 & 6.94 & 74.35 & \multirow{3}{*}{72.09} \\
\hline & Sink & 80.05 & 29.82 & 0.99 & 93.06 & 25.65 & \\
\hline & Feed & 100 & 25.25 & 3.17 & 100.00 & 100.00 & \\
\hline \multirow{3}{*}{5.6} & Float & 19.74 & 7.09 & 11.82 & 6.63 & 72.90 & \multirow{3}{*}{71.61} \\
\hline & Sink & 80.26 & 29.84 & 1.01 & 93.37 & 27.10 & \\
\hline & Feed & 100 & 25.35 & 3.14 & 100.00 & 100.00 & \\
\hline \multirow{3}{*}{5.7} & Float & 19.72 & 7.21 & 11.62 & 6.57 & 71.48 & \multirow{3}{*}{70.91} \\
\hline & Sink & 80.28 & 29.85 & 1.03 & 93.43 & 28.52 & \\
\hline & Feed & 100 & 25.39 & 3.12 & 100.00 & 100.00 & \\
\hline
\end{tabular}


Table C- 8 Effect of collector dosage on dolomite flotation.

\begin{tabular}{|c|c|c|c|c|c|c|c|}
\hline \multirow{2}{*}{ Collector Dosage, lb/ton } & \multirow{2}{*}{ Product } & \multirow{2}{*}{$\mathrm{Wt}, \%$} & \multicolumn{2}{|c|}{ Grade, $\%$} & \multicolumn{2}{|c|}{ Recovery, \% } & \multirow{2}{*}{ SI } \\
\hline & & & $\mathrm{P}_{2} \mathrm{O}_{5}$ & $\mathrm{MgO}$ & $\mathrm{P}_{2} \mathrm{O}_{5}$ & $\mathrm{MgO}$ & \\
\hline \multirow{3}{*}{1} & Float & 18.64 & 7.91 & 11.73 & 8.58 & 68.26 & \multirow{3}{*}{6.09} \\
\hline & Sink & 81.36 & 28.82 & 1.3 & 91.42 & 31.74 & \\
\hline & Feed & 100 & 24.92 & 3.24 & 100.00 & 100.00 & \\
\hline \multirow{3}{*}{1.2} & Float & 19.53 & 7.9 & 11.82 & 8.20 & 72.12 & \multirow{3}{*}{9.06} \\
\hline & Sink & 80.47 & 29.26 & 1.23 & 91.80 & 27.88 & \\
\hline & Feed & 100 & 25.09 & 3.30 & 100.00 & 100.00 & \\
\hline \multirow{3}{*}{1.4} & Float & 20.65 & 8.06 & 11.91 & 8.31 & 76.89 & \multirow{3}{*}{1.96} \\
\hline & Sink & 79.35 & 29.64 & 1.12 & 91.69 & 23.11 & \\
\hline & Feed & 100 & 25.18 & 3.35 & 100.00 & 100.00 & \\
\hline \multirow{3}{*}{1.6} & Float & 21.21 & 8.14 & 11.69 & 8.40 & 78.83 & \multirow{3}{*}{3.10} \\
\hline & Sink & 78.79 & 29.82 & 1.02 & 91.60 & 21.17 & \\
\hline & Feed & 100 & 25.22 & 3.28 & 100.00 & 100.00 & \\
\hline \multirow{3}{*}{1.8} & Float & 21.74 & 8.21 & 11.94 & 8.80 & 81.17 & \multirow{3}{*}{4.02} \\
\hline & Sink & 78.26 & 29.89 & 0.94 & 91.20 & 18.83 & \\
\hline & Feed & 100 & 25.18 & 3.33 & 100.00 & 100.00 & \\
\hline \multirow{3}{*}{2} & Float & 22.95 & 8.32 & 11.52 & 10.39 & 82.40 & \multirow{3}{*}{3.12} \\
\hline & Sink & 77.05 & 29.83 & 0.95 & 89.61 & 17.60 & \\
\hline & Feed & 100 & 24.89 & 3.38 & 100.00 & 100.00 & \\
\hline
\end{tabular}


Table C- 9 Effect of pico-nano bubbles on $\mathrm{P}_{2} \mathrm{O}_{5}$ recovery of varying sizes.

\begin{tabular}{|c|l|l|c|c|c|c|c|c|}
\hline \multirow{2}{*}{$\begin{array}{c}\text { Size range } \\
\text { (um) }\end{array}$} & \multicolumn{5}{|c|}{ With pico-nano bubbles } & \multicolumn{4}{c|}{ Without pico-nano bubbles } \\
\cline { 2 - 10 } & Wt., $\%$ & $\mathrm{P}_{2} \mathrm{O}_{5}, \%$ & $\mathrm{P}_{2} \mathrm{O}_{5}, \%$ & $\mathrm{P}_{2} \mathrm{O}_{5}$ recovery, $\%$ & Wt. $\%$ & $\mathrm{P}_{2} \mathrm{O}_{5}, \%$ & $\mathrm{P}_{2} \mathrm{O}_{5}, \%$ & $\mathrm{P}_{2} \mathrm{O}_{5}$ recovery, \% \\
\hline$-700+600$ & 67.62 & 31.83 & 6.04 & 91.67 & 68.06 & 26.83 & 16.34 & 77.78 \\
\hline$-600+425$ & 68.83 & 32.72 & 6.38 & 91.89 & 71.94 & 27.72 & 16.28 & 81.36 \\
\hline$-425+355$ & 73.23 & 33.58 & 7.62 & 92.34 & 77.75 & 28.98 & 18.42 & 84.61 \\
\hline$-355+150$ & 75.81 & 33.67 & 8.45 & 92.59 & 79.84 & 29.57 & 19.65 & 85.63 \\
\hline$-150+106$ & 71.42 & 33.82 & 6.32 & 93.04 & 76.46 & 29.82 & 13.42 & 87.83 \\
\hline$-106+75$ & 71.46 & 33.59 & 6.93 & 92.39 & 79.70 & 28.59 & 15.73 & 87.71 \\
\hline-75 & 71.10 & 32.43 & 7.41 & 91.50 & 79.58 & 27.43 & 16.51 & 86.62 \\
\hline
\end{tabular}




\section{VITA}

Yu Xiong was born on February 19, 1985 in Pingjiang County, Hunan province, P.R. China. He joined WVU's Department of Mining Engineering in August 2010. Prior to joining WVU, Yu earned his B.S. in Mineral Processing Engineering and M.S. degrees in Minerals \& Materials Engineering from China University of Mining and Technology (Beijing) in July 2007 and 2010, respectively. Yu's current research has focused on the study of pico-nano bubble enhanced

column flotation system. He currently holds two patents for the preparation methods of environmental friendly material. 